Ivo Sechi Nazareno

\title{
MÉTODO DINÂMICO PARA DETEÇÃO DO PEBS E "SHADOWING METHOD" PARA CÁLCULO DO PONTO DE EQUILÍBRIO DE CONTROLE EM ESTUDOS DE ESTABILIDADE TRANSITÓRIA
}

Dissertação apresentada à Escola de Engenharia de São Carlos da Universidade de São Paulo, como parte dos requisitos para a obtenção do Título de Mestre em Engenharia Elétrica.

ORIENTADOR: Prof. Dr. Newton Geraldo Bretas

São Carlos

2003 
Candidato: Engenheiro IVO SECHI NAZARENO

Dissertação defendida e julgada em 11-08-2003 perante a Comissão Julgadora:

huoton yodso Bu?

Prof. Tit. NEWTON GERALDO BRETAS (Orientador)

(Escola de Engenharia de São Carlos/USP)

Luís Inmanda Costa Cllenta

Prof. Dr. LUIS FERYANDO COSTA ALBERTO

(Escola de Engenharid de São Carlos/USP)

Prof. Liv. Doc. LAURENCE DUARTE COLVARA

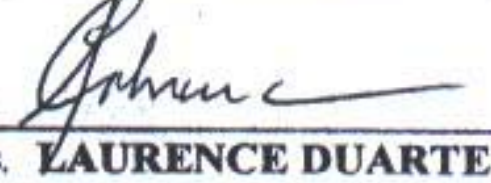

(UNESP/Campus de Bauru)
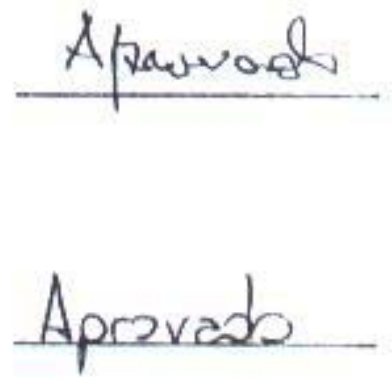

Aprovada

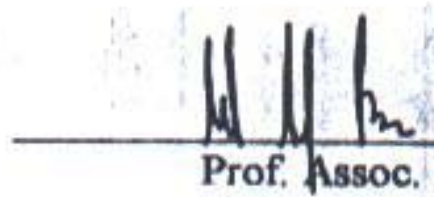

Coordenador do Programa de Pós-Graduaçĩo em Engenharia Elétrica

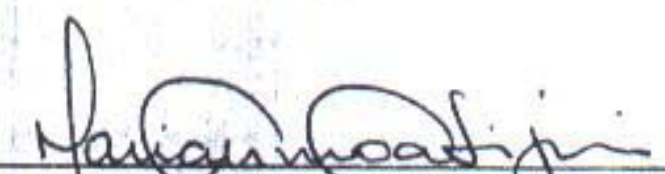

Profa. Assoc. MARIA DO CARMO CATJJURI

Presidente da Comissão de Pós-Graduaçăo 
A minha mãe, Aparecida, pela dedicação de sua vida à minha educação. 


\section{Agradecimentos}

Ao Professor Doutor Newton Geraldo Bretas, pela orientação e ensinamentos;

Ao Professor Doutor Luís Fernando Costa Alberto, pela orientação e ensinamentos; Aos amigos do Laboratório de Análises Computacionais, pelo companherismo e ensinamentos;

Ao meu pai, Engenheiro Julio Bosco Nazareno, pelas discussões e ensinamentos;

À minha esposa Silmara e ao meu filho Carlos Eduardo;

À minha irmã e colega de mestrado, Julia Sechi Nazareno;

Aos docentes, funcionários e colegas do departamento de Engenharia Elétrica;

À Universidade de São Paulo, pela estrutura;

À Fundação de Amparo à Pesquisa do Estado de São Paulo - FAPESP, pela bolsa de estudo concedida; 
"E aqueles que por obras valerosas Se vão da lei da Morte libertando, Cantando espalharei por toda parte, Se a tanto me ajudar o engenho e arte."

Canto I, 2 de Os Lusíadas, Luís de Camões 


\section{Resumo}

NAZARENO, I. S. (2003). Método dinâmico para deteção do PEBS e "Shadowing Method" para cálculo do ponto de equilibrio de controle em estudos de estabilidade transitória. Dissertação (Mestrado) - Escola de Engenharia de São Carlos, Universidade de São Paulo, São Carlos, 2003.

No estudo de estabilidade transitória, as não linearidades inerentes aos sistemas aliadas a grande dimensão do problema, contribuem para que as análises dos sistemas de potência sejam muito complexas. O estudo clássico de estabilidade transitória utiliza soluções numéricas iterativas de um conjunto de equações diferenciais associadas à dinâmica do sistema, visando a obtenção do tempo crítico de abertura. Porém, este não é o processo mais adequado à aplicações em tempo real devido ao esforço computacional exigido em tais iterações numéricas. Os métodos diretos são adequados para análises em tempo real, já que obtêm as informações necessárias sem a solução explícita de equações diferenciais. Dentre os métodos diretos existentes, as idéias de Lyapunov associadas ao princípio de invariância de LaSalle destacam-se por serem métodos energéticos e diretos adequados ao estudo de estabilidade em sistemas não lineares. Baseados em tais idéias, diversos métodos de estimativa da região de estabilidade foram propostos. Dentre estes, o BCU tem sido aceito como o mais eficiente para a determinação do tempo crítico de abertura. Apesar do BCU ser bastante eficiente, existem casos de falha do mesmo. Este trabalho visa eliminar dois problemas relacionados ao BCU: o primeiro problema advém do fato de que nem sempre o máximo de energia potencial ocorre nas vizinhanças do PEBS. O segundo problema está associado aos casos em que a trajetória do sistema gradiente reduzido não passa nas vizinhanças do ponto de equilíbrio de controle. Para solucionar estes dois problemas utiliza-se um método dinâmico para a deteção do "exit point" e o "Shadowing Method" para cálculo do ponto de equilíbrio de controle. Testes com os dois algoritmos mostram que eles encontram soluções para casos de falha do PEBS e BCU, porém problemas de deteção dos pontos de interesse ainda persistem. Alguns métodos alternativos, baseados nos algoritmos citados são propostos, bem como aspectos de melhoria de convergência dos mesmos.

Palavras-chave: estabilidade transitória; métodos diretos; tempo real; 


\section{Abstract}

NAZARENO, I. S. (2003). A dynamic method to PEBS detection and the Shadowing Method to calculate the controlling unstable equilibrium point in transient stability studies. M. Sc. Dissertation - Escola de Engenharia de São Carlos, Universidade de São Paulo, São Carlos, 2003

In transient stability assessment, the nonlinearities of the systems and the dimension of the problem contribute to the complexity of the analysis in power systems. The classical numerical solution to obtain the critical clearing time (cct) has been used, but it is time-consuming and not adequate for real-time applications. The direct methods have the adequacy for real-time analysis because they get the necessary information for stability without the explicit solution of the set of differential equations associated to the system dynamics. Among the existing methods of power system transient stability analysis, Lyapunov ideas associated to LaSalle's invariance principle are very important. Inspired by these ideas, methods to estimate the stability region have been obtained. One of them is the BCU, that has been accepted as the most efficient method in the determination of the critical cct. Despite BCU's efficiency, it fails in many cases. The main objective of this research is to solve two problems associated to the $\mathrm{BCU}$ : the first problem is the fact that not always the maximum of potential energy occurs in the neighborhood of PEBS. The second problem is the fact that in many cases the trajectory of the reduced gradient system does not pass in the neighborhood of the controlling unstable equilibrium point. For the solution of these problems it will be used a dynamic method for the exit point detection and the Shadowing Method to calculate the the controlling unstable equilibrium point. Tests have shown that the aforementioned robust algorithms find the solutions for many cases for which BCU and PEBS method fails, but many cases of fail persist. Some alternative methods, based in the mentioned algorithms are proposed, and so, aspects to improve its convergency.

Key-words: transient stability; direct methods; real time; 


\section{Lista de Figuras}

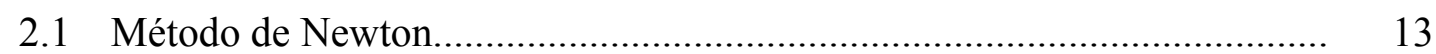

2.2 Transformação de Park.......................................................................... 15

2.3 Uma máquina ligada a um sistema elétrico............................................... 16

2.4 Circuito equivalente a figura 2.3 com gerador representado pelo modelo clássico.

3.1 Discretização da Potência acelerante e da velocidade no tempo para o método passo-a-passo............................................................................. 22

3.2 Sistema multimáquinas..................................................................... 23

3.3 Uma Máquina versus Barramento Infinito através de uma Linha de Transmissão Dupla - Sistema OMIBS pré-falta..................................................... 28

3.4 Sistema OMIBS falta............................................................................ 29

3.5 Sistema OMIBS pós-falta..................................................................... 29

3.6 Curva $P$ - $\delta$ para o sistema OMIBS........................................................ 31

3.7 Conceito de Estabilidade....................................................................... 32

4.1 Curva $P-\delta$, Critério das Áreas Iguais................................................... 42

4.2 Representação Geométrica dos Conjuntos na Prova do Teorema de

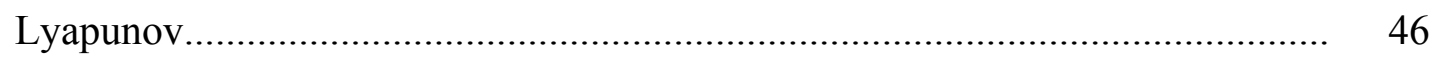

4.3 Curva de Nível de uma Função de Lyapunov................................................... 47

4.4 Área de Atração do Ponto de Equilíbrio Estável do Sistema Pós-falta............ 49

4.5 Aproximação Local da Fronteira de Estabilidade....................................... 63

4.6 Esboço de uma bacia energética............................................................... 64

4.7 Gráfico da Energia Potencial x Ângulo...................................................... 65

4.8 Fronteira da Área de Atração do Sistema de 3 Barras............................... 66

4.9 Sistema de 3 Barras................................................................................ 67

4.10 Curva Equipotencial do Sistema de 3 Barras para Curto Trifásico Sólido na Linha 1-2 Próximo a Barra 2 e "Exit Point" Calculado pelo Método PEBS... 68

4.11 Energia Potencial com Pontos $x_{1}$ e $x_{2}$ como Máximos Locais................... 69 
$4.12 x_{1}$ e $x_{2}$ como Ponto de Equilíbrio na Fronteira de Estabilidade do

Sistema Pós-falta

4.13 Ilustração do Algoritmo BCU.

4.14 Curva Equipotencial do Sistema de 3 Barras para Curto Trifásico Sólido na Linha 1-2 Próximo a Barra 2 e Ponto de equilíbrio de Controle Calculado pelo Método PEBS.

5.1 Cruzamento não Ortogonal da Trajetória em Falta com o PEBS............... 78

5.2 Superfície Irregular do PEBS.................................................................. 79

5.3 Falha da Deteção do "Exit Point" pelo algoritmo PEBS........................... 80

5.4 PEBS dinâmico....................................................................... 82

5.5 Problemas Associados a Deteção do p.e.i. de Controle............................. 83

5.6 Sistema de Duas Máquinas versus Barramento Infinito........................... 85

5.7 Retrato de Fase do Sistema de Duas Máquinas versus Barramento Infinito.

5.8 Falha da Deteção do p.e.i. de controle pelo algoritmo BCU................... 87

5.9 "Shadowing Method"............................................................................. 88

5.10 Ciclos do "Shadowing Method"............................................................ 89

6.1 Atuação do algoritmo PEBS dinâmico na deteção do "exit point" correto.

6.2 Atuação do algoritmo PEBS dinâmico associado ao "Shadowing Method" na deteção do "exit point" e do p.e.i. de controle corretos.................... 93

6.3 "Shadowing Method" na deteção do p.e.i. de controle correto................... 95

6.4 Sistema de 14 barras do IEEE.................................................................. 96

6.5 $1^{\circ}$ conjunto- Gráficos de estabilidade para tcr de 210[ms].................... 99

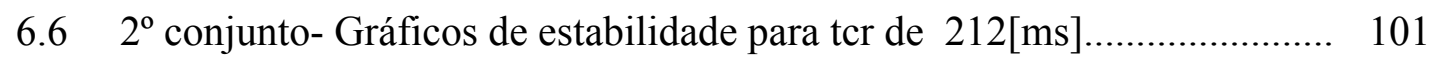

$6.7 \quad 3^{\circ}$ conjunto- Gráficos de estabilidade de $1^{\mathrm{o}}$ "swing"............................... 104

6.8 Sistema New England...................................................................... 106

7.1 Falha do algoritmo PEBS dinâmico......................................................... 111

7.2 Esboço do novo Algoritmo PEBS dinâmico proposto................................. 114

7.3 Esboço do algoritmo "Shadowing Method" modificado.......................... 116 anexo b.1 Esquemas de eliminação por colunas $(a)$ e por linhas $(b) \ldots \ldots \ldots \ldots \ldots \ldots . . . . . .129$ 


\section{Lista de Tabelas}

6.1 tcr's e energias para sistema de 3 geradores do caso base............................ 91

6.2 tcr's para sistema de 3 geradores com impedância de falta.......................... 93

6.3 tcr's para sistema de 3 geradores do com impedância de falta..................... 94

6.4 tcr's e energias para sistema de 3 geradores com geração de $270 \mathrm{MW}$ em

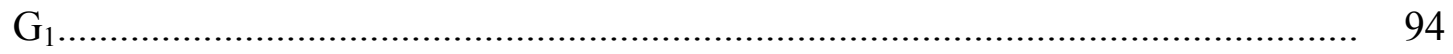

6.5 tcr's e energias para sistema de 14 barras do caso base................................. 98

6.6 tcr's e energias para caso base do sistema New England............................... 109

7.1 Comparação do número de falhas do algoritmo "shadowing method" em relação ao BCU para os casos analisados.............................................................. 114 


\section{Lista de Abreviaturas e Siglas}

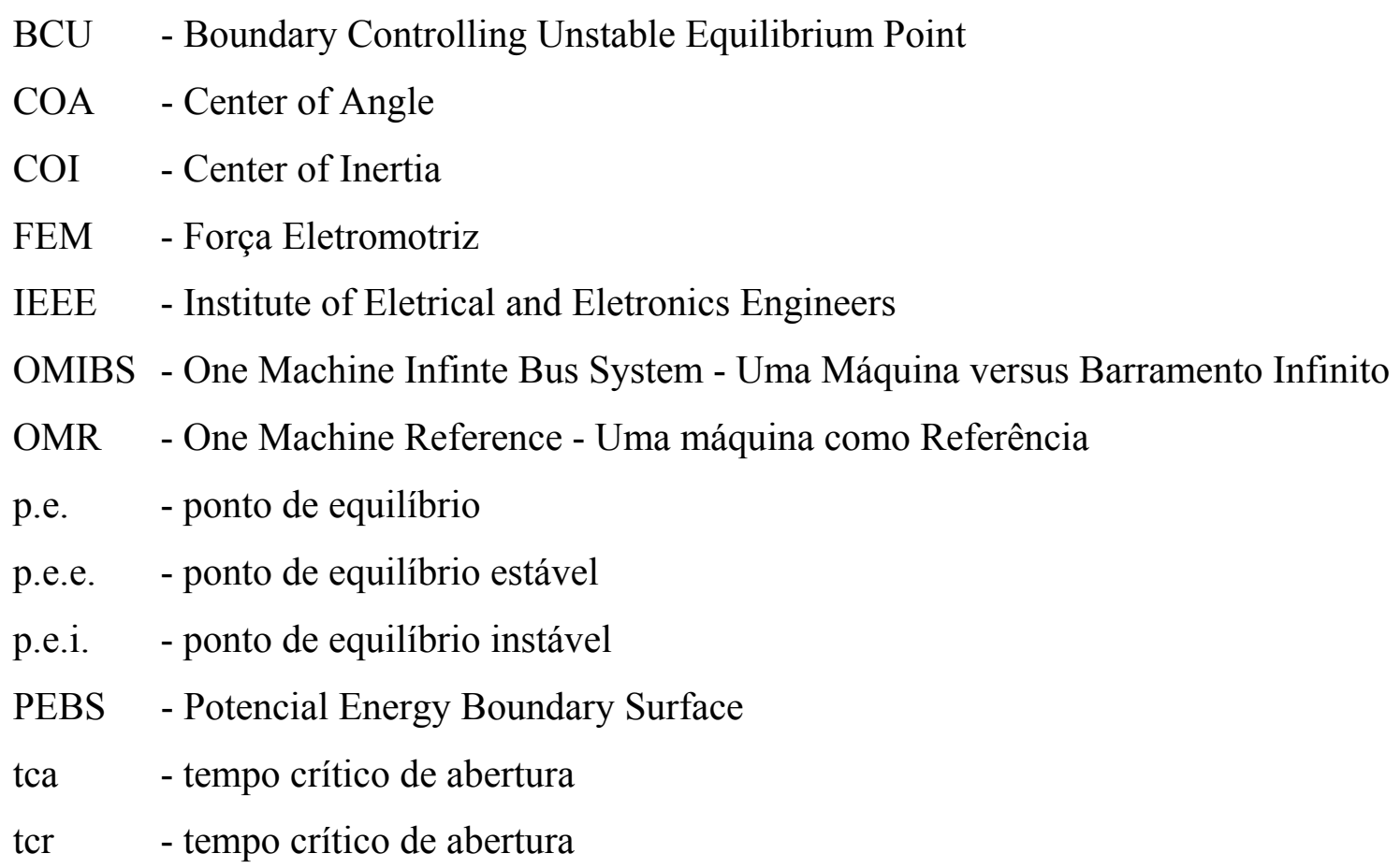




\section{Lista de Símbolos}

$\partial A\left(x_{s}\right)$ - fronteira de estabilidade do p.e.e. $x_{s}$

$\alpha \quad$ - ângulo de defasagem entre a referência fixa e a referência girante no tempo igual a zero

$\delta_{c r} \quad$ - ângulo crítico de abertura

$\delta_{i} \quad$ - ângulo do rotor da máquina $\mathrm{i}$

$\delta_{m}(t) \quad$ - ângulo mecânico formado entre o rotor e a referência girante

$\delta_{\text {new }} \quad$ - ângulo encontrado após passo fixo na direção do gradiente

$\phi\left(x_{p}, t\right)$ - solução do sistema com condição inicial $x_{p}$

$\theta_{i} \quad$ - ângulo do rotor da máquina i referenciado ao COA

$\theta_{k m} \quad$ - diferença dos ângulos de carga da barra $k$ para a barra $m$

$\omega_{m} \quad$ - velocidade angular elétrica

$\omega_{s} \quad$ - referência girante à velocidade síncrona

$\widetilde{\omega}_{i} \quad$ - velocidade angular referenciada ao COA

$A\left(x_{s}\right) \quad$ - área de atração ou região de estabilidade do p.e.e. $x_{s}$

$\bar{A}\left(x_{s}\right) \quad$ - fecho da área de atração do p.e.e. $x_{s}$

$B_{k m} \quad$ - susceptância da linha $k-m$

D - constante de amortecimento

$E_{i} \quad$ - Força Eletromotriz da máquina $i$

$f_{0} \quad$ - freqüência da rede elétrica

$G_{k m} \quad$ - condutância da linha $k-m$

H - constante de tempo

$h$ - número de passos de integração do PEBS dinâmico 


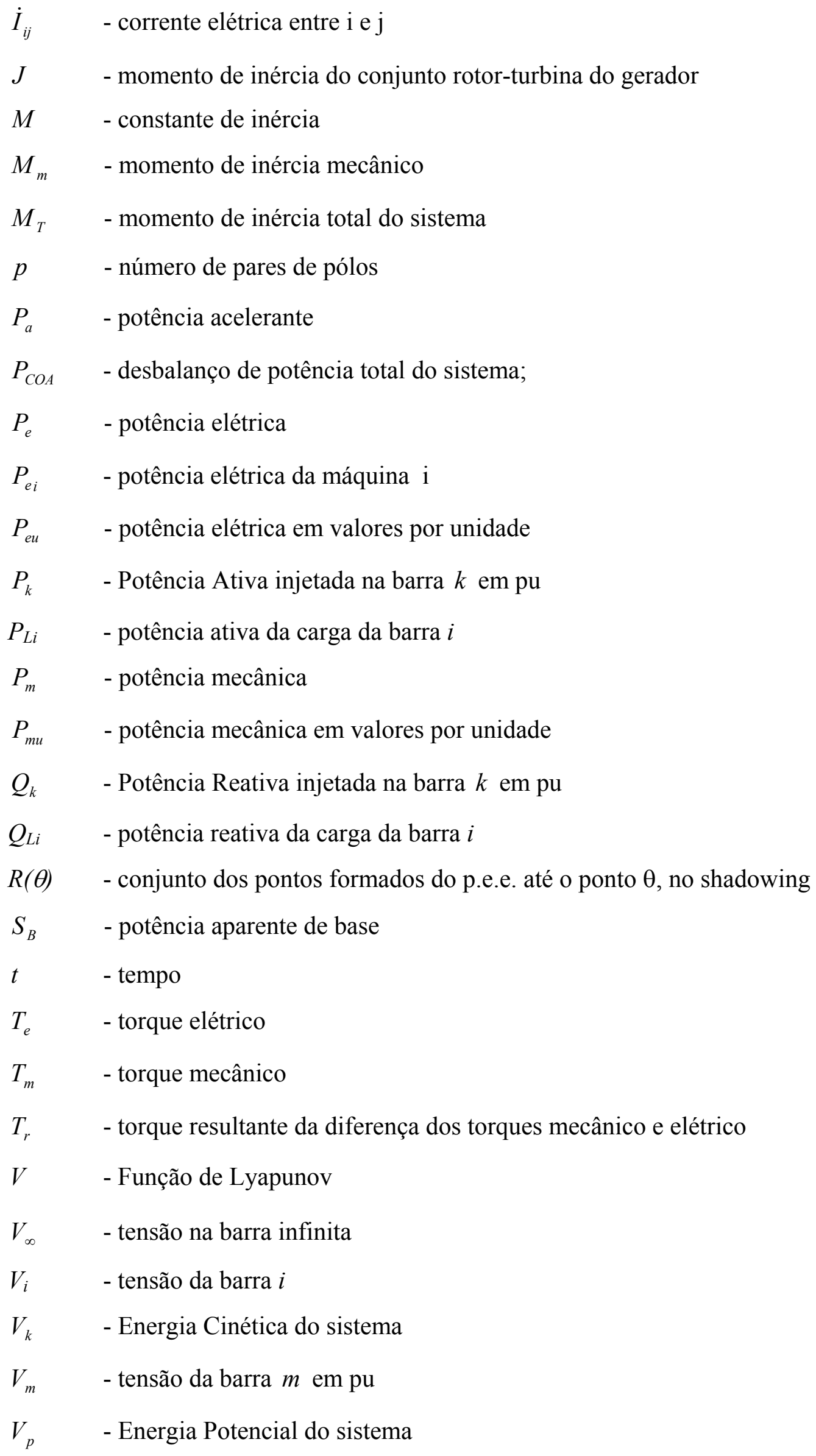




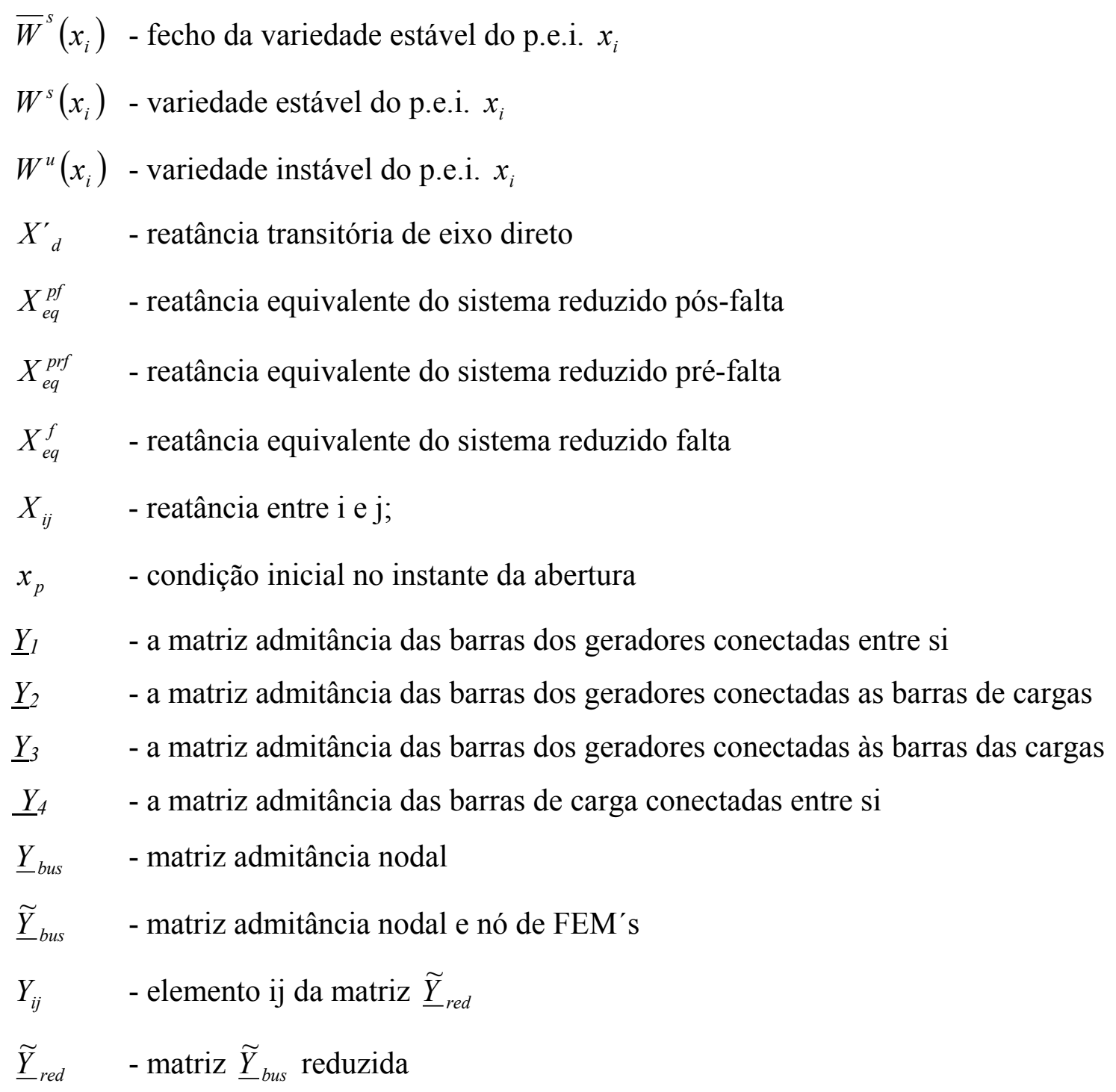




\section{Sumário}

RESUMO vi vi v vis

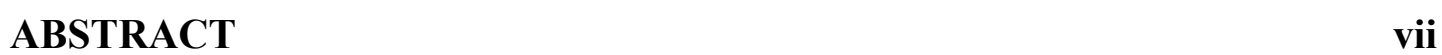

1 INTRODUÇÃO 1

1.1 Estabilidade Transitória em Sistemas de Potência...................................... 1

1.2 Objetivos de estudo e Organização do Trabalho......................................... 3

2 ESTABELECIMENTO DO PROBLEMA E MODELAGEM DO SISTEMA ELÉTRICO ASSOCIADO AO ESTUDO DE ESTABILIDADE TRANSITÓRIA $\mathbf{5}$

2.1 Objetivos dos estudos de estabilidade em Sistemas elétricos................ 6

2.2 Modelagem do Problema Dinâmico para o Estudo de Estabilidade

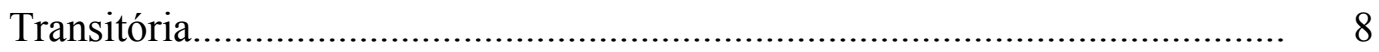

2.3 Modelo Estático Pré-Estabilidade......................................................... 12

2.4 Modelagem Clássica de Máquinas Síncronas para o Estudo de

Estabilidade

3 ESTABILIDADE TRANSITÓRIA EM SISTEMAS ELÉTRICOS DE POTÊNCIA

3.1 Divisão do Problema no Tempo.................................................................. 19

3.2 Solução Numérica pelo método passo-a-passo ....................................... 20

3.3 Sistema Multimáquinas........................................................................... 22

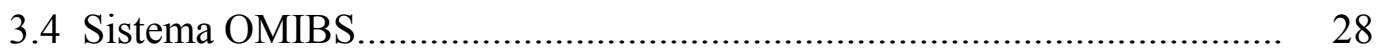

3.5 Sincronismo frente a Estabilidade - Um problema de referencial............ 31

3.6 Uma Máquina como Referência.............................................................. 33 
4 ESTABILIDADE TRANSITÓRIA POR MÉTODOS DIRETOS 37

4.1 Critério das Áreas Iguais.................................................................... 39

4.2 Teoria dos Sistemas Dinâmicos Autônomos ............................................ 43

4.3 O Método de Lyapunov para Sistemas Autônomos................................. 44

4.4 Definição da Área de Atração............................................................... 48

4.5 Aplicação dos Métodos Diretos e sua Função Energia à Sistemas de

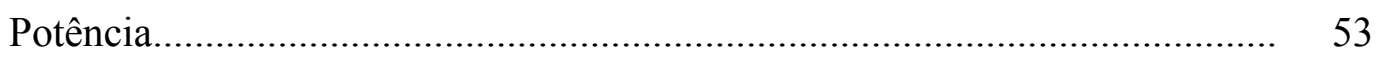

4.6 Evolução dos Métodos Diretos............................................................. 57

4.7 Método PEBS ............................................................................ 63

4.8 Sistema Gradiente Associado ao Modelo Clássico - Fundamentação Teórica do PEBS.................................................................................. 68

4.9 Método BCU ("Boundary Controlling Unstable Equilibrium Point")..... 73

5 ESTADO DA ARTE: PROBLEMAS E SOLUÇÕES DO PEBS E BCU 76

5.1 Problemas Associados a Deteção do "Exit Point"..................................... 77

5.2 PEBS dinâmico.............................................................................. 80

5.3 Problemas Associados a Deteção do Ponto de equilíbrio Instável de

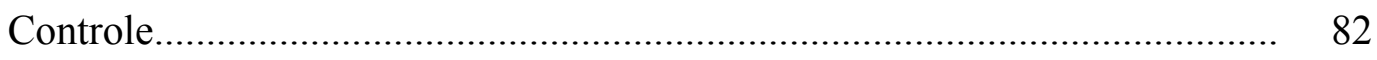

5.4 Shadowing Method........................................................................ 87

6 RESULTADOS OBTIDOS

6.1 Sistema de 3 Barras com 3 Geradores.................................................. 90

6.2 Sistema de 14 Barras com 5 máquinas (bus14 do IEEE)........................ 95

6.3 Sistema New England - 39 barras (10 geradores).................................. 106

6.4 Considerações finais dos testes realizados............................................ 109

7 RESULTADOS OBTIDOS

7.1 Discussão dos resultados obtidos pelo algoritmo PEBS dinâmico............ 110

7.2 Propostas para melhoria do algoritmo PEBS dinâmico............................. 112

7.3 Discussão dos resultados obtidos pelo algoritmo "Shadowing Method".. 114

7.4 Proposta para melhoria do algoritmo "Shadowing Method".................... 115 
A.1 Método de Integração Numérica de Euler Simples............................... 124

A.2 Método de Integração Numérica de Runge-Kutta................................ 125

$\begin{array}{ll}\text { Apêndice B } & 127\end{array}$

B.1 Eliminação de Gauss....................................................................... 127

$\begin{array}{lr}\text { Apêndice C } & 130\end{array}$

C.1 Carga de Arquivo com Dados do Sistema de 14 Barras do IEEE.......... 130

C.2 Carga de Arquivo com Dados do Sistema de 39 Barras - New

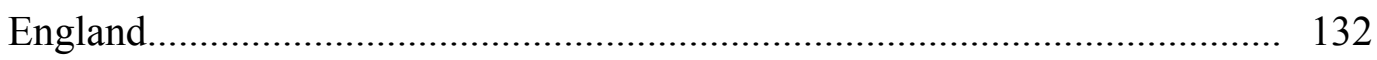




\section{Capítulo 1}

\section{INTRODUÇÃO}

\subsection{Estabilidade Transitória em Sistemas de Potência}

A análise de estabilidade transitória é um dos mais complexos e atraentes problemas em sistema elétricos de potência. As não linearidades inerentes aos sistemas aliadas à grande dimensão do problema tornam o comportamento dos sistemas de potência muito complexos. Para compreender melhor estes sistemas, conceitos matemáticos modernos da teoria de sistemas dinâmicos têm sido utilizados.

$\mathrm{O}$ estudo de estabilidade em sistemas de potência traduz-se matematicamente no estudo da estabilidade de um conjunto de equações diferenciais não lineares e autônomo. Como este conjunto não possui solução analítica, a abordagem clássica utiliza-se de inúmeras soluções numéricas iterativas para a obtenção do tempo crítico de abertura. Obviamente este processo não é adequado a aplicações em tempo real.

Métodos diretos são adequados para análises de estabilidade transitória em tempo real, uma vez que informações a respeito da estabilidade podem ser obtidas sem a necessidade da solução explícita das equações diferenciais. Dentre os métodos diretos existentes, os resultados de Lyapunov associados ao princípio de invariância de LaSalle, têm se destacado por serem métodos energéticos e diretos adequados ao estudo de estabilidade de sistemas não lineares. Dos resultados de Lyapunov originaram-se uma grande quantidade de métodos para efetuar a estimativa da região de estabilidade dos sistemas de potência. O conceito de ponto de equilíbrio instável de controle foi concebido e uma grande variedade de metodologias para calculá-lo foi desenvolvida. 
Entre estas metodologias, o método BCU ('Boundary Controlling Unstable Equilibrium Point") tem sido aceito pela comunidade científica como sendo o método mais eficiente para a determinação do tempo crítico de abertura. Sua eficiência é conseqüência de um embasamento teórico sólido que permitiu definir precisamente o ponto de equilíbrio instável de controle. Maiores detalhes a respeito deste método podem ser encontrados em Chiang et al. (1994), em Alberto (1997), onde uma análise detalhada deste método foi realizada ou em Bretas e Alberto (2000).

Embora o BCU seja um método bastante eficiente, existe uma grande quantidade de casos em que o BCU falha. Uma das causas de falha do BCU é analisada detalhadamente no artigo de Llamas et al. (1995). Estes mostram alguns exemplos em que o BCU prediz estabilidade mas o sistema perde o sincronismo em "swings" subseqüentes ao primeiro. Llamas et al. associam o problema à não satisfação da condição de transversalidade que é exigida para o desenvolvimento teórico do BCU, e não é testada na implementação computacional deste. Em verdade, todos os métodos que utilizam o conceito de ponto de equilíbrio de controle analisam a estabilidade do sistema apenas para o primeiro "swing". Se os amortecimentos não forem suficientemente grandes, o sistema poderá possuir energia para tornar-se instável nos "swings" subseqüentes. Em outras palavras, o ponto de equilíbrio de controle é determinado relativamente ao modo de instabilidade existente no sistema durante a falta. Após a eliminação do defeito, outros modos de instabilidade podem surgir devido a energia acumulada pelo sistema durante a falta.

Um outro problema encontrado no algoritmo BCU está associado a um problema numérico relacionado a deteção do PEBS ("Potential Energy Boundary Surface") ou do "exit point". Quando o "exit point" ou ponto de saída não é encontrado corretamente, o algoritmo BCU falha na determinação do ponto de equilíbrio de controle correto levando a estimativas da área de atração incorretas ou mesmo a resultados não conclusivos. Este problema numérico foi observado em diversas situações. Uma delas ocorre quando há máquinas fortemente acopladas, ou seja, coerentes. Uma outra situação bastante comum em que o BCU falha ocorre quando a resistência de falta não é nula. 


\subsection{Objetivos de Estudo e Organização do Trabalho}

O escopo deste trabalho se resume na aplicação dos algoritmos propostos por Scruggs e Mili (2001) e Treinen et al. (1996) para a deteção correta do "exit point" e do ponto de equilíbrio instável de controle a as conclusões sobre a robustez e aplicabilidade destes métodos em tempo real.

Scruggs e Mili (2001) propuseram um método dinâmico para verificar quando a trajetória em falta cruza o PEBS. Para esta verificação, utiliza-se um sistema gradiente associado. Simula-se o sistema gradiente a partir do instante inicial da falta, verificando para cada passo, se o ponto resultante está ou não dentro de uma área de atração do sistema pós-falta. Procura-se, então, o "exit point" até o instante que o processo de verificação informa que tal ponto é instável. A robustez do método reside no fato de que o processo de verificação proposto baseia-se na própria definição do que é o PEBS, e é rápido o suficiente para não prejudicar o método direto.

Treinen et al. (1996) propuseram o "shadowing method" para sobrepujar falhas na deteção do ponto de equilíbrio de controle quando do uso do algoritmo BCU. Explorando o formato e o fluxo nas vizinhanças da variedade estável do ponto de equilíbrio instável de controle, esta técnica consegue convergir eficientemente para tal ponto de controle em situações onde o algoritmo BCU falha.

Visando tal objetivo, o trabalho foi elaborado com a seguinte organização:

No capítulo 2 estuda-se a modelagem de sistemas de potência para o estudo de estabilidade transitória. Deduz-se a equação de "swing" como sendo a equação diferencial representante da dinâmica das máquinas síncronas do sistema. O modelo clássico de máquinas síncronas é apresentado e a modelagem de um sistema de potência para estudos estáticos (fluxo de carga) também é apresentada resumidamente.

No capítulo 3 discute-se a estabilidade transitória clássica. A solução numérica clássica é descrita. A equação de "swing" é desenvolvida para aplicações em sistemas multimáquinas e no caso particular de sistemas de uma máquina versus barramento infinito. Uma descrição de como o problema da estabilidade em sistemas multimáquinas pode ser visto como sendo um problema de sincronismo entre geradores é estudada. Referenciais clássicos são descritos: uma máquina como referência (OMR) e referência no centro de ângulo (COA). 
No capítulo 4 discute-se a abordagem e as fundamentações dos métodos diretos para o estudo de estabilidade transitória. O método de Lyapunov é estudado baseado na teoria de sistemas dinâmicos autônomos, e uma função do tipo energia, baseado nos estudos de Lyapunov é então descrita. O desenvolvimento dos métodos diretos na literatura, bem como a convergência dos estudos dos métodos diretos para novas técnicas de estimativa da área de atração são descritos, terminando-se pelos estudos associados ao PEBS e BCU, que são duas destas técnicas.

No capítulo 5 são descritos e exemplificados os problemas associados aos métodos diretos PEBS e BCU e propostos os algoritmos PEBS dinâmico e "shadowing method" como algoritmos robustos capazes de sobrepujar as deficiências e falhas descritas do PEBS e BCU.

No capítulo 6 são mostrados os resultados obtidos com os métodos robustos na predição da estabilidade para três sistemas: 3 barras, 14 barras e 39 barras (New England).

No capítulo 7 discussões a respeito dos resultados e falhas dos métodos implementados são realizadas. Novas metodologias mais refinadas, baseadas em tais métodos robustos, são propostas.

No capítulo 8 são descritas as conclusões deste trabalho. 


\section{Capítulo 2}

\section{ESTABELECIMENTO DO PROBLEMA E MODELAGEM DO SISTEMA ELÉTRICO ASSOCIADO AO ESTUDO DE ESTABILIDADE TRANSITÓRIA}

Os modelos de sistemas de potência para o estudo de estabilidade transitória descrevem através de equações matemáticas o comportamento dinâmico do sistema elétrico de potência. Os modelos matemáticos são, então, implementados em programas computacionais, que simulam o comportamento do sistema elétrico quando da ocorrência de uma situação de contingência.

O objetivo deste capítulo é situar o problema de estabilidade transitória dentre os variados problemas associados aos sistemas elétricos de potência, bem como, o estudo da modelagem matemática associada ao problema.

Primeiramente, será visto a classificação do estudo de estabilidade em pequenas perturbações e transitória, sendo esta divisão necessária, de acordo com os diferentes objetivos da análise em sistemas elétricos de potência, fato que leva a diferentes modelos representativos do sistema. Já na seção 2, será deduzida a equação de "swing", que é uma equação diferencial que representa a dinâmica da máquina associada a um sistema elétrico em estudo e que será utilizada nos estudos de estabilidade transitória como parte do modelo representante do sistema elétrico. A seção 3 descreve as equações representantes do modelo estático de um sistema de potência, bem como a forma de obtenção, através de um algoritmo, dos estados associados a este problema estático. Estes estados são importantes porque são as condições iniciais do estudo de 
estabilidade transitória. A seção 4 descreve a modelagem clássica de máquinas síncronas associadas ao estudo de estabilidade transitória, onde se busca uma representação das grandezas envolvidas na operação do gerador, enquanto equipamento mais importante para o estudo de estabilidade transitória em sistemas elétricos de potência.

\subsection{Objetivos dos Estudos de Estabilidade em Sistemas Elétricos}

O estabelecimento do estudo de estabilidade, bem como outros estudos em sistemas elétricos de potência, está profundamente relacionado aos objetivos que este estudo deseja alcançar. Os modelos representativos utilizados, como é o caso dos modelos de máquinas síncronas, podem ser mais ou menos simplificados, de acordo com o objetivo do estudo. Neste contexto, objetivos diferentes levam a modelos diferentes. No estudo de estabilidade é exatamente isto que acontece. Dependendo do objetivo, modela-se o sistema, que é então estudado da maneira mais eficiente para o modelo proposto. Como o objetivo deste trabalho consiste no estudo de estabilidade transitória, será visto como o problema estará representado, para que este objetivo seja alcançado.

Um sistema elétrico de potência é composto, basicamente, de geradores síncronos, linhas de transmissão e cargas. A operação do sistema em regime permanente é aquela em que suas grandezas não variam com o tempo, o que implica que não existe desbalanço energético, ou seja, a potência gerada é igual à potência consumida mais as perdas inerentes ao sistema. Nesta situação, os geradores síncronos têm velocidades angulares constantes, e os ângulos de fase do sistema permanecem constantes, garantindo um fluxo de carga constante no sistema. Nesta situação é dito que o sistema está em um ponto de operação estável.

O sistema permanecerá neste ponto até que algum distúrbio aconteça. Estes distúrbios no sistema podem ser aumentos ou diminuições de carga, ou contingências severas, como curto-circuitos. Nestes casos, o comportamento dinâmico do sistema mediante as perturbações se torna algo importante, pois o sistema agora, está submetido a um desbalanço de potência, e é necessário que ele retorne a uma operação estável. Aspectos qualitativos e quantitativos do comportamento dinâmico do sistema, bem 
como as atuações necessárias à estabilização do sistema são o escopo do estudo de estabilidade de sistemas elétricos de potência.

O estudo de estabilidade se divide, basicamente, em dois: estabilidade de pequenas perturbações e estabilidade transitória, ou a grandes perturbações. Esta divisão do estudo deve-se a diferença de objetivos no estudo, fato que leva a modelagens diferentes para cada um dos estudos em sua aplicação a sistemas elétricos de potência.

Quando o objetivo do estudo de estabilidade é a reação do sistema a pequenas perturbações, onde se entende por pequenas perturbações as variações de carga comuns ao dia-a-dia da operação de sistemas de potência, ou então, faltas aleatórias que resultam em curto-circuitos brandos, que por sua vez, são rapidamente eliminados pelo sistema de proteção, sem afetar significativamente a transmissão de potência. Dentro deste contexto, as equações diferenciais do sistema podem ser linearizadas em torno do ponto de operação estável, uma vez que o sistema está submetido a pequenas perturbações que não afastam significativamente as variáveis de estado deste ponto de operação. O modelo representante, então, é um conjunto de equações diferenciais invariantes no tempo, do tipo:

$$
\dot{x}=A \cdot x
$$

e a análise de estabilidade é feita através da teoria de sistemas lineares, e está diretamente associada ao estudo dos autovalores da matriz $A$.

Já no estudo de estabilidade transitória, o sistema está sujeito a grandes distúrbios, que ocasionam situações de desbalanço de potência, a partir de onde o sistema pode, por si só, encontrar um ponto de operação estável, ou seja, um equilíbrio no sistema, isto o leva ao pleno atendimento energético, ou ainda, muitas vezes o sistema pode não encontrar este equilíbrio, e uma intervenção torna-se necessária para que o sistema volte a operar estavelmente. Entende-se como intervenção, por exemplo, a atuação do sistema de proteção para a eliminação de uma falta, ou até um alívio de carga caso seja necessário.

Neste estudo, como as perturbações são grandes, as não-linearidades inerentes ao sistema elétrico não podem ser desprezadas. O objetivo do estudo de estabilidade transitória recai, então, na verificação da manutenção do sincronismo entre os geradores do sistema em um curto intervalo de tempo após a ocorrência do defeito. Logo, o modelo matemático do sistema é um conjunto de equações diferenciais não-lineares. 
Pelo fato de estar se tratando de situações envolvendo tempos de no máximo alguns segundos, a atuação de controladores pode, em alguns casos ser desprezada.

Após a intervenção, o sistema adquire uma nova configuração, e nesta nova configuração o sistema deve atingir um novo ponto de operação estável, partindo de uma situação desbalanceada, ou seja, como houve um desbalanço de potência, as máquinas do sistema não mantiveram as velocidades angulares constantes, porém o sistema mesmo desequilibrado deve ser capaz de retornar a um ponto de operação estável.

Se a trajetória do sistema convergir para um ponto de operação estável, após a intervenção, o sistema é dito transitoriamente estável. O tempo máximo em que a intervenção tem de ocorrer para que o sistema permaneça estável é dito tempo crítico de abertura (tcr). Logo se a intervenção ocorrer após o tempo crítico de abertura, o sistema é transitoriamente instável, e caso contrário, transitoriamente estável. A determinação do tempo crítico de abertura é, portanto o objetivo principal do estudo de estabilidade transitória.

\subsection{Modelagem do Problema Dinâmico para o Estudo de Estabilidade Transitória}

Para o estudo de estabilidade é necessário um modelo matemático que represente o comportamento do sistema elétrico. No caso de estabilidade transitória, um modelo matemático que descreve o comportamento dinâmico do sistema pode ser obtido aplicando um balanço de potência em cada máquina do sistema. Com este procedimento obtém-se a tão conhecida equação de "swing".

Como pode ser visto em Ramos et al. (2000), em um gerador a potência mecânica é fornecida por um elemento primário, e a energia é transformada em potência elétrica deixando o sistema em equilíbrio. Quando o sistema se desequilibra, a parte da energia que sobra ou falta é transformada em potência acelerante ou desacelerante do rotor da máquina. Da mecânica, tem-se a equação:

$$
J \cdot \ddot{\theta}=T_{r}
$$

onde:

- $\quad J$ - momento de inércia do conjunto rotor-turbina do gerador[kg. $\left.\mathrm{m}^{2}\right]$; 
- $\theta$ - ângulo mecânico do rotor com relação ao eixo de referência fixo [rad];

- $T_{r}$ - torque resultante [N.m];

onde $T_{r}$ é o torque resultante da diferença do torque mecânico, proveniente do agente motor, e o torque elétrico, que advém da potência elétrica, através de campos magnéticos. Logo:

$$
T_{r}=T_{m}-T_{e}
$$

O ângulo mecânico do rotor com relação a um eixo fixo $\theta$, transforma-se em um problema quando do estudo de sistemas elétricos, pelo fato de o mesmo ser uma função do tempo quando o sistema opera em regime permanente. Para solucionar este problema escolhe-se o sistema referencial angular rotativo e síncrono (referência girante), que no caso do Brasil, é de $60 \mathrm{~Hz}$ (freqüência elétrica de operação). Para isso tem-se:

$$
\theta(t)=\left(\omega_{s} \cdot t+\alpha\right)+\delta_{m}(t)
$$

onde:

- $\left(\omega_{s} \cdot t+\alpha\right)$ - referência girante à velocidade síncrona;

- $\quad \alpha$ - ângulo de defasagem entre a referência fixa e a referência girante no tempo $t=0$;

- $\delta_{m}(t)$ - ângulo mecânico formado entre o rotor e a referência girante;

Derivando-se duas vezes a equação (2.4) com relação ao tempo, tem-se:

$$
\ddot{\theta}(t)=\ddot{\delta}_{m}(t)
$$

Apesar da mudança de referência podemos observar que a aceleração angular é independente da referência utilizada, logo a equação que descreve o comportamento dinâmico ao longo do tempo na referência estática é a mesma que descreve o comportamento dinâmico ao longo do tempo na referência girante. Portanto, rearranjando-se a equação (2.1), tem-se:

$$
J \cdot \ddot{\delta}=T_{r}
$$

e substituindo o resultado na equação (2.3), tem-se (2.7):

$$
J \cdot \ddot{\delta}=T_{m}-T_{e}
$$

Para obter um conjunto de equações diferenciais que defina um espaço de estados para a máquina, é mais conveniente escrever a equação (2.7) em termos do ângulo $\delta_{e}$, que é o ângulo formado entre a referência girante e o eixo do campo magnético que 
envolve o rotor, pois o torque elétrico $T_{e}$ será uma função deste ângulo. O ângulo $\delta_{m} \mathrm{e}$ o ângulo elétrico $\delta_{e}$ estão relacionados por:

$$
\delta_{e}=\frac{p}{2} \cdot \delta_{m}
$$

onde:

- $\quad p$ - número de pares de pólos da máquina;

Da mesma maneira, pode-se relacionar a velocidade mecânica com a elétrica, através da equação:

$$
\omega_{e}=\frac{p}{2} \cdot \omega_{m}
$$

Nestas novas variáveis a equação (2.7) pode ser escrita como:

$$
\frac{2}{p} \cdot J \cdot \ddot{\delta}_{e}=T_{m}-T_{e}
$$

Como o momento de inércia $J$ de uma máquina não é comumente fornecido pelos fabricantes, mas sim a constante de inércia $H$, pode-se escrever:

$$
J=\frac{2 \cdot H \cdot S_{B}}{\omega_{0 m}^{2}}
$$

onde:

- $S_{B}$ - potência aparente trifásica base da máquina;

- $\omega_{0 m}^{2}$ - velocidade mecânica síncrona do sistema;

- $\frac{S_{B}}{\omega_{0 m}^{2}}$ - é o torque base $T_{B}$;

Pode-se reescrever (2.10), utilizando-se (2.9) e (2.11), resultando em:

$$
\frac{2 \cdot H}{\omega_{0 e}} \cdot \dot{\omega}_{e}=\frac{T_{m}-T_{e}}{T_{B}}
$$

onde:

- $\omega_{0 e}$ - velocidade elétrica síncrona do sistema;

Passando a equação (2.12) para valores por unidade, obtém-se a equação (2.13):

$$
2 \cdot H \cdot \dot{\omega}_{u}=T_{m u}-T_{e u}
$$

onde: 
- $\omega_{u}=\frac{\omega_{e}}{\omega_{0 e}}-$ valor em p.u. da velocidade angular do campo (em relação à referência girante);

- $T_{m u}=\frac{T_{m}}{T_{B}}$ - valor em p.u. do torque mecânico;

- $T_{e u}=\frac{T_{e}}{T_{B}}$ - valor em p.u. do torque elétrico;

Esta equação é chamada de equação de oscilação ou equação de "swing", e não introduz erros decorrentes de aproximações na modelagem da oscilação da máquina.

Outro tipo de equação de "swing" comumente utilizada em estudos de estabilidade transitória considera que a velocidade angular $\omega_{m}$ tem uma variação muito pequena durante o período transitório, pois caso contrário, ocorreria a perda de sincronismo rapidamente, e o sistema tornar-se-ia instável. Com isso, pode-se considerar que o momento angular do rotor $M_{m}=J \cdot \omega_{m}$ é constante. Multiplicando ambos os lados da equação (2.7) por $\omega_{m}$, podemos obter uma nova equação de "swing" que tem como parâmetro o momento angular $M_{m}$, constante por hipótese. Obviamente, um erro decorrente desta hipótese estará presente neste equacionamento, e alguns artigos da literatura sugerem que um termo de amortecimento pode ser incluído na nova equação para compensar este erro.

Escrevendo a equação (2.13) em relação ao ângulo elétrico $\delta_{e}$, em valores p.u. e com a aproximação discutida, tem-se:

$$
M \cdot \ddot{\delta}_{e}+D \cdot \dot{\delta}_{e}=P_{m u}-P_{e u}
$$

onde:

$$
\text { - } \quad M=\frac{2 \cdot M_{m}}{p \cdot S_{B}}=\frac{2 \cdot J \cdot \omega_{m}}{p \cdot S_{B}}
$$

Não existe nenhum procedimento padronizado para se encontrar um valor apropriado para a constante de amortecimento $D$ neste caso. Alguns indicativos para o cálculo desta constante podem ser encontrados em Anderson e Fouad (1977).

A equação (2.15) também é conhecida como equação de "swing", como dito anteriormente, e será utilizada no desenvolvimento deste trabalho. 


\section{3 -Modelo Estático do Problema Pré-Estabilidade}

Como dito na seção anterior, o sistema operando em regime permanente é um sistema estável. Neste caso a aceleração angular é nula porque a potência mecânica injetada pelo elemento primário é igual a potência elétrica solicitada pelo sistema elétrico.

Esta característica de operação prévia ao problema de estabilidade é obtida também através de um modelo do sistema, só que um modelo estático, que consiste essencialmente na determinação do estado de equilíbrio da rede de energia elétrica. Esta modelagem utiliza um conjunto de equações algébricas associadas a inequações representantes dos limites dos equipamentos modelados. Neste estudo as variações no tempo são consideradas lentas o suficiente para que efeitos transitórios possam ser ignorados.

A este tipo de estudo é dado o nome de fluxo de carga ou fluxo de potência.

Neste texto não serão discutidos aspectos do fluxo de carga, por não ser o escopo do trabalho, mas serão mostradas as equações estáticas do fluxo de carga, bem como uma explicação da sua solução para que o trabalho não fique prejudicado pela falta de caracterização da obtenção das condições iniciais das variáveis de estado do estudo de estabilidade transitória.

Das leis de Kirchhoff, deduzem-se as equações abaixo, para a potência ativa e reativa, que são as equações básicas do fluxo de carga:

$$
\begin{aligned}
& P_{k}=V_{k} \sum_{m \in K} V_{m} \cdot\left(G_{k m} \cdot \cos \theta_{k m}+B_{k m} \cdot \operatorname{sen} \theta_{k m}\right) \\
& Q_{k}=V_{k} \sum_{m \in K} V_{m} \cdot\left(G_{k m} \cdot \operatorname{sen} \theta_{k m}-B_{k m} \cdot \cos \theta_{k m}\right)
\end{aligned}
$$

onde:

- $K$ - conjunto de todas as barras que se conectam a barra $k$;

- $k=1, \ldots$, número de barras ;

- $\quad P_{k}$ - Potência Ativa injetada na barra $k$ em pu;

- $\quad Q_{k}$ - Potência Reativa injetada na barra $k$ em pu;

- $\quad V_{k}$ - tensão da barra $k$ em pu;

- $\quad V_{m}$ - tensão da barra $m$ em pu;

- $G_{k m}$ - condutância da linha $k-m$; 
- $\quad B_{k m}$ - susceptância da linha $k-m$;

- $\theta_{k m}$ - diferença dos ângulos de carga da barra $k$ para a barra $m$;

A resolução de um sistema de equações algébricas como as descritas acima por processos iterativos, bem como a consideração da atuação de dispositivos de controle e dos limites do sistema, constituem-se na solução do fluxo de carga para sistemas elétricos de potência.

Por se tratar de um sistema de equações algébricas não-lineares, a solução dar-se-á através de métodos iterativos (numéricos). Dentre os métodos existentes, que são inúmeros, geralmente escolhe-se o método de Newton ou o método Desacoplado Rápido, por serem os que possuem maior interesse prático, conforme Monticelli (1983).

Ainda segundo Monticelli (1983), a resolução de sistemas algébricos pelo método de Newton tem o seguinte formato:

Seja o método de Newton para um sistema unidimensional:

$$
g(x)=0
$$

Determina-se o valor de $x$ onde $g(x)$ se anula. Esta solução corresponde ao ponto em que a curva corta o eixo $x$ na figura abaixo:

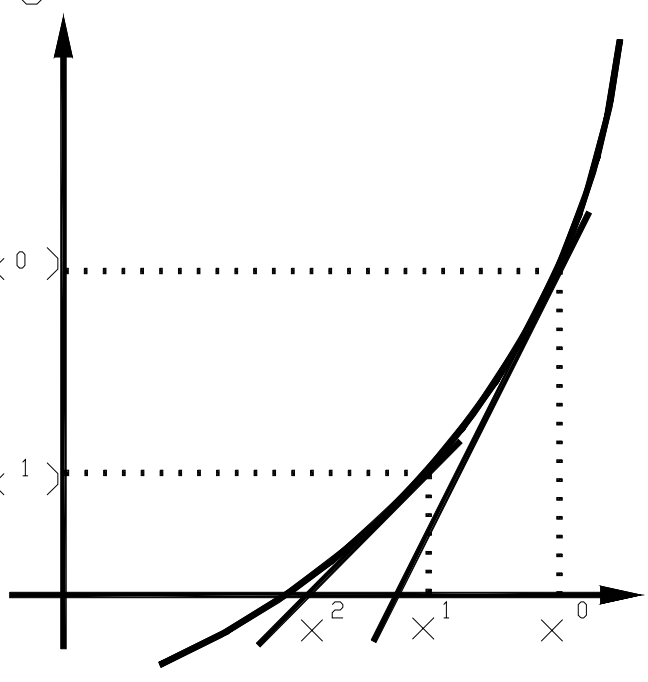

Figura 2.1 - Método de Newton

A resolução iterativa segue os passos:

i) $k=0$ e $x=x^{k}$; 
ii) Partindo de um ponto $x^{k}$, calcula-se o valor de $g(x)$ para este ponto;

iii) Compara-se o valor calculado acima com a tolerância especificada, se $\left|g\left(x^{k}\right)\right|<\varepsilon$, pare;

iv) Lineariza-se a função $g(x)$ em torno do ponto calculado no passo $i$, por intermédio da série de Taylor:

$$
g\left(x^{k}+\Delta x^{k}\right) \cong g\left(x^{k}\right)+g^{\prime}\left(x^{k}\right) \cdot \Delta x^{k}
$$

onde $\mathrm{g}^{\prime}(\mathrm{x})=\mathrm{dg} / \mathrm{dx}$;

v) Resolve-se o problema linearizado até que:

$$
g\left(x^{k}\right)+g^{\prime}\left(x^{k}\right) \cdot \Delta x^{k}=0
$$

vi) faz-se $k=k+1$, e retorna-se ao passo ii, até o passo iii ser atendido;

Encontrado o ponto que atende a solução do sistema de equações representantes do modelo estático do sistema de potência, têm-se os dados iniciais do estudo de estabilidade transitória.

\section{4 -Modelagem Clássica de Máquinas Síncronas para Estudo de Estabilidade Transitória}

A representação das máquinas síncronas consiste em um problema no estudo de engenharia elétrica. Esta representação é feita através de modelos de máquinas, que são gerados, por sua vez, a partir de hipóteses simplificadoras. Estas hipóteses simplificadoras são soluções de compromisso em relação ao objetivo do estudo, e por isso, alguns modelos apesar de simples, escondem muitos detalhes e aproximações.

Na modelagem de máquinas síncronas, quando uma referência é fixada ao estator, as grandezas eletromagnéticas medidas através da referência fixa apresentam variações no tempo, devido ao movimento do rotor. Estas variações serão funções do ângulo $\theta$, como mostrado na figura 2.2 .

Uma simplificação do modelo pode ser feita através do uso de uma referência girante que acompanhe o movimento do rotor, criando para o estator novas variáveis que são independentes do tempo. Esta simplificação pode ser feita com uma mudança de variáveis chamada Transformação de Park. 
A Transformação de Park gera três novas correntes $i_{0}, i_{d}$ e $i_{q}$, onde $i_{d}$ corresponde à "projeção" das correntes de fase ao longo de um eixo paralelo ao eixo magnético do enrolamento de campo, denominado de eixo direto (eixo d), e $i_{q}$ corresponde à "projeção" das correntes de fase ao longo de um eixo atrasado de $90^{\circ}$ em relação ao eixo direto, chamado de eixo em quadratura (eixo q). A variável $i_{0}$ é uma corrente estacionária, proporcional à corrente de seqüência zero.

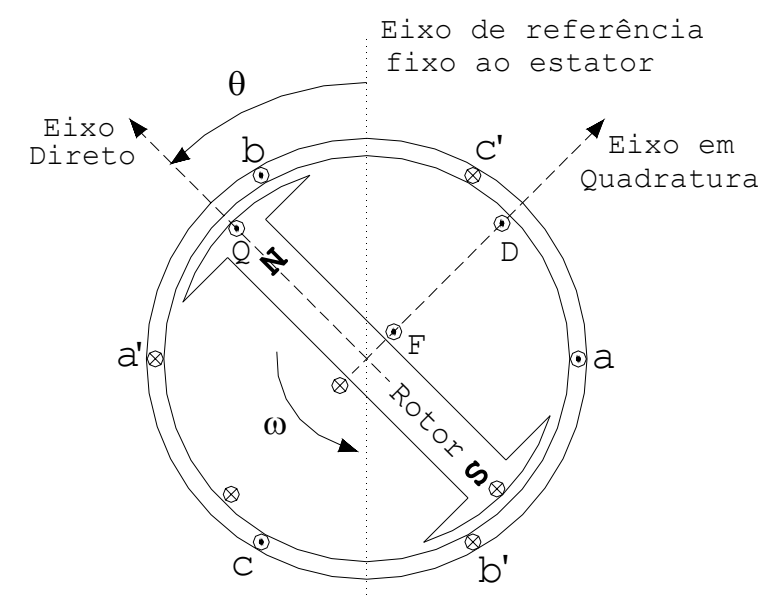

Figura 2.2- Transformação de Park

Alguns modelos simplificados têm sido largamente usados no estudo de estabilidade transitória, devido as suas simplicidades e eficiências, como os modelos clássico, um eixo e dois eixos.

Em muitas análises, utiliza-se o modelo clássico para a análise de estabilidade transitória, pois este modelo simplificado do gerador, consiste apenas em uma máquina como uma fonte de tensão atrás de uma impedância. As principais simplificações deste modelo são:

- Reguladores de Tensão não estão presentes e excitação manual é utilizada. Isto implica que em regime de operação, a magnitude da tensão da fonte do modelo é determinada pela corrente de campo que é constante;

- Circuitos amortecedores são desconsiderados (subtransitórios desprezados);

- Decaimento do fluxo do circuito de campo é desprezado;

- A potência mecânica injetada pelo elemento primário é considerada constante;

- A saliência tem efeito pequeno e é desprezada para estudo da estabilidade transitória; 
Considere a figura 2.3, onde o gerador G representa uma usina elétrica composta de vários geradores. O gerador está conectado a uma linha de transmissão (LINHA) em circuito duplo através de um transformador $(\mathrm{T})$. A linha está conectada ao sistema elétrico através da impedância equivalente $\left(\mathrm{Z}_{\mathrm{T}}\right)$.

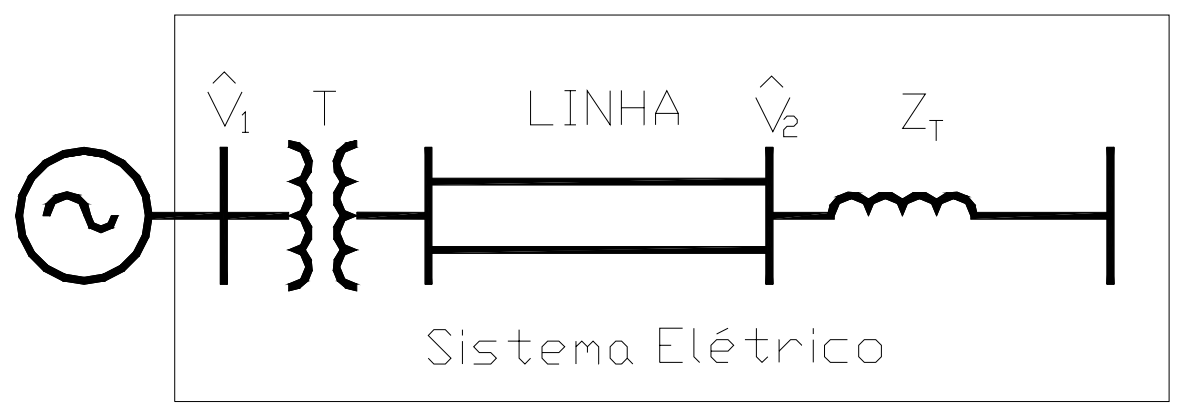

Figura 2.3- Uma máquina ligada um sistema elétrico

Baseado no modelo clássico, o circuito equivalente fica:

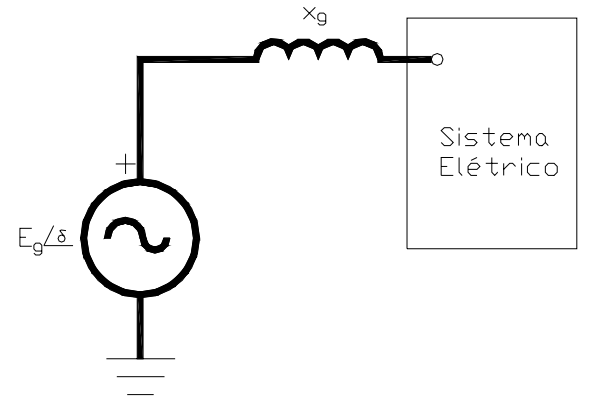

Figura 2.4-Circuito equivalente à figura 2.3 com gerador representado pelo modelo clássico

onde:

- $x_{g}$ é igual a reatância síncrona $x_{d}$ para análise em regime permanente e igual a $x_{d}^{\prime}$ para análise transitória;

- $E_{g}$ é proporcional ao fluxo de campo concatenado, que é suposto constante;

Portanto, para o modelo clássico de gerador, as equações diferenciais relatam apenas o movimento do rotor, como demonstrado na seção 2.2 para a equação de "swing". 


\section{Capítulo 3}

\section{ESTABILIDADE TRANSITÓRIA EM SISTEMAS ELÉTRICOS DE POTÊNCIA}

O estudo de estabilidade transitória em sistemas eletroenergéticos passa a ter sentido quando os sistemas elétricos vão ganhando grandes dimensões e se tornando complexos. Nestes sistemas, como é o caso do atual sistema brasileiro, confiabilidade de operação, custos de operação, qualidade de fornecimento entre outras características, são muito importantes. Dentre as características esperadas de um sistema elétrico, está a robustez a contingências, pequenas ou grandes, a qual se dá o nome de estabilidade, como descrito no capítulo anterior. Estabilidade, então, é a capacidade de permanecer operando, mesmo com restrições, quando do acontecimento de um evento (perturbação) que tire o sistema de um ponto de operação normal (estável).

Obviamente, o estudo de estabilidade está associado a uma margem de manobra, ou folgas existentes em um sistema elétrico, ou seja, sistemas muito carregados tendem a ser menos robustos a perturbações devido a operação próxima aos limites dos equipamentos associados a ele, da geração até o atendimento de carga. Porém, folgas e margens, além de representarem segurança dinâmica para o sistema também representam custos para sua operação. Uma relação de compromisso entre a operação dinâmica segura e seu custo de operação deve ser encontrada, para que o sistema ofereça qualidade e custo módico ao seu usuário.

Dentro deste contexto, estudos de estabilidade transitória e dinâmica, tendem a mostrar o comportamento dinâmico de um sistema analisado, seja para estudo de seu carregamento e definição de uma possível margem de segurança, seja para estudos referentes a problemas estruturais, como curto-circuitos. 
Neste capítulo, a estabilidade transitória será discutida sobre sua forma clássica. Primeiramente, o problema será definido no tempo, ou seja, serão mostradas as divisões necessárias do estudo durante o tempo de análise, sendo que o objetivo desta divisão é representar, através de conjuntos de equações diferenciais, um sistema com 3 topologias de rede elétrica diferentes.

$\mathrm{Na}$ segunda seção será discutida a solução computacionalmente óbvia, para um conjunto de equações diferenciais, que é a solução numérica (passo-a-passo) através de uma discretização a passos pequenos no tempo. O objetivo deste tipo de solução é a busca do tempo crítico de abertura, através da análise da estabilidade da solução das equações diferenciais ordinárias do sistema, enquanto o tempo de abertura vai aumentando.

$\mathrm{Na}$ terceira seção será discutido como o problema pode ser modelado para o estudo de estabilidade em um sistema multimáquinas. O objetivo desta modelagem é a busca de uma equação diferencial aplicável a sistemas multimáquinas. Hipóteses simplificadoras da rede elétrica associadas ao uso do modelo clássico de máquinas síncronas e a consideração de cargas como sendo de impedância constante, permitem a redução da rede aos nós das FEM's e a dedução da equação diferencial, conseqüentemente.

Na quarta seção será discutido o sistema OMIBS, que é uma forma de simplificação do estudo do sistema multimáquinas, defrontando apenas a máquina que se quer estudar, contra o resto do sistema, que é considerado muito grande (infinito) em relação à máquina em questão. O objetivo desta descrição é o fato de que muitas vezes os estudos de estabilidade são realizados em sistemas OMIBS, onde se pode verificar especificamente o comportamento da única máquina, estudando a estabilidade de uma maneira mais simplificada. Através do estudo em sistemas OMIBS, obtém-se exemplos simples que permitem explicações muito didáticas a respeito da estabilidade de um sistema.

$\mathrm{Na}$ quinta seção será tratado o problema do sincronismo frente a estabilidade. $\mathrm{O}$ objetivo é mostrar que a estabilidade pode ser vista como o sincronismo entre geradores, desde que algumas considerações sejam colocadas. Através do estudo do sincronismo entre geradores, pode-se considerar o sistema instável ou estável apenas através da equiparação das grandezas dinâmicas envolvidas.

Finalmente, a sexta e sétima seções representam duas formas de se referenciar o estudo de estabilidade, transformando-o em um estudo de sincronismo. A sexta seção 
descreve a referência em relação a uma máquina (OMR), e a sétima seção descreve a referência em relação ao centro de ângulo, ou centro de inércia.

\subsection{Divisão do Problema no Tempo}

Matematicamente, começa-se pela divisão do problema do estudo de estabilidade transitória em 3 sub-problemas: pré-falta, falta e pós-falta. Esta divisão é necessária pelo fato de que as equações diferenciais representantes do sistema baseiam-se na estrutura, ou topologia, da rede elétrica.

Como se estuda uma falha estrutural em uma rede, ou seja, estuda-se uma contingência que muda a topologia da rede, as características do sistema se alteram quando do advento de um defeito, e se alteram novamente, quando o defeito é eliminado, ou seja, têm-se 3 conjuntos de equações diferenciais diferentes representando 3 intervalos de tempo, onde:

- O sistema pré-falta representa a operação do sistema elétrico antes da contingência, ou seja, a situação de equilíbrio antes da ocorrência de um defeito;

- O sistema falta representa o sistema durante a contingência, ou seja, período no qual o sistema sofre um defeito (por exemplo: curto-circuito);

- O sistema pós-falta representa o sistema após o término da contingência, ou seja, após a eliminação do defeito;

Logo, a condição inicial das equações diferenciais ordinárias do sistema falta é o ponto final do estudo do sistema estável pré-falta, ou seja, a condição inicial de tratamento do sistema falta será obtida através da condição final do sistema pré-falta e, analogamente, o ponto inicial do sistema pós-falta será obtido do ponto final do sistema em falta, ou seja, o ponto inicial de estudo do sistema pós-falta será o ponto onde o defeito foi eliminado. Nestas condições, o principal problema de estabilidade transitória é garantir o retorno a um ponto de operação que é representado por um ponto de equilíbrio estável no sistema pós-falta: $\mathrm{x}_{\mathrm{s}}$, ou seja:

$$
\left(\lim _{\substack{p \\ t \rightarrow \infty}}\left(x_{p}, t\right)=x_{s}\right)
$$


onde:

- $\phi\left(x_{p}, t\right)$ é a solução do sistema após a eliminação da falta com condição inicial $x_{p}$

- $\quad x_{p}$ condição inicial dada pelo sistema falta no instante da abertura;

O conjunto de equações diferenciais representantes do sistema é descrito por 3 conjuntos de equações distintos, como abaixo:

- Sistema Pré-falta:

$$
M \cdot \ddot{\delta}+D \cdot \dot{\delta}=P_{m u}-P_{e u}^{p r f}=0 \quad\left\{\begin{array}{l}
t \leq 0 \\
\delta(t)=\delta^{0}, \dot{\delta}(t)=0 \\
i=1, \ldots, n
\end{array}\right.
$$

- Sistema em Falta:

$$
M \cdot \ddot{\delta}+D \cdot \dot{\delta}=P_{m u}-P_{e u}{ }^{f}=0 \quad\left\{\begin{array}{l}
0 \leq t \leq t_{a} \\
\delta(0)=\delta^{0}, \dot{\delta}(0)=0 \\
i=1, \ldots, n
\end{array}\right.
$$

- Sistema Pós-falta:

$$
M \cdot \ddot{\delta}+D \cdot \dot{\delta}=P_{m u}-P_{e u}^{p f}=0 \quad\left\{\begin{array}{l}
t \geq t_{a} \\
\delta^{p f}\left(t_{a}\right)=\delta^{f}\left(t_{a}\right) \\
i=1, \ldots, n
\end{array}\right.
$$

\subsection{Solução Numérica pelo método passo-a-passo}

O modelo matemático do sistema elétrico para a análise de estabilidade transitória é um conjunto de equações diferenciais que representa a dinâmica das máquinas do sistema, como descrito anteriormente. Como não existe solução analítica para as 
equações de "swing", métodos numéricos devem ser implementados para a obtenção da solução. Este tipo de solução numérica é conhecido como passo-a-passo.

Vários são os métodos numéricos para solução de equações diferenciais. Dentre os de caráter mais prático, por serem de simples implementação, estão os métodos explícitos de Euler Simples e Runge-Kutta de $2^{\mathrm{a}}$ e $4^{\mathrm{a}}$ ordens. No anexo A encontram-se os algoritmos destes métodos.

Neste tipo de solução de equações diferenciais (solução numérica), as equações são integradas no tempo, para passos muito pequenos, e as variáveis do sistema são consideradas constantes nestes intervalos, pelo fato de suas variações serem muito pequenas. De fato, o que ocorre é uma discretização do tempo, com intervalos mínimos, para solução de uma equação diferencial no tempo.

Suponha a equação de "swing" com o amortecimento desprezado, que pode, então, ser descrita da seguinte forma:

$$
\left\{\begin{array}{l}
\frac{d \delta}{d t}=\omega \\
\frac{d \omega}{d t}=\frac{P_{a}}{M}
\end{array}\right.
$$

onde:

- $\quad P_{a}=P_{m}-P_{e}$, é a potência acelerante;

Em um intervalo, diga-se o i-ésimo, de $t_{i}$ para $t_{i+1}$, a potência acelerante $P_{a}$ é assumida constante no intervalo, então:

$$
\omega_{(i+1)}=\omega_{i}+\frac{\Delta t}{M} \cdot P_{a(i)}
$$

A velocidade calculada em $t_{i}$ é assumida constante durante o intervalo até o tempo $t_{i+1}$, onde:

$$
\delta_{(i+1)}=\delta_{(i)}+\Delta t \cdot \omega_{(i+1)}
$$

Graficamente, a discretização pode ser vista na figura 3.1: 

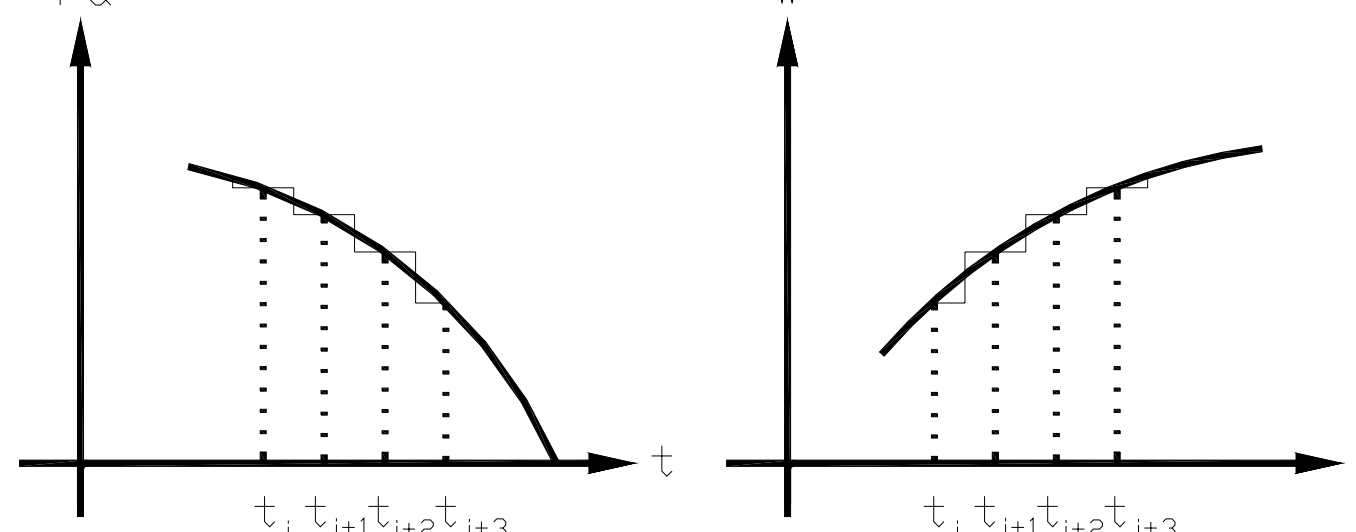

Figura 3.1- Discretização da Potência acelerante e da velocidade no tempo para o método passo-a-passo

Observa-se, então, que através da discretização das soluções do sistema de equações diferenciais no tempo obtém-se a solução aproximada do sistema.

Uma vez obtida a maneira de solucionar o sistema, aplicar-se-á a ele uma falta por um tempo pré-determinado, de tal maneira que, quando o tempo crítico de abertura for alcançado, e o sistema tornar-se instável, pára-se a integração, ou seja, quando o incremento no passo de integração tornar o sistema instável, a integração deve ser interrompida, e o tempo associado ao número de passos desta integração deve ser computado como sendo o tempo crítico de abertura. De fato, simular-se-á o sistema até que o mesmo fique instável. Se o incremento de um passo levar o sistema à instabilidade, o tempo crítico de abertura foi encontrado.

\subsection{Sistema Multimáquinas}

Esta seção dedica-se a modelagem do problema de estabilidade para sistemas multimáquinas baseado nos modelos descritos no capítulo 2 .

As hipóteses simplificadoras existentes no estudo de estabilidade transitória em sistema multimáquinas consistem em: 
- A rede elétrica opera em regime permanente senoidal e é considerada estática diante da eletromecânica dos geradores;

- O modelo clássico de máquina síncrona é utilizado;

- As cargas são consideradas impedâncias constantes e obtidas do fluxo de carga não-linear, bem como o módulo e ângulo das tensões das barras;

- A potência mecânica é considerada constante;

O sistema elétrico representado na figura 3.2 mostra o sistema equivalente a um sistema multimáquinas. Os geradores são considerados fontes de tensão ligados a rede elétrica através de uma reatância de eixo direto $x^{\prime}{ }_{d}$. Estas condições iniciais são consideradas como sendo o sistema pré-falta.

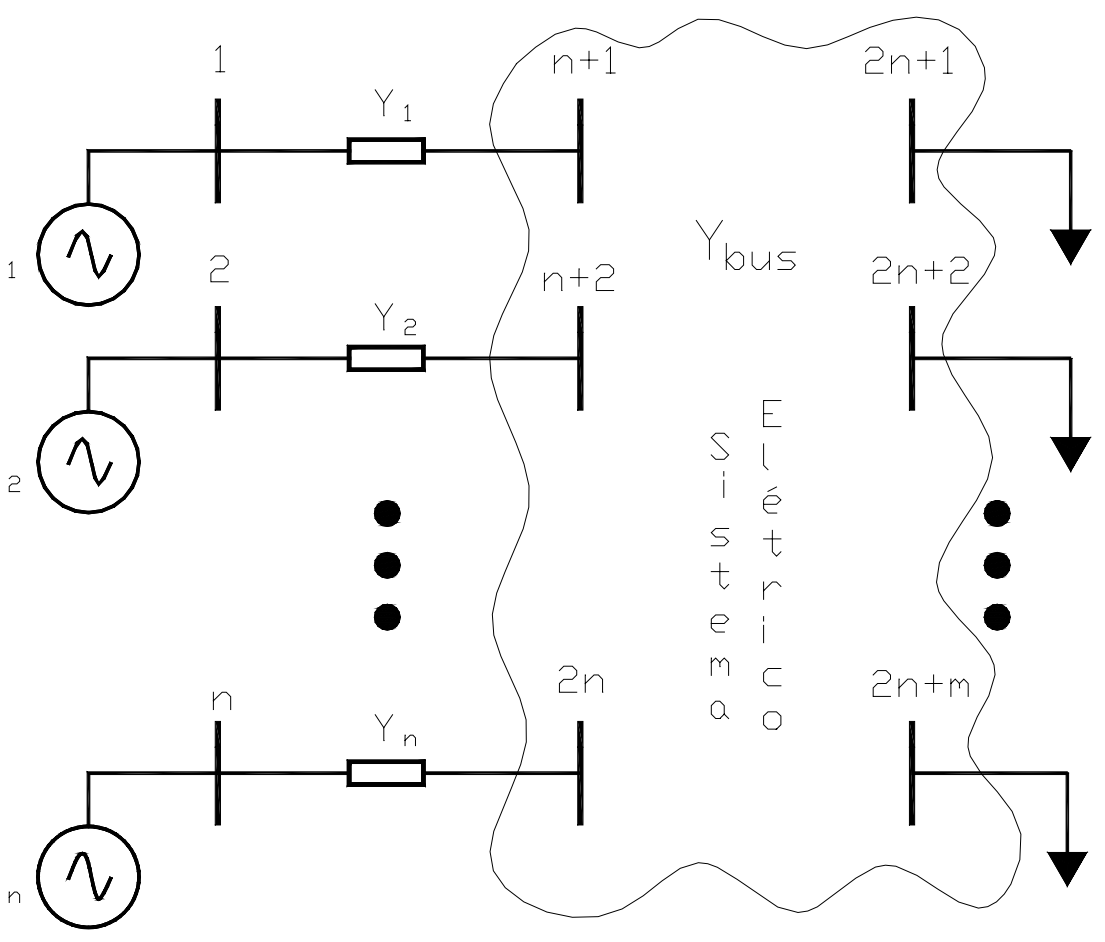

Figura 3.2- Sistema Multimáquinas

Onde a matriz de admitâncias $Y_{b u s}$ que representa a topologia do sistema elétrico e é dado pela equação:

$$
\begin{gathered}
n \\
\underline{Y}_{b u s}=\left[\begin{array}{ll}
\underline{Y}_{1} & \underline{Y}_{2} \\
\underline{Y}_{3} & \underline{Y}_{4}
\end{array}\right] n \\
m
\end{gathered}
$$


onde:

- $\quad \underline{Y}_{l}$ representa a matriz de admitâncias $n \times n$ que contém dados do sistema das $n$ barras dos geradores conectadas entre si;

- $\underline{Y}_{2}$ representa a matriz de admitâncias $n \times m$ que conecta as $n$ barras dos geradores às $m$ barras das cargas do sistema;

- $\underline{Y}_{3}$ representa a matriz de admitâncias $m \times n$ que conecta as $n$ barras dos geradores às $m$ barras das cargas do sistema;

- $\underline{Y}_{4}$ representa a matriz de admitâncias $m \times m$ que contém dados do sistema das $m$ barras de carga conectadas entre si;

As cargas do sistema que estão conectadas as $m$ últimas barras do sistema da figura 3.2 devem ser transformadas em admitâncias constantes de carga, uma vez que uma das suposições do modelo é a de que as impedâncias permaneceriam constantes durante o fenômeno transitório, logo, as cargas que são geralmente dadas em potências ativa e reativa devem ser transformadas em admitâncias através da equação:

$$
Y_{L i}=\frac{P_{L i}-Q_{L i}}{\left|V_{i}\right|}, \text { onde } i=2 n+1, \ldots, 2 n+m
$$

onde:

- $\quad P_{L i}$ é a potência ativa que representa a carga ativa da barra $i$;

- $Q_{L i}$ é a potência reativa que representa a carga reativa da barra $i$;

- $\quad V_{i}$ é a tensão da barra $i$;

É possível que existam cargas nas barras que conectam os geradores ao sistema elétrico, neste caso, estas cargas também devem ser transformadas através da equação (3.9), ou seja, neste caso $i=n+1, \ldots, 2 n+m$.

Para as $n$ primeiras barras do sistema descrito na figura 3.2, que representam os nós internos (fictícios) dos geradores, é possível montar uma matriz admitância diagonal $n \times n$, com as reatâncias transitórias convertidas para admitâncias, que representem as mesmas, como na equação (3.10):

$$
\underline{Y}_{G}=\left[\begin{array}{ccc}
Y_{G_{1}} & \cdots & 0 \\
\vdots & \ddots & \vdots \\
0 & \cdots & Y_{G_{n}}
\end{array}\right] n
$$


Analogamente, é possível montar uma matriz admitância $(m+n) \mathrm{x}(m+n)$, que represente as cargas do sistema, já transformadas em admitâncias de carga pela equação (3.9):

$$
\begin{gathered}
n \\
\underline{Y}_{L}=\left[\begin{array}{cc}
\underline{Y}_{L G} & 0 \\
0 & \underline{Y}_{L L}
\end{array}\right] n=\left[\begin{array}{ccc}
Y_{L 1} & \cdots & 0 \\
\vdots & \ddots & \vdots \\
0 & \cdots & Y_{L m+n}
\end{array}\right] m+n
\end{gathered}
$$

Finalmente, monta-se a matriz $\underline{\tilde{Y}}_{\text {bus }}$ que representa o sistema como um todo, desde o nó fictício das forças eletromotrizes dos geradores até as cargas constantes do sistema, passando pela rede elétrica. Esta matriz está na equação (3.12):

$$
\underline{\widetilde{Y}}_{\text {bus }}=\left[\begin{array}{ccc}
n & n & m \\
\underline{Y}_{G} & -\underline{Y}_{G} & 0 \\
-\underline{Y}_{G} & \underline{Y}_{1}+\underline{Y}_{G}+\underline{Y}_{L G} & \underline{Y}_{2} \\
0 & \underline{Y}_{3} & \underline{Y}_{4}+\underline{Y}_{L L}
\end{array}\right] n
$$

Como objetivo é buscar uma equação de "swing" para utilização em sistemas multimáquinas, apenas as funções que contém os ângulos rotóricos interessarão. Fica interessante efetuar uma redução na matriz $\underline{Y}_{\text {bus }}$, para que a mesma fique expressa somente em relação aos nós das forças eletromotrizes (FEM's) e para isto neste momento particiona-se a matriz (3.12), como a equação (3.13):

$$
\begin{aligned}
& n n+m \\
& \underline{\widetilde{Y}}_{b u s}=\left[\begin{array}{ll}
\underline{Y}_{A} & \underline{Y}_{B} \\
\underline{Y}_{C} & \underline{Y}_{D}
\end{array}\right] n+m
\end{aligned}
$$

Ao considerar-se todas as admitâncias de cargas constantes, as injeções de corrente em cada barra de carga tornam-se nulas, uma vez que toda corrente que chega a barra de carga atende a carga. Portanto, apenas as barras de geração têm injeção de corrente, logo se tem:

$$
\begin{aligned}
& n \quad n+m \\
& {\left[\begin{array}{c}
\underline{I}_{G i n j} \\
\underline{0}
\end{array}\right]=\left[\begin{array}{ll}
\underline{Y}_{A} & \underline{Y}_{B} \\
\underline{Y}_{C} & \underline{Y}_{D}
\end{array}\right] \cdot\left[\begin{array}{c}
\underline{E}_{G} \\
\underline{E}_{L}
\end{array}\right] \begin{array}{c}
n \\
n+m
\end{array}}
\end{aligned}
$$

Expandindo a equação (3.14), tem-se:

\footnotetext{
${ }^{1}$ de $Y_{L 1}$ até $Y_{L n}$, ou seja $\underline{Y}_{L G}$, estão as admitâncias de carga conectadas as barras de geração, que representam as cargas que possam estar conectadas nestas barras.
} 


$$
\left\{\begin{array}{l}
\underline{I}_{G i n j}=\underline{Y}_{A} \cdot \underline{E}_{G}+\underline{Y}_{B} \cdot \underline{E}_{L} \\
\underline{0}=\underline{Y}_{C} \cdot \underline{E}_{G}+\underline{Y}_{D} \cdot \underline{E}_{L}
\end{array}\right.
$$

Substituindo, $\underline{E}_{L}$ da equação (3.15), tem-se:

$$
\begin{aligned}
& \underline{0}=+\underline{Y}_{D} \cdot \underline{E}_{L} \Rightarrow \underline{Y}_{D} \cdot \underline{E}_{L}=\underline{Y}_{C} \cdot \underline{E}_{G} \Rightarrow \\
& \underline{E}_{L}=\underline{Y}_{D}^{-1} \cdot \underline{Y}_{C} \cdot \underline{E}_{G} \\
& \underline{I}_{G i n j}=\underline{Y}_{A} \cdot \underline{E}_{G}+\underline{Y}_{B} \cdot\left(\underline{Y}_{D}{ }^{-1} \cdot \underline{Y}_{C} \cdot \underline{E}_{G}\right) \Rightarrow \\
& \underline{I}_{G i n j}=\left[\underline{Y}_{A}+\underline{Y}_{B} \cdot \underline{Y}_{D}{ }^{-1} \cdot \underline{Y}_{C}\right] \cdot \underline{E}_{G}=\underline{\widetilde{Y}}_{r e d} \cdot \underline{E}_{G}
\end{aligned}
$$

Logo, em (3.16) obteve-se a expressão reduzida para $\underline{\widetilde{Y}}_{\text {bus }}$.

Evidentemente, o cálculo matemático da inversa da matriz admitância nodal em um processo é algo que demanda muito tempo e esforço computacional, tornando-se algo proibitivo em sistemas de grande porte. Neste sentido implementa-se o processo de redução de Gauss para redução da matriz $\underline{\underline{Y}}_{\text {bus }} \mathrm{O}$ anexo B contém a descrição do processo de redução de Gauss.

Uma vez obtidas as expressões das injeções de correntes no sistema reduzido aos nós das FEM's, é possível verificar a injeção do fluxo de potência ativa nestes nós através da equação (3.17):

$$
P_{e i}=\operatorname{Re}\left[E_{i} \cdot I_{i}^{*}\right]
$$

onde:

- $i$ é um dos nós das FEM's dos geradores;

- $E_{i}=\left|E_{i}\right| \angle \delta_{i}$;

Logo, de (3.17) e (3.16), tem-se:

$$
P_{e i}=\operatorname{Re}\left[E_{i} \cdot \sum_{j=1}^{j=n} Y_{i j}^{*} \cdot E_{j}^{*}\right]
$$

onde:

- $Y_{i j}=G_{j}+j \cdot B_{j}=\left|Y_{i j}\right| \angle \phi_{i j}$ é um elemento da matriz $\underline{\underline{Y}}_{b u s}$ reduzida;

Substituindo os valores de $Y_{i j}$ e $E_{j}$ pelas expressões descritas em (3.17), tem-se: 


$$
P_{e i}=\left|E_{i}\right|^{2} \cdot G_{i i}+\sum_{\substack{j=1 \\ i \neq j}}^{j=n}\left|E_{i}\right|\left|E_{j} \| Y_{i j}\right| \cdot\left\{\cos \left[\phi_{i j}-\left(\delta_{i}-\delta_{j}\right)\right]\right\}
$$

Decompondo-se a função, co-seno de (3.19), conforme a identidade trigonométrica: $\cos (a-b)=\cos a \cos b+\operatorname{sen} a \operatorname{sen} b$, tem-se:

$$
P_{e i}=\left|E_{i}\right|^{2} \cdot G_{i i}+\sum_{\substack{j=1 \\ i \neq j}}^{j=n}\left|E_{i}\right|\left|E_{j}\right|\left|Y_{i j}\right| \cdot\left[\cos \phi_{i j} \cdot \cos \left(\delta_{i}-\delta_{j}\right)+\operatorname{sen} \phi_{i j} \cdot \operatorname{sen}\left(\delta_{i}-\delta_{j}\right)\right]
$$

Para simplificar a notação, serão definidas duas constantes:

$$
\begin{aligned}
& D_{i j} \stackrel{\Delta}{=}\left|E_{i}\right|\left|E_{j}\right||| Y_{i j}\left|\cdot \cos \phi_{i j}=\right| E_{i}|| E_{j}|| G_{i j} \mid \\
& C_{i j} \stackrel{\Delta}{=}\left|E_{i}\right|\left|E_{j} \| Y_{i j}\right| \cdot \operatorname{sen} \phi_{i j}=\left|E_{i}\right|\left|E_{j}\right|\left|B_{i j}\right|
\end{aligned}
$$

Logo, a equação (3.20) fica:

$$
P_{e i}=\left|E_{i}\right|^{2} \cdot G_{i i}+\sum_{\substack{j=1 \\ i \neq j}}^{j=n}\left[D_{i j} \cdot \cos \left(\delta_{i}-\delta_{j}\right)+C_{i j} \cdot \operatorname{sen}\left(\delta_{i}-\delta_{j}\right)\right]
$$

Finalmente, substituindo-se na equação de "swing" representante da dinâmica do sistema, tem-se:

$$
\left\{\begin{array}{l}
\dot{\delta}=\omega \\
M \cdot \ddot{\delta}+D \cdot \dot{\delta}=P_{m u}-\left|E_{i}\right|^{2} \cdot G_{i i}+\sum_{\substack{j=1 \\
i \neq j}}^{j=n}\left[D_{i j} \cdot \cos \left(\delta_{i}-\delta_{j}\right)+C_{i j} \cdot \operatorname{sen}\left(\delta_{i}-\delta_{j}\right)\right]
\end{array}\right.
$$

A equação (3.23) representa, então, a equação de "swing" de uma máquina para um sistema multimáquinas. 


\subsection{Sistema OMIBS}

Em estudos de estabilidade, é possível ver duas modelagens:

- Sistemas multimáquinas;

- Sistemas OMIBS (uma máquina versus barramento infinito);

De fato sistemas OMIBS são uma simplificação do estudo multimáquinas, onde se considera o resto sistema muito grande em relação à máquina que se quer estudar, podendo tratar o resto do sistema como uma máquina infinita, ou seja, uma máquina com momento de inércia infinito e potência ilimitada, não sendo sensível as variações dinâmicas da máquina conectada a ela.

Esta seção dedica-se ao estudo do sistema OMIBS no contexto do problema de estabilidade transitória, como uma maneira de simplificar o estudo de estabilidade em um sistema multimáquinas, quando o objetivo do estudo refere-se apenas a uma máquina do sistema em questão.

Grandes sistemas elétricos podem ser considerados barras infinitas quando conectados a máquinas pequenas. A figura 3.3 ilustra um sistema OMIBS:

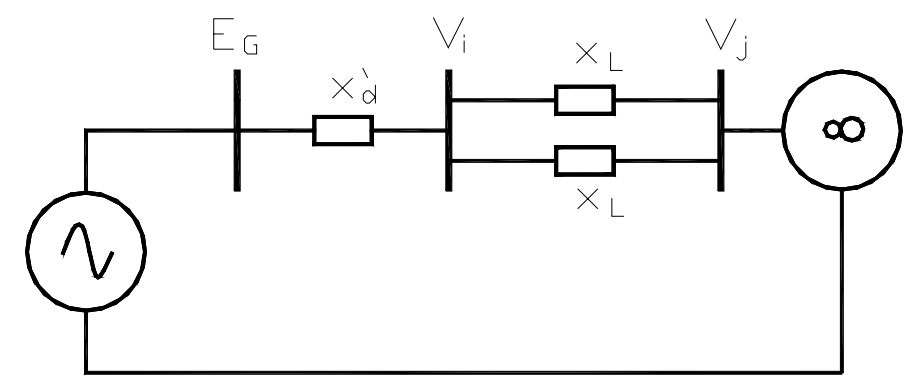

Figura 3.3 - Uma Máquina versus Barramento Infinito através de uma Linha de Transmissão Dupla - Sistema OMIBS pré-falta

As premissas adotadas para este tratamento são:

- A barra infinita é considerada estática diante da dinâmica do gerador;

- O modelo clássico de máquina síncrona é utilizado;

- A potência mecânica é considerada constante; 
A barra infinita é um referencial de tensão e um referencial angular do sistema, como a barra "slack" é para um fluxo de carga, logo, é comum adotar-se a tensão nesta barra com o valor em módulo de 1 p.u., com ângulo $0^{\circ}$, fixando-se então a referência nestes valores.

A dedução do conjunto de equações diferenciais para sistemas OMIBS (equações de "swing") será obtida através da aplicação de uma falta no sistema representado pela figura 3.3. A falta será aplicada no centro de uma de suas linhas de transmissão, que resulta em um sistema com a topologia de falta representada pelo diagrama unifilar da figura 3.4:

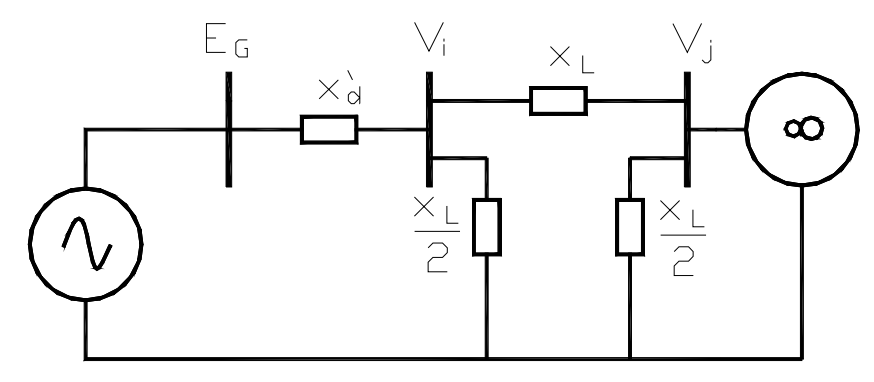

Figura 3.4 -Sistema OMIBS falta

Após a eliminação da contingência devido a atuação do sistema de proteção, a topologia do sistema muda novamente. O diagrama unifilar da figura 3.5 representa esta situação:

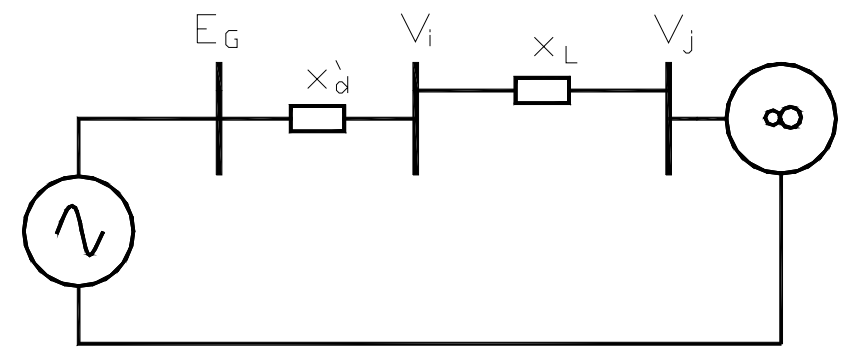

Figura 3.5 -Sistema OMIBS pós-falta

Cada um dos diagramas, que representa cada uma das divisões temporais do problema, é representado por um conjunto de equações diferenciais. A força eletromotriz (FEM), que é considerada constante durante todo o tempo de estudo, 
devido ao modelo de máquina utilizado, deve ser calculada baseado nas características do sistema pré-falta.

Para o sistema pré-falta, pode-se obter o fasor corrente $\stackrel{\circ}{I}_{i j}$ através da equação (3.24):

$$
\stackrel{\circ}{I}_{i j}=\frac{\stackrel{\circ}{V}_{i} \cdot \stackrel{\circ}{V}_{j}}{j \cdot X_{i j}}
$$

A tensão no gerador $\stackrel{\circ}{E}_{G}$ é, então, dada por:

$$
\stackrel{\circ}{E}_{G}=\stackrel{\circ}{V}_{i}+\stackrel{\circ}{I}_{i j} \cdot\left(X_{d}^{\prime}{ }_{d}+\frac{X_{L}}{2}\right)
$$

Onde:

- $\frac{X_{L}}{2}$ é a reatância equivalente das linhas de transmissão em paralelo;

Pela modelagem considerada, esta tensão permanecerá constante durante todo estudo do fenômeno transitório. Pode-se, então, calcular a potência elétrica do sistema pré-falta:

$$
P_{e}^{p r f}=\frac{E_{G} \cdot V_{\infty}}{X_{e q}^{p r f}} \cdot \operatorname{sen}\left(\delta_{i}\right)
$$

onde:

- $V_{\infty}$ é a tensão na barra infinita (geralmente 1 p.u.);

- $X_{e q}^{p r f}$ é a reatância equivalente do sistema reduzido ao nó da FEM (no caso da figura 3.3, o circuito equivalente composto pela reatância transitória e as reatâncias das linhas de transmissão);

- $\delta_{i}$ é a diferença angular entre o fasor tensão do gerador e o fasor tensão da barra infinita;

Logo, a equação de "swing" que representa o modelo dinâmico do sistema pré-falta é dado por:

$$
M \cdot \ddot{\delta}=P_{m}-P_{e}^{p r f}=P_{m}-\frac{E_{G} \cdot V_{\infty}}{X_{e q}^{p r f}} \cdot \operatorname{sen}\left(\delta_{i}\right)
$$

Após a obtenção do modelo dinâmico representativo do sistema pré-falta, deve-se verificar o comportamento do sistema falta para a contingência aplicada (figura 3.4). Com o mesmo procedimento utilizado no cálculo do sistema pré-falta, obteve-se a equação de "swing" que representa o modelo dinâmico do sistema falta: 


$$
M \cdot \ddot{\delta}=P_{m}-P_{e}^{f}=P_{m}-\frac{E_{G} \cdot V_{\infty}}{X_{e q}^{f}} \cdot \operatorname{sen}\left(\delta_{i}\right)
$$

onde:

- $\quad X_{e q}^{f}$ é a reatância equivalente do sistema reduzido ao nó da FEM (no caso da figura 3.4, o circuito equivalente composto pela reatância transitória e a reatância equivalente da transformação delta-estrela do circuito formado pelas linhas de transmissão nesta situação);

Após a obtenção do modelo dinâmico representativo do sistema falta, deve-se verificar o comportamento do sistema pós-falta, obtido após a eliminação da contingência devido a atuação do sistema de proteção. Com o mesmo procedimento utilizado no cálculo do sistema pré-falta e no cálculo do sistema falta, obtém-se a equação de "swing" que representa o modelo dinâmico do sistema pós-falta:

$$
M \cdot \ddot{\delta}=P_{m}-P_{e}^{p f}=P_{m}-\frac{E_{G} \cdot V_{\infty}}{X_{e q}^{p f}} \cdot \operatorname{sen}\left(\delta_{i}\right)
$$

onde:

- $\quad X_{e q}^{p f}$ é a reatância equivalente do sistema reduzido ao nó da FEM (no caso da figura 3.5, o circuito equivalente composto pela reatância transitória e a reatância da linha de transmissão que sobrou);

A figura 3.6 ilustra a curva $P-\delta$, dos 3 sistemas obtidos para a contingência simulada:

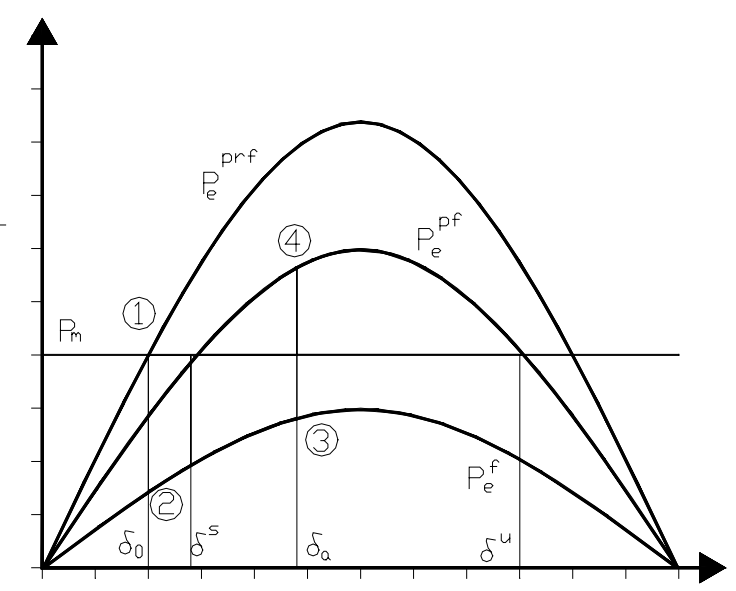

Figura 3.6 - Curva $P$ - $\delta$ para o sistema OMIBS 
Neste caso, como a curva da situação falta fica abaixo da reta da potência mecânica o sistema acelera, porém isto não é necessariamente uma verdade e sim um exemplo. Pode-se verificar também que a curva do sistema pós falta está acima da reta da potência mecânica, o que diz que o sistema tem um ponto estável para o sistema pósfalta. Caso esta curva tivesse seu máximo abaixo da reta da potência mecânica, o sistema aceleraria indefinidamente, mostrando que a contingência levou o sistema a instabilidade. A análise de estabilidade do sistema representado nesta figura será realizada na seção 1 do capítulo 4 .

\subsection{Sincronismo frente à Estabilidade - Um Problema de Referencial}

A idéia de estabilidade pode ser definida matematicamente, como pode ser visto em Bretas e Alberto (2000):

Definição: Diz-se que a solução de equilíbrio $x_{0}$ de um sistema autônomo, descrito pelas equações diferenciais $\dot{x}=f(x)$, é estável no sentido de Lyapunov (ou somente estável), se para cada número $\varepsilon>0$, existir um número real $\delta>0$, tal que para toda condição inicial $x\left(t_{0}\right)$ satisfazendo a desigualdade $\left\|x\left(t_{0}\right)-x_{0}\right\|<\delta$, a trajetória do sistema $x(t)$ satisfaz a desigualdade $\left\|x\left(t_{0}\right)-x_{0}\right\|<\varepsilon$ para todo $t>t_{0}$.

Ou seja, trajetórias iniciando próximas de $x_{0}$ não se afastam da solução de equilíbrio para $t>t_{0}$. Como pode ser visto na figura 3.7:

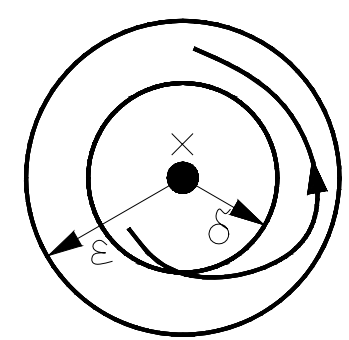

Figura 3.7 - Conceito de estabilidade 
Porém, muitas vezes a palavra estabilidade em sistemas elétricos refere-se ao sincronismo entre as máquinas do sistema, ou seja, o fato de seus ângulos rotóricos permanecerem oscilando conjuntamente. O conceito matemático de sincronismo é bem diferente do conceito matemático de estabilidade, uma vez que exige dois entes que devem permanecer oscilando conjuntamente. Existem diversas definições de sincronismo na literatura, entretanto, em sistemas elétricos de potência entende-se por sincronismo o fato de duas soluções permanecerem oscilando dentro de certos limites pré-estabelecidos. Logo se tem como definição possível:

Definicão: Diz-se que as soluções $x_{t}$ e $y_{t}$ estão sincronizadas, se e somente se $\|x(t)-y(t)\|<L$, para todo $t>t_{0}$,

onde o número $L$ pode ser escolhido de acordo com os limites do sistema.

Em sistemas multimáquinas a relação entre o sincronismo e a estabilidade não se dá de forma direta, pela ausência de uma referência. É necessário, então, que se introduza no sistema multimáquinas um referencial girante à velocidade síncrona. Uma forma de obter esta referência é através da transformação de um sistema composto por $n$ máquinas em um sistema composto por $n-1$ máquinas mais uma máquina que preserva o referencial. A necessidade deste referencial fica evidente pelo fato de que se as máquinas acelerassem indefinidamente, porém conjuntamente, o sincronismo seria mantido, mas a velocidade estaria longe da velocidade síncrona.

Para sobrepujar esta característica do sistema, adota-se um referencial, transformando-se novamente o estudo de sincronismo entre geradores no estudo de estabilidade de um conjunto de equações diferenciais apropriados. A adoção deste referencial será abordada de duas maneiras:

- Uma máquina como referência (OMR);

- Centro de Ângulo como referência (COA ou COI);

\subsection{Uma Máquina como Referência}

Uma das maneiras encontradas para solucionar o problema do referencial é utilizar uma máquina como referência, fazendo com o sistema tenha $2 n-2$ equações diferenciais representantes do sistema, mais duas equações como referência. Subtraindo-se as $2 n-2$ 
equações da referência, obtém-se um conjunto de equações diferenciais que representam o sistema. Tomando-se a n-ésima máquina como referência tem-se a equação (3.30).

$$
\begin{aligned}
& \left\{\begin{array}{l}
\dot{\omega}_{1 n}=\dot{\omega}_{1}-\dot{\omega}_{n}=\frac{P_{m 1}-P_{e 1}}{M_{1}}-\frac{P_{m n}-P_{e n}}{M_{n}} \\
\vdots \quad \vdots \\
\dot{\omega}_{(n-1) n}=\dot{\omega}_{(n-1)}-\dot{\omega}_{n}=\frac{P_{m(n-1)}-P_{e(n-1)}}{M_{(n-1)}}-\frac{P_{m n}-P_{e n}}{M_{n}} \\
\dot{\delta}_{1 n}=\dot{\delta}_{1}-\dot{\delta}_{n}=\omega_{1}-\omega_{n} \\
\vdots \quad \vdots \quad \\
\dot{\delta}_{(n-1) n}=\dot{\delta}_{(n-1)}-\dot{\delta}_{n}=\omega_{(n-1)}-\omega_{n}
\end{array}\right. \\
& \left\{\begin{array}{l}
\dot{\omega}_{n}=\frac{P_{m n}-P_{e n}}{M_{n}} \\
\dot{\delta}_{n}=\omega_{n}
\end{array}\right.
\end{aligned}
$$

Esta formulação é chamada de problema de estabilidade utilizando uma máquina como referência. No equilíbrio deste sistema todas as máquinas possuirão mesma velocidade e mesma aceleração. A prova simples de que o sincronismo entre máquinas representa a estabilidade de um conjunto de equações diferenciais apropriado pode ser encontrada em Bretas e Alberto (2000).

\subsection{Centro de Ângulo como Referência}

Outra maneira encontrada para solucionar o problema do referencial é utilizar o centro de ângulo (COA - "Centre of Angle") ou centro de inércia (COI - "Centre of Inertia") como referência. O objetivo desta utilização, que é baseado nas conjecturas físicas do centro de massa mecânico, é dar à representação um significado físico mais evidente.

Por definição o centro de ângulo é:

$$
\delta_{0}=\frac{1}{M_{T}} \cdot \sum_{i=1}^{n} M_{i} \cdot \delta_{i} \text { onde: } M_{T}=\sum_{i=1}^{n} M_{i}
$$

A velocidade angular do COA é obtida através da derivada de (3.31): 


$$
\omega_{0}=\frac{1}{M_{T}} \cdot \sum_{i=1}^{n} M_{i} \cdot \omega_{i}
$$

Derivando-se novamente:

$$
M_{T} \cdot \dot{\omega}_{0}=\sum_{i=1}^{n}\left(P_{m}-P_{e}\right)=P_{C O A}
$$

A equação (3.33) representa a dinâmica do sistema do COA, onde $P_{C O A}$ representa o desbalanço de potência do sistema como um todo. Substituindo $P_{e}$ da equação (3.33), tem-se:

$$
P_{C O A}=\sum_{i=1}^{i=n}\left(P_{m i}-E_{i}^{2} \cdot G_{i i}\right)-2 \cdot \sum_{i=1}^{i=n-1} \sum_{\substack{j=i+1 \\ j \neq i}}^{j=n} D_{i j} \cdot \cos \left(\delta_{i}-\delta_{j}\right)
$$

Tomando-se, então o COA como referência, tem-se novos estados relativos ao COA:

$$
\begin{aligned}
& \theta_{i}=\delta_{i}-\delta_{0} \\
& \dot{\theta}_{i}=\widetilde{\omega}_{i}=\omega_{i}-\omega_{0}
\end{aligned}
$$

Logo a equação de "swing", sem amortecimento, referenciada ao COA fica:

$$
\left\{\begin{array}{l}
\dot{\widetilde{\omega}}_{i}=\frac{P_{m_{i}}-P_{e_{i}}}{M_{i}}-\frac{1}{M_{T}} \cdot P_{C O A} \\
\dot{\theta}_{i}=\widetilde{\omega}_{i}
\end{array} i=1, \ldots, n\right.
$$

Esta formulação é chamada de problema de estabilidade utilizando o centro de ângulo como referência. No equilíbrio deste sistema todas as máquinas possuirão mesma velocidade e mesma aceleração.

Da definição de $\theta_{i}$ observa-se que os ângulos relativos não são linearmente independentes, e a eles se aplica a seguinte condição:

$$
\sum_{i=1}^{i=n} M_{i} \cdot \theta_{i}=0
$$

De fato, a condição da equação (3.36) implica que o sistema depende exclusivamente de $2 n$ - 2 equações referenciadas ao COA, que por sua vez depende de $2 n$ equações. Assim, quando da utilização do COA como referência, n-1 ângulos são obtidos, e um é referido aos outros. Esta conclusão permite verificar que o sistema referencial COA equivale ao sistema OMR (uma máquina como referência) descrito na seção anterior. 
O sistema referencial COA é muito utilizado na literatura, quando do estudo de estabilidade transitória por métodos diretos, que será tema do próximo capítulo. Esta utilização deve-se ao fato de que este sistema referencial dá uma interpretação física mais evidente à função energia utilizada por estes métodos. 


\section{Capítulo 4}

\section{ESTABILIDADE TRANSITÓRIA POR MÉTODOS DIRETOS}

Como brevemente mencionado no capítulo anterior, os métodos diretos foram propostos para sobrepujar a inadequacidade das análises de estabilidade pelo método passo-a-passo (integração numérica) em aplicações em tempo real. Neste sentido, a característica ímpar destes métodos reside no fato de que eles predizem a estabilidade sem a necessidade da utilização da integração numérica, obtendo o tcr ou tca (tempo crítico de abertura), de maneira rápida computacionalmente, viabilizando sua utilização em aplicações de tempo real.

A integração pelo método passo-a-passo resolve numericamente as equações diferenciais representantes do modelo não-linear do sistema de potência. Esta resolução, no entanto, consome muito tempo computacional, devido ao processo iterativo com passos muito pequenos, necessário para que a solução numérica correspondente seja próxima, o suficiente, do comportamento real do sistema. Obviamente uma ferramenta que consome muito tempo computacional não pode ser aplicada para soluções em tempo real, onde se entende por soluções em tempo real a deteção de problemas, obtenção de dados, processamento destes, tomada de decisões e finalmente atuação no sistema no momento da contingência.

Uma das buscas realizadas pelos pesquisadores de estabilidade transitória consiste exatamente em encontrar métodos que possam ser aplicados em tempo real, pelo menos a tempo de disparar ações preventivas. Uma das conclusões óbvias deste processo de busca é o fato de que soluções numéricas iterativas não são aplicáveis, e portanto, as 
soluções por métodos numéricos descritos anteriormente não são aplicáveis neste contexto.

Os métodos de obtenção de respostas de estabilidade que não utilizam soluções numéricas iterativas foram chamados na literatura de métodos diretos.

Este capítulo trata do desenvolvimento dos métodos diretos através de uma pesquisa bibliográfica, desde o início dos estudos até o estado da arte. Trata-se, neste capítulo, das definições e da modelagem destes métodos para a aplicação em sistemas elétricos.

Primeiramente, na seção 1 será descrito o critério das áreas iguais, que pode ser visto como uma tentativa prévia da obtenção do tcr por um método direto, sem a resolução explícita das equações diferenciais que regem o comportamento do sistema pós-falta. Este critério será demonstrado em um sistema OMIBS, e chegar-se-á a expressão de cálculo do tcr sem a solução das equações diferenciais ordinárias do sistema pós-falta.

$\mathrm{Na}$ segunda seção tem início o embasamento dos métodos diretos, através da consolidação dos conhecimentos de sistemas dinâmicos. O objetivo é mostrar como o modelo dinâmico do sistema elétrico de potência se insere, e quais suas características, num conjunto maior de sistemas dinâmicos.

A terceira seção descreve os estudos de Lyapunov, que fornecem as condições suficientes para que uma função explicite a estabilidade ou instabilidade de um sistema. Estes estudos representam parte da fundamentação dos métodos diretos, e por isso serão descritos.

$\mathrm{Na}$ quarta seção caracteriza-se completamente a área de atração, baseado nos estudos de Chiang et al. (1987), cujo objetivo é fundamentar teoricamente os métodos diretos, objetivando a estruturação do problema para aplicação em estudos de estabilidade transitória.

A quinta seção dedica-se a obtenção de uma função energia (do tipo de Lyapunov) aplicável a sistemas elétricos de potência em sistemas multimáquinas, e conseqüentemente, para sistemas OMIBS. Através desta função energia consegue-se, então, encontrar um parâmetro comparativo (energia), que serve para determinar a estabilidade ou não de um sistema elétrico de potência.

A sexta seção dedica-se a pesquisa bibliográfica relativa aos métodos diretos, tendo como objetivo demonstrar a evolução temporal do estudo, até o estado da arte, fundamentando o objetivo deste trabalho. Com esta evolução, a predição consistente da fronteira da área de atração, bem como, a busca de um ponto de equilíbrio nesta 
fronteira, que seja responsável pela condição ou não de estabilidade, tornam-se os objetivos dos métodos diretos, e os processos de estimativa evoluirão nestas buscas. Com esta evolução chega-se a dois algoritmos que são descritos e exemplificados nas seções sete e nove, PEBS e BCU respectivamente.

O PEBS, seção 7, busca circundar o problema de deteção do ponto de equilíbrio de controle, no qual a direção da trajetória de falta seria usada na determinação da margem de estabilidade do sistema. Um ponto chamado de "exit point", na direção da falta, seria encontrado e a estabilidade deste ponto representaria a estabilidade do sistema elétrico.

A seção 8 dedica-se a fundamentação dos algoritmos PEBS e BCU, baseada nos estudos de Chiang et al. (1988) de caracterização do sistema gradiente associado ao sistema original. O objetivo desta seção é criar a base teórica dos algoritmos PEBS e BCU que serão estudados neste trabalho.

A seção 9 dedica-se ao estudo do algoritmo BCU, proposto por Chiang et al. (1994). Devido a uma definição precisa do ponto de equilíbrio instável de controle, o método BCU busca este ponto através da fronteira da região de estabilidade, iniciando-se no PEBS. Pelo fato de não se tratar de uma aproximação, como é o caso do PEBS, obtémse a predição de estabilidade de maneira mais correta.

\subsection{Critério das Áreas Iguais}

Este critério está fundamentado no conceito de energia dos sistemas físicos. Esta energia depende exclusivamente de seu estado, ou seja, velocidade e posição. Da equação do movimento de uma partícula, segundo a $2^{\mathrm{a}}$ lei de Newton:

$$
m \cdot \frac{d v}{d t}=F(x)
$$

Multiplicando-se pela velocidade $v$, pode-se eliminar a variável tempo:

$$
m \cdot v \cdot \frac{d v}{d t}=F(x) \cdot \frac{d x}{d t} \Leftrightarrow m \cdot v \cdot d v=F(x) \cdot d x
$$

Integrando-se a equação acima desde um certo estado $\left(x_{1}, v_{1}\right)$ até um outro estado $\left(x_{2}, v_{2}\right)$ do corpo em estudo, obtém-se: 


$$
\begin{aligned}
& \int_{v_{1}}^{v_{2}} v \cdot d v=\int_{x_{1}}^{x_{2}} F(x) \cdot d x \\
& \underbrace{\frac{1}{2} \cdot m \cdot v_{2}{ }^{2}-\frac{1}{2} \cdot m \cdot v_{1}}_{\Delta E_{c}}=\underbrace{\int_{x_{1}}^{x_{2}} F(x) \cdot d x}_{-\Delta E_{p}}
\end{aligned}
$$

logo:

$$
\begin{aligned}
& \Delta E_{c}=\frac{1}{2} \cdot m \cdot v_{2}^{2}-\frac{1}{2} \cdot m \cdot v_{1}^{2} \\
& \Delta E_{p}=-\int_{x_{1}}^{x_{2}} F(x) \cdot d x
\end{aligned}
$$

Escolhida uma referência, pode-se definir a função energia de maneira absoluta. Seja a referência definida pela posição $x_{0}$ e pela velocidade $v=0$. Então, a energia total é definida por:

$$
\begin{aligned}
& E_{T}=E_{c}+E_{p} \\
& E_{c}(v)=\frac{1}{2} \cdot m \cdot v^{2} \\
& E_{p}(x)=-\int_{x_{0}}^{x_{1}} F(x) \cdot d x
\end{aligned}
$$

Os sistemas em que a integral não é dependente do caminho são conhecidos como sistemas conservativos, e diz-se que $E_{p}$ é uma primeira integral destes sistemas e pode ser descrito assim:

$$
m \ddot{x}=-\frac{d E_{p}(x)}{d x}
$$

Esta equação mostra que a força atua no sentido inverso do gradiente da função energia potencial.

O sistema de uma máquina versus barramento infinito (OMIBS) é um sistema conservativo, caso as perdas por amortecimento sejam desprezadas. Logo, pode-se definir uma função energia para o sistema de potência neste caso. Algumas premissas são consideradas neste critério:

- Potência mecânica constante;

- Amortecimento desprezado;

- Modelo clássico para máquinas síncronas; 
Este método é baseado no fato de que se o sistema é estável no primeiro "swing", o que faz com que o ângulo do rotor, após a falta, alcance um valor máximo, e então fique oscilando em torno do valor final. De fato é assumido que existe um equilíbrio no sistema pós-falta. Portanto a estabilidade é obtida pela monitoração da variação da velocidade angular do rotor, garantindo que ela se torne zero após a perturbação.

A equação de "swing" para um sistema OMIBS é:

$$
M \cdot \frac{d \omega}{d t}=P_{m}-\frac{E_{G} \cdot E_{\infty}}{X} \cdot \operatorname{sen}(\delta)=P_{m}-P_{e_{\text {max }}} \cdot \operatorname{sen}(\delta)
$$

Para se obter a função energia referente a este sistema, primeiramente multiplica-se a equação (4.7) por $\omega$ e obtém-se:

$$
\begin{aligned}
& M \cdot \omega \cdot \frac{d \omega}{d t}=\left[P_{m}-\frac{E_{G} \cdot E_{\infty}}{X} \cdot \operatorname{sen}(\delta)\right] \cdot \frac{d \delta}{d t}=\left[P_{m}-P_{e_{\text {max }}} \cdot \operatorname{sen}(\delta)\right] \cdot \frac{d \delta}{d t} \Leftrightarrow \\
& \Leftrightarrow M \cdot \omega \cdot d \omega=\left[P_{m}-P_{e_{\text {max }}} \cdot \operatorname{sen}(\delta)\right] \cdot d \delta
\end{aligned}
$$

Então, integra-se a equação acima, tomando como referência a velocidade angular nula e o ângulo do equilíbrio estável $\delta_{s}$ e têm-se:

$$
\left\{\begin{array}{l}
E_{c}=\frac{M \cdot \omega^{2}}{2} \\
E_{p}=-P_{m} \cdot\left(\delta-\delta_{s}\right)-P_{e_{\max }} \cdot\left[\cos (\delta)-\cos \left(\delta_{s}\right)\right]
\end{array}\right.
$$

A figura 4.1 mostra a curva $P-\delta$ : 


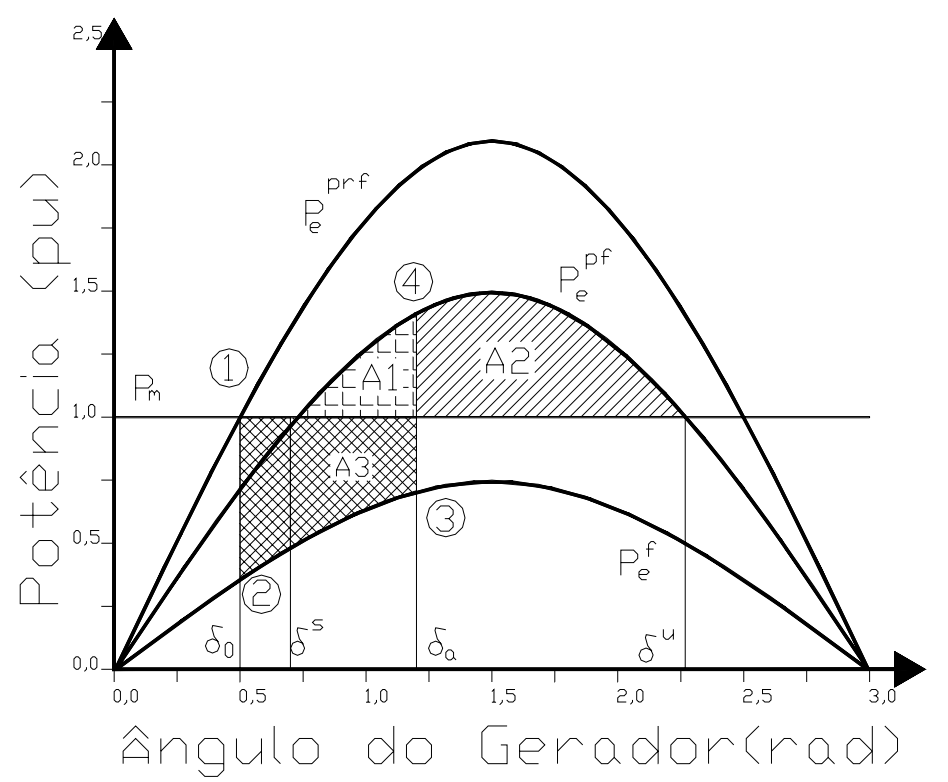

Figura 4.1 - Curva $P$ - $\delta$, Critério das Áreas Iguais

A integral da energia potencial, para a área $A_{3}$ fica:

$$
\Delta E_{c}=-\Delta E_{p}=\int_{\delta_{0}}^{\delta_{a}}\left(P_{m}-P_{e}^{f}\right) \cdot d \delta
$$

Porém, a energia cinética no instante inicial é nula, logo, a energia cinética no momento da abertura será:

$$
E_{c}=\Delta E_{c}=\int_{\delta_{0}}^{\delta_{a}}\left(P_{m}-P_{e}^{f}\right) \cdot d \delta=A_{3}
$$

Logo, a energia crítica do sistema se dá quando a energia total no instante da abertura (4) for igual a energia potencial do ponto de equilíbrio $\delta_{u}$, ou seja:

$$
A_{3}+A_{1}=A_{1}+A_{2} \Leftrightarrow A_{3}=A_{2}
$$

Portanto, se o defeito for eliminado de tal maneira que a área 3 seja menor que a área 2 o sistema é estável, e caso contrário instável.

Igualando-se as áreas acima, através de suas integrais de energia potencial, é possível extrair uma expressão para o cálculo do ângulo crítico de abertura, que será aquele ângulo limite entre a estabilidade e a instabilidade:

$$
\cos \left(\delta_{c r}\right)=\frac{P_{m} \cdot\left(\delta_{0}-\delta^{u}\right)+P_{e_{\max }}{ }^{f} \cdot \cos \left(\delta_{0}\right)-P_{e_{\max }}^{p f} \cdot \cos \left(\delta^{u}\right)}{\left(P_{e_{\max }}{ }^{f}-P_{e_{\max }}{ }^{p f}\right)}
$$


Observa-se, então, que o ângulo crítico de abertura foi obtido sem a solução numérica das equações diferenciais. É justamente essa característica que define um método direto. Porém, o objetivo do estudo é a obtenção de um tempo crítico de abertura, logo, uma simulação numérica do sistema em falta será feita até que o ângulo crítico se iguale ao ângulo do sistema em falta. O tempo em que isto acontece será o tempo crítico de abertura.

\section{2 - Teoria dos Sistemas Dinâmicos Autônomos}

O modelo obtido para estudo de estabilidade em sistemas elétricos de potência é um conjunto de equações diferenciais ordinárias que representa a dinâmica do sistema em estudo, ou seja, o sistema elétrico de potência é tratado como um sistema dinâmico para o estudo de estabilidade. Neste contexto, uma breve descrição da teoria de sistemas dinâmicos se faz necessária para fundamentar o estudo de estabilidade.

Grande parte dos sistemas dinâmicos são descritos por equações diferenciais de $1^{\mathrm{a}}$ ordem do tipo $\dot{x}=f$, onde a função $f$ pode depender das próprias variáveis de estado $x$, do tempo $t$ e ainda de uma fonte externa $u$.

Os sistemas elétricos de potência pertencem a uma classe distinta de sistemas não dependentes da variável tempo, nem de elementos forçantes $u$,ou seja, são sistemas do tipo $(f(t, x)=f(x))$, chamados de sistemas autônomos.

Seja o sistema autônomo abaixo:

$$
\dot{x}=f(x)
$$

onde: $f: D \rightarrow \Re^{n}$ é uma função continuamente diferenciável em um domínio $D \subset \mathfrak{R}^{n}$ em $\mathfrak{R}^{n}$. Suponha que $\bar{x} \in D$ seja um ponto de equilíbrio de (4.14), tal que:

$$
f(\bar{x})=0
$$

Suponha que $\bar{x} \neq 0$, e considere a seguinte mudança de variáveis $y=x-\bar{x}$, a derivada de $y$ é dada por:

$$
\dot{y}=\dot{x}=f(x)=f(y+\bar{x}) \stackrel{\Delta}{=} g(y), \text { onde } g(0)=0
$$


Desta forma o sistema $\dot{y}=g(y)$, na variável $y$, possui o ponto de equilíbrio na origem. Conclui-se portanto que, sem perda de generalidade, pode-se sempre assumir que $f(x)$ satisfaz $f(0)=0$, e estudar a estabilidade na origem $\bar{x}=0$.

Exatamente para retratar o problema na origem é que esta passagem foi descrita. Para os problemas de estabilidade transitória que não tiverem ponto de equilíbrio na origem, é sempre possível encontrar, sem nenhuma perda de generalidade, um novo sistema que tenha ponto de equilíbrio na origem, e que represente o sistema antigo completamente.

\subsection{O Método de Lyapunov para Sistemas Autônomos}

O estudo de estabilidade por métodos diretos permite a predição da estabilidade sem a solução explícita das equações diferencias que representam o sistema elétrico de potência. Porém, além de predizer a estabilidade de pontos de equilíbrio, os métodos diretos fornecem caminhos para estimar a área de atração.

Existe a necessidade, então, da criação de funções que explicitem a estabilidade ou instabilidade de um sistema. Como pode ser visto em Vidyasagar (1993), se fosse possível definir, em algum sentido, a energia total de um sistema, a qual tivesse a propriedade de ser zero na origem e positiva em outros lugares, ou seja, ter um mínimo local ou global em 0 , conseqüentemente, se o sistema, originalmente na origem, fosse perturbado, o nível de energia do sistema aumentaria, e então, a partir daí, olhar-se-ia para o comportamento dinâmico do sistema, e dependendo da função energia utilizada, poder-se-ia concluir sobre a estabilidade.

Neste contexto entram as idéias do método de Lyapunov, que por sua vez se baseiam nas idéias de Lagrange (1800):

"Se uma certa posição de repouso de um sistema mecânico conservativo é um ponto de mínimo da energia potencial, então esta é uma posição de equilíbrio estável. Caso contrário, a posição é instável."

Lyapunov, generalizando as idéias de Lagrange, ou generalizando o conceito de energia mecânica de um sistema, estabeleceu o seguinte teorema: 
Teorema de Lyapunov(4.1):

Seja $x=0$, um ponto de equilíbrio do sistema (4.14), e $D \subset \mathfrak{R}^{n}$ um domínio contendo $x=0$. Seja uma função de classe $C^{l}, V: D \rightarrow \mathfrak{R}$, conhecida como função de Lyapunov, definida positiva, onde:

$$
V(0)=0 \text { e } V(x)>0 \text { em } D-\{0\}
$$

Então, se:

a)

$$
\dot{V}(x) \leq 0 \text { em } D-\{0\}:
$$

sua derivada no tempo seja semi-definida negativa, então, a solução do sistema dinâmico associado é estável;

b) $\dot{V}(x)<0$ em $D-\{0\}$ : sua derivada no tempo seja definida negativa, então, a solução do sistema dinâmico associado é assintoticamente estável;

A demonstração do teorema de Lyapunov torna-se necessária para o entendimento da modelagem dos métodos diretos, bem como para a coerência desta dissertação.

A prova do teorema de Lyapunov descrita a seguir pode ser encontrada, por exemplo, em Khalil (1996):

Prova: Para um dado $\varepsilon>0$, escolhe-se $r \in(0, \varepsilon]$ tal que:

$$
B_{r}=\left\{x \in \mathfrak{R}^{n}\|x\| \leq r\right\} \subset D
$$

Seja $\alpha=\min _{\|x\|=r} V(x)$. Então, da equação (4.17), conclui-se que $\alpha>0$. Fazendo $\beta \in(0, \alpha)$, tem-se:

$$
\Omega_{\beta}=\left\{x \in B_{r} \mid V(x) \leq \beta\right\}
$$

Logo $\Omega_{\beta}$ está no interior de $B_{r}$, como pode ser visto na figura 4.2 : 


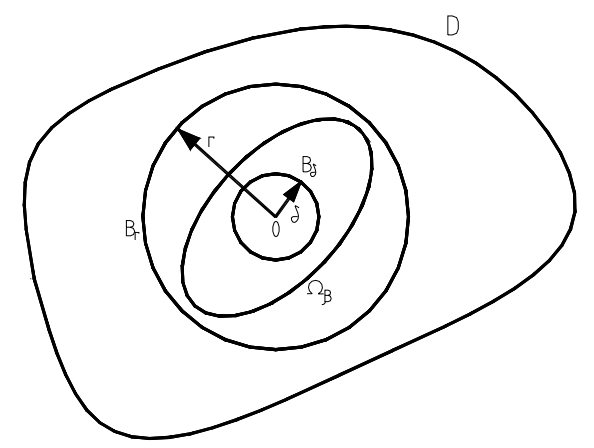

Figura 4.2 - Representação geométrica dos conjuntos na prova do teorema de Lyapunov

$\Omega_{\beta}$ é um conjunto com a característica de que as trajetórias que se iniciam dentro dele em $t=0$, nele permanecem para $t \geq 0$, pois conforme (4.18):

$$
\dot{V}(x(t)) \leq 0 \Rightarrow V(x(t)) \leq V(x(0)) \leq \beta, \forall t \geq 0
$$

Uma vez que $\Omega_{\beta}$ é um conjunto compacto, conclui-se que a equação 4.14 tem uma única solução definida para todo o tempo $t \geq 0$, onde $x(0) \in \Omega_{\beta}$. Se $V(x)$ é contínua e $V(0)=0$, existe um $\delta>0$, tal que:

$$
\|x\| \leq \delta \Rightarrow V(x)<\beta,
$$

Então:

$$
B_{\delta} \subset \Omega_{\beta} \subset B_{r}
$$

e,

$$
x(0) \in B_{\delta} \Rightarrow x(0) \in \Omega_{\beta} \Rightarrow x(t) \in \Omega_{\beta} \Rightarrow x(t) \in B_{r}
$$

Portanto,

$$
\|x(0)\| \leq \delta \Rightarrow\|x(t)\|<r \leq \varepsilon, \quad \forall t \geq 0
$$

mostra que o ponto de equilíbrio $x=0$ é estável.

Para provar a estabilidade assintótica, é necessário mostrar que $x(t) \rightarrow 0$ quando $t \rightarrow \infty$, ou seja, para todo $a>0$ arbitrário, existe um $T>0$, tal que $\|x(t)\|<a$, para todo $t>T$.Por repetição dos argumentos prévios, sabe-se que para todo $a>0$, pode-se escolher $b>0$, tal que $\Omega_{b} \supset B_{a}$. Portanto, é suficiente mostrar que $V(x(t)) \rightarrow 0$, quando $t \rightarrow \infty$. Uma vez que, $V(x(t))$ é monotonamente decrescente e limitado inferiormente por zero, portanto:

$$
V(x(t)) \rightarrow c \geq 0 \text { quando } t \rightarrow \infty
$$


Para mostrar que $c=0$, será utilizado o argumento da contradição. Suponha que $c>0$. Pela continuidade de $V(x)$, existe um $d>0$, tal que $B_{d} \subset \Omega_{c}$. O limite de $V(x(t)) \rightarrow c>0$ implica que a trajetória de $x(t)$ fica fora da bola $B_{d}$ para todo $t \geq 0$. Seja $-\gamma=\max _{d \leq\|x\| \leq r} \dot{V}(x)$, então por (4.18), $-\gamma<0$, de tal forma que:

$$
V(x(t))=V(x(0))+\int_{0}^{t} \dot{V}(x(\tau)) \cdot d \tau \leq V(x(0))-\gamma \cdot t
$$

Uma vez que o lado direito da expressão pode eventualmente se tornar negativo, a inequação contradiz a suposição de que $c>0$.

Uma função contínua e diferenciável $V(x)$ satisfazendo (4.17) e (4.18), é chamada de função de Lyapunov. A superfície, $V(x)=c$, para algum $c>0$, é chamada de superfície de Lyapunov ou curva de nível.

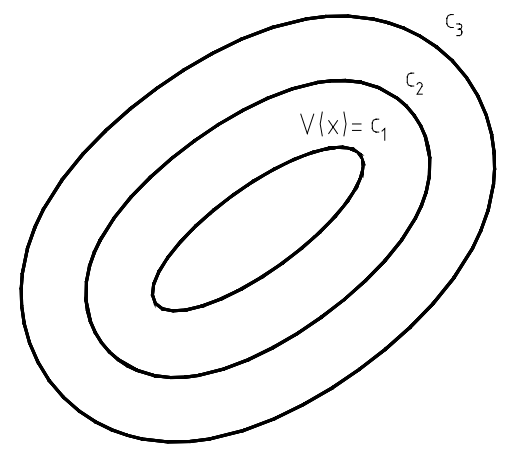

Figura 4.3 - Curva de Nível de uma Função de Lyapunov

A condição $\dot{V} \leq 0$ implica que quando a trajetória cruza a superfície de Lyapunov, $V(x)=c$, ela se move para dentro do conjunto $\Omega_{c}=\left\{x \in \mathfrak{R}^{n} \mid V(x) \leq c\right\}$ e dentro deste conjunto não consegue mais sair. Quando $\dot{V} \leq 0$, a trajetória move-se de uma superfície de Lyapunov para outra mais interior, com menor $c$. Com o decréscimo de $c$, a superfície de Lyapunov, $V(x)=c$, encolhe em direção a origem, mostrando que a trajetória alcança a origem, enquanto o tempo avança. Se for conhecido apenas que $\dot{V} \leq 0$, não se pode garantir que a trajetória alcançará a origem, porém pode-se concluir que a origem é estável, desde que a trajetória esteja contida dentro de uma bola $B_{\varepsilon}$ para uma dada condição inicial $x(0)$, permanecendo no interior de uma superfície de Lyapunov que contém a bola. Já para $\dot{V} \geq 0$, pelo mesmo raciocínio, a trajetória movese de uma superfície de Lyapunov para outra mais exterior, com maior $c$. Com o 
acréscimo de $c$, a superfície de Lyapunov, $V(x)=c$, aumenta na direção contrária a da origem, mostrando que a trajetória se afasta da origem, enquanto o tempo avança.

\subsection{Definição da Área de Atração}

Como dito anteriormente, a análise de estabilidade pelo método passo-a-passo é inadequada para aplicações em tempo real, já que necessita de soluções numéricas de equações diferenciais que consomem muito tempo computacional. Para possibilitar aplicações em tempo real os métodos diretos são propostos, uma vez que são mais adequados para tal fim, devido ao fato de não utilizarem soluções explícitas das equações diferenciais para estimação do tempo crítico de abertura.

Matematicamente, começa-se pela divisão do problema (estudo de estabilidade transitória através de métodos diretos) em 3 sub-problemas: pré-falta, falta e pós-falta, como descrito na seção 3.1 do capítulo 3. Da equação (3.1), para se predizer se a solução do sistema $(\phi)$ retorna ao ponto de equilíbrio estável do sistema pós-falta, é necessário obter-se uma estimativa da região de estabilidade do sistema pós-falta. Com a estimativa da região de estabilidade, pode-se verificar se o defeito é eliminado antes de atingir o ponto no qual a trajetória do sistema em falta abandona esta área de atração, predizendo se o sistema permanecerá estável.

As fundamentações do modelo dos métodos diretos para cálculo do tempo crítico de abertura (predição da estabilidade) que seguem neste relatório têm palavras escritas em itálico que representam os fundamentos inseridos no estudo pela nova abordagem proposta.

Seja um sistema dinâmico autônomo representado na equação (4.14), onde a função $f(x)$ é de classe $C^{l}, \mathfrak{R}^{n}$ em $\mathfrak{R}^{n}$, onde a classe $C^{l}$ é uma classe particular de funções que são contínuas e diferenciáveis e suas derivadas são contínuas.

Para este sistema são necessárias e descritas terminologias que podem ser encontradas, por exemplo, em Bretas e Alberto (2000). Um ponto $\left(x_{i}\right)$ qualquer do sistema dinâmico descrito acima, é dito ponto de equilibrio (p.e.) se $f\left(x_{i}\right)=0$. Diz-se que um ponto de equilíbrio é hiperbólico se a matriz Jacobiana $J\left(x_{i}\right)$, calculada no ponto $x_{i}$, do sistema linearizado neste ponto não tem autovalores com parte real zero. Diz-se que um p.e. hiperbólico, $x_{s}$,é estável (p.e.e.), se todos os autovalores da matriz 
Jacobiana calculada em $x_{s}$, têm parte real negativa, caso contrário o p.e. é dito instável (p.e.i.). O tipo de um p.e.i. é definido pelo número de autovalores com parte real positiva que a matriz Jacobiana têm, ou seja, com 1 autovalor com parte real positiva, o p.e.i. é de tipo-1, e assim por diante. O conjunto formado pelos p.e`s do sistema da equação (4.14) será chamado de $E$, e o conjunto formado pelos p.e`s de tipo-1 do mesmo sistema será chamado de $E_{1}$.

Um sistema é dito globalmente estável se a origem é estável e para qualquer condição inicial dada para o mesmo, a solução se aproxima da origem quando o tempo tende ao infinito. Em sistemas não lineares nem sempre ocorre a estabilidade global, sendo que esta condição fica restrita a um conjunto de condições iniciais, contidas no espaço $\mathfrak{R}^{n}$, que possuem trajetórias que convergem para o p.e.e. $x_{s}$. No caso de sistemas de potência a determinação deste conjunto de condições iniciais é o principal objetivo das análises. A esse conjunto é dado o nome de área de atração ou região de estabilidade $A\left(x_{s}\right)$ :

$$
A\left(x_{s}\right) \stackrel{\Delta}{=}\left\{\left.x \in \mathfrak{R}^{n}\right|_{t \rightarrow \infty} \phi(x, t)=x_{s}\right\}
$$

A fronteira de estabilidade, ou seja, a região limítrofe da região de estabilidade, e o fecho de $A\left(x_{s}\right)$ são representados, respectivamente por $\partial A\left(x_{s}\right)$ e $\bar{A}\left(x_{s}\right)$.

A figura 4.4 representa a área de atração de um sistema de potência:

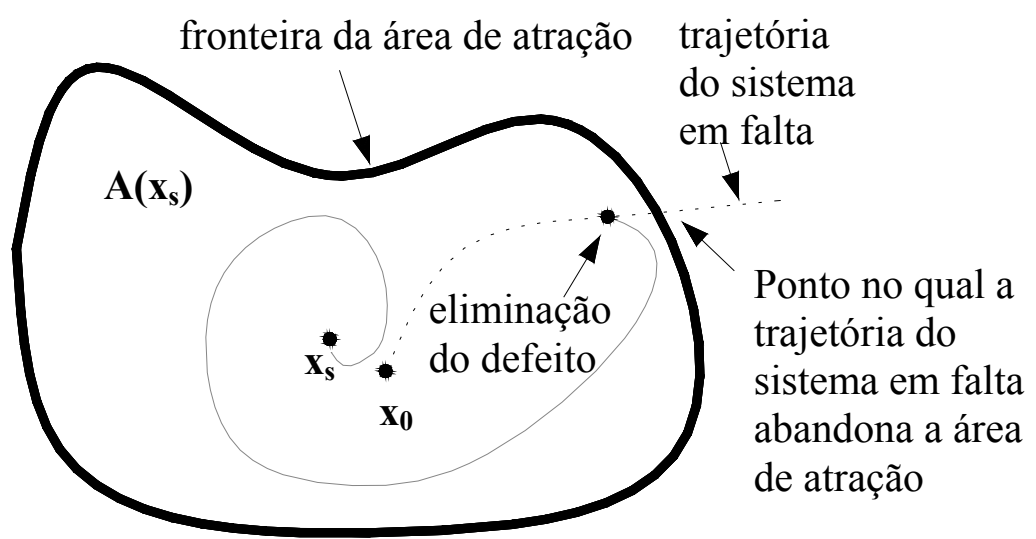

Figura 4.4- Área de atração do ponto de equilíbrio estável do sistema pós-falta 
Onde:

- $x_{s}$ é o ponto de equilíbrio estável do sistema pós-falta;

- $x_{0}$ é o ponto de equilíbrio estável do sistema pré-falta;

- $A\left(x_{s}\right)$ é a região de estabilidade do sistema pós falta;

Portanto, se o defeito for eliminado antes de atingir o ponto no qual a trajetória do sistema em falta abandona a área de atração, o sistema permanecerá estável.

Sendo $x_{i}$ um p.e. hiperbólico de (4.14), define-se variedade estável ("stable manifold") $W^{s}\left(x_{i}\right)$ como:

$$
W^{s}\left(x_{i}\right)=\left\{x \in \mathfrak{R}^{n} \mid \phi(x, t) \rightarrow x_{i}, \text { quando } t \rightarrow \infty\right\}
$$

e variedade instável ("unstable manifold") $W^{u}\left(x_{i}\right)$ como:

$$
W^{u}\left(x_{i}\right)=\left\{x \in \mathfrak{R}^{n} \mid \phi(x, t) \rightarrow x_{i}, \text { quando } t \rightarrow-\infty\right\}
$$

obs: ambos conjuntos são invariantes;

A teoria do método BCU requer que os pontos de equilíbrio instáveis de controle pertençam à fronteira da área de atração do p.e.e. do sistema pós-falta, e para esse atendimento é necessário que a condição de transversalidade seja satisfeita e que o número de pontos de equilíbrio na fronteira da área de atração seja finito, onde se entende que condição de transversalidade é a característica de que todas as variedades estáveis e instáveis dos pontos de equilíbrio instáveis da fronteira de estabilidade devem se interceptar transversalmente. Matematicamente, a condição de transversalidade é atendida se:

- em todo ponto da interseção $x \in(A \cap B)$, onde $A$ e $B$ são variedades em $\mathfrak{R}^{n}$, os espaços tangentes $A$ e $B$ em $x$, geram o espaço tangente de $\mathfrak{R}^{n}$ em $x$ :

$$
T_{x}(A)+T_{x}(B)=R^{n}, \operatorname{para} x \in(A \cap B)
$$

- $\quad A$ e $B$ não se interseccionarem;

Após estas definições, vê-se que são necessárias algumas considerações referentes ao sistema dinâmico autônomo a ser estudado. Sejam as considerações 1, 2 e 3 para sistemas dinâmicos: 
1. todos os pontos de equilibrio da região de fronteira de estabilidade devem ser hiperbólicos;

2. a condição de transversalidade deve ser satisfeita;

3. o teorema de Lyapunov (4.1) deve ser satisfeito;

As considerações 1 e 2 acima dizem que o sistema dinâmico que contém estas características é do tipo Morse-Smale, e ainda que os conjuntos dinâmicos Morse-Smale são densos dentro do conjunto dos sistemas dinâmicos. Os sistemas de potência estão contidos dentro do conjunto dos sistemas dinâmicos que têm características de campo vetorial Morse-Smale.

Considere o teorema de Lyapunov (4.1), que também pode ser, encontrado em Bretas e Alberto (2000), Chiang et al. (1987) e Hale e Koçak (1991). A função definida pelo teorema, função de Lyapunov, é algumas vezes denominada "função energia" do sistema dinâmico, uma vez que a mesma pode representar em alguns casos a energia de um sistema.

Devido a esta representação, algumas conclusões são possíveis a respeito das considerações e do teorema de Lyapunov; as considerações 1 e 2, a respeito dos sistemas dinâmicos, são propriedades genéricas que garantem a estabilidade estrutural de sistemas dinâmicos. As condições a e b, do teorema de Lyapunov, implicam que a trajetória caminhe em direção ao ponto de equilíbrio estável ou divirja em direção ao infinito, o que garante que comportamentos dinâmicos caóticos ou oscilatórios, como ciclos limites, não ocorram. E, finalmente, se os pontos de equilíbrio são hiperbólicos, eles são isolados.

A teoria fundamental a respeito da formação de regiões de estabilidade diz que a fronteira da região de estabilidade é formada pela união das variedades estáveis dos pontos de equilíbrio instáveis que pertencem à fronteira de estabilidade. Os dois teoremas abaixo dão as condições necessárias e suficientes para que um p.e.i. esteja na fronteira de estabilidade:

Teorema 4.2: (Condição necessária e suficiente para um p.e.i. estar na fronteira da área de atração)

Para o sistema dinâmico da equação 4.14, que satisfaz as considerações 1,2 e 3, $x_{i}$ é um ponto de equilibrio instável na fronteira da região de estabilidade $\partial A\left(x_{s}\right)$ de um ponto de equilibrio estável $x_{s}$, se e somente se $W^{u}\left(x_{i}\right) \cap A\left(x_{s}\right) \neq \phi$; 
Teorema 4.3: (Caracterização da fronteira de estabilidade)

Para o sistema dinâmico da equação (4.14), que satisfaz as considerações 1, 2 e 3, seja $x_{i}, i=1,2, \ldots$, um ponto de equilíbrio instável na fronteira da região de estabilidade $\partial A\left(x_{s}\right)$ de um ponto de equilíbrio estável $x_{s}$, então:

$$
\partial A\left(x_{s}\right)=\bigcup_{x_{i} \in E \cap \partial A} W^{s}\left(x_{i}\right)
$$

As provas destes dois teoremas podem ser encontradas em Chiang et al. (1987).

Seja $x_{k}^{1}, \mathrm{k}=1,2, \ldots$ um p.e.i de tipo-1 na fronteira de estabilidade $\partial A\left(x_{s}\right)$. Uma vez que as variedades estáveis destes pontos têm dimensão n-1, e onde as dimensões dos demais pontos de equilíbrio são menores que n-1, o seguinte corolário do teorema 4.3 é descrito:

Corolário 4.1: Para o sistema dinâmico descrito na equação (4.14), satisfazendo as considerações 1, 2 e 3 , seja $x_{k}^{1}, k=1,2, \ldots$ um p.e.i tipo-1 do sistema dinâmico da expressão (4.14), na fronteira da região de estabilidade $\partial A\left(x_{s}\right)$, isto é, $x_{k}^{1} \in E_{1} \cap \partial A$. Então:

$$
\partial A\left(x_{s}\right)=\bigcup_{x_{k}^{1} \in E_{1} \cap \partial A} \bar{W}^{s}\left(x_{k}^{1}\right)
$$

onde $\bar{W}^{s}\left(x_{k}^{1}\right)$ representa o fecho de $W^{s}\left(x_{k}^{1}\right)$.

Das considerações acima realizadas, Chiang et al., extraíram resultados significativos a respeito da relação dos pontos de equilíbrio e das funções energia. Estes resultados serão reapresentados aqui.

Teorema 4.4: (Função Energia e Pontos de Equilíbrio)

a. Se o sistema dinâmico representado na expressão (4.14) satisfaz as considerações 1, 2 e 3, então, na variedade estável $W^{s}\left(x_{i}\right)$ de um ponto de equilíbrio $x_{i}$, o ponto aonde a função energia alcança um mínimo é exatamente no equilíbrio $x_{i}$, isto é:

$$
V\left(x_{i}\right)=\min _{x \in W^{s}\left(x_{i}\right)} V(x)
$$

b. Para o sistema dinâmico da equação (4.14), que satisfaz as considerações 1, 2 e 3, na fronteira da região de estabilidade $\partial A\left(x_{s}\right)$ de $x_{s}$, 
o ponto no qual a função energia alcança um mínimo deve ser um ponto de equilibrio de tipo-1;

c. Para o sistema dinâmico da equação (4.14), que satisfaz as considerações 1, 2 e 3, se for admitido que a região de estabilidade $A\left(x_{s}\right)$ de $x_{s}$ é limitada, então, na fronteira de estabilidade $\partial A\left(x_{s}\right)$ de $x_{s}$, o ponto no qual a função energia alcança um máximo deve ser um ponto de equilíbrio de tipo-n, chamado em língua inglesa de "source";

Através destas demonstrações a fronteira de estabilidade ou fronteira da área de atração fica completamente caracterizada. Esta caracterização, que é a base do estudo dos métodos diretos, foi descrita ao mesmo tempo em que as nomenclaturas e definições correspondentes a estes métodos foram mencionadas.

Este embasamento será, daqui em diante, utilizado para a modelagem do problema de estabilidade por métodos diretos e sua função energia. A visão matemática do problema será substituída pela visão de sistemas de potência (sincronismo), recorrendose aos conceitos matemáticos, anteriormente descritos, quando os mesmos se fizerem necessários.

\section{5 - Aplicação dos Métodos Diretos e sua Função Energia a Sistemas de Potência}

O modelo matemático de um sistema de potência para o estudo de estabilidade transitória é um conjunto de equações diferenciais não lineares, onde o objetivo, do ponto de vista matemático, é determinar se a trajetória do sistema pós-falta tende para o p.e.e. pós-falta.

O método energético baseia-se nos conceitos da mecânica, de que é possível definir uma função energia associada a um sistema, afim de estudá-lo sem a necessidade do estudo de seu movimento completo, ou seja, conclui-se a respeito dos estados iniciais e finais de um sistema, sem conhecer o caminho percorrido pelo mesmo. Baseado nesta idéia energética é possível descobrir se o estado final de um sistema de potência é estável ou não, sem conhecer o caminho descrito, isto é, sem a integração numérica 
passo-a-passo, que consome muito tempo computacional e impede aplicações em tempo real.

Seja um sistema de equações diferenciais dado por:

$$
\left\{\begin{array}{l}
\dot{\theta}=\omega \\
\dot{\omega}=f(\theta, \omega)
\end{array}\right.
$$

Uma função $\mathrm{V}(\theta, \omega)$ é dita uma quantidade conservada por (4.35) se $\frac{d V}{d t}=0$, ou seja $\mathrm{V}$ é constante para todo $\mathrm{t}$ ao longo das soluções. As funções energia utilizadas na mecânica são as primeiras integrais de sistemas conservativos, porém não existem metodologias para se construírem as primeiras integrais, a não ser para sistemas de $2^{\mathrm{a}}$ ordem. Logo é possível ver que para um sistema de $2^{\mathrm{a}}$ ordem, é possível estudar o comportamento de um sistema (concluir sobre seu estado inicial e final) sem resolver explicitamente a equação diferencial que o descreve. O critério das áreas iguais (seção 4.1), por exemplo, utiliza este procedimento energético para o cálculo do ângulo crítico de abertura.

Para o sistema que descreve o comportamento de uma máquina (modelo clássico seção 2.4, capítulo 2) contra um barramento infinito (seção 3.4, capítulo 3), tem-se:

$$
\left\{\begin{array}{l}
\dot{\delta}=\omega \\
M \cdot \dot{\omega}=P_{m}-P_{\text {emáx }} \cdot \operatorname{sen} \delta
\end{array}\right.
$$

Seja:

$$
\mathrm{V}(\delta, \omega)=\frac{1}{2} \cdot M \cdot \omega^{2}-P_{m} \cdot\left(\delta-\delta^{s}\right)-P_{e \max } \cdot\left(\cos \delta-\cos \delta^{s}\right)
$$

uma função energia (Lyapunov) associada ao problema de uma máquina versus barramento infinito. Pode-se facilmente ver que V é uma $1^{\mathrm{a}}$ integral do sistema (4.36).

No problema citado, de uma máquina versus um barramento infinito (“One Machine Infinite Bus System - OMIBS"), através do conceito de conservação da energia, resolve-se o problema da estabilidade transitória, porém em problemas multimáquinas, onde o sistema não é considerado conservativo, é necessário um conhecimento profundo do campo vetorial para a solução do problema de estabilidade. Os conceitos deste campo vetorial podem ser encontrados em Bretas e Alberto (2000), em Hale e Koçak (1991) e em Lima (1977). 
Após a obtenção da área de atração que não é simples e está caracterizada na seção anterior, o problema da estabilidade transitória em sistemas de potência fica resolvido, simulando-se o sistema até que este atravesse a fronteira da região de estabilidade; o tempo decorrido até este cruzamento é o tempo crítico de abertura, ou tempo máximo de duração da falta para que se garanta a estabilidade do sistema.

No estudo de estabilidade em sistemas conservativos, a força atua no sentido negativo do gradiente da energia potencial. Lyapunov, generalizando as idéias de Lagrange, estabeleceu teoremas a respeito dos sistemas autônomos, definindo uma função, dita de Lyapuvov, e um caminho para a estimação da região de estabilidade. Seus teoremas são condições suficientes, porém não necessárias, o que faz com que as estimativas da área de atração sejam conservadoras.

Não existem métodos sistemáticos para encontrar uma função de Lyapunov para sistemas de ordem maior ou igual a 3, em geral as funções energia fornecem um indicativo para encontrá-las.

O desenvolvimento da função energia utilizada neste estudo pode ser encontrado em Bretas e Alberto (2000), e foi proposto primeiramente por Aylett (1958).

A função energia é obtida multiplicando-se a i-ésima equação de "swing" referenciada ao $\operatorname{COA}(3.36$, seção 7 , capítulo 3$)$ por $\widetilde{\omega}_{i}$. Este procedimento é análogo a multiplicar a força pela velocidade, a fim de obter a potência em um sistema mecânico. A multiplicação resulta em:

$$
\begin{aligned}
\sum_{i=1}^{n}\left[M_{i} \frac{d \widetilde{\omega}_{i}}{d t}\right. & -\left(P_{m i}-\left|E_{i}\right|^{2} \cdot G_{i i}\right)+\sum_{\substack{j=1 \\
j \neq i}}^{n}\left[C_{i j} \cdot \operatorname{sen}\left(\theta_{i}-\theta_{j}\right)+\right. \\
& \left.\left.+D_{i j} \cdot \operatorname{sen}\left(\theta_{i}-\theta_{j}\right)\right]+\frac{M_{i}}{M_{T}} \cdot P_{C O A}\right] \cdot \widetilde{\omega}_{i}=0
\end{aligned}
$$

Porém, $\widetilde{\omega}_{i}=\frac{d \theta_{i}}{d t}$, podendo-se escrever a equação (4.33) assim:

$$
\begin{aligned}
\sum_{i=1}^{n} M_{i} \cdot \widetilde{\omega}_{i} \cdot \frac{d \widetilde{\omega}_{i}}{d t} & -\sum_{i=1}^{n}\left(P_{m i}-\left|E_{i}\right|^{2} \cdot G_{i i}\right) \cdot \frac{d \theta_{i}}{d t}+ \\
& +\sum_{i=1}^{n} \sum_{\substack{j=1 \\
j \neq i}}^{n}\left[C_{i j} \cdot \operatorname{sen}\left(\theta_{i}-\theta_{j}\right)+D_{i j} \cdot \cos \left(\theta_{i}-\theta_{j}\right)\right] \cdot \frac{d \theta_{i}}{d t}+ \\
& +\sum_{i=1}^{n} \frac{M_{i}}{M_{T}} \cdot P_{C O A} \cdot \frac{d \theta_{i}}{d t}=0
\end{aligned}
$$


Por definição, sabe-se que $C_{i j}=C_{j i}$ e $D_{i j}=D_{j i}$. Logo, se obtêm as seguintes igualdades:

$$
\begin{aligned}
& \sum_{i=1}^{n} \sum_{\substack{j=1 \\
j \neq i}}^{n} C_{i j} \cdot \operatorname{sen}\left(\theta_{i}-\theta_{j}\right) \frac{d \theta_{i}}{d t}=\sum_{i=1}^{n-1} \sum_{j=i+1}^{n} C_{i j} \cdot \operatorname{sen}\left(\theta_{i}-\theta_{j}\right) \cdot \frac{d\left(\theta_{i}-\theta_{j}\right)}{d t} \\
& \sum_{i=1}^{n} \sum_{\substack{j=1 \\
j \neq i}}^{n} D_{i j} \cdot \cos \left(\theta_{i}-\theta_{j}\right) \frac{d \theta_{i}}{d t}=\sum_{i=1}^{n-1} \sum_{j=i+1}^{n} D_{i j} \cdot \cos \left(\theta_{i}-\theta_{j}\right) \cdot \frac{d\left(\theta_{i}+\theta_{j}\right)}{d t}
\end{aligned}
$$

Também por definição, da referência angular COA, sabe-se que: $\sum_{i=1}^{n} M_{i} \cdot \widetilde{\omega}_{i}=0$, logo, tem-se também a igualdade:

$$
\sum_{i=1}^{n} \frac{M_{i}}{M_{T}} \cdot P_{C O A} \cdot \frac{d \theta_{i}}{d t}=\frac{P_{C O A}}{M_{T}} \cdot \sum_{i=1}^{n} M_{i} \cdot \widetilde{\omega}_{i}=0
$$

Integrando-se (4.39), do tempo $t=0$ até $t$, após substituição de (4.40), (4.41) e (4.42) em (4.39), obtêm-se:

$$
\begin{aligned}
V(\theta, \widetilde{\omega}) & =\int_{0}^{t} \sum_{i=1}^{n} M \cdot \widetilde{\omega}_{i} \cdot \frac{d \widetilde{\omega}_{i}}{d t} \cdot d t-\int_{0}^{t} \sum_{i=1}^{n}\left(P_{m_{i}}-E_{i}^{2} \cdot G_{i i}\right) \cdot \frac{d \theta_{i}}{d t} \cdot d t+ \\
& +\int_{0}^{t} \sum_{i=1}^{n-1} \sum_{j=i+1}^{n} C_{i j} \cdot \operatorname{sen}\left(\theta_{i}-\theta_{j}\right) \cdot \frac{d\left(\theta_{i}-\theta_{j}\right)}{d t} \cdot d t+ \\
& +\int_{0}^{t} \sum_{i=1}^{n-1} \sum_{j=i+1}^{n} D_{i j} \cdot \cos \left(\theta_{i}-\theta_{j}\right) \cdot \frac{d\left(\theta_{i}+\theta_{j}\right)}{d t} \cdot d t
\end{aligned}
$$

Eliminando-se a variável tempo, pelo fato de se admitir que no tempo $t=0$, o sistema esteja no ponto de equilíbrio estável $\left(\theta^{s}, 0\right)$, e que no tempo $t$, o sistema esteja no ponto $(\theta, \widetilde{\omega})$, obtém-se a seguinte expressão para a função energia:

$$
\begin{aligned}
V(\theta, \widetilde{\omega}) & =\int_{0}^{\widetilde{\omega}} \sum_{i=1}^{n} M \cdot \widetilde{\omega}_{i} \cdot d \widetilde{\omega}_{i}-\int_{\theta^{s}}^{\theta} \sum_{i=1}^{n}\left(P_{m_{i}}-E_{i}^{2} \cdot G_{i i}\right) \cdot d \theta_{i}+ \\
& +\sum_{i=1}^{n-1} \sum_{j=i+1}^{n} \int_{\theta_{i}^{s}-\theta_{j}^{s}}^{\theta_{i}-\theta_{j}} C_{i j} \cdot \operatorname{sen}\left(\theta_{i}-\theta_{j}\right) \cdot d\left(\theta_{i}-\theta_{j}\right)+ \\
& +\sum_{i=1}^{n-1} \sum_{j=i+1}^{n} \int_{\theta_{i}^{s}-\theta_{j}^{s}}^{\theta_{i}+\theta_{j}} D_{i j} \cdot \cos \left(\theta_{i}-\theta_{j}\right) \cdot d\left(\theta_{i}+\theta_{j}\right)
\end{aligned}
$$

Resolvendo-se as integrais, tem-se: 


$$
\begin{aligned}
V(\theta, \widetilde{\omega}) & =\sum_{i=1}^{n} \frac{1}{2} \cdot M \cdot \widetilde{\omega}_{i}^{2}-\sum_{i=1}^{n}\left(P_{m_{i}}-E_{i}^{2} \cdot G_{i i}\right) \cdot\left(\theta_{i}-\theta_{i}^{s}\right)- \\
& -\sum_{i=1}^{n-1} \sum_{j=i+1}^{n} C_{i j} \cdot\left[\cos \left(\theta_{i}-\theta_{j}\right)-\cos \left(\theta_{i}^{s}-\theta_{j}^{s}\right)\right] \\
& +\sum_{i=1}^{n-1} \sum_{j=i+1}^{n} \int_{\theta_{i}^{s}-\theta_{j}^{s}}^{\theta_{i}+\theta_{j}} D_{i j} \cdot \cos \left(\theta_{i}-\theta_{j}\right) \cdot d\left(\theta_{i}+\theta_{j}\right)
\end{aligned}
$$

Porém a última parcela da expressão da energia é uma integral dependente do caminho, o que significa que o sistema não é conservativo quando as condutâncias de transferência são diferentes de zero. Apesar disto, esta função tem sido empregada com sucesso em aplicações envolvendo grandes sistemas. Para isso, aproxima-se o caminho de integração da integral dependente do caminho, por uma reta, e obtém-se:

$$
\begin{aligned}
& \sum_{i=1}^{n-1} \sum_{j=i+1}^{n} \int_{\theta_{i s}-\theta_{j s}}^{\theta_{i}-\theta_{j}} D_{i j} \cdot \cos \left(\theta_{i}-\theta_{j}\right) \cdot d\left(\theta_{i}+\theta_{j}\right) \cong \\
& \cong \sum_{i=1}^{n-1} \sum_{j=i+1}^{n} D_{i j} \cdot \frac{\theta_{i}+\theta_{j}-\theta_{i s}-\theta_{j s}}{\theta_{i}-\theta_{j}-\theta_{i s}+\theta_{j s}}\left[\operatorname{sen}\left(\theta_{i}-\theta_{j}\right)-\operatorname{sen}\left(\theta_{i s}-\theta_{j s}\right)\right]
\end{aligned}
$$

Esta aproximação está deduzida em Bretas e Alberto (2000).

\subsection{Evolução dos Métodos Diretos}

Os estudos dos métodos diretos para predição da estabilidade de sistemas elétricos, foram propostos por Gless (1966) e El-abiad e Nagappan (1966), baseados na teoria de Lyapunov, evitando-se a resolução explícita das equações diferenciais do sistema, que é feito através de integração numérica.

Kakimoto et al. (1978) e Athay et al. (1979) propuseram o ponto de equilíbrio instável de controle, na qual a direção da trajetória de falta seria usada na determinação da margem de estabilidade do sistema.

Em Chiang et al. (1987) foram descritos dois teoremas que caracterizam completamente a região de estabilidade e foi estudada a modelagem clássica do problema de estabilidade transitória de sistemas de potência através de métodos diretos. A caracterização completa da área de atração realizada na seção 4.4 deste capítulo demonstrou ser algo muito complexo quando aplicado a sistemas de potência. Apesar da teoria matemática precisa descrita e citada, não se obteve até o momento um processo sistemático aplicável a sistemas elétricos de potência. Com isso, vários métodos foram propostos na literatura, como tentativas de se estimar a área de atração. Dentre dos 
métodos diretos propostos, baseados nos estudos de Lyapunov, estão os descritos abaixo:

- Ponto de equilíbrio de menor Energia;

- Pontos de Equilíbrio Instáveis Aproximados e Modos de Instabilidade;

- Critério da Aceleração;

- Potencial Energy Boundary Surface (PEBS);

- Boundary Controlling Unstable Equilibrium Point (BCU);

Primeiramente foi proposto na literatura a deteção do ponto de equilíbrio instável de menor energia ("closest unstable equilibrium point”) para a estimação da estabilidade do sistema pós-falta, onde se comparava o valor da função energia de todos os pontos de equilíbrio instáveis da fronteira de estabilidade e utilizava-se o de menor energia. Então se determinava uma estimativa da região de estabilidade baseada neste ponto (neste nível energético). Comparando a energia do sistema em falta com a do ponto de equilíbrio instável de menor energia, era prevista a estabilidade (caso a energia do sistema em falta fosse maior que a do ponto determinado o sistema seria instável e ao contrário, estável). Duas deficiências evidentes desta consideração são: a estimativa muito conservadora da área de atração e a necessidade de se calcular todos os pontos de equilíbrio instáveis na fronteira da área de atração. Muitas vezes, o ponto de menor energia era um ponto distante da trajetória da falta em consideração, o que fazia com que a estimativa do tcr (tempo crítico de abertura) ficasse muito reduzida, ou seja, na teoria do "closest unstable equilibrium point" desenvolvida, a região de estabilidade era exclusivamente dependente do sistema pós-falta, sendo independente da trajetória da falta, e por isso a predição da estabilidade ficava muito conservadora.

Isto fez com que a abordagem dada a este estudo da área de atração ficasse restrita a apenas alguns estudos devido ao conservadorismo de suas predições, e também pela necessidade de se calcular os inúmeros pontos de equilíbrio de um sistema elétrico de grande porte, o que levava a grande consumo de tempo computacional, ou seja, o inegável fato de não se levar a trajetória ou direção da falta em consideração, penalizou muito a estimativa da área de atração por este método, instigando pesquisadores a considerarem a direção da falta para predição da estabilidade. 
Em Chiang et al. (1989) foi caracterizado um destes estudos envolvendo o ponto de equilíbrio instável de menor energia para avaliação da segurança dinâmica de um sistema de potência, onde foi verificado, como dito anteriormente, que a predição da estabilidade através da consideração deste ponto, é muito conservadora devido ao fato da não consideração da trajetória de falta. Porém, esta predição de estabilidade muito conservadora tem aplicações quando se procura avaliar a robustez de um sistema elétrico. A verificação de que o uso do ponto de equilíbrio instável de menor energia na predição da estabilidade transitória leva a resultados muito conservadores já tinha sido percebido por Athay et al. (1979), motivo pelo qual foram propostos o ponto de equilíbrio instável de controle e o PEBS.

Os pesquisadores atentaram-se ao fato do cálculo de pontos de equilíbrio instáveis impedir o sucesso do método acima descrito. Logo, uma nova idéia surgiu no sentido de aproximar o cálculo destes pontos, evitando o esforço computacional de outrora. Porém ao se tentar criar uma associação entre os pontos de equilíbrio instáveis e os modos de instabilidade do sistema, verificou-se que o número de combinações possíveis que gerariam pontos de equilíbrio instáveis seria muito grande, inviabilizando também esta metodologia do ponto de vista computacional. As estimativas do tempo crítico obtidas por este método ainda foram conservadoras, e problemas de convergência associados ao método de Newton utilizado para encontrar os verdadeiros pontos de equilíbrio, iniciando-se nos aproximados, foram verificados.

Devido aos problemas computacionais associados ao cálculo desnecessário de vários pontos de equilíbrio, e também devido ao fato das predições de estabilidade obtidas, com os dois métodos citados acima, serem conservadoras; surgiram na literatura métodos que tentaram se utilizar da trajetória da falta, como base para a predição de qual ponto de equilíbrio seria o mais importante para determinada falta. Esta idéia, bem razoável, baseia-se no fato de que para faltas ou contingências diferentes, existem acelerações diferentes nas máquinas do sistema, que fazem com que pontos de equilíbrios diferentes sejam responsáveis pela definição da estabilidade ou instabilidade de um sistema, pelo menos para o $1^{\mathrm{o}}$ "swing".

A primeira idéia que surgiu foi a de verificar qual máquina tinha maior aceleração inicial, proporcionalmente a sua constante de inércia. A máquina escolhida por este critério de aceleração seria a máquina para a qual se procuraria um ponto de equilíbrio instável aproximado associado, e determinar-se-ia a energia crítica do sistema. Poderiase também utilizar um ponto de equilíbrio aproximado como condição inicial do método 
de Newton-Raphson, do ponto de equilíbrio instável, e então se obter o valor da energia crítica.

A partir dos estudos realizados, verificou-se que nem sempre a máquina que detinha maior relação de aceleração inicial era a máquina que definia o ponto de equilíbrio instável importante. As vezes outra máquina acelerava mais em um tempo maior, sendo ela a responsável por definir o ponto. Isso inviabilizou aplicações do critério de aceleração.

O método PEBS, proposto por Athay (1979), surgiu para tentar solucionar o problema da estimativa da área de atração eliminando o cálculo explícito dos pontos de equilíbrio instáveis, encontrando, na direção da falta, uma aproximação local da fronteira de estabilidade do sistema. Em Chiang et al. (1988) apresentou-se a fundamentação teórica do PEBS (Potencial Energy Boudary Surface) para análise da estabilidade transitória em sistemas de potência.

Foi proposto, então, o denominado ponto de equilíbrio instável de controle (do inglês: "controlling unstable equilibrium point"). Este ponto seria o ponto de equilíbrio, que na direção da falta, seria o responsável pela definição da estabilidade. A consideração deste ponto retirou o problema do conservadorismo na predição de estabilidade, porém, agora, já não se poderia garantir que as estimativas estariam dentro da área de atração, não se garantindo a estabilidade em "swings" posteriores, ou estabilidade "multi-swing".

A proposta do uso ponto de equilíbrio instável de controle ("controlling unstable equilibrium point - c.u.e.p") na predição de estabilidade considera a trajetória da falta, ou seja, a região de estabilidade é estimada localmente. A idéia desta técnica reside nas deficiências das anteriores, que é o fato de não ser necessária a estimativa completa da área de atração, mas sim, somente a parte importante para o estudo. Porém, um problema e uma dificuldade ficam evidentes: o problema se dá pelo fato de só se garantir a estabilidade de $1^{\circ}$ "swing" e a dificuldade é que não é fácil encontrar o ponto de equilíbrio instável de controle.

Quando o ponto de equilíbrio instável de controle foi proposto, nada foi dito no sentido de como se encontrar este ponto. O PEBS, como já foi dito, não calcula explicitamente o ponto de equilíbrio instável de controle. Para calcular este ponto diversos métodos foram propostos culminando na proposta do método BCU (Boundary Controlling Unstable Equilibrium Point). Chiang et al. (1994) definiu que o ponto de equilíbrio instável de controle é o ponto de equilíbrio instável, cuja variedade estável 
contém o "exit point", ou ponto onde a trajetória de falta deixa a região de estabilidade. Para calcular o ponto acima descrito, o BCU baseia-se na relação entre a fronteira de estabilidade do modelo clássico de sistemas de potência e a fronteira de estabilidade do sistema reduzido que é definido apenas no espaço dos ângulos. O BCU utiliza esta relação quando calcula o ponto de equilíbrio instável de controle da fronteira de estabilidade do sistema gradiente reduzido, e não na fronteira de estabilidade do sistema do modelo clássico. Isto é feito devido a facilidade de cálculo do ponto de equilíbrio instável de controle no espaço dos ângulos.

Llamas et al. (1995), observaram alguns problemas associados ao algoritmo BCU. Foram dados alguns exemplos onde o mesmo falha na predição da estabilidade. Esta falha já havia sido encontrada por Chiang et al. (1988), e diz respeito a não satisfação da condição de transversalidade necessária para o funcionamento do algoritmo, mas que não é verificada pelo mesmo.

A condição de transversalidade que fora anteriormente mencionada como uma condição necessária para funcionamento do algoritmo BCU, é analisada em Alberto e Bretas (1999) para sistemas de uma máquina versus barramento infinito. A condição de transversalidade está intimamente relacionada com os parâmetros do sistema e recai sobre o fato de que todas as variedades estáveis e instáveis dos pontos de equilíbrio instáveis, que pertençam à fronteira da área de atração, devem cruzar-se transversalmente. Apesar desta condição ser muito forte, o BCU não a verifica, comprometendo a predição de estabilidade.

Treinen et al. (1996) desenvolveram uma técnica melhorada para cálculo do ponto de equilíbrio instável de controle chamada de "shadowing method". Esta técnica melhorada veio corrigir dois problemas do algoritmo BCU. O primeiro problema é associado ao fato do algoritmo procurar um ponto de mínimo local partindo do "exit point" calculado pelo PEBS, mínimo este, que pode não ser encontrado e causar uma falha do algoritmo. O segundo problema deve-se ao fato do algoritmo usar o ponto de mínimo local calculado, como condição inicial para encontrar o ponto de equilíbrio instável de controle, porém o ponto inicial (mínimo local) pode não estar na região de convergência do ponto de equilíbrio instável de controle, e então o algoritmo não encontra ou encontra um outro ponto de equilíbrio instável, predizendo erroneamente a estabilidade transitória do sistema de potência.

O "shadowing method" proposto por Treinen et al. (1996) corrige os dois problemas do algoritmo BCU através da utilização da variedade estável do ponto de equilíbrio 
instável de controle. A técnica consiste na utilização do fluxo e da forma da superfície de energia equipotencial em torno da variedade estável do ponto de equilíbrio instável de controle. O "shadowing method" corrige o "exit point" através do fluxo do sistema gradiente na vizinhança da variedade estável do ponto de equilíbrio instável de controle, obtendo uma seqüência de finita de pontos que converge ao ponto de equilíbrio instável de controle. Com isso a técnica descrita evita o cálculo do mínimo local partindo do "exit point" e garante a proximidade do ponto final da seqüência calculada em relação ao ponto de equilíbrio instável de controle, garantindo então, uma condição inicial na região de convergência para encontrar o ponto de equilíbrio instável de controle.

Scruggs e Mili (2001) propõem um método dinâmico de deteção do PEBS para predição de estabilidade transitória em sistemas de potência. $\mathrm{O}$ artigo mostra dois problemas associados a deteção do "exit point". O primeiro problema deve-se ao fato de que os métodos de deteção do "exit point" (gradiente e "ray") consideram que a trajetória de falta cruzará o PEBS ortogonalmente, o que não é sempre verdade, uma vez que não se conhece a trajetória da falta. Esta consideração faz com que o "exit point" estimado afaste-se em muitos casos do real "exit point", predizendo-se erroneamente a estabilidade transitória. O segundo problema está associado a consideração de que a energia potencial de um sistema em falta cresce até cruzar o PEBS, no entanto, esta afirmação nem sempre é verdade, fazendo com que o "exit point" seja encontrado antecipadamente.

O método dinâmico, proposto por Scruggs et al., para evitar os dois problemas mencionados anteriormente, baseia-se na própria definição do PEBS, ou seja, o método verifica se os pontos da trajetória de falta estão dentro da fronteira da área de atração do sistema gradiente através de uma integração com número e tamanho de passos predefinidos. Esta metodologia faz com que o encontro do "exit point" seja independente da trajetória de falta e independente do cruzamento ortogonal da trajetória de falta com o PEBS, eliminando os dois problemas iniciais.

Rodrigues et al. (1996, 2000 e 2001) discutem o princípio de invariância de LaSalle. Os estudos da teoria de conjuntos invariantes agem no sentido de expandir o número de problemas a serem considerados através das funções de Lyapunov, no qual os métodos diretos estão fundamentados, possibilitando o tratamento de sistemas não lineares até então não solucionáveis através das funções de Lyapunov. 
Os métodos PEBS e BCU são os que mais se destacaram na estimação da área de atração, e ainda são os objetivos de estudo desta pesquisa e serão analisados separadamente em detalhes.

\subsection{Método PEBS}

O método PEBS (do inglês:"Potencial Energy Boundary Surface") foi proposto, inicialmente por Kakimoto et al. em (1978) e expandido por Athay et al. (1979) com o objetivo de circundar o problema de deteção do ponto de equilíbrio de controle, no qual a direção da trajetória de falta seria usada na determinação da margem de estabilidade do sistema. Para uma dada trajetória de falta, o método encontra uma aproximação da fronteira da área de atração, como representado na figura 4.5:

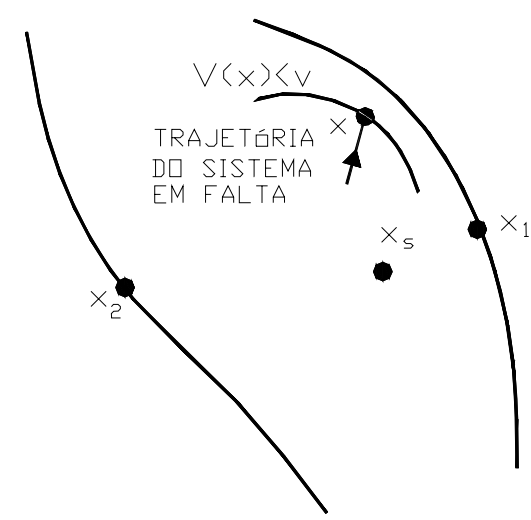

Figura 4.5 - Aproximação local da fronteira de estabilidade

Nesta seção será mostrada a idéia motivacional, com base heurística do PEBS, bem como seu algoritmo baseado nestas idéias.

A superfície de energia potencial pode ser vista como uma bacia energética ao redor do ponto de equilíbrio estável, associado a uma função energia que pode ser separada em duas componentes, uma de energia cinética e outra de energia potencial. Alguns dos pontos extremos da função energia potencial coincidem com a fronteira de 
estabilidade, ou a borda desta bacia, onde residem os pontos de equilíbrio instáveis. A figura 4.6 esboça esta situação.

Baseado nesta informação integram-se as equações diferenciais do sistema em falta até que o nível energético do sistema seja igual ao nível energético do PEBS, ou seja, integram-se as equações diferenciais até que os ângulos e as velocidades angulares resultem, numa energia associada total, igual à

do PEBS. Uma explicação bastante eficiente para o PEBS é dada em Bretas e Alberto (2000), que compara o sistema a uma bola dentro de uma bacia energética cuja fronteira é o PEBS, bacia esta que é análoga a uma hidrográfica. A falta é equivalente a aplicação de uma força nesta bola, de forma a tentar retirá-la da bacia que a contém. Logo a força máxima, na direção perpendicular à linha do "divisor de águas", que poderia ser aplicada à bola seria aquela que fizesse com que a mesma chegasse ao "divisor de águas" com velocidade nula, sendo que se a energia fosse suficiente para que a bola passasse pelo "divisor de águas" da bacia, o sistema seria considerado instável, caso contrário, estável. O PEBS veio solucionar o problema concernente a estimativa da área de atração através da eliminação do cálculo dos pontos de equilíbrio instáveis, como discutido na seção 4.2 deste capítulo.

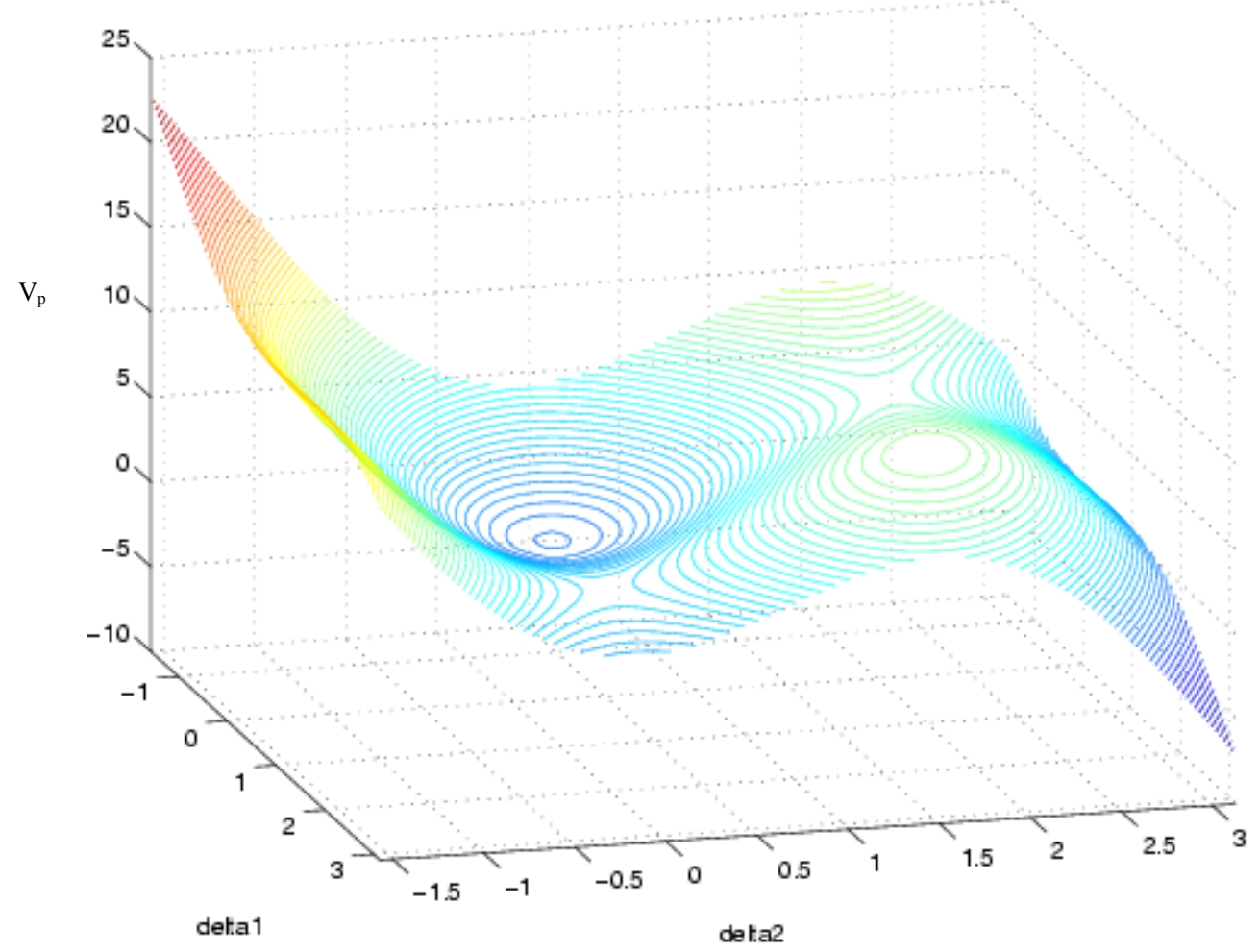

Figura 4.6: Esboço de uma bacia energética 
Eis a idéia do método:

Seja a função energia para o sistema : $V(\delta, \omega)$, que pode ser dividida em $V(\delta, \omega)=V_{k}(\delta, \omega)+V_{p}(\delta, \omega):$

- $V_{k}(\delta, \omega)$ : Energia Cinética;

- $V_{p}(\delta, \omega)$ : Energia Potencial;

Nos pontos de equilíbrio do sistema a velocidade é nula e $V_{p}(\delta)$ é um ponto extremo em relação a $\delta$. Traçando-se um gráfico de energia potencial em relação ao ângulo $\delta$ em um sistema OMIBS, tem-se a seguinte figura:

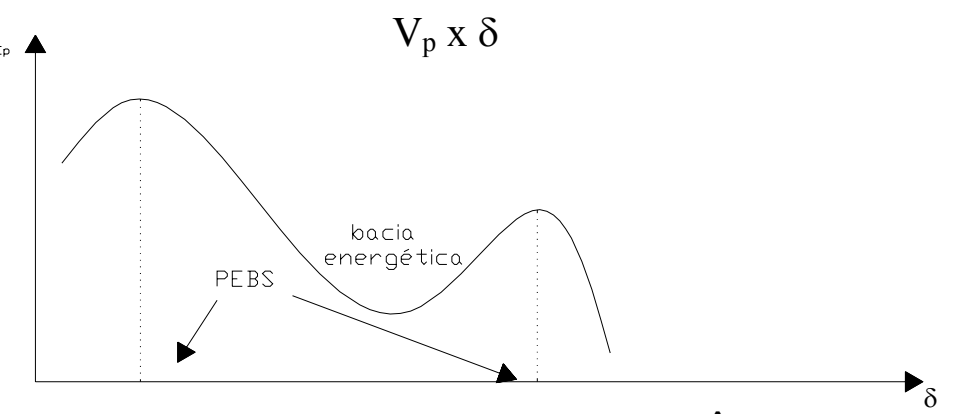

Figura 4.7 : Gráfico da Energia Potencial x Ângulo

A fronteira da bacia energética formada com os pontos extremos da energia potencial, como pode ser visto na figura 4.7, é conhecida como PEBS. Utilizando-se desta fronteira, o algoritmo do PEBS simula o sistema em falta através de solução numérica das equações diferenciais que representam o sistema elétrico, até que o ângulo ( $)$ cruze o PEBS. Este ponto é chamado de "exit point".

No problema multimáquinas, o ponto de equilíbrio estável está localizado na parte mais baixa da bacia de energia potencial, sendo a sua fronteira definida pelos pontos extremos da função energia, e por linhas (variedades) que unem estes pontos. $\mathrm{O}$ exemplo de bacia energética da figura 4.8 mostra este fato. 


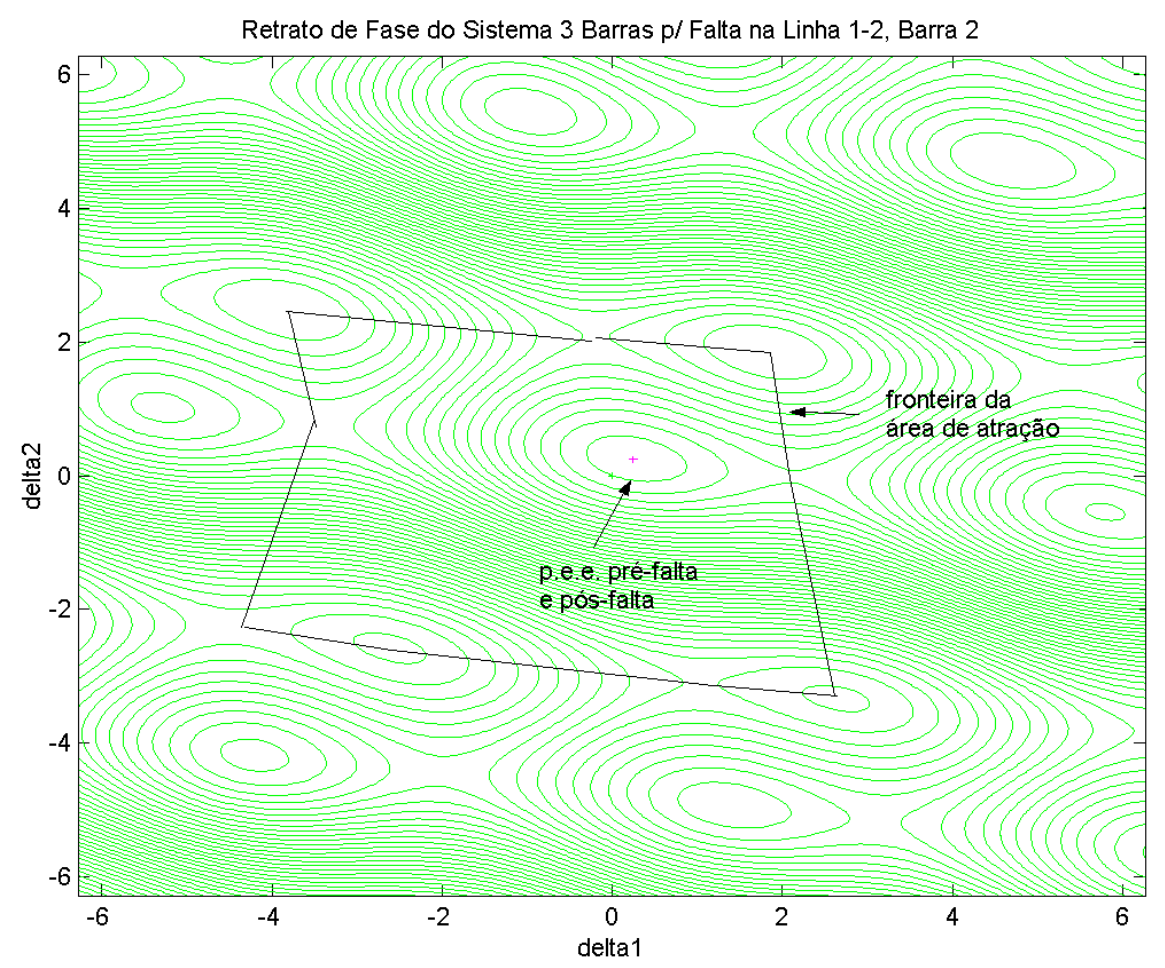

Figura 4.8-Fronteira da área de atração do sistema de 3 barras (referência angular COA)

Baseado nesta metodologia, o PEBS evita o cálculo de pontos de equilíbrio instáveis para a estimativa da área de atração, o que evita esforço computacional desnecessário. Seja o seu algoritmo:

Algoritmo PEBS:

a) Verifica-se o ponto no qual a trajetória do sistema em falta cruza o PEBS $\left(V_{p}(\delta)\right.$ é máximo); $\delta^{*}$ é este ponto;

b) A energia potencial que é relacionada ao ângulo $\delta^{*}$ é a energia crítica do sistema, se a energia do sistema em falta for menor que a energia crítica no momento da abertura, o sistema é estável;

Matematicamente o PEBS é a fronteira da área de atração do seguinte sistema gradiente associado ao sistema original: 


$$
\dot{\delta}=-\frac{\partial V_{p}(\delta)}{\partial \delta}=P_{m}-P_{e}
$$

Como exemplificação do método PEBS para um sistema elétrico, seja o sistema elétrico composto por 3 barramentos, descrito na figura 4.9 abaixo, onde os dados do sistema já representam um fluxo de carga convergido, representando o sistema pré-falta até o acontecimento de uma contingência.

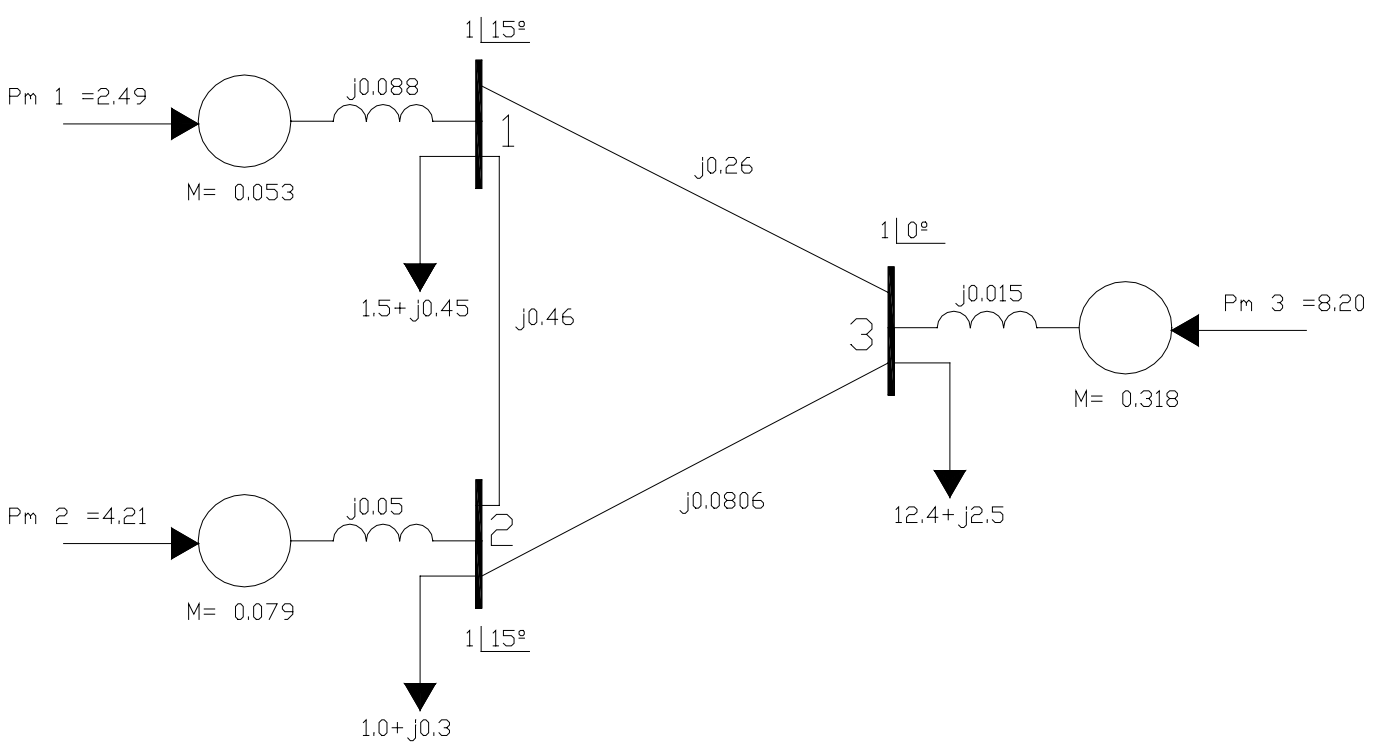

Figura 4.9- Sistema de 3 barras

O sistema descrito foi submetido a uma contingência, curto-circuito trifásico sólido, na linha 1-2 próximo a barra 2, de maneira que a própria barra tivesse de ser eliminada. Nestas condições, aplicando a análise pelo método PEBS, utilizando o COA como referência e a função energia descrita no capítulo anterior, obteve-se a seguinte bacia energética da figura 4.10: 


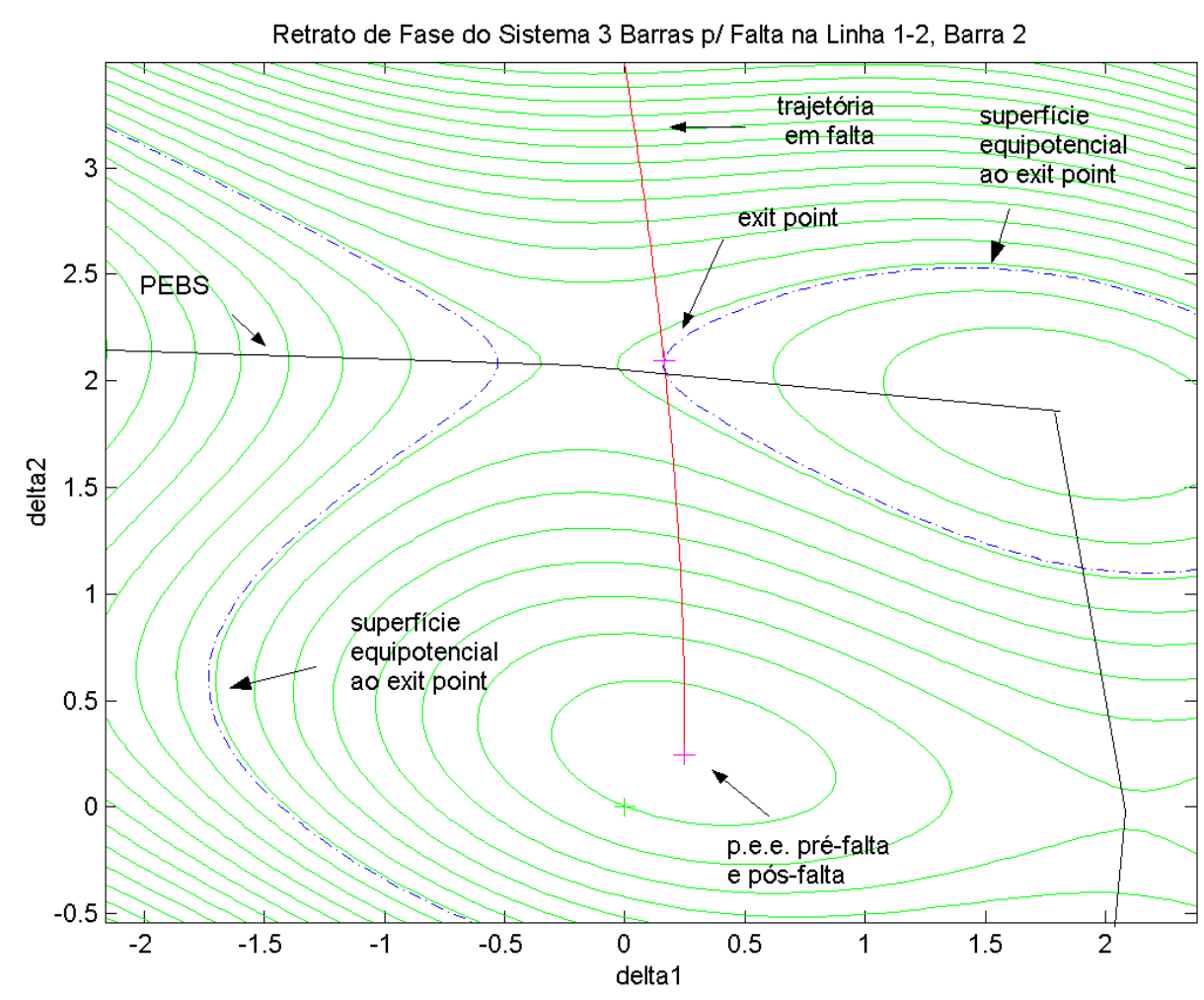

Figura 4.10 - Curva equipotencial do sistema de 3 barras para curto trifásico sólido na linha 1-2 próximo a barra 2 e "exit point" calculado pelo método PEBS

\subsection{Sistema Gradiente Associado ao Modelo Clássico - Fundamentação Teórica do PEBS}

O método PEBS, para uma dada trajetória de falta, encontra uma aproximação da fronteira da área de atração, como representado nas figuras 4.7 e 4.8. O encontro desta aproximação local da fronteira de estabilidade é feito através de um sistema dimensionalmente reduzido e computacionalmente mais eficiente. Essa redução é proveniente dos argumentos heurísticos que criaram o PEBS, como discutido na seção anterior. Porém apenas quando Chiang et al. (1988) analisaram o problema, é que constatações a respeito do sistema gradiente associado foram demonstradas matematicamente, fundamentando o PEBS. Esta fundamentação está resumida abaixo, para não deixar o conceito do PEBS sem base teórica.

Seja o sistema descrito pelas equações diferenciais: 


$$
\left\{\begin{array}{l}
\frac{d}{d t} x=\dot{x} \\
M \cdot \ddot{x}=-D \cdot \dot{x}-k \cdot \operatorname{sen} x+p
\end{array}\right.
$$

onde: $x=\delta$, é o ângulo de fase da máquina em um sistema OMIBS;

Os pontos de equilíbrio são:

$$
x=\operatorname{sen}^{-1} \frac{p}{k}, \quad \dot{x}=0
$$

Seja $x_{s}$ o ponto de equilíbrio estável de interesse e $V(x, \dot{x})$ a função energia do sistema 4.35 acima:

$$
V(x, \dot{x})=V_{k}(\dot{x})+V_{p}(x)=\frac{1}{2} \cdot m \cdot(\dot{x})^{2}-p \cdot\left(x-x_{s}\right)-k \cdot\left(\cos x-\cos x_{s}\right)
$$

Nos pontos de equilíbrio de sistemas da forma do (4.43), tem-se:

- $\dot{x}=0$;

- $V_{P}(x)$ é um máximo local com respeito a $x$;

A figura 4.11 representa a função energia $V_{p}($.$) :$

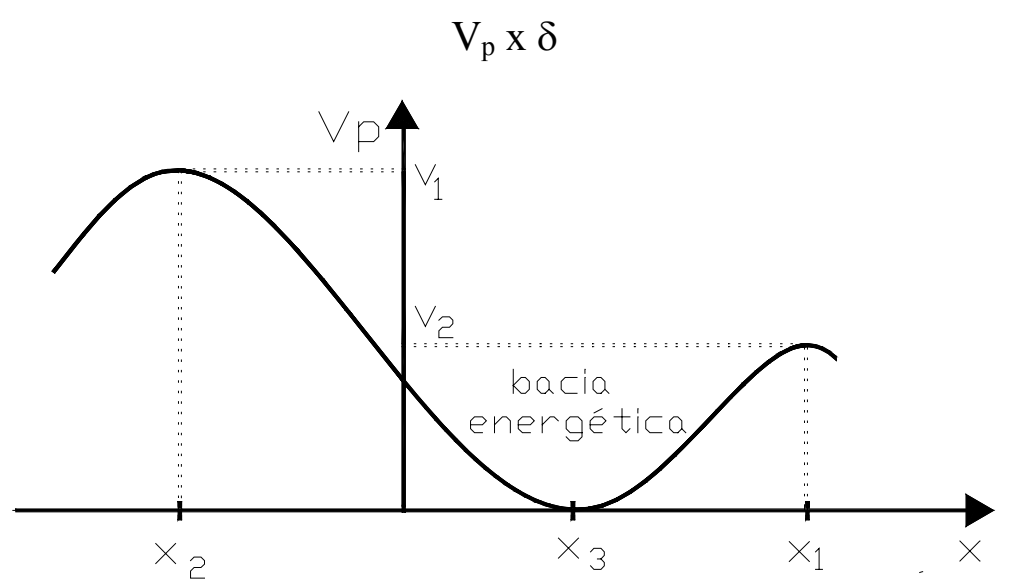

Figura 4.11- Energia Potencial com pontos $x_{1}$ e $x_{2}$ como máximos locais

A figura 4.12 mostra uma idéia qualitativa da fronteira de estabilidade de um sistema (4.48): 


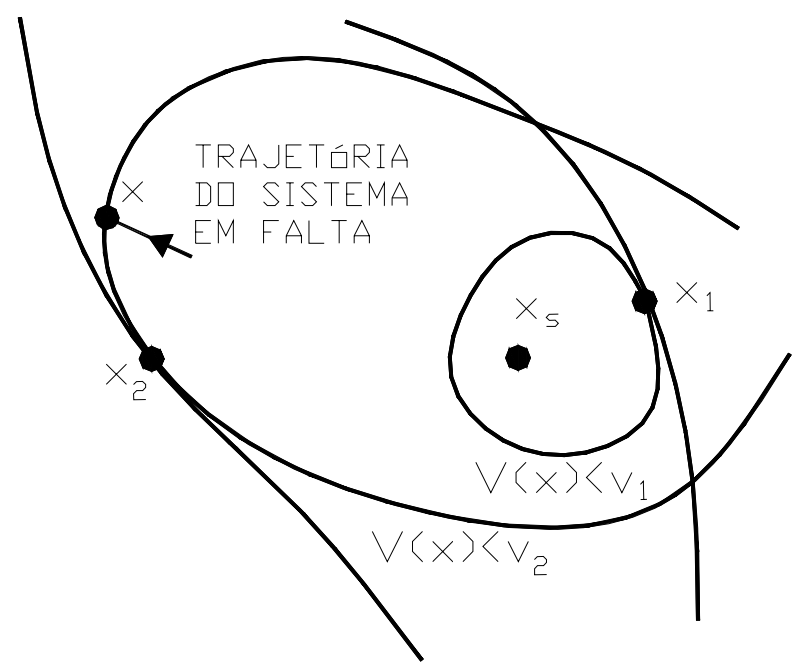

Figura $4.12-x_{1}$ e $x_{2}$ como p.e.s na fronteira de estabilidade do sistema pós-falta.

É possível notar que:

- a intersecção da fronteira de estabilidade de $x_{s}$ do sistema reduzido mostrado na figura 4.11 com o conjunto $\{(x, \dot{x}): \dot{x}=0, x \in \mathfrak{R}\}$ é a região $P \stackrel{\Delta}{=}\left\{(x, \dot{x}): x_{2}<x<x_{1}, \dot{x}=0\right\}$

- A fronteira da região unidimensional $P$ no espaço de $x$ consiste de dois pontos $x_{1}$ e $x_{2}$;

- Os pontos $\left\{x_{1}, x_{2}\right\}$ são caracterizados como máximos locais da função energia potencial $V_{p}(\cdot)$;

A extensão destas idéias do sistema OMIBS para o sistema multimáquinas não é trivial. Devido a base heurística do método PEBS é difícil enxergar quando o método provém uma boa aproximação local ou não para a fronteira de estabilidade, e em quais condições ele a faz.

A abordagem para fundamentação teórica do PEBS no problema multimáquinas, é baseado em Varaya (1985), que vê o PEBS como a fronteira de estabilidade do sistema gradiente associado, ao sistema original, conforme a equação (4.47), cujo, o modelo clássico (equação de "swing") para $n$ geradores é: 


$$
\left\{\begin{array}{l}
\dot{\delta}=\omega \\
M \cdot \dot{\omega}=-D \cdot \omega-\frac{\partial V_{p}(\delta)}{\partial \delta}
\end{array}\right.
$$

onde $\delta, \omega \in \mathfrak{R}^{n}$ e $M, D$ são matrizes diagonais positivas.

A motivação por trás da abordagem é o fato da energia potencial ser a função energia do sistema gradiente. E ainda pelo fato de todos os pontos de equilíbrio estarem no subespaço $\{(\delta, \omega): \omega=0\}$ e nestes pontos $V(\delta, \omega)=V_{p}(\delta)$.

Para determinar o relacionamento entre a fronteira de estabilidade do sistema gradiente associado com o sistema clássico, a equação (4.51) será transformada passo-apasso, via perturbação, até alcançar a equação (4.47). Reescrevendo a equação do modelo clássico para $n$ máquinas:

$$
M \cdot \ddot{\delta}+D \cdot \dot{\delta}+\frac{\partial V_{p}}{\partial \delta}=0
$$

E reescrevendo também, a equação do modelo gradiente associado:

$$
\dot{\delta}+\frac{\partial V_{p}(\delta)}{\partial \delta}=0
$$

Se o termo $M \cdot \ddot{\delta}$ for suprimido, tem-se:

$$
D \cdot \dot{\delta}+\frac{\partial V_{p}}{\partial \delta}=0 \text { e } \dot{\delta}+\frac{\partial V_{p}(\delta)}{\partial \delta}=0
$$

Para suprimir o termo $M \cdot \ddot{\delta}$, considera-se um passo intermediário:

$$
\varepsilon \cdot I \cdot \ddot{\delta}+D \cdot \dot{\delta}+\frac{\partial V_{p}}{\partial \delta}=0
$$

onde:

- $\varepsilon$ é um coeficiente suficientemente pequeno;

- $\quad$ é a matriz identidade; 
Logo, para determinar a relação entre as fronteiras de estabilidade dos sistemas gradiente associado e clássico utilizam-se os seguintes passos:

$1^{\circ}$ passo: determina-se o relacionamento entre as fronteiras de estabilidade dos sistemas de 4.54:

$$
\dot{\delta}=-D^{-1} \cdot \frac{\partial V_{p}}{\partial \delta} \text { e } \dot{\delta}=-\frac{\partial V_{p}(\delta)}{\partial \delta}
$$

onde $D^{-1}$, é a inversa da matriz $D$, e também é uma matriz diagonal positiva;

$2^{\circ}$ passo: determina-se o relacionamento entre as fronteiras de estabilidade dos sistemas (4.52) e (4.55):

$$
\left\{\begin{array}{l}
\dot{\delta}=\omega \\
M \cdot \dot{\omega}=-D \cdot \omega-\frac{\partial V_{p}(\delta)}{\partial \delta}
\end{array}\right.
$$

$\mathrm{e}$

$$
\left\{\begin{array}{l}
\dot{\delta}=\omega \\
\varepsilon \cdot I \cdot \dot{\omega}=-D \cdot \omega-\frac{\partial V_{p}(\delta)}{\partial \delta}
\end{array}\right.
$$

$3^{\circ}$ passo: determina-se o relacionamento entre as fronteiras de estabilidade dos sistemas:

$$
\dot{\delta}=-D^{-1} \cdot \frac{\partial V_{p}}{\partial \delta}
$$

$\mathrm{e}$

$$
\left\{\begin{array}{l}
\dot{\delta}=\omega \\
\varepsilon \cdot I \cdot \dot{\omega}=-D \cdot \omega-\frac{\partial V_{p}(\delta)}{\partial \delta}
\end{array}\right.
$$

A abordagem empregada para estabelecer o relacionamento entre a fronteira de estabilidade dos sistemas é similar para os passos 1 e 2, onde primeiramente deriva-se uma completa caracterização da fronteira de estabilidade dos sistemas descritos nestes dois passos. Depois, é conduzida uma análise qualitativa na variação da fronteira de estabilidade, quando o campo vetorial destes sistemas é perturbado. Já no passo 3, usase a técnica de perturbação singular para mostrar o relacionamento entre a fronteira de 
estabilidade dos sistemas 4.59 e 4.60. A caracterização da fronteira de estabilidade para os 3 passos pode ser encontrada em Chiang et. al. (1988).

\subsection{Método BCU ("Boundary Controlling Unstable Equilibrium Point")}

Para a deteção do ponto de equilíbrio instável de controle da região de estabilidade, o BCU ("Boundary Controlling Unstable Equilibrium Point"), foi proposto por Chiang et al. (1994).

O algoritmo baseia-se na relação da fronteira da área de atração do sistema pós-falta entre o modelo original e o modelo reduzido (gradiente associado). Logo, como visto na seção anterior, encontrando-se os pontos de equilíbrio instáveis de controle do sistema gradiente associado, encontram-se os pontos de equilíbrio instáveis de controle do sistema do modelo original, ou seja, através do sistema do modelo gradiente associado se encontram os pontos de equilíbrio instáveis de controle do sistema do modelo original. Dentre as vantagens de se utilizar o sistema gradiente está a redução do sistema original (de $2 n-1$ para $n-1$ variáveis), porém existe um desenvolvimento de teoria em sistemas dinâmicos para verificar se essa relação é possível, como descrito na seção anterior.

Como os campos vetoriais associados ao sistema dinâmico autônomo em questão são dissipativos e são Morse-Smale, a fronteira da área de atração destes sistemas é formada pela união das variedades estáveis dos pontos de equilíbrio instáveis que pertencem à fronteira da área de atração. Sob certas hipóteses, o ponto de equilíbrio instável de controle $\left(\delta^{c o}\right)$ do sistema gradiente associado pertencerá à fronteira da área de atração deste sistema se e somente se o ponto de equilíbrio instável de controle $\left(\delta^{c o}, 0\right)$ pertencer à fronteira de estabilidade do sistema original. Esta associação entre os pontos de equilíbrio instáveis sugere a utilização do sistema gradiente reduzido associado para o cálculo do ponto de equilíbrio instável de controle relativo a uma condição de falta do sistema original.

O algoritmo BCU, para a deteção do ponto de equilíbrio instável de controle através da utilização do modelo do sistema gradiente associado fica assim: 
Algoritmo BCU:

- Ao longo da trajetória do sistema em falta $(\delta(t), \omega(t))$, encontra-se o "exit point" $\delta^{*}$ que é o ponto no qual a trajetória projetada $\delta(t)$ atinge o primeiro máximo local da energia potencial $V_{p}(\bullet)$.

- Utiliza-se o ponto $\delta^{*}$ como sendo condição inicial e integra-se o sistema reduzido pós-falta até encontrar o primeiro mínimo local de $\sum_{i=1}^{n}\left\|f_{i}(\delta)\right\|$. Seja este $\delta_{o}^{*}$

- Utiliza-se o ponto $\delta_{o}{ }^{*}$ como estimativa inicial para resolver $f(\delta)=0$. Seja $\delta_{c o}{ }^{*}$ o zero de fencontrado.

- $\left(\delta_{c o}{ }^{*}, 0\right)$ será o ponto de equilíbrio de controle relativo à trajetória em falta $(\delta(t), \omega(t))$

A figura 4.13 ilustra o algoritmo.

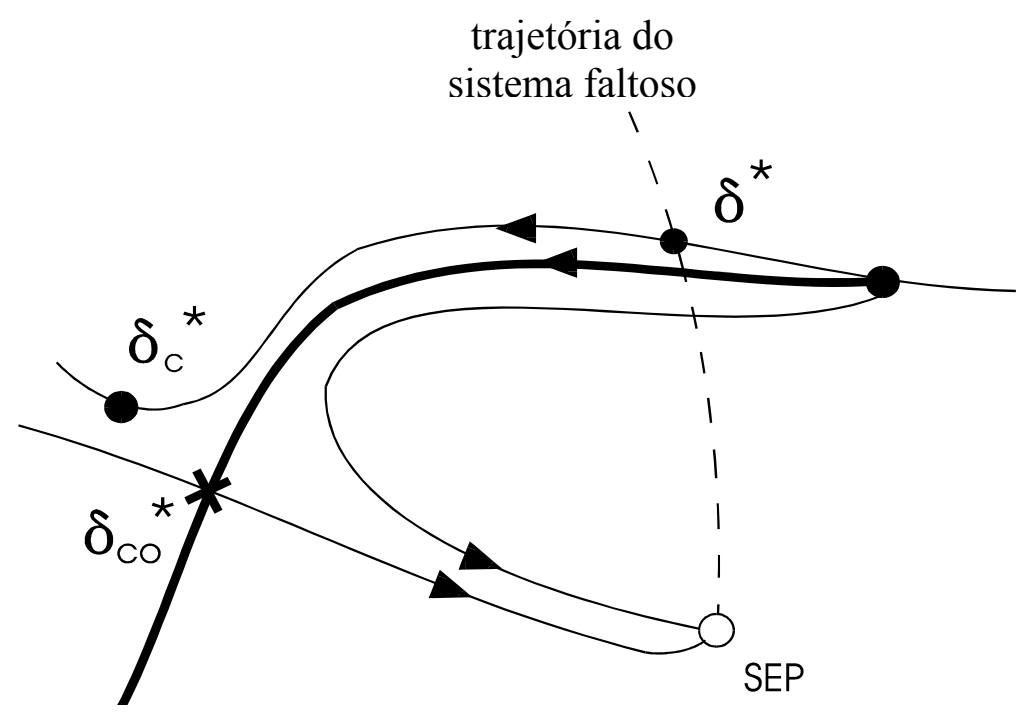

Figura 4.13 - Ilustração do algoritmo BCU

Para o sistema de 3 barras representado pela figura 4.9, obteve-se, para a mesma falta descrita na seção 4.9, o ponto de equilíbrio de controle obtido pelo método BCU. A figura 4.14 representa a bacia energética para este caso: 


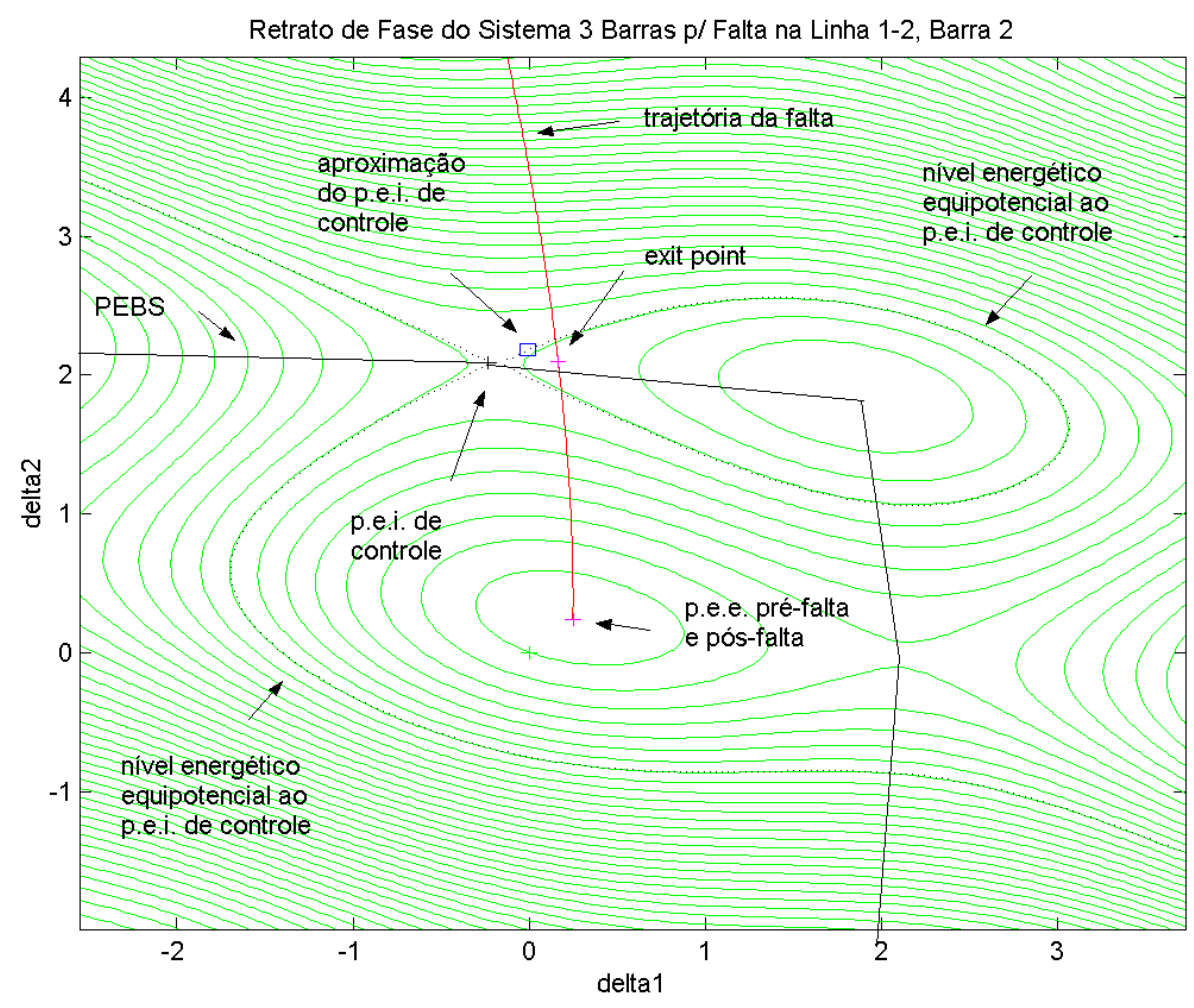

Figura 4.14 - Curva equipotencial do sistema de 3 barras para curto trifásico sólido na linha 1-2 próximo a barra 2 e p.e.i. de controle calculado pelo método BCU 


\section{Capítulo 5}

\section{ESTADO DA ARTE: PROBLEMAS E SOLUÇÕES DO PEBS E BCU}

Os métodos diretos, dentre eles o PEBS e o BCU, vêm sendo muito estudados pelos pesquisadores de estabilidade de sistemas elétricos de potência por se destacarem dentre os outros métodos diretos. O PEBS se destaca por ser de simples implementação possibilitando aplicações práticas em tempo real. Apesar desta simplicidade, o algoritmo pode por vezes levar a estimativas não conservadoras da área de atração. Já o BCU tem formulação matemática precisa para a busca do ponto de equilíbrio instável de controle, evitando tais predições não conservadoras da área de atração, porém, o algoritmo tem uma implementação que demanda maior esforço computacional.

Apesar de suas qualidades, ambos algoritmos têm problemas associados à deteção dos pontos de equilíbrio de controle e "exit points". Como é comum a muitos algoritmos, eles se baseiam em características, nem sempre testadas, quando do estudo de um sistema elétrico.

Esta pesquisa tem como objetivo a eliminação de problemas relacionados a deteção do "exit point" via método PEBS e do ponto de equilíbrio instável de controle via método BCU. Estudos vêm sendo realizados, dentre eles um método dinâmico para a deteção do PEBS (Scruggs e Mili (2001)) e o "shadowing method" para a deteção do ponto de equilíbrio instável de controle (via BCU) (Treinen et al. (1996)).

Uma vez mencionados os métodos para deteção do tempo crítico de abertura através de análises diretas, serão descritas aqui as fragilidades de ambos algoritmos para a percepção dos problemas nos quais os algoritmos PEBS e BCU falham. 


\subsection{Problemas associados a deteção do "exit point"}

Os problemas associados à deteção do "exit point", através do método PEBS, estão associados às condições do cruzamento da trajetória em falta com a fronteira de estabilidade. A própria definição do que é o "exit point" diz que este é o ponto em que a trajetória em falta cruza a fronteira de estabilidade. Como foi visto no capítulo anterior, a caracterização da fronteira da área de atração não é algo simples, apesar de matematicamente estar completamente caracterizada. Isto trás problemas que foram parcialmente sobrepujados pelos métodos PEBS e BCU, quando da associação do sistema gradiente reduzido com o modelo clássico, e da aproximação local da área de atração.

Porém, é evidente que as aproximações tanto da região de estabilidade, quanto dos pontos de equilíbrios encontrados, gerarão problemas quando submetidos a diferentes contingências. Uma das situações de mais clarividência dos problemas associados as aproximações, é o estudo de estabilidade "multiswing". Com a caracterização apenas local da área de atração, não se pode garantir a permanência dentro da área de atração para "swings" subseqüentes ao primeiro, uma vez que tais oscilações poderão estar fora da localidade estudada.

Dentro deste contexto, é que existe o desenvolvimento de algoritmos que tentam dar robustez aos métodos diretos. Da equação (4.42), sabe-se que o PEBS é a fronteira da área de atração do sistema gradiente associado, que têm propriedades que foram exploradas para a criação de métodos práticos de deteção do "exit point", que são:

- propriedade (1): o PEBS é formado pelas variedades estáveis dos pontos de equilíbrio instáveis na fronteira da área de atração do sistema reduzido, ou seja, conforme Scruggs e Mili (2001), o PEBS forma uma variedade fechada de dimensão $n-2$ no espaço dos ângulos que é usualmente suave e de raio aproximadamente constante, em relação ao p.e.e. pós-falta; 
- propriedade (2): um ponto do PEBS caracteriza-se por um máximo de energia potencial na direção normal ao PEBS;

Esta dependência da geometria faz com que em alguns casos, o "exit point" encontrado possa estar muito longe do PEBS, afastando muito a estimativa (predição da estabilidade) da realidade.

O método PEBS utiliza o conceito de energia que resulta em um índice escalar $(\mu$ ou energia), que é obtido através da comparação do nível energético de um ponto sobre a trajetória em falta com o nível máximo de energia potencial sobre a trajetória de falta.

O método assume, ainda, que a trajetória de falta cruzará o PEBS ortogonalmente, porém isto é razoável apenas para cruzamentos com formas como a da superfície de energia potencial descrita na propriedade (1) (para o sistema gradiente associado), e não para trajetórias em falta no sistema dinâmico completo (sistema inicialmente obtido), onde energia é inserida no sistema, o que pode culminar em situações que a direção da trajetória em falta caminha para pontos com ângulos agudos no PEBS, como a figura abaixo:

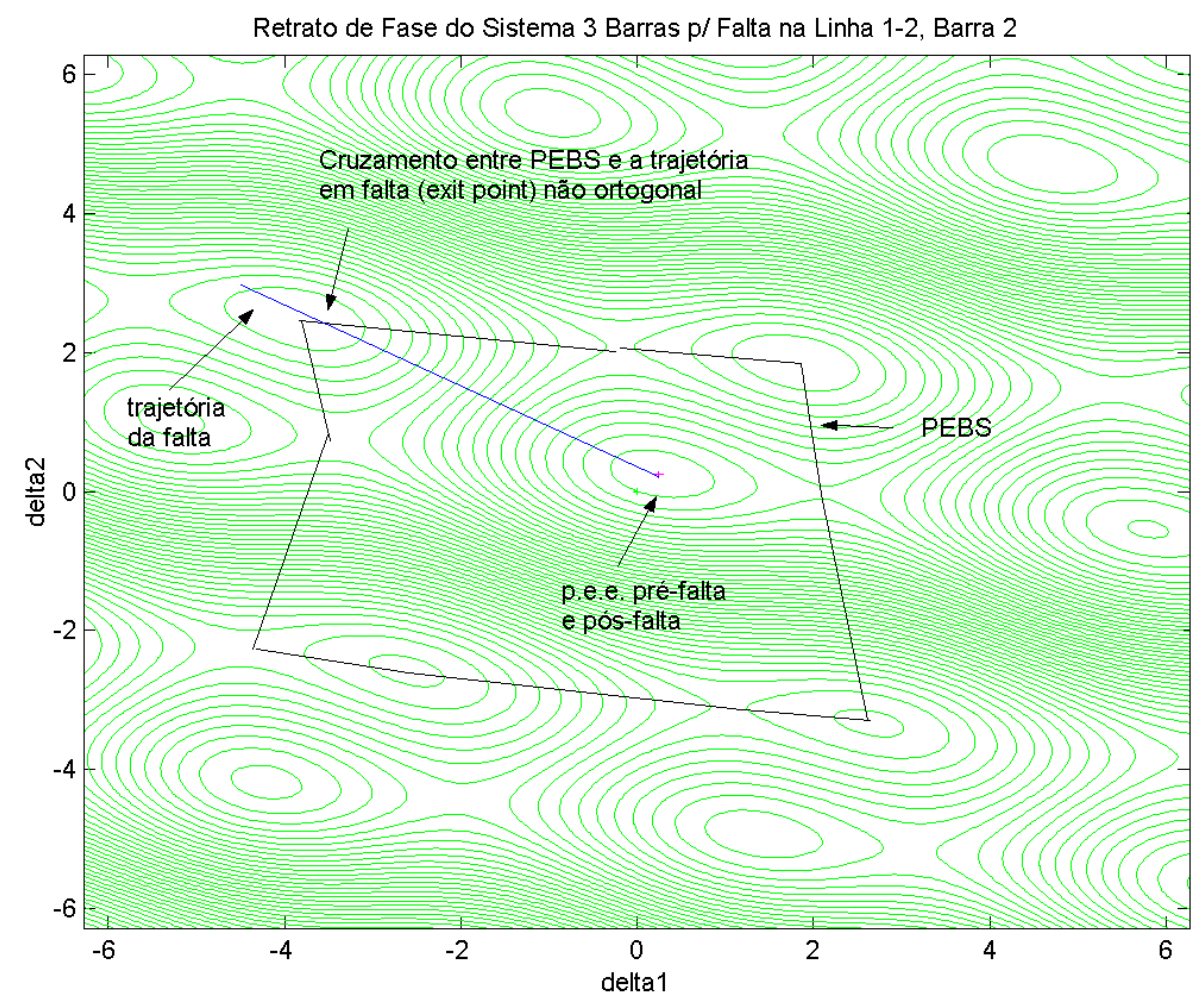

Figura 5.1 - Cruzamento não ortogonal da trajetória em falta com o PEBS 
A outra consideração é o fato de que se supõe que a energia do sistema cresce durante a falta, até o cruzamento do PEBS, o que não é sempre verificado. Como o algoritmo busca um máximo na direção de falta, caso a superfície tenha uma ondulação nesta mesma direção, o método encontra um "exit point" em algum lugar que não o PEBS, como pode ser visto na figura 5.2:

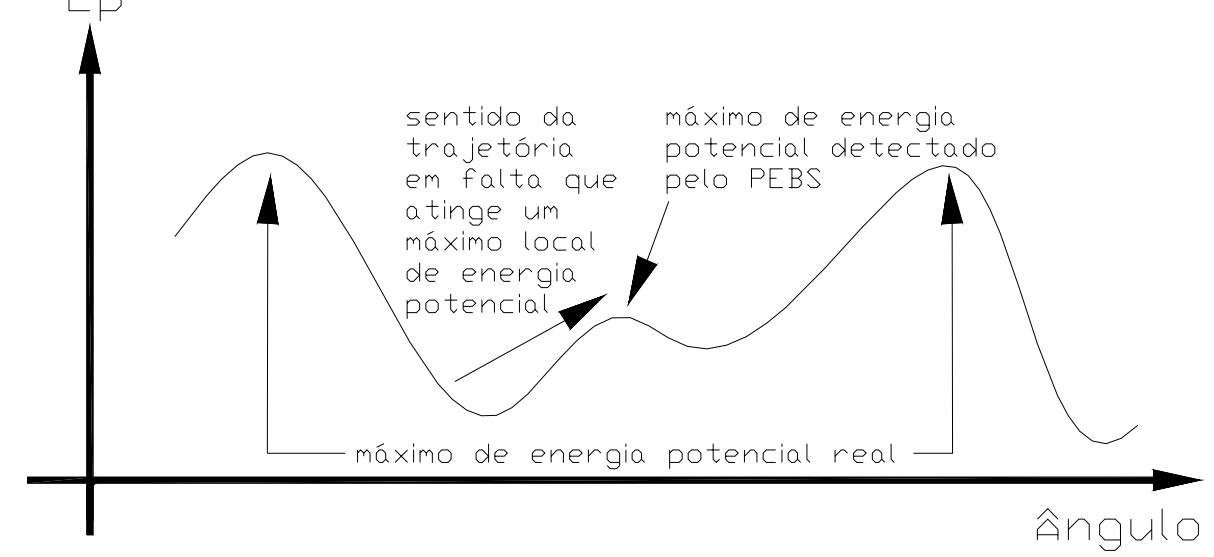

Figura 5.2: Superfície Irregular do PEBS

Para a exemplificação final do problema de deteção do "exit point", submeteu-se o sistema de 3 barras da figura 4.9 a uma falta na linha 1-2 próxima a barra 2, com impedância de falta de 0,045 pu. A trajetória resultante exibe uma oscilação na direção de saída do PEBS. Este comportamento apresenta problemas com relação a propriedade (2), como mostrado na figura 5.2. Como o sistema têm "swings" dentro da área de atração para a falta em questão, encontra-se através de $V p$, um máximo na direção da falta, predizendo-se erroneamente o PEBS. Deve-se notar que decorre muito tempo até o cruzamento real com o PEBS, como pode ser visto na figura 5.3: 


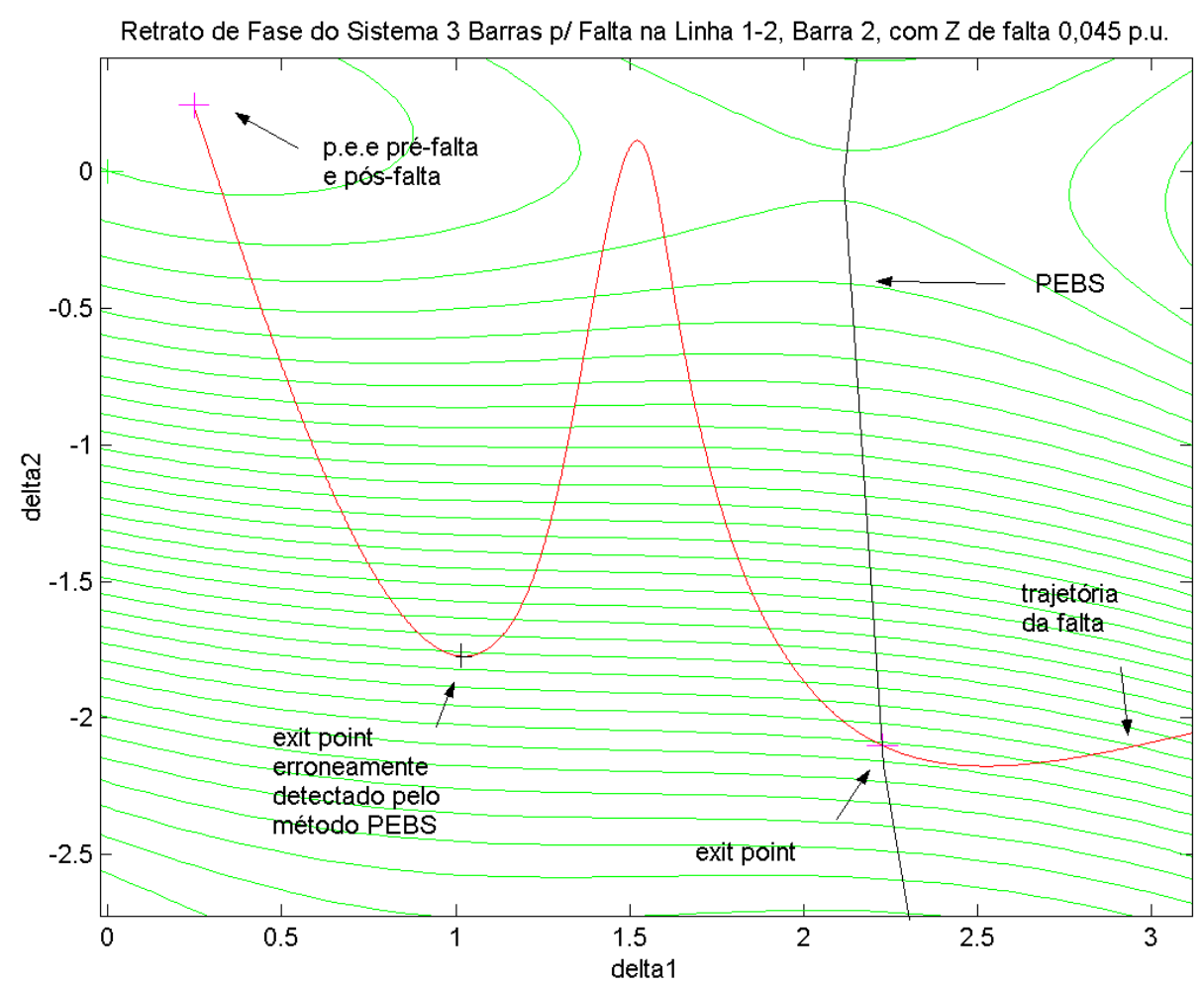

Figura 5.3 - Falha da deteção do "exit point" pelo algoritmo PEBS

\subsection{PEBS dinâmico}

Para solução dos problemas associados à deteção do "exit point" mencionados na seção anterior, foi proposto por Scruggs e Mili (2001), um método dinâmico para deteção do "exit point" do método PEBS, que explora a própria definição do PEBS, que é o fato de que o mesmo é definido como a fronteira da região de atração do sistema gradiente associado.

É possível testar, a qualquer momento, se um estado $\delta$ está dentro do PEBS, ou seja, simula-se o sistema pós-falta para os ângulos do estado $\delta$ em questão, e se verifica se os novos pontos de operação encontrados estão mais próximos do p.e.e. Para isto basta realizar a integração numérica para o sistema pós-falta e testar sua convergência ao p.e.e. Esse teste, de uma maneira diferenciada, é exatamente o que a proposta de um modelo dinâmico para cálculo do PEBS (PEBS dinâmico) faz. Como o processo de integração é muito lento, passos fixos são propostos, ou seja, a integração é limitada a um número de passos, e a verificação de que o estado em teste $\delta^{\mathbf{0}}$ está contido, ou não, no PEBS é feita. 
A maior vantagem deste método é que ele é baseado na própria definição do PEBS, e não nas características da superfície de energia potencial. Outra vantagem é que ele é independente da trajetória de falta, permitindo conclusões mais gerais a respeito do comportamento do "exit point". Esta metodologia dinâmica para deteção do PEBS, será chamada, de agora em diante, de PEBS dinâmico.

O algoritmo de funcionamento do método gradiente dinâmico ou PEBS dinâmico, como aqui é chamado, é dado abaixo:

Algoritmo do PEBS dinâmico:

1. Calcular a distância angular $\delta_{d 1}$ do p.e.e. pós-falta ao estado atual $\delta$.

$$
\text { Seja } \delta=\delta^{0}
$$

2. Em $\delta$, encontre o vetor unitário normalizado $\bar{u}$, na direção do gradiente de energia potencial $\dot{\delta}^{r}$, dado por: $u=\frac{\dot{\delta}^{r}}{\sqrt{\sum_{i=1}^{n-1}\left(\dot{\delta}_{i}^{r}\right)^{2}}} ;$

3. Calcular $\delta_{\text {new }}$, um novo ponto no espaço- $\delta$, dado por: $\delta_{\text {new }}=\delta+u \delta_{d 1} / h$, onde $h e ́$ um inteiro maior que 0.

4. Seja $\delta=\delta_{\text {new }}$ e repita o passo 2 para h iterações;

5. Calcule a distância $\delta_{d 2}$, no espaço- $\delta$, entre o ângulo $\delta_{\text {new }}$ resultante e o p.e.e. pósfalta, encontrando um escalar $\mu$, para o algoritmo PEBS dinâmico: $\mu_{P D}\left(\delta^{0}\right)=\delta_{d 1}$ $\delta_{d 2} ;$

6. Se $\mu_{P D}\left(\delta^{0}\right)>0, \delta^{0}$ está dentro do PEBS, caso contrário, não; 
A figura 5.4 ilustra o algoritmo acima:

Retrato de Fase de um Sistema de 3 barras qualquer

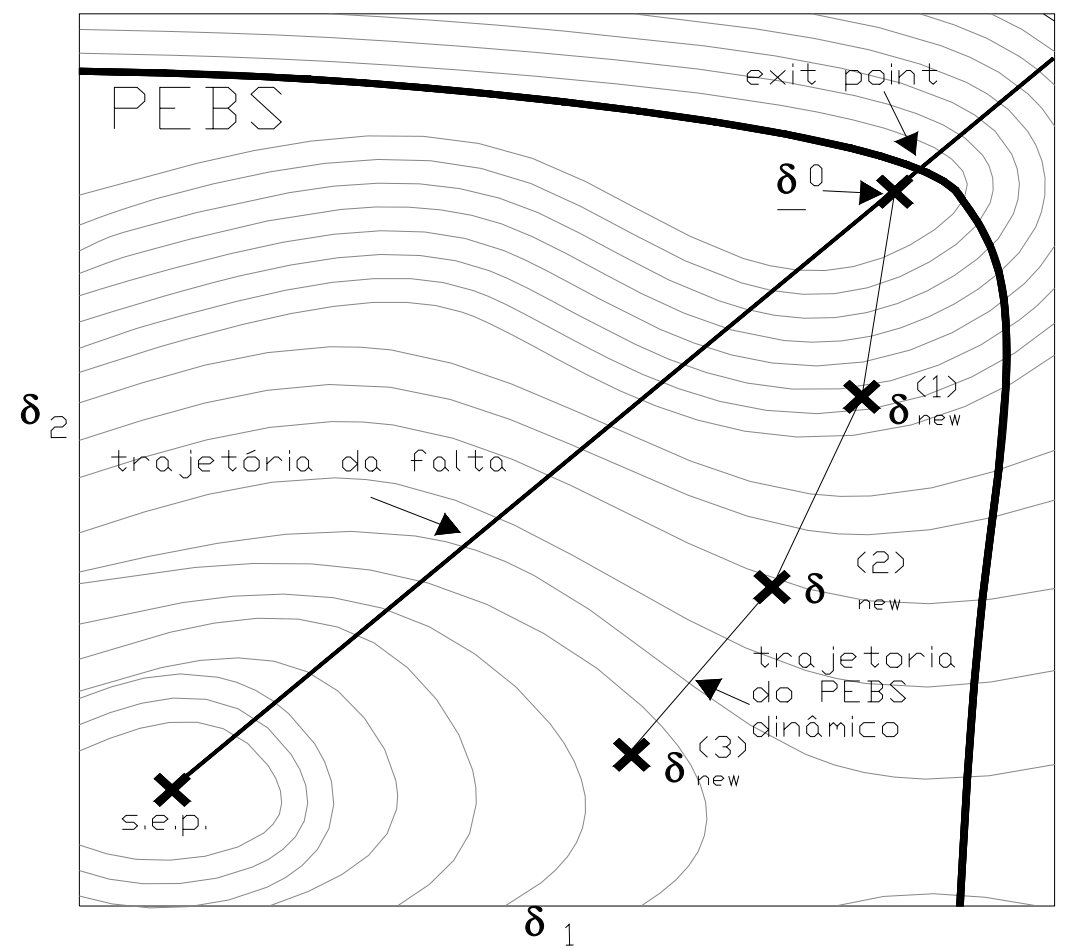

Figura 5.4 - PEBS dinâmico

\subsection{Problemas associados a deteção do ponto de equilíbrio instável de controle}

Embora o método BCU venha sendo utilizado com sucesso para análises de estabilidade transitória de primeiro "swing" em muitos sistemas de potência e em diversas situações de falta, existe uma grande quantidade de casos nos quais o BCU pode falhar. Algumas destas dificuldades foram vislumbradas originalmente no trabalho de Chiang et al. (1994), mas não foram completamente resolvidas. As condições nas quais estas dificuldades podem ocorrer não estão bem estabelecidas fazendo com que a ocorrência do problema seja imprevisível.

Apesar de se encontrar um "exit point" (PEBS ou PEBS dinâmico como primeiro passo do BCU), existem problemas para a deteção de um mínimo local de energia potencial (segundo passo do algoritmo BCU), e quando este mínimo local consegue ser 
encontrado, ele não pertence à região de atração do ponto de equilíbrio instável de controle, o que faz com que o algoritmo encontre o ponto de equilíbrio instável de controle errado, ou seja, existem casos em que a trajetória do sistema gradiente reduzido não passa nas vizinhanças do ponto de equilíbrio de controle. Isso ocorre quando o gradiente da energia potencial é bastante acentuado nas vizinhanças do PEBS.

Treinen et al. (1996) apresentaram dois problemas genéricos de deteção do ponto de equilíbrio de controle. Para a visualização dos problemas, seja a figura 5.5:

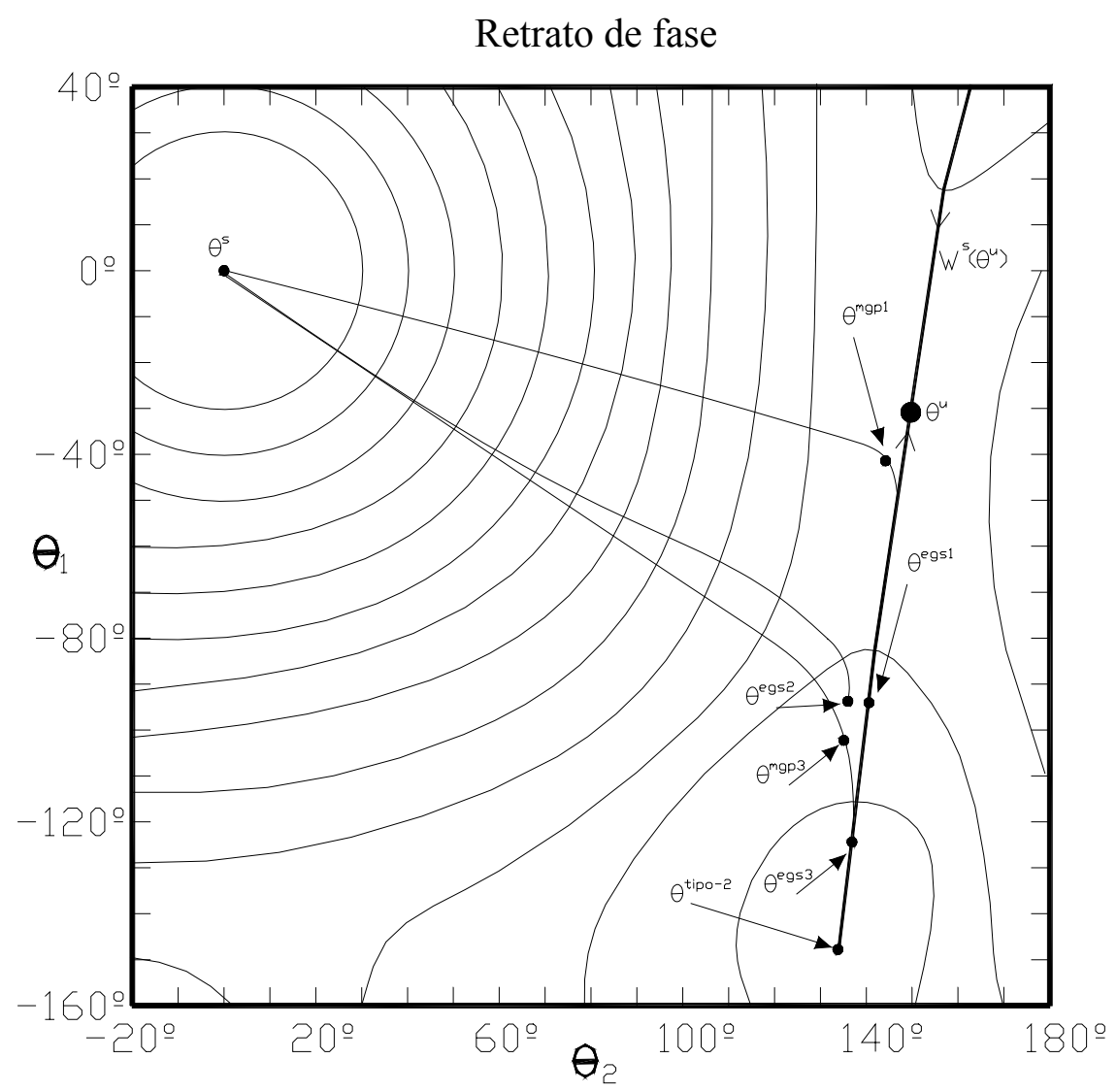

Figura 5.5 - Problemas associados a deteção do p.e.i. de controle

Onde:

- $\quad \theta^{s}$ é o p.e.e pós-falta;

- $\theta^{u}$ é o p.e.i de controle;

- $\theta^{m g p}$ é o ponto de mínimo gradiente ;

- $W^{s}\left(\theta^{u}\right)$ é a variedade estável do p.e.i de controle;

- $\theta^{\text {egs }}$ é o "exit point" do passo-1 do BCU;

- $\theta^{\text {tipo-2 }}$ é o p.e.i. de tipo-2 na fronteira de estabilidade; 
$1^{\text {o }}$ Problema demonstrado por Treinen et al.(1996):

Pode não existir o ponto de mínimo gradiente encontrado ao longo da trajetória $\phi_{g s}\left(\theta^{\text {egsa }}, t\right)$, fato que é mostrado na figura 5.5, com $\theta^{\text {egsa }}=\theta^{\text {egs } 2}$ como ponto de partida. Se não existe ponto de mínimo gradiente encontrado, o sistema ou irá para o infinito, ou convergirá para o p.e.e pós-falta; a deteção do ponto de equilíbrio de controle irá falhar, resultando na predição errada da estabilidade transitória.

$2^{\circ}$ Problema demonstrado por Treinen et al.(1996):

Quando um ponto de mínimo gradiente é encontrado, é esperado que $\theta^{u}$ seja resultado de uma solução de $\dot{\theta}=-\nabla V_{P E}=-\frac{\partial V_{P E}}{\partial \theta}$, com $\theta^{m g p}$ como ponto inicial. Isto, no entanto, pode não ser verdade. $\theta^{m g p}$ pode não estar no domínio de convergência de $\theta^{u}$ para cada algoritmo de solução utilizado. Isto pode ser visto na figura através do ponto $\theta^{\text {egsa }}=\theta^{\text {egs } 3}$.

Existe um ponto de mínimo gradiente resultante $\theta^{m g p}=\theta^{m g p 3}$, mas quando aplica-se o algoritmo de solução não-linear, não se chega em $\theta^{u}$, e sim em um p.e.i. de tipo-2 como o $\theta^{\text {tipo-2 }}$ da figura 5.5.

Um p.e.i de tipo-2 em torno de um p.e.i. de tipo-1 tem, em geral, maior valor de energia potencial, uma vez que a energia decresce ao longo da trajetória do sistema gradiente. Obviamente, baseando-se a predição de estabilidade em p.e.i's diferentes do p.e.i de controle, leva-se a avaliações não conservadoras de estabilidade.

Serão mostrados mais dois exemplos de falha do algoritmo BCU, relacionados ao sistema da figura 4.9. O exemplo ilustra a situação onde o BCU falha, para um caso de máquinas fortemente acopladas. Seja o sistema de 2 geradores versus barramento infinito apresentado na figura 5.6. O parâmetro $X$ é a reatância da linha 1-2. Um curto circuito ocorre na barra 2 e desaparece após um certo tempo de tal forma que o sistema pós-falta é igual ao pré-falta. Para valores da reatância $X$ grandes, o BCU funciona perfeitamente. Para valores de $X$ pequenos $(X=0,04 p u)$, o BCU pode apresentar problemas. Utilizando-se um passo de integração de $0,05 \mathrm{~s}$ e com $X=0,04 p u$ obteve-se o retrato de fase da figura 5.7. 


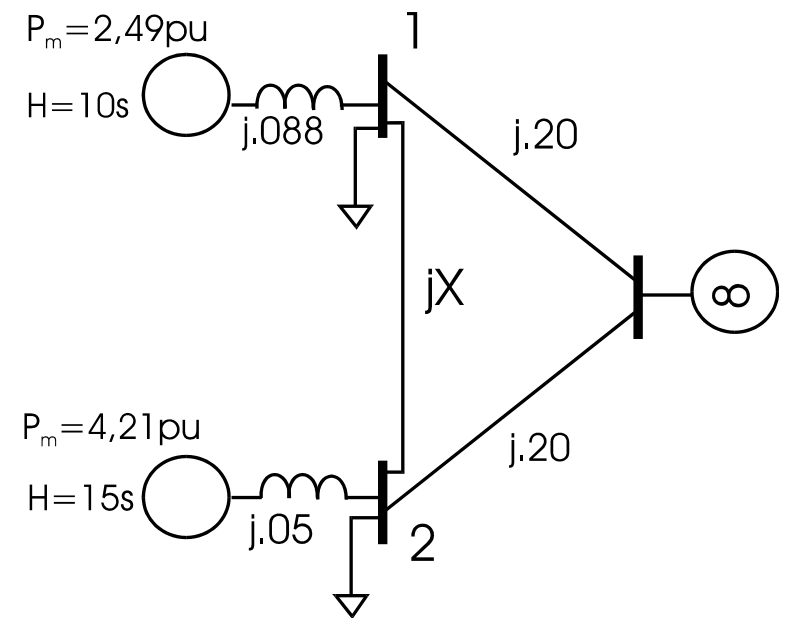

Figura 5.6 - Sistema de duas máquinas versus barramento infinito

Retrato de Fase de um Sistema de 2 barras versus um barramento infinito

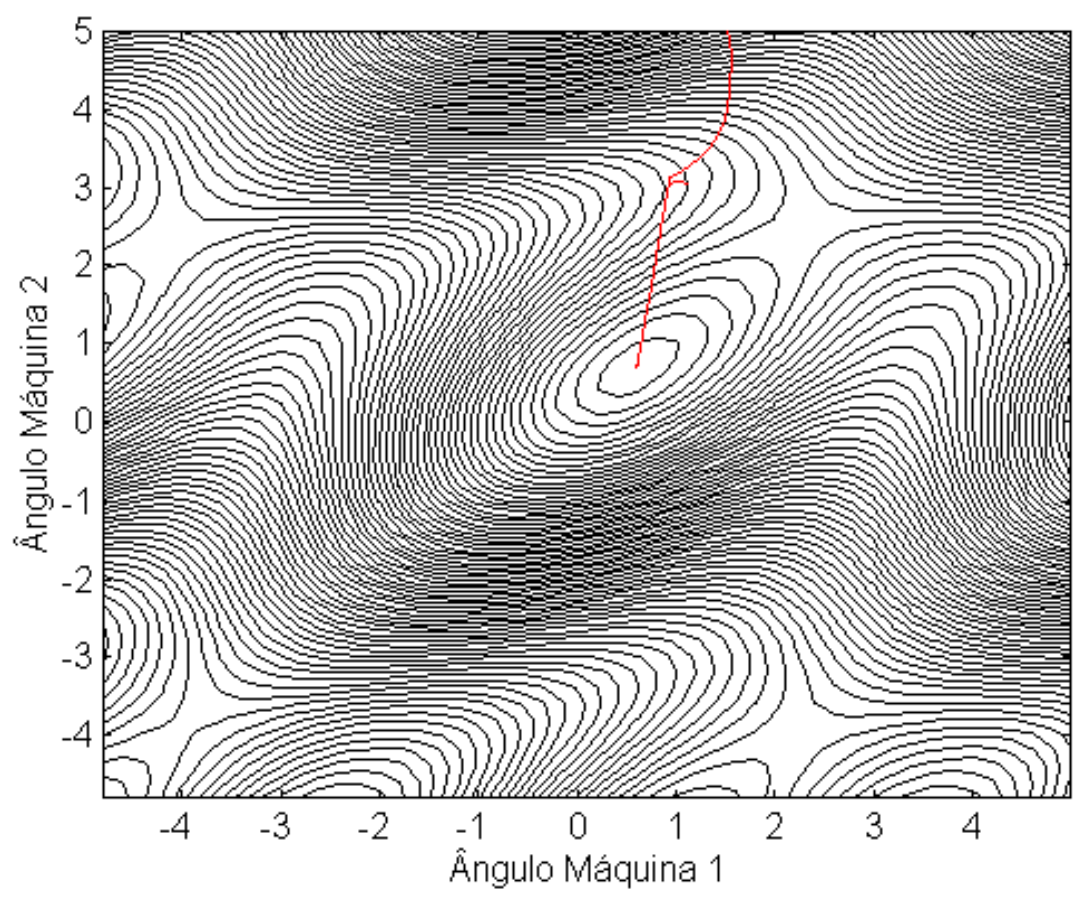

Figura 5.7 - Sistema de duas máquinas versus barramento infinito

A falha do BCU para esta situação é um problema numérico relacionado ao passo 2 do algoritmo BCU. A simulação do sistema em falta gera uma seqüência de pontos, e uma aproximação correta do "exit point" é obtida no passo 1 do algoritmo. Obviamente 
esta aproximação não pertencerá exatamente ao PEBS embora esteja muito próxima dele. A falha ocorre porque a trajetória do sistema gradiente reduzido não passa nas proximidades do ponto de equilíbrio de controle. Poderá não existir o mínimo local da norma $\sum_{i=1}^{n}\left\|f_{i}(\delta)\right\|$ ao longo da trajetória do sistema reduzido pós-falta ou mesmo se esta existir este mínimo estará longe do ponto de equilíbrio de controle correto.

Se o passo de integração for reduzido, o novo "exit point" obtido estará mais próximo da fronteira da área de atração do sistema reduzido fazendo com que a trajetória do sistema reduzido no passo 2 do algoritmo passe mais próximo das vizinhanças do ponto de equilíbrio de controle. No caso de sistemas com acoplamento forte entre as máquinas, o passo de integração deverá ser bem pequeno, pois o gradiente da energia potencial na direção de unir as máquinas é muito grande. Qualquer erro na determinação do "exit point" poderá fazer com que a trajetória do sistema reduzido pósfalta se afaste rapidamente do ponto de equilíbrio de controle impossibilitando a convergência do algoritmo. Isto acontece porque o PEBS neste caso é uma linha de máximos muito acentuada onde existe um despenhadeiro na curva de energia para ambos os lados do PEBS, então qualquer erro na determinação do "exit point" faz com que a trajetória do sistema reduzido "caia" por este despenhadeiro afastando-se rapidamente da variedade estável do ponto de equilíbrio de controle como mostra a figura 5.7. O processo de teste de convergência e redução do passo de integração pode tornar o processo computacional lento.

O outro exemplo de problema de deteção do ponto de equilíbrio de controle associado ao método BCU, diz respeito ao comportamento do algoritmo quando este atua na busca do ponto de equilíbrio de controle próximo a uma bifurcação sela-nó, que pode ocorrer quando da mudança de carregamento de um sistema. O ponto de equilíbrio instável de controle, neste caso é um ponto que está próximo a uma bifurcação. Com a variação do carregamento do sistema, algo que é comum durante a operação do mesmo, este ponto de equilíbrio se afasta ou se aproxima do ponto de bifurcação. Neste caso foi verificado empiricamente que, o BCU não consegue identificar o ponto de equilíbrio de controle correto, e prediz erroneamente a estabilidade. Seja a figura 5.8, que representa a situação descrita para o sistema de 3 barras da figura 4.9, com geração do gerador 1 em 270 [MW], submetido a uma falta trifásica sólida na linha 1-3, próximo a barra 3. 


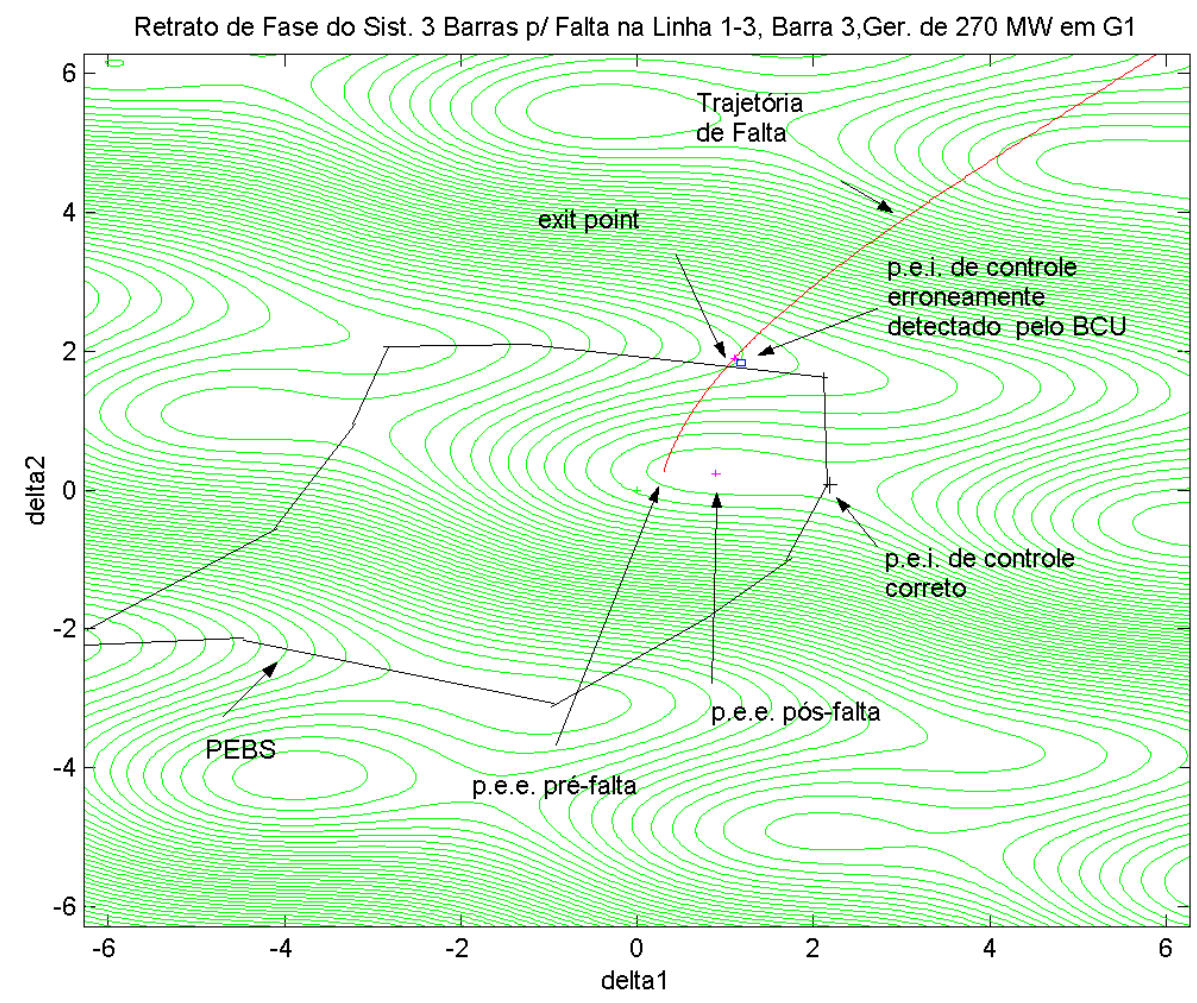

Figura 5.8 - Falha da deteção do p.e.i. de controle pelo algoritmo BCU

\section{4 - Shadowing Method}

O "shadowing method" foi proposto por Treinen et al (1996) para a solução dos problemas associados a deteção do ponto de equilíbrio de controle. A idéia deste método parte da utilização da variedade estável do ponto de equilíbrio instável de controle $W^{s}\left(\theta^{u}\right)$. Esta utilização é feita através do fluxo e da forma da superfície de energia equipotencial em torno desta variedade. Basicamente, o "shadowing method" utiliza o fluxo do gradiente na vizinhança da variedade estável do ponto de equilíbrio instável de controle, por um tempo relativamente pequeno, para se aproximar do ponto de equilíbrio instável de controle. O resultado é então corrigido para um outro mais próximo da variedade em questão, e o procedimento é repetido. Desta forma, obtém-se uma seqüência de pontos, os quais convergem ao ponto de equilíbrio instável de controle. O final da seqüência de pontos calculados deve estar bem próxima do ponto de equilíbrio instável de controle, de tal maneira que, utilizando como condição inicial o ponto final da seqüência calculada, consegue-se determinar o ponto de equilíbrio instável de controle. Ou seja, após o "shadowing method", resolve-se o passo 3 do 
algoritmo da maneira convencional, pois o método garante a proximidade do ponto de equilíbrio instável de controle.

A figura 5.9 ilustra o processo:

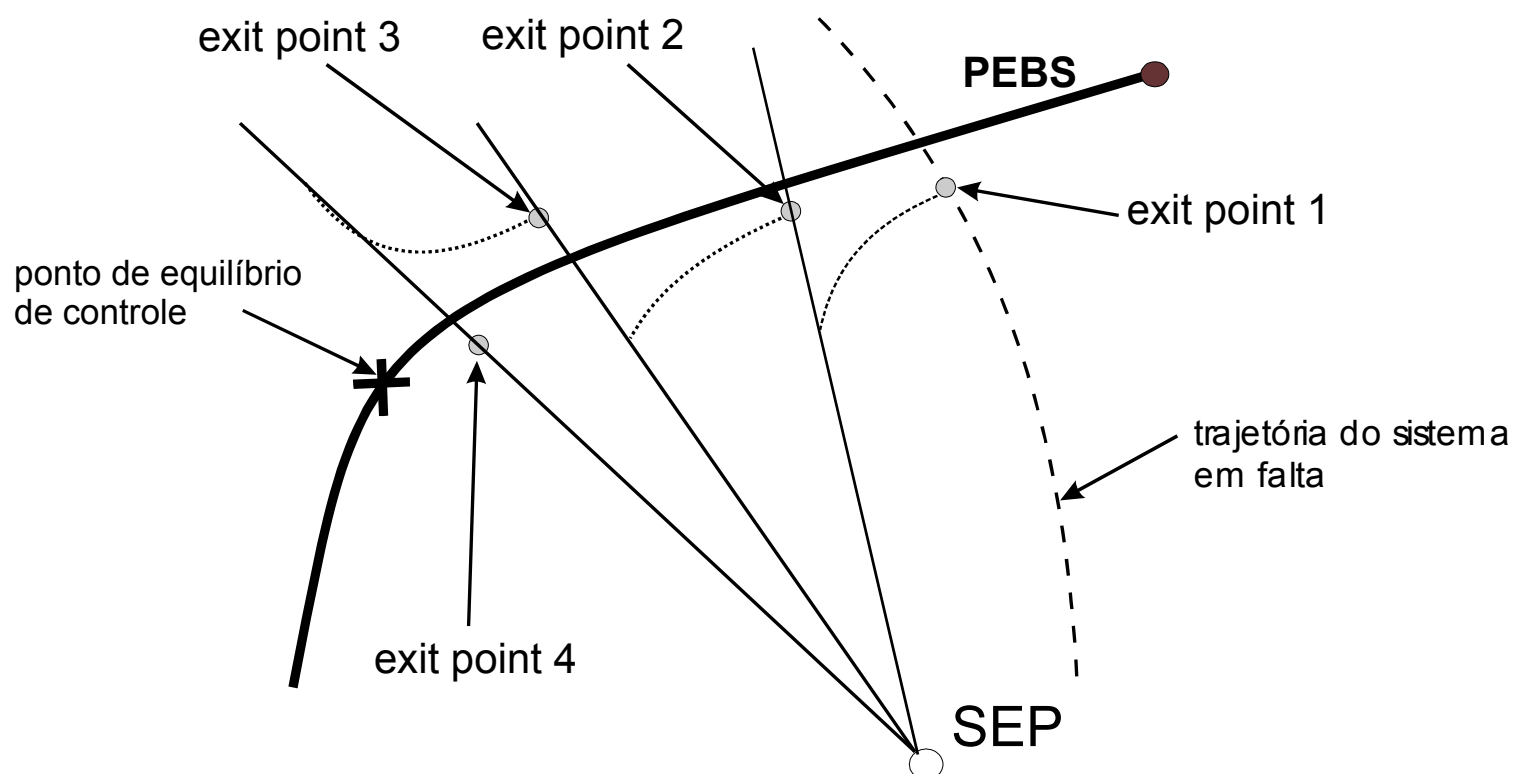

Figura 5.9: "Shadowing Method"

O "shadowing method" segue o algoritmo abaixo:

Algoritmo do "Shadowing Method":

Um ciclo genérico de 3 passos começando com o i-ésimo ciclo, onde $i \in[1, \ldots, N]$ é dado por:

1. Seja $\theta^{r i}=\phi_{g s}\left(\theta^{m(i-1)}, t_{i}\right)$,com $t_{i}$ relativamente pequeno;

2. Forme um conjunto "ray"(raio) $R\left(\theta^{r i}\right)=\left\{\theta: \theta=\left(\theta^{r i}-\theta^{s}\right) \cdot \alpha+\theta^{s}, \alpha \geq 0\right\}$

3. Determinar o ponto $\theta^{m i} \in R\left(\theta^{r i}\right)$ que satisfaz $-\frac{\partial V_{P E}}{\partial \theta^{m i}} \cdot\left(\theta^{m i}-\theta^{s}\right)=0$. Isto pode ser feito através do método de Newton com $\theta^{\text {ri }}$ como ponto inicial.

onde: 
- $\phi_{g s}\left(\theta^{m(i-1)}, t_{i}\right)$ é a solução do sistema gradiente $\dot{\theta}=-\nabla V_{P E}=-\frac{\partial V_{P E}}{\partial \theta}$ em $\mathfrak{R}^{n}-1$, com condição inicial em $\theta^{m(i-1)}$, ou seja, para um $t_{i}$ relativamente pequeno, simula-se numericamente o sistema gradiente, obtendo ao final deste tempo $\theta^{r i}$;

- $-\frac{\partial V_{P E}}{\partial \theta^{m i}} \cdot\left(\theta^{m i}-\theta^{s}\right)=0$ significa uma condição de extremo (máximo) da função energia ao longo da reta formada pelo conjunto $R\left(\theta^{r i}\right)$;

A figura 5.10 representa o algoritmo do método para dois ciclos:

- Primeiro ciclo: s-1 a s-3;

- Segundo ciclo: s-4 a s-6;

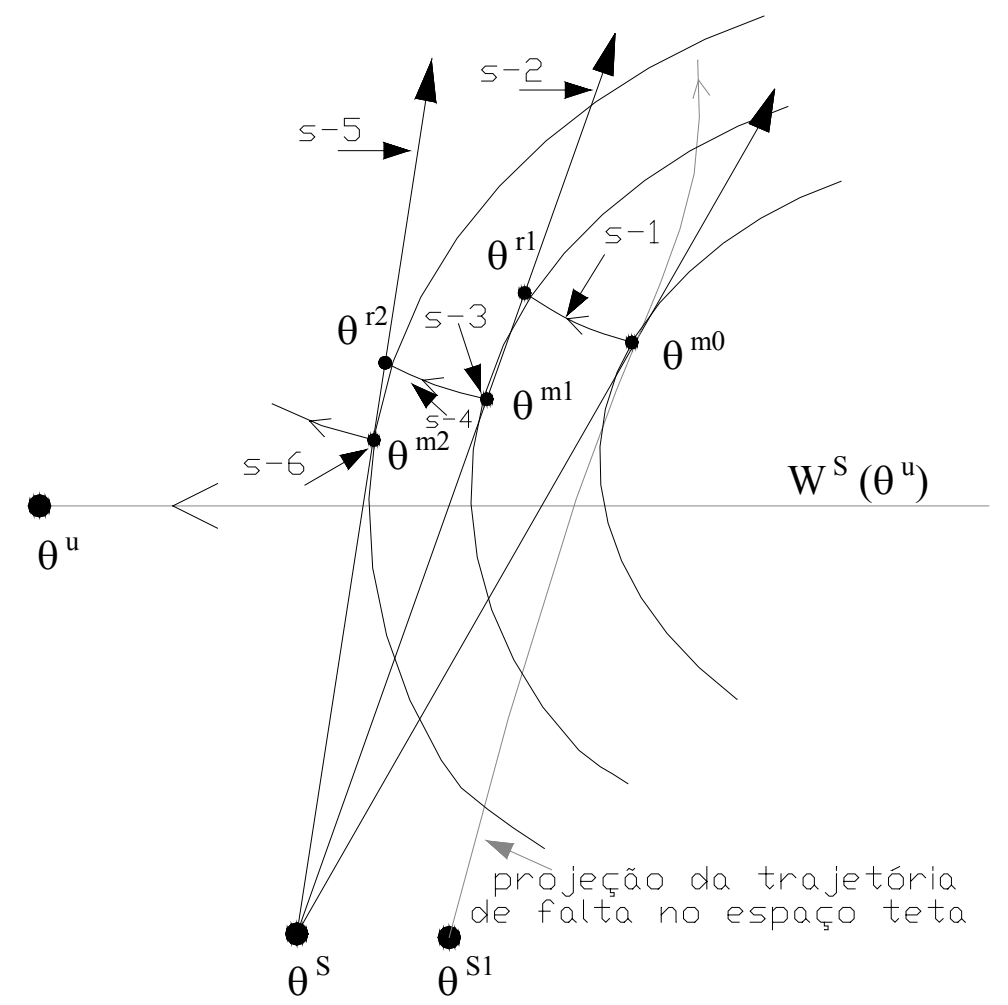

Figura 5.10: ciclos do "Shadowing Method" 


\section{Capítulo 6}

\section{RESULTADOS OBTIDOS}

Foi implementado um programa computacional para simulação dos estudos de estabilidade transitória. Este programa foi implementado para aplicações em sistemas multimáquinas, conforme as características e modelos descritos até agora. Nele é possível fazer simulações de estabilidade por métodos diretos ou pelo método de integração numérica; pode-se utilizar o COA ou OMR como referência. Foram implementados também os métodos diretos PEBS e BCU, e os métodos PEBS dinâmico e o "shadowing method", como métodos diretos robustos.

Três sistemas simulados no programa terão seus resultados apresentados.

\subsection{Sistema de 3 barras com 3 geradores}

Um dos sistemas simulados foi o representado na figura 4.9, do capítulo 4.

Serão mostrados aqui os resultados obtidos para curto-circuitos simulados, utilizando todos os métodos diretos implementados, bem como o resultado obtido pela simulação numérica.

Simulação do caso base: $O$ sistema representado pela figura 4.9 foi submetido a um curto-circuito trifásico sólido em todas as suas linhas, próximos a todas as suas barras. Os resultados obtidos estão descritos na tabela 6.1, onde:

- $\quad$ a $1^{\mathrm{a}}$ coluna representa a linha de aplicação do curto-circuito (falta);

- a $2^{\mathrm{a}}$ coluna representa a barra próxima a falta;

- a $3^{a}$ coluna representa o tempo crítico de abertura (predição da estabilidade via PEBS) para a falta aplicada (referência angular: COA);

- a $4^{\text {a }}$ coluna representa o tempo crítico de abertura (predição da estabilidade via $\mathrm{BCU}$ ) para a falta aplicada (referência angular: $\mathrm{COA}$ ); 


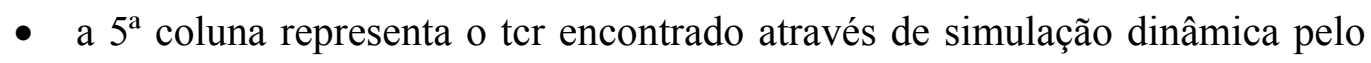
processo de integração numérica para o primeiro "swing" do sistema, com referência angular na última máquina (máquina 3);

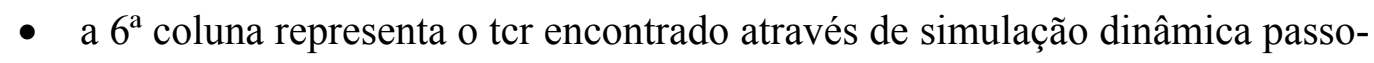
a-passo para o todos os "swings" do sistema (estabilidade "multi-swing"), com referência angular no COA; (tempo de simulação de 4 [s])

- $\quad$ a $7^{\mathrm{a}}$ coluna representa o tcr encontrado através de simulação dinâmica passoa-passo para o todos os "swings" do sistema (estabilidade "multi-swing"), com referência angular na última máquina; (tempo de simulação de 4 [s])

- as colunas de 8 a 11 representam quais máquinas perderam sincronismo (tornando o sistema instável) e quais foram seus comportamentos (A-aceleração e D desaceleração)

- A penúltima coluna representa a energia potencial do "exit point" encontrada pelo método PEBS;

- A última coluna representa a energia potencial do p.e.i. de controle encontrada pelo método BCU;

\begin{tabular}{|c|c|c|c|c|c|c|c|c|c|c|c|c|}
\hline \multirow{2}{*}{\multicolumn{2}{|c|}{\begin{tabular}{c|c}
1 & 2 \\
Curto- \\
circuito \\
\end{tabular}}} & 3 & 4 & 5 & 6 & 7 & 8 & 9 & 10 & 11 & 12 & 13 \\
\hline & & \multicolumn{5}{|c|}{ Tempo crítico [ms] } & \multicolumn{4}{|c|}{ Estabilidade $\left(\mathrm{n}^{\mathrm{o}}-\mathrm{A} / \mathrm{D}\right)^{2}$} & \multicolumn{2}{|c|}{$\begin{array}{l}\text { Energia } \\
(\mathrm{pu})\end{array}$} \\
\hline \multirow[b]{2}{*}{ Linh: } & \multirow[b]{2}{*}{$\begin{array}{c}\text { 3ar } \\
\text { ra }\end{array}$} & \multicolumn{3}{|c|}{$1^{\circ}$ swing } & \multicolumn{2}{|c|}{ Multiswing } & \multicolumn{2}{|c|}{$1^{\circ}$ swing } & \multicolumn{2}{|c|}{ Multiswing } & \multirow{2}{*}{$\begin{array}{l}\mathrm{P} \\
\mathrm{E} \\
\mathrm{B} \\
\mathrm{S}\end{array}$} & \multirow[b]{2}{*}{$\begin{array}{l}\mathrm{B} \\
\mathrm{C} \\
\mathrm{U}\end{array}$} \\
\hline & & PEBS & $\begin{array}{l}\mathrm{B} \\
\mathrm{C} \\
\mathrm{U}\end{array}$ & $\begin{array}{l}\mathrm{O} \\
\mathrm{M} \\
\mathrm{R}\end{array}$ & $\begin{array}{l}\mathrm{C} \\
\mathrm{O} \\
\mathrm{A}\end{array}$ & $\begin{array}{l}\mathrm{O} \\
\mathrm{M} \\
\mathrm{R}\end{array}$ & $\begin{array}{c}\text { Máq } \\
\text { (PEBS) }\end{array}$ & $\begin{array}{c}\text { Máq } \\
(\mathrm{OMR})\end{array}$ & $\begin{array}{l}\text { Máq } \\
\text { COA' }\end{array}$ & $\begin{array}{c}\text { Máq } \\
\text { (OMR) }\end{array}$ & & \\
\hline $1-2$ & 1 & 178 & 178 & 178 & 174 & 174 & $1-A$ & $1-\mathrm{A}$ & $1-\mathrm{A}$ & $1-\mathrm{A}$ & 2,1 & 2,0 \\
\hline $1-2$ & 2 & 198 & 198 & 200 & 194 & 194 & $2-A$ & $2-A$ & $1-\mathrm{A}$ & $1-\mathrm{A}$ & 6,0 & 5,8 \\
\hline $1-3$ & 1 & 88 & 92 & 100 & 98 & 94 & $1-\mathrm{A}$ & $1-\mathrm{A}$ & $1-\mathrm{A}$ & $1-\mathrm{A}$ & 0,5 & 0,5 \\
\hline $1-3$ & 3 & 380 & 380 & 342 & 254 & 256 & $2 \mathrm{~A}^{2} \mathrm{D}^{3}$ & $1-\mathrm{A}$ & $1-\mathrm{A}$ & $1-\mathrm{A}$ & 5,5 & 4,4 \\
\hline $2-3$ & 2 & -4 & - & - & - & - & 2A3D & $2 \mathrm{~A} 3 \mathrm{D}$ & 2A3D & $2 \mathrm{~A} 3 \mathrm{D}$ & - & - \\
\hline $2-3$ & 3 & - & - & - & - & - & 2A3D & $2 \mathrm{~A} 3 \mathrm{D}$ & 2A3D & $2 \mathrm{~A} 3 \mathrm{D}$ & - & - \\
\hline
\end{tabular}

Tabela 6.1: tcr's e energias para sistema de 3 geradores do caso base

A análise destas simulações nos mostra que tanto o PEBS quanto o BCU encontraram valores corretos para as faltas simuladas. No curto-circuito simulado na linha 1-3, próximo a barra 1, a energia e o tcr encontrados pelo BCU são maiores que a

\footnotetext{
${ }^{2}$ ( $\left.\mathrm{n}^{\mathrm{o}}-\mathrm{A} / \mathrm{D}\right)$ : número da máquina - Acelerou /Desacelerou.

3 2A3D: significa que a máquina 2 acelerou e a 3 desacelerou;

4 - : significa que o dado indicado não foi obtido pelo algoritmo
} 
energia e o tcr obtidos pelo PEBS. Isto acontece devido a um arredondamento numérico e é um caso específico. Neste caso, a trajetória de falta passa muito próxima ao p.e.i. de controle, sendo que o "exit point" encontrado fica em um nível energético pouco menor que o p.e.i. de controle.

No caso dos curtos na linha 2-3, não foi encontrado um ponto de equilíbrio estável para o sistema pós-falta, porque a contingência é muito severa para o sistema, que não tem solução neste caso.

Apesar deste sistema ser simples e de pequeno porte, existem casos em que os algoritmos falham. Para estes casos de falha utilizam-se o PEBS dinâmico e o "shadowing method", como tentativa de obter o resultado correto para o sistema.

Simulação do caso com impedância de falta: na seção 5.1 foi mostrado um caso de falha de deteção do "exit point" através do método PEBS. Para o mesmo caso, que é uma falta na linha 1-2 próximo a barra 2 com impedância de falta de 0,045 pu, obtevese, utilizando o algoritmo PEBS dinâmico com 10 passos $(h=10)$ na direção do gradiente, o retrato de fase da figura 6.1:

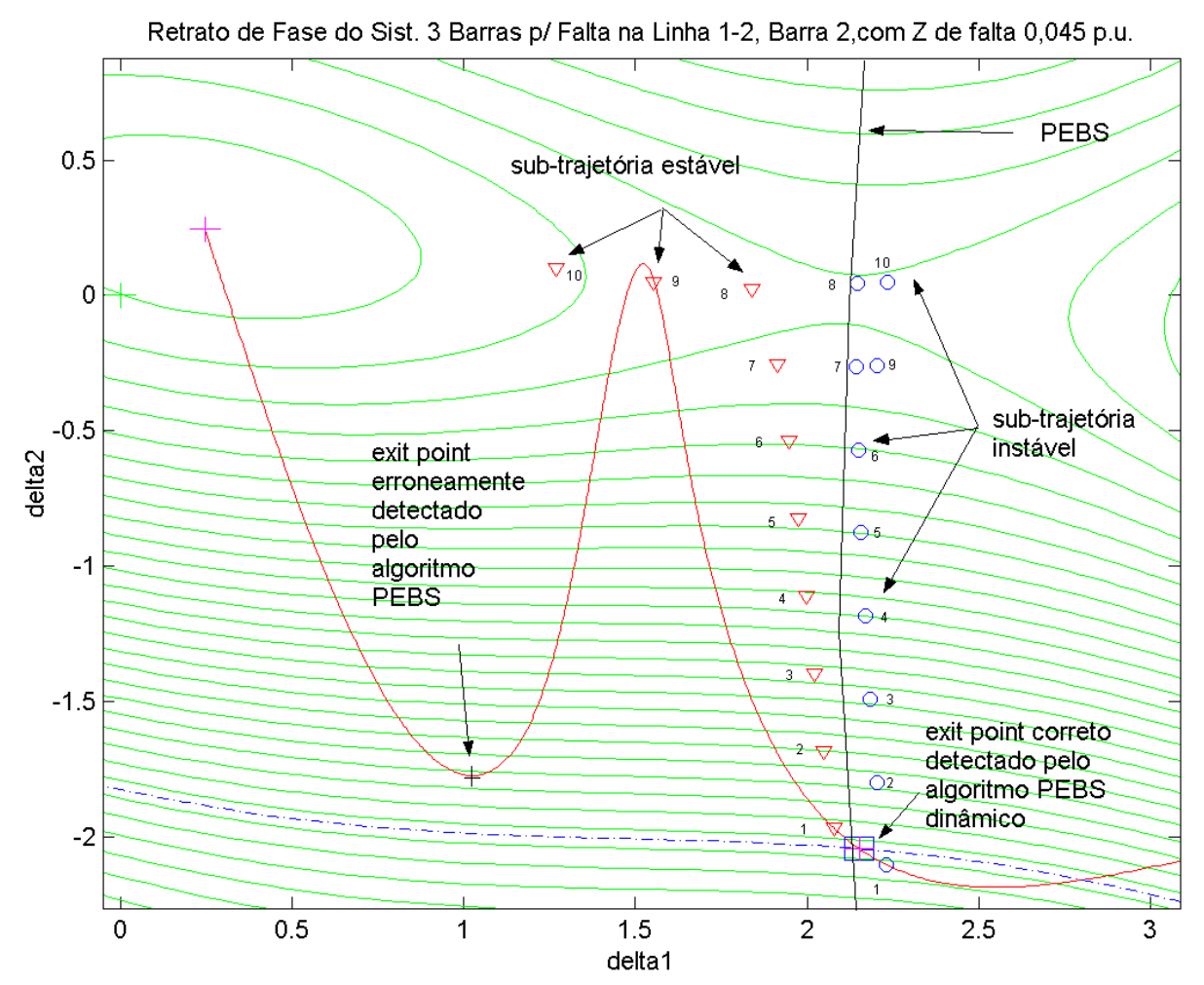

Figura 6.1: Atuação do algoritmo PEBS dinâmico na deteção do "exit point" correto

Os resultados obtidos para este sistema estão descritos na tabela 6.2, onde:

- Ep é a energia potencial do ponto de interesse encontrado pelo algoritmo; 
- BCU dinâmico é o algoritmo BCU, com "exit point" encontrado pelo método PEBS dinâmico;

\begin{tabular}{|c|c|c|c|c|c|c|}
\hline \multicolumn{2}{|c|}{ Curto-circuito } & & \multicolumn{4}{c|}{ Método Direto } \\
\hline Linha & Barra & & PEBS & BCU & PEBS Dinâmico & BCU Dinâmico \\
\hline \multirow{2}{*}{$1-2$} & 2 & tcr [ms] & 366 & 1192 & 1186 & 1930 \\
\cline { 3 - 7 } & & Ep (pu) & 16,77 & 19,86 & 19,71 & 26,52 \\
\hline
\end{tabular}

Tabela 6.2 - tcr's para sistema de 3 geradores com impedância de falta

Pode-se perceber que o algoritmo PEBS dinâmico reconhece o comportamento oscilatório do sistema dentro da área de atração, simulando o mesmo, até encontrar o "exit point" verdadeiro. Verifica-se porém, que as energias e o tcr's encontrados pelos algoritmos BCU e BCU dinâmico são maiores que as energias e os tcr's encontrados pelos métodos PEBS e PEBS dinâmico. Como descrito por Treinen et al. (1996), e explicado na seção 5.3, o algoritmo de solução não chega ao p.e.i de controle, mas sim a um p.e.i de tipo-2, que neste caso tem energia potencial maior, levando o algoritmo a predições não conservadoras de estabilidade (tcr maior).

Submetendo o sistema ao "shadowing method" na tentativa da deteção do p.e.i. de controle, obteve-se o resultado, que pode ser visto na figura 6.2:

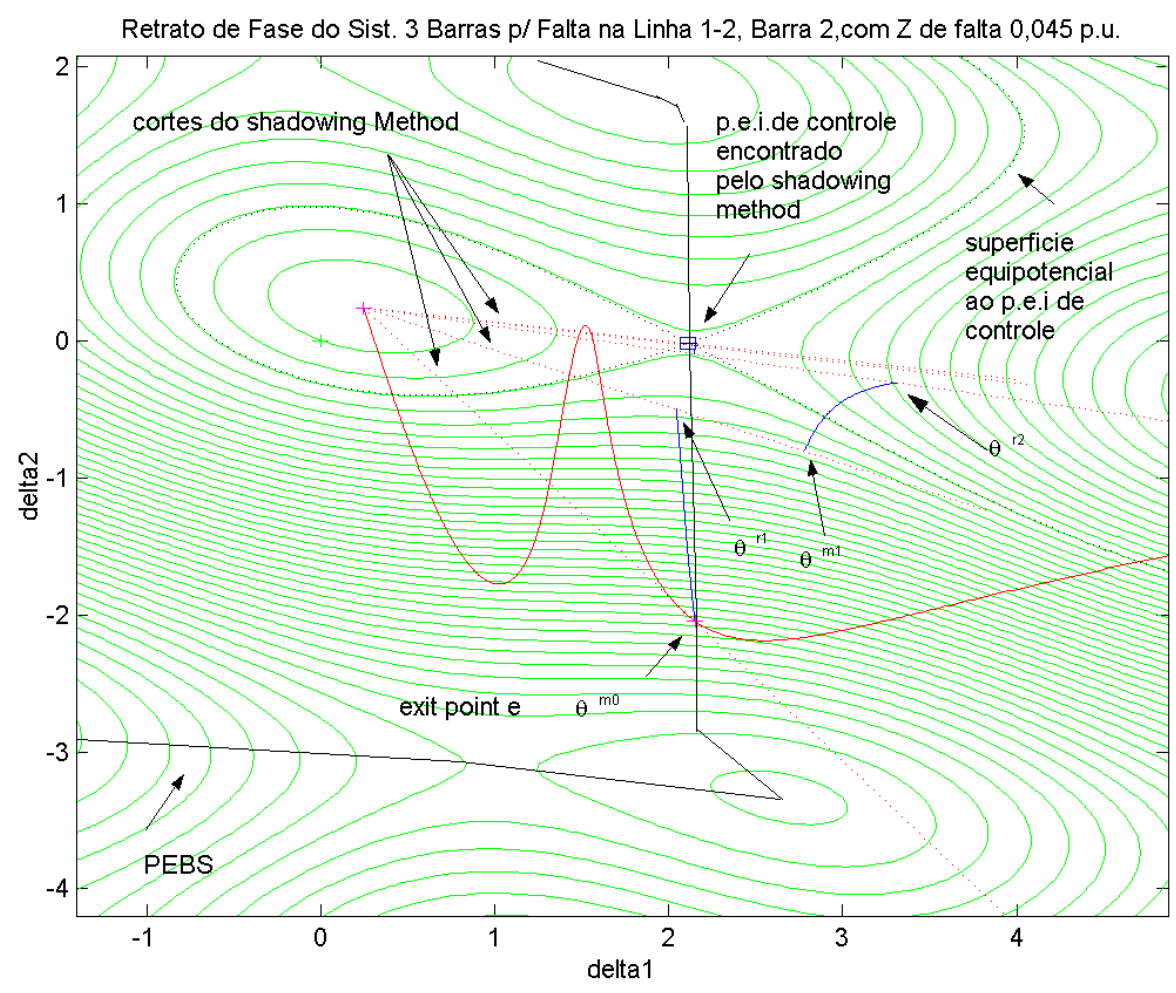

Figura 6.2: Atuação do algoritmo PEBS dinâmico associado ao "Shadowing Method" na deteção do "exit point" e do p.e.i. de controle corretos. 
Observa-se, então que com o "shadowing method", encontra-se o p.e.i de controle correto, que impõe ao sistema a seguinte condição para estabilidade:

\begin{tabular}{|c|c|c|c|c|}
\hline \multicolumn{2}{|c|}{ Curto-circuito } & & \multicolumn{2}{|c|}{ Método Direto } \\
\hline Linha & Barra & & PEBS Dinâmico & "Shadowing Method" Dinâmico \\
\hline \multirow{2}{*}{$1-2$} & \multirow{2}{*}{2} & tcr $[\mathrm{ms}]$ & 1186 & 90 \\
\cline { 3 - 5 } & & $\mathrm{Ep}(\mathrm{pu})$ & 19,71 & 2,01 \\
\hline
\end{tabular}

Tabela 6.3 - tcr's para sistema de 3 geradores com impedância de falta

Observa-se, então, que somente através da utilização conjunta dos algoritmos propostos por Scruggs e Mili (2001) e por Treinen et al. (1996), pôde-se solucionar o problema para o caso oscilatório descrito.

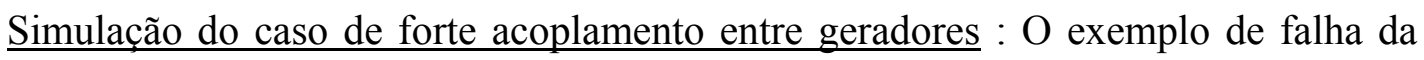
deteção do p.e.i. de controle pelo método BCU da figura 5.8, também foi analisado numericamente e graficamente. A tabela 6.4 mostra os resultados obtidos:

\begin{tabular}{|c|c|c|c|c|c|c|}
\hline \multicolumn{2}{|c|}{ Curto-circuito } & \multicolumn{4}{|c|}{ Método Direto } \\
\hline Linha & Barra & & PEBS & PEBS Dinâmico & BCU & "Shadowing Method" \\
\hline \multirow{2}{*}{$1-3$} & 3 & $\begin{array}{c}\text { Tcr } \\
{[\mathrm{ms}]}\end{array}$ & 350 & 350 & - & 10 \\
\cline { 3 - 7 } & $\mathrm{Ep} \mathrm{(pu)}$ & 6,8 & 6,8 & - & 0,24 \\
\hline
\end{tabular}

Tabela 6.4 - tcr e energia para sistema de 3 geradores com geração de $270 \mathrm{MW}$ em G

Neste caso não existe problema de deteção do "exit point", o que pode ser percebido pelo fato do algoritmo PEBS dinâmico obter o mesmo resultado do algoritmo PEBS convencional.

Porém, na deteção do p.e.i. de controle, o algoritmo BCU falha e se perde na sua busca. Este fato é devido a não localização do mínimo do gradiente local, associado ao passo 2 do algoritmo. Quando esta localização falha o BCU falha, como descrito por Treinen et al. (1996) quando do desenvolvimento do "shadowing method".

O retrato de fase da figura 6.3 ilustra a deteção do p.e.i de controle neste caso: 


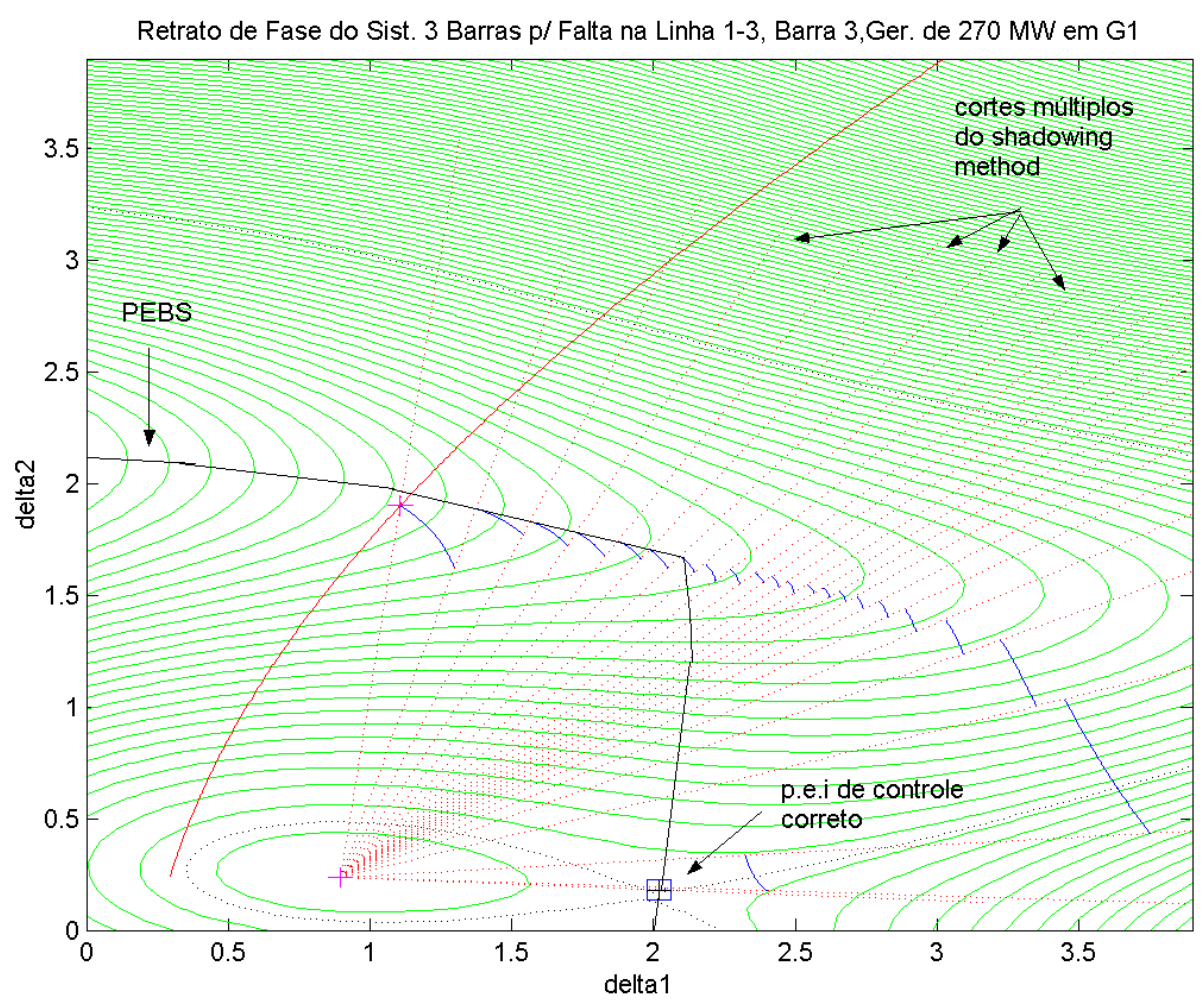

Figura 6.3 - "Shadowing Method" na deteção do p.e.i. de controle correto

O mínimo local associado ao passo 2 do algoritmo BCU não foi localizado neste caso devido as condições da superfície energética criadas pela geração elevada do gerador 1. Com o aumento da geração, houve primeiramente uma bifurcação sela-nó, onde a sela que representava o p.e.i. de controle e a sela de tipo-2 coalesceram em um único ponto de equilíbrio degenerado. Com o aumento da geração continuado, este equilíbrio degenerado desaparece, desconfigurando o p.e.i de controle na região, que agora passou a ser o p.e.i de controle mostrado na figura 6.3. O algoritmo de solução do BCU se perdeu na busca do p.e.i. de controle, porém o "shadowing method" conseguiu, devido a sua robustez, explorar as características distintas das variedades na fronteira do PEBS, buscando o ponto de equilíbrio de controle correto.

\subsection{Sistema de 14 barras (bus14 do IEEE)}

O sistema de 14 barras do IEEE foi estudado para as contingências em todas as suas barras para o caso base cujos dados estão descritos no anexo $\mathrm{C}$.

A figura 6.4 representa o sistema: 


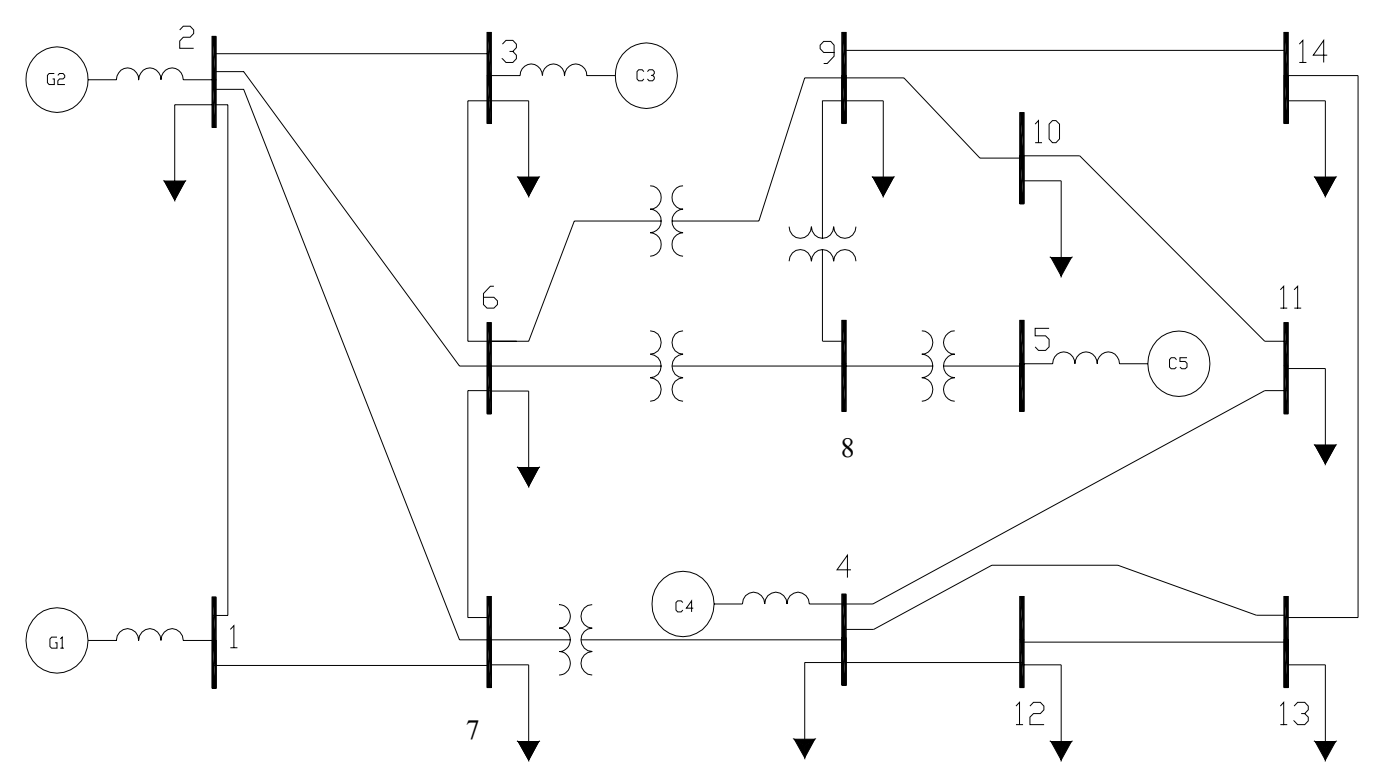

Figura 6.4: Sistema de 14 barras do IEEE

Simulação do caso base: O sistema representado pela figura 6.4 foi submetido a um curto-circuito trifásico sólido em todas as suas linhas, próximos a todas as suas barras. Os resultados obtidos estão descritos na tabela 6.5 , onde:

- $\quad$ a $1^{\text {a }}$ coluna representa a linha de aplicação do curto-circuito (falta);

- a $2^{\mathrm{a}}$ coluna representa a barra próxima a falta;

- a $3^{\mathrm{a}}$ coluna representa o tempo crítico de abertura calculado via PEBS para a falta aplicada (referência angular: COA);

- a $4^{\text {a }}$ coluna representa o tcr calculado via PEBS dinâmico para a falta aplicada (referência angular: COA);

- a $5^{\mathrm{a}}$ coluna representa o tcr calculado via BCU para a falta aplicada (referência angular: COA);

- a $6^{\mathrm{a}}$ coluna representa o tcr calculado via BCU, com "exit point" calculado pelo método PEBS dinâmico, para a falta aplicada (referência angular: COA);

- a $7^{\mathrm{a}}$ coluna representa o tcr calculado via "shadowing method", para a falta aplicada (referência angular: COA);

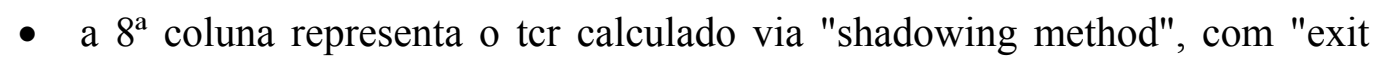
point" calculado pelo método PEBS dinâmico, para a falta aplicada (referência: COA);

- a $9^{a}$ coluna representa o tcr encontrado através de simulação dinâmica pelo processo de integração numérica para o primeiro "swing" do sistema, com referência angular na última máquina; 
- a $10^{\mathrm{a}}$ coluna representa o tcr encontrado através de simulação dinâmica pelo processo de integração numérica para o todos os "swings" do sistema (estabilidade "multi-swing"), com referência angular no COA; (tempo de simulação de 4 [s])

- a $11^{\mathrm{a}}$ coluna representa o tcr encontrado através de simulação dinâmica passo-a-passo para o todos os "swings" do sistema (estabilidade "multi-swing"), com referência angular última máquina; (tempo de simulação de 4 [s])

- a $12^{\mathrm{a}}$ coluna representa as energias potenciais dos "exit points" calculados pelo método PEBS;

- a $13^{\mathrm{a}}$ coluna representa as energias potenciais dos "exit points" calculados pelo método PEBS dinâmico;

- a $14^{\mathrm{a}}$ coluna representa as energias potenciais dos p.e.i.s de controle calculados pelo método BCU;

- a $15^{\mathrm{a}}$ coluna representa as energias potenciais dos p.e.i.s de controle calculados pelo "shadowing method", com "exit points" calculados pelo método PEBS dinâmico;

\begin{tabular}{|c|c|c|c|c|c|c|c|c|c|c|c|c|c|c|}
\hline \multicolumn{2}{|c|}{$\begin{array}{l}\text { Curto- } \\
\text { circuito }\end{array}$} & \multicolumn{9}{|c|}{ tempo crítico [ms] } & \multicolumn{4}{|c|}{ energia (pu) } \\
\hline \multirow{3}{*}{$\begin{array}{c}\mathrm{L} \\
\mathrm{i} \\
\mathrm{n} \\
\mathrm{h} \\
\mathrm{a}\end{array}$} & \multirow{3}{*}{$\begin{array}{l}\mathrm{B} \\
\mathrm{a} \\
\mathrm{r} \\
\mathrm{r} \\
\mathrm{a}\end{array}$} & \multicolumn{6}{|c|}{ Métodos Diretos } & \multicolumn{3}{|c|}{ solução numérica } & \multirow{3}{*}{$\begin{array}{l}\mathrm{P} \\
\mathrm{E} \\
\mathrm{B} \\
\mathrm{S}\end{array}$} & \multirow{3}{*}{$\begin{array}{c}\mathrm{P} \\
\mathrm{E} \\
\mathrm{B} \\
\mathrm{S} \\
\text { din. }\end{array}$} & \multirow{3}{*}{$\begin{array}{l}\mathrm{B} \\
\mathrm{C} \\
\mathrm{U}\end{array}$} & \multirow{3}{*}{$\begin{array}{l}\text { SM } \\
\text { din }\end{array}$} \\
\hline & & \multicolumn{2}{|c|}{ exit point } & \multicolumn{4}{|c|}{ p.e.i. de controle } & \multirow[b]{2}{*}{$\begin{array}{c}\text { OMR } \\
1^{\circ} \\
\text { swg }\end{array}$} & \multirow[b]{2}{*}{$\begin{array}{c}\text { COA } \\
\text { Multi } \\
\text { Swg }\end{array}$} & \multirow[b]{2}{*}{$\begin{array}{c}\text { OMR } \\
\text { Mult } \\
\text { Swg }\end{array}$} & & & & \\
\hline & & $\begin{array}{l}\mathrm{P} \\
\mathrm{E} \\
\mathrm{B} \\
\mathrm{S}\end{array}$ & $\begin{array}{l}\text { PEBS } \\
\text { din. }\end{array}$ & $\begin{array}{l}\mathrm{B} \\
\mathrm{C} \\
\mathrm{U}\end{array}$ & $\begin{array}{c}\text { BCU } \\
\text { Din }\end{array}$ & SM & $\begin{array}{l}\text { SM. } \\
\text { din }\end{array}$ & & & & & & & \\
\hline $1-2^{5}$ & 1 & 114 & 116 & - & - & 140 & 140 & 120 & 110 & 110 & 0,34 & 0,36 & - & 0.52 \\
\hline $1-2^{5}$ & 2 & 218 & 220 & - & - & 234 & 234 & 232 & 210 & 210 & 0,44 & 0,44 & - & 0.52 \\
\hline $1-7^{6}$ & 1 & 228 & 230 & - & - & 176 & 176 & 230 & 220 & 220 & 1,86 & 1,90 & - & 0,95 \\
\hline $1-7^{6}$ & 7 & 398 & 400 & - & - & 318 & 318 & 404 & 384 & 384 & 1,62 & 1,63 & - & 0,95 \\
\hline $2-3^{6}$ & 2 & 332 & 334 & - & - & 304 & 304 & 338 & 328 & 328 & 1,62 & 1,65 & - & 1,27 \\
\hline $2-3$ & 3 & 516 & 514 & 488 & 488 & 488 & 488 & 580 & 512 & 516 & 1,43 & 1,42 & 1,27 & 1,27 \\
\hline $2-6$ & 2 & 346 & 348 & 328 & 328 & 268 & 268 & 352 & 336 & 336 & 1,94 & 1,96 & 1,69 & 1,02 \\
\hline $2-6^{6}$ & 6 & 420 & 422 & - & - & 320 & 320 & 424 & 404 & 404 & 1,92 & 1,94 & - & 1,02 \\
\hline $2-7^{6}$ & 2 & 348 & 350 & - & - & 270 & 270 & 354 & 340 & 340 & 2,00 & 2,03 & - & 1,06 \\
\hline $2-7^{6}$ & 7 & 416 & 416 & - & - & 316 & 316 & 420 & 400 & 400 & 2,04 & 2,04 & - & 1,06 \\
\hline $3-6$ & 3 & 540 & 538 & 518 & 518 & 472 & 472 & 602 & 570 & 570 & 1,84 & 1,82 & 1,71 & 1,42 \\
\hline $3-6^{6}$ & 6 & 426 & 426 & - & - & 326 & 326 & 430 & 412 & 412 & 2,04 & 2,04 & - & 1,10 \\
\hline $4-7$ & 4 & 524 & 520 & 488 & 488 & 488 & 488 & 654 & 548 & 548 & 1,14 & 1,12 & 0,96 & 0,96 \\
\hline $4-7^{6}$ & 7 & 400 & 400 & - & - & 316 & 316 & 404 & 384 & 384 & 1,70 & 1,70 & - & 0,96 \\
\hline $4-11$ & 4 & 578 & 576 & 556 & 556 & 556 & 556 & 646 & 610 & 610 & 1,74 & 1,73 & 1,64 & 1,64 \\
\hline $4-11$ & 11 & 1394 & 1388 & 1364 & 1364 & 1364 & 1364 & - & 1642 & 1642 & 1,18 & 1,17 & 1,07 & 1,07 \\
\hline $4-12$ & 4 & 580 & 578 & 558 & 558 & 558 & 558 & 644 & 610 & 610 & 1,76 & 1,75 & 1,64 & 1,64 \\
\hline
\end{tabular}

${ }_{6}^{5}$ método BCU e "shadowing method" falham na deteção do p.e.i. de controle;

${ }^{6}$ método BCU falha na deteção do ponto; 


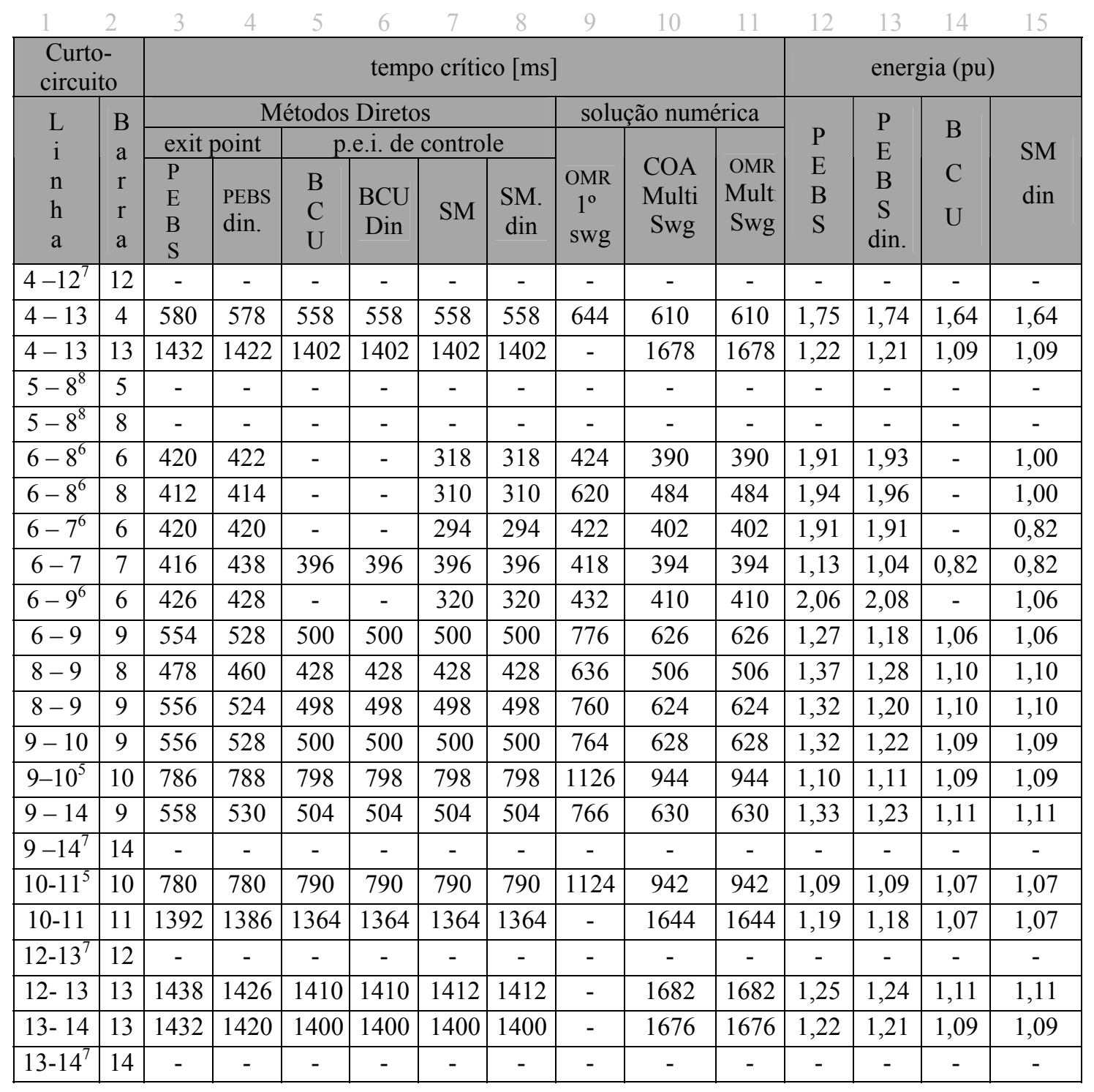

Tabela 6.5: tcr's e energias para sistema de 14 barras do caso base

As figuras, 6.5 a, b, c, d e e, 6.6 a, b, c, d e e, e 6.7 a, b, c, d e e, ilustram o comportamento dinâmico das máquinas do sistema quando submetidos a uma contingência trifásica sólida na linha 1-2 próximo a barra 2 para o sistema de 14 barras do IEEE.

Os três primeiros gráficos, a , b e c da figura 6.5, representam o sistema para um tempo de abertura de 210 ms calculado em relação ao COA, e os dois últimos d e e, representam o sistema para um tempo de abertura de $210 \mathrm{~ms}$ calculado utilizando as

\footnotetext{
${ }^{5}$ método BCU e "shadowing method" falham na deteção do p.e.i. de controle;

${ }^{6}$ método BCU falha na deteção do ponto;

${ }^{7}$ sistema permanece estável apesar da falta;

${ }^{8}$ Neste caso ocorre ilhamento do sistema. A barra 5 fica isolada do resto do sistema. Logo não é possível analisar a estabilidade de tal circuito analisando o sistema como um todo, mas é possível analisar a estabilidade em cada uma das ilhas. Neste caso a ilha que contém o gerador 5 é instável a partir do primeiro instante de abertura da linha. Porém a outra ilha (resto do sistema) é estável.
} 
equações dinâmicas das máquinas. Em ambos os casos o comportamento do sistema é estável. A figura 6.6 tem a mesma notação apresentada na figura 6.5, porém o tempo de abertura é 2 ms maior (1 passo de integração) (212ms), o que leva o sistema a instabilidade. Os três primeiros gráficos da figura 6.7 abaixo contêm a simulação para o tempo de abertura indicado pelo método PEBS convencional $(218 \mathrm{~ms})$, e os últimos dois gráficos contêm o tempo de instabilidade em primeiro "swing" (232ms) calculado pelas equações diferenciais do sistema (Análise da estabilidade de $1^{\circ}$ swing).

Seja a figura 6.5 , representando as simulações para o tcr de $210[\mathrm{~ms}]$ :

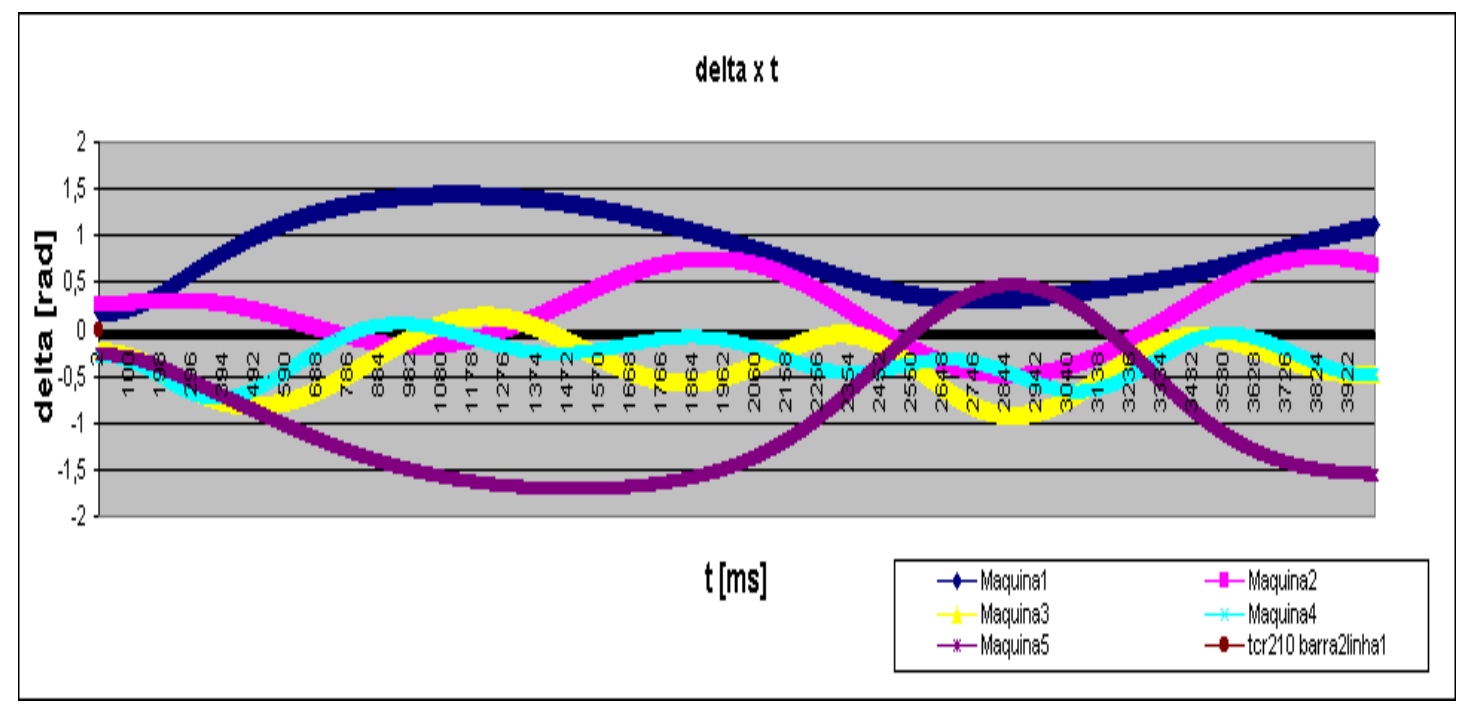

Figura 6.5 a: $\delta$ x t para $210[\mathrm{~ms}]$ na referência COA

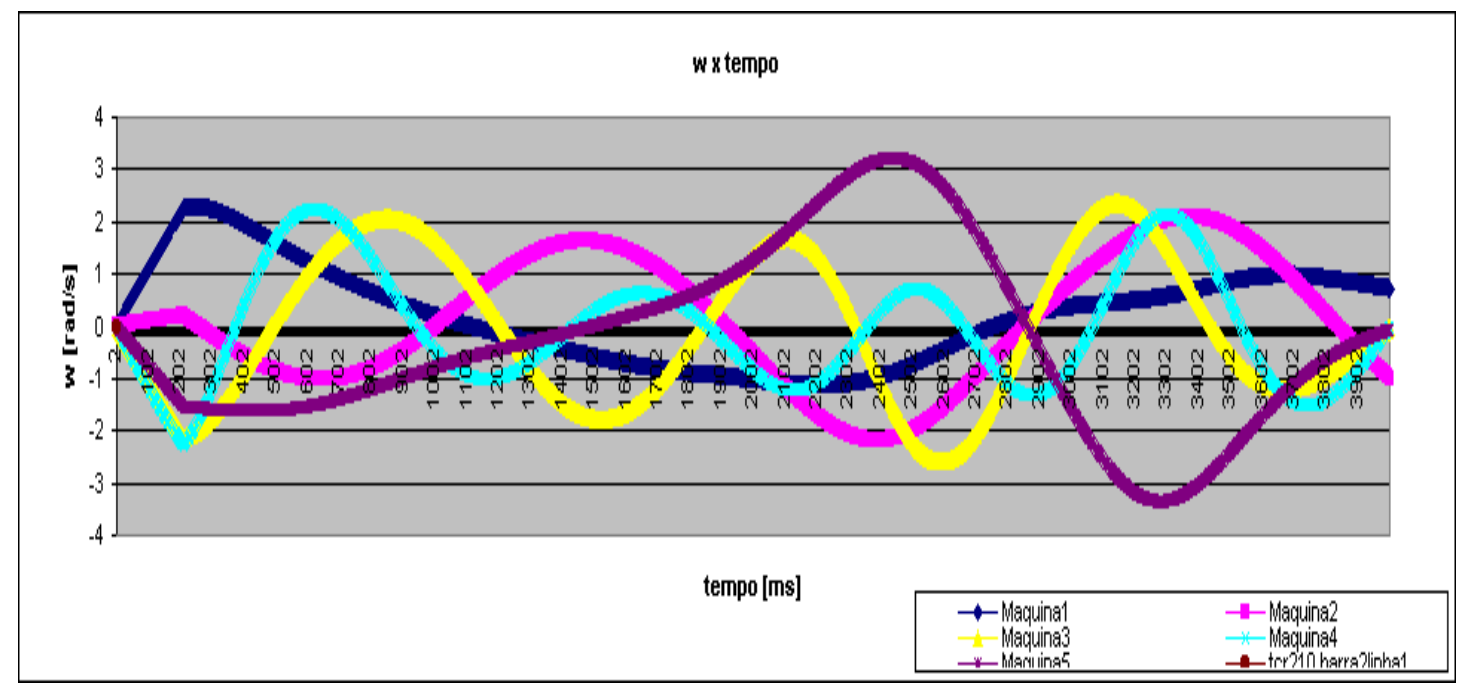

Figura 6.5 b: $\omega$ x t para $210[\mathrm{~ms}]$ na referência COA 


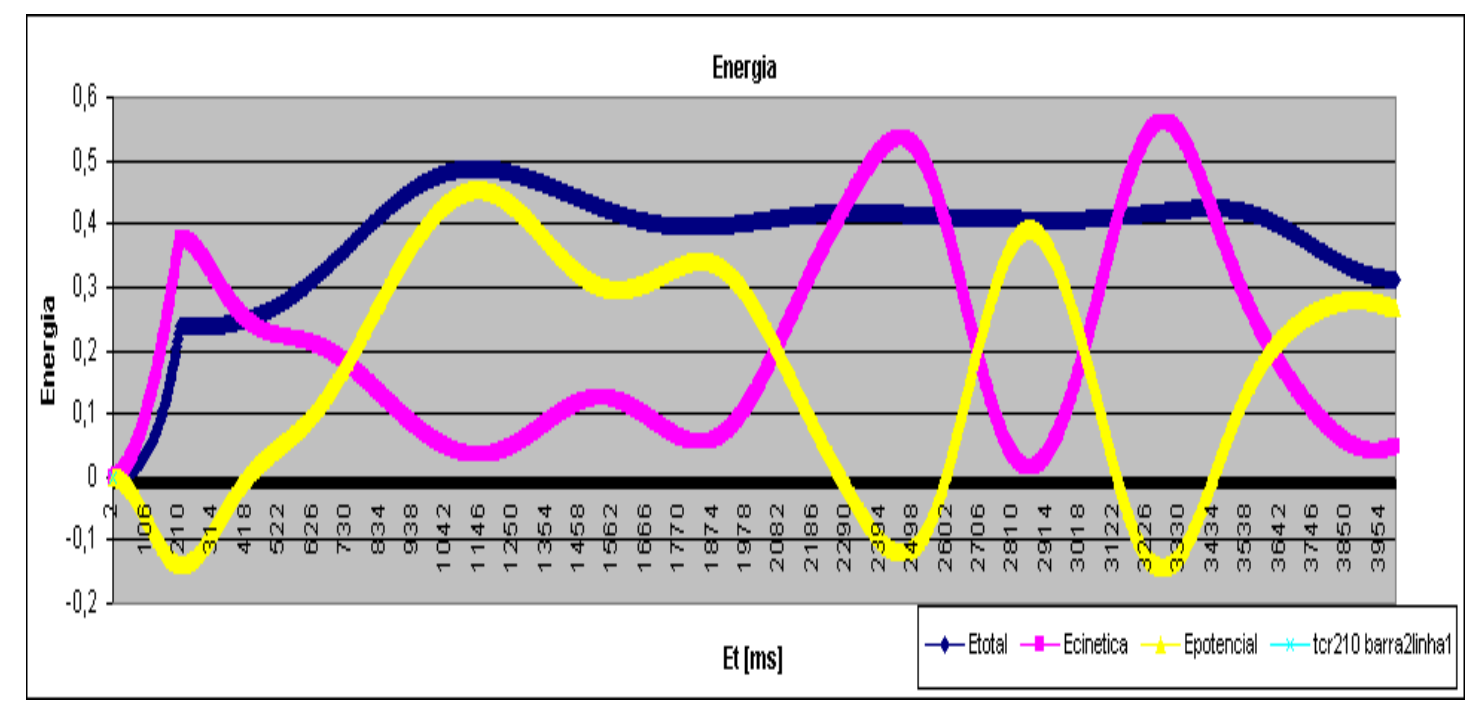

Figura 6.5 c: $E_{p}$ x t para $210[\mathrm{~ms}]$ na referência COA

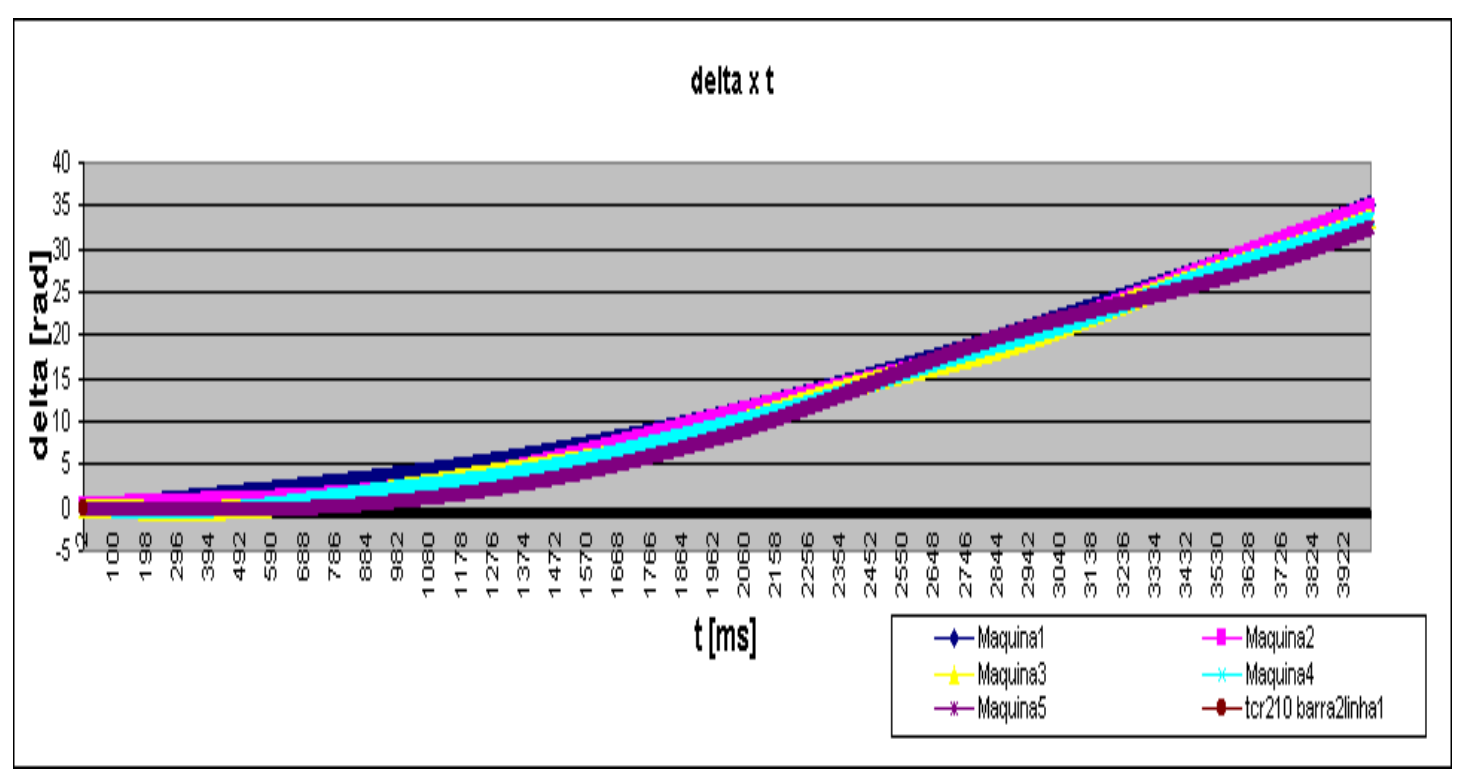

Figura 6.5 d: $\delta$ x t para $210[\mathrm{~ms}]$ para simulação convencional 


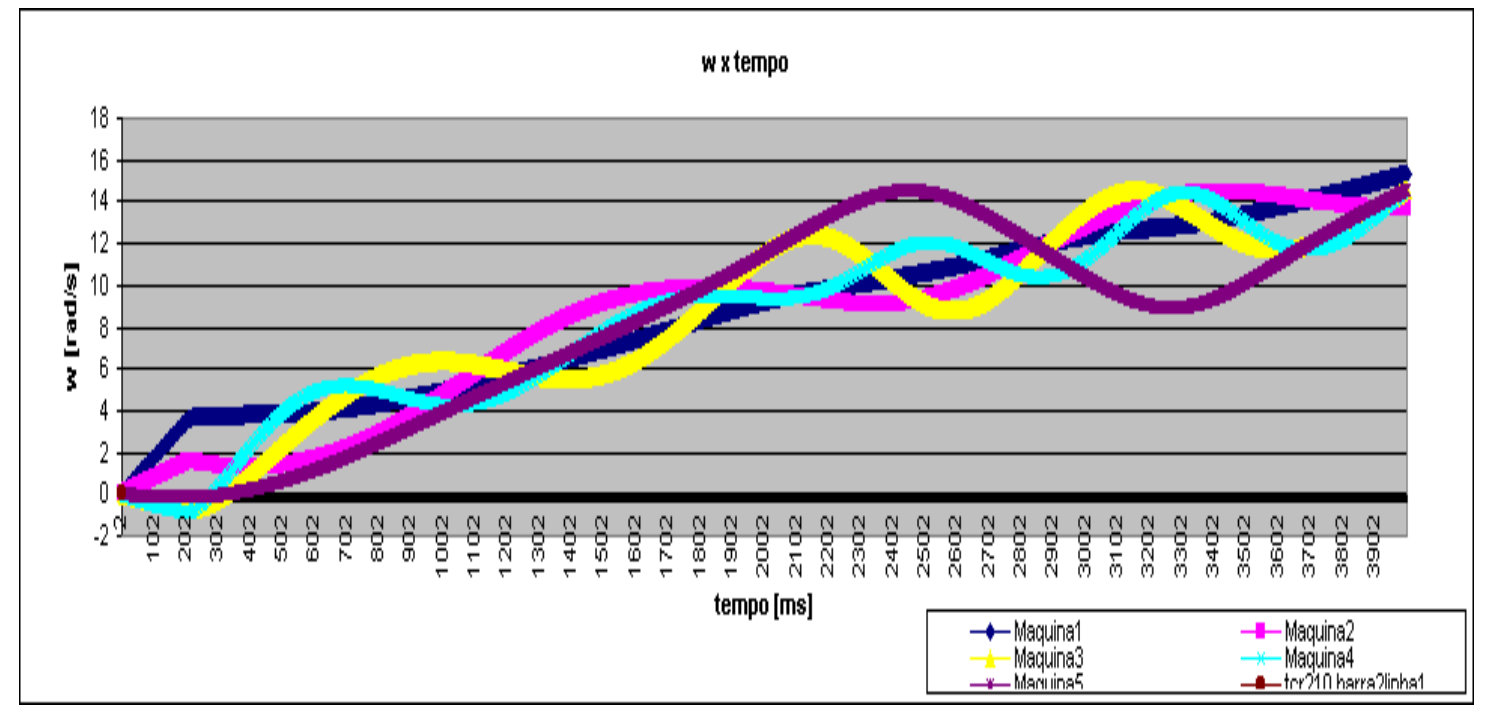

Figura 6.5 e: $\omega$ x t para $210[\mathrm{~ms}]$ para simulação convencional

Seja a figura 6.6, representando as simulações para o tcr de $212[\mathrm{~ms}]$ :

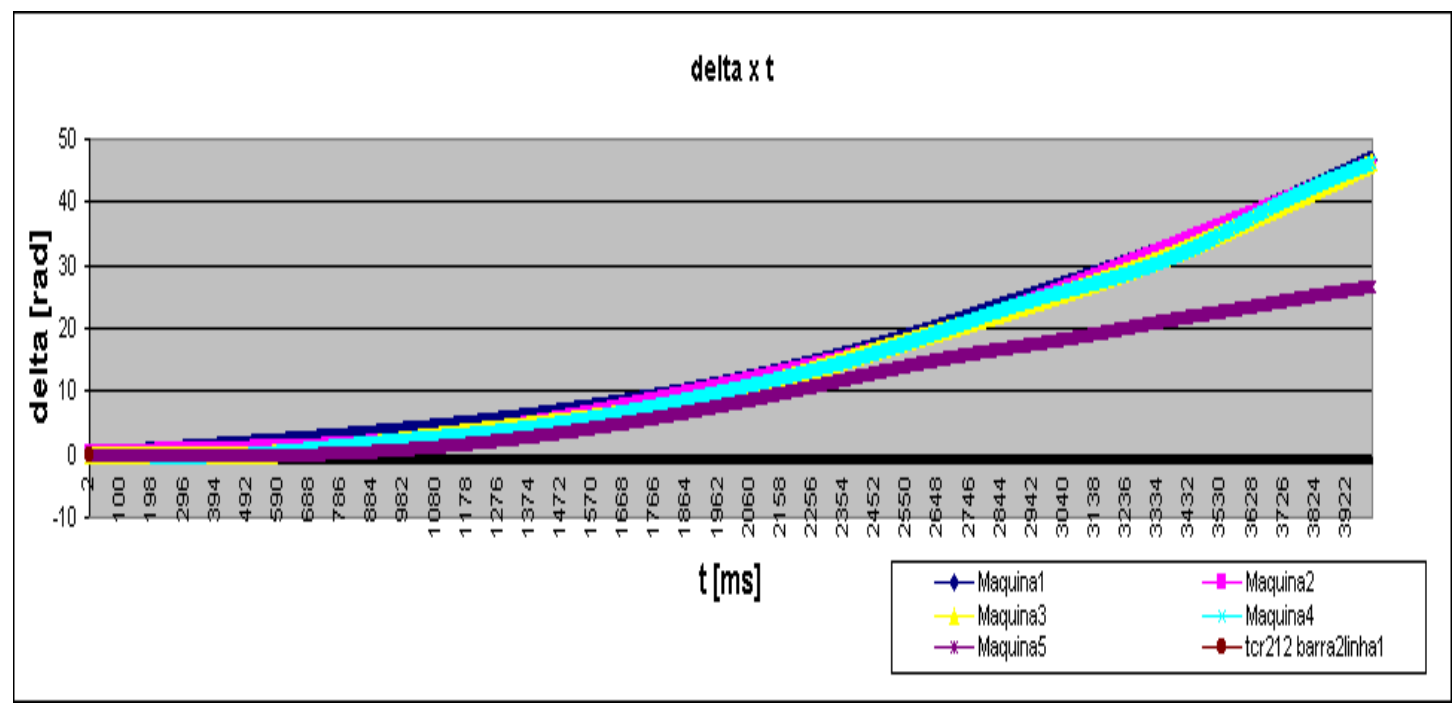

Figura 6.6 a: $\delta$ x t para $212[\mathrm{~ms}]$ na referência COA 


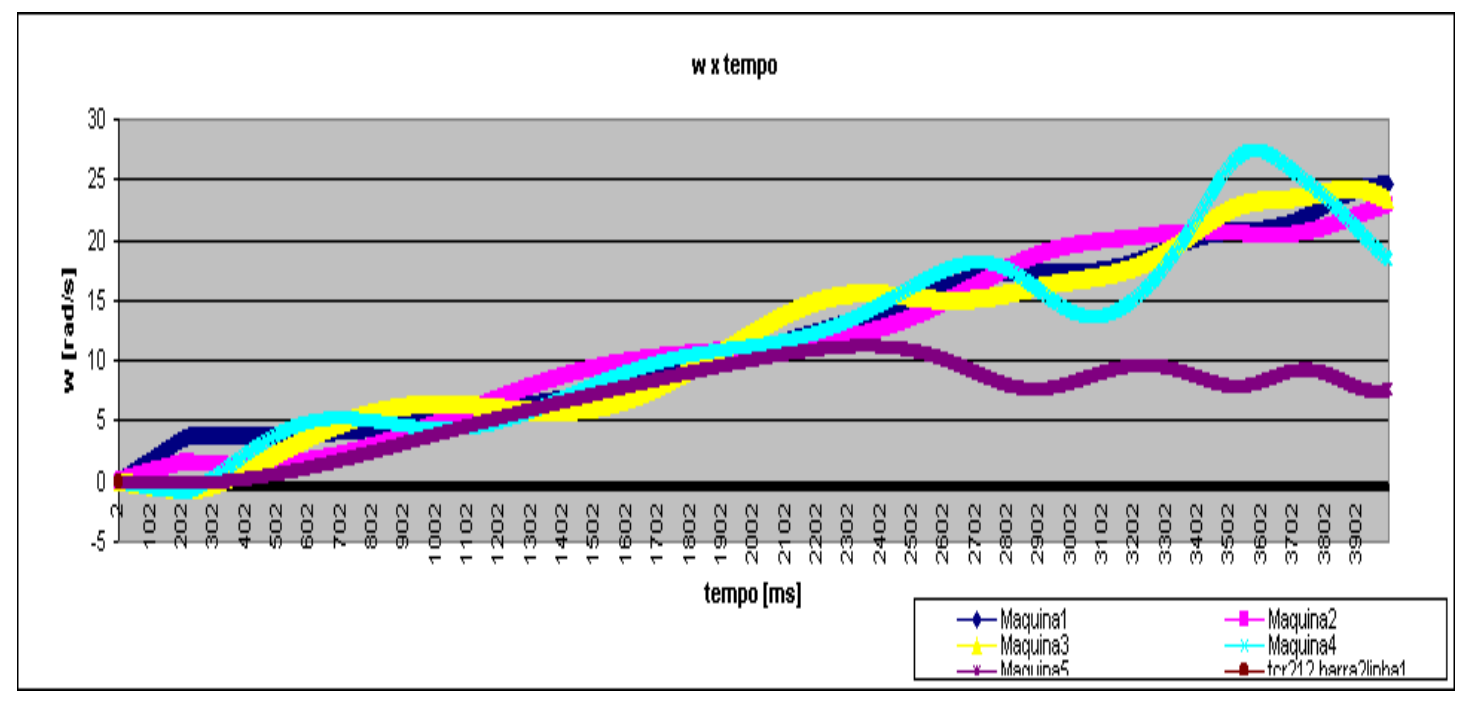

Figura 6.6 b: $\omega \times \mathrm{x}$ t para $212[\mathrm{~ms}]$ na referência COA

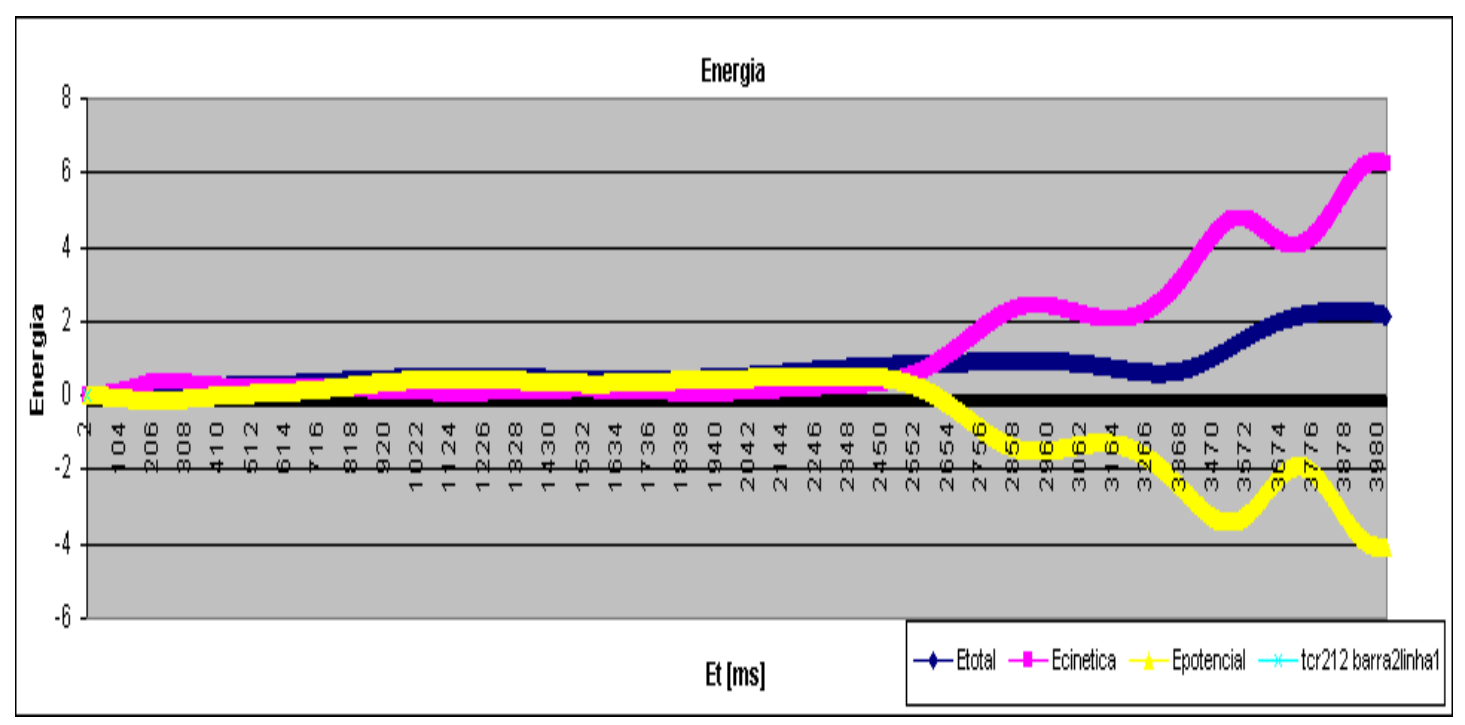

Figura 6.6 c: $\mathrm{E}_{\mathrm{p}} \mathrm{x}$ t para $212[\mathrm{~ms}]$ na referência COA 


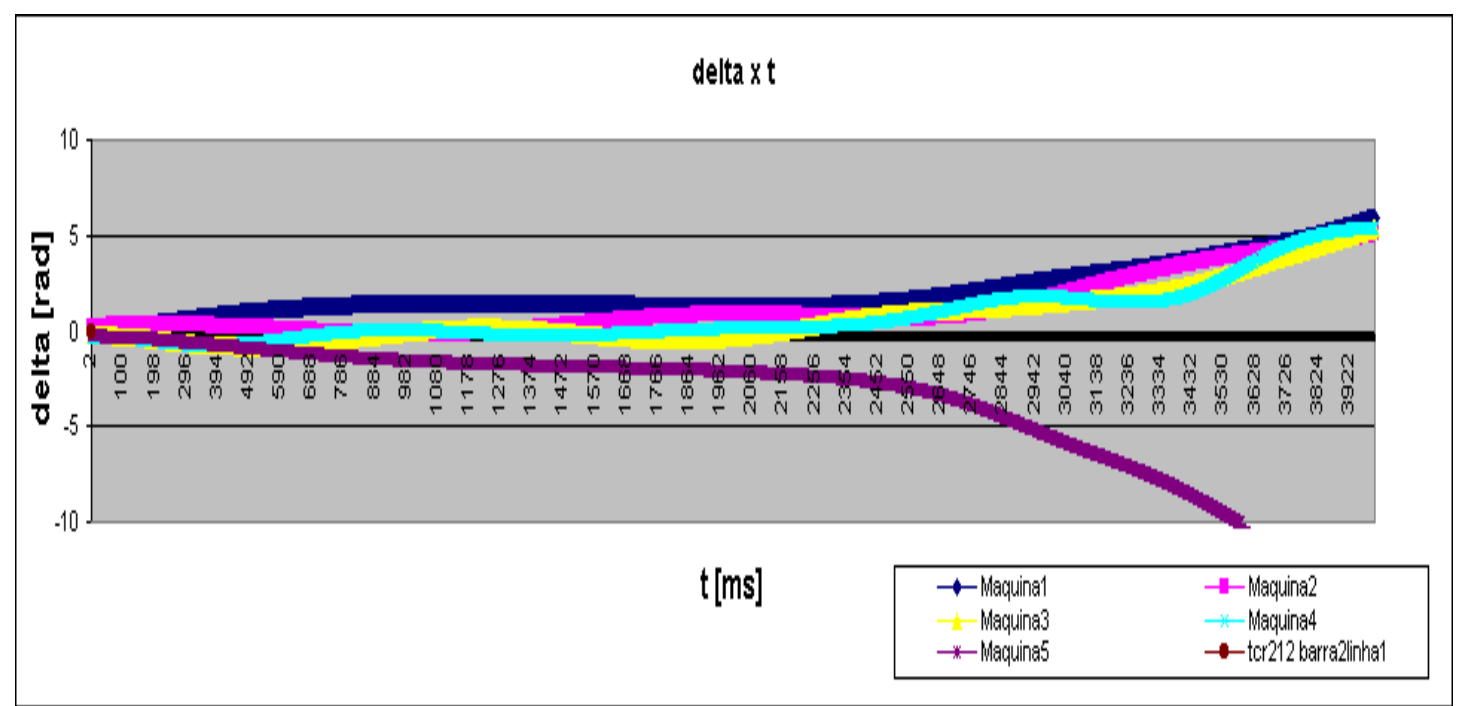

Figura $6.6 \mathrm{~d}: \delta \mathrm{x}$ t para $212[\mathrm{~ms}]$ para simulação convencional

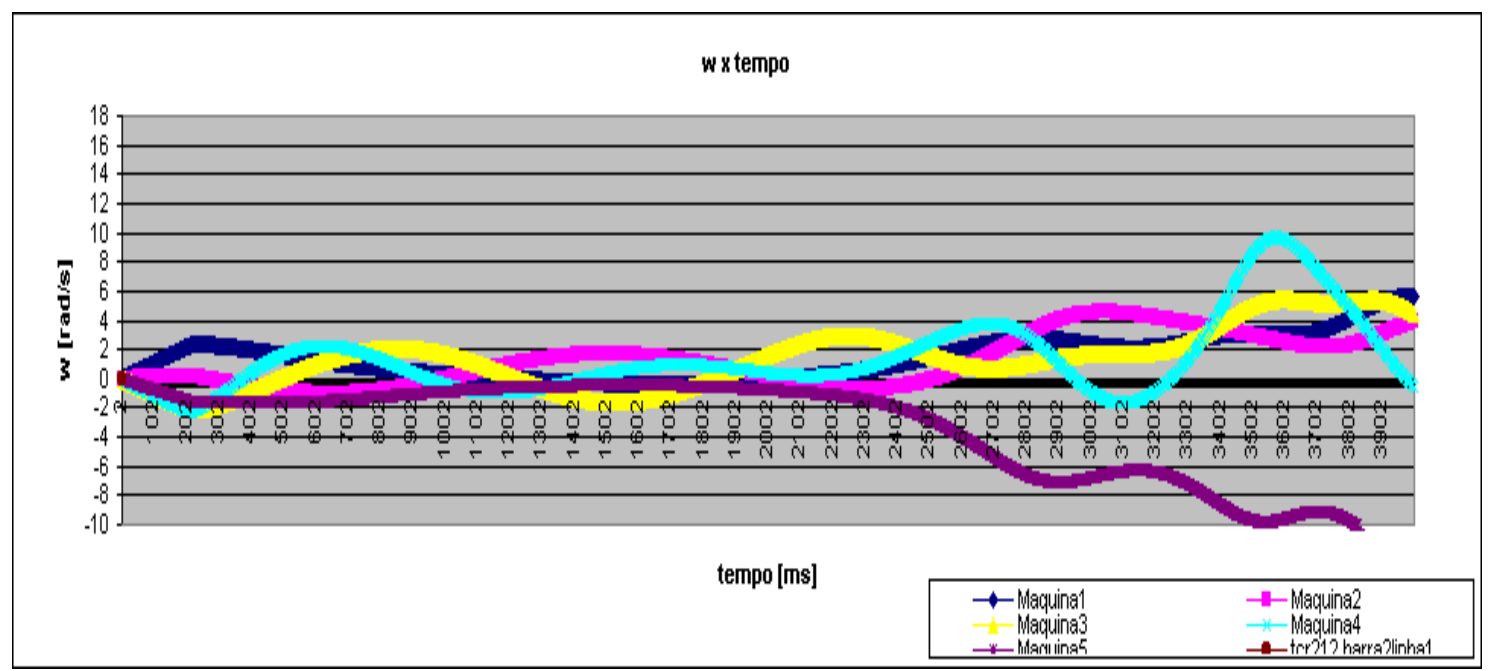

Figura 6.6 e: $\omega$ x t para $212[\mathrm{~ms}]$ para simulação convencional

Seja a figura 6.7, contendo as simulações para os tcr's calculados pelo PEBS para a estabilidade de $1^{\circ}$ "swing" através de simulação dinâmica: 


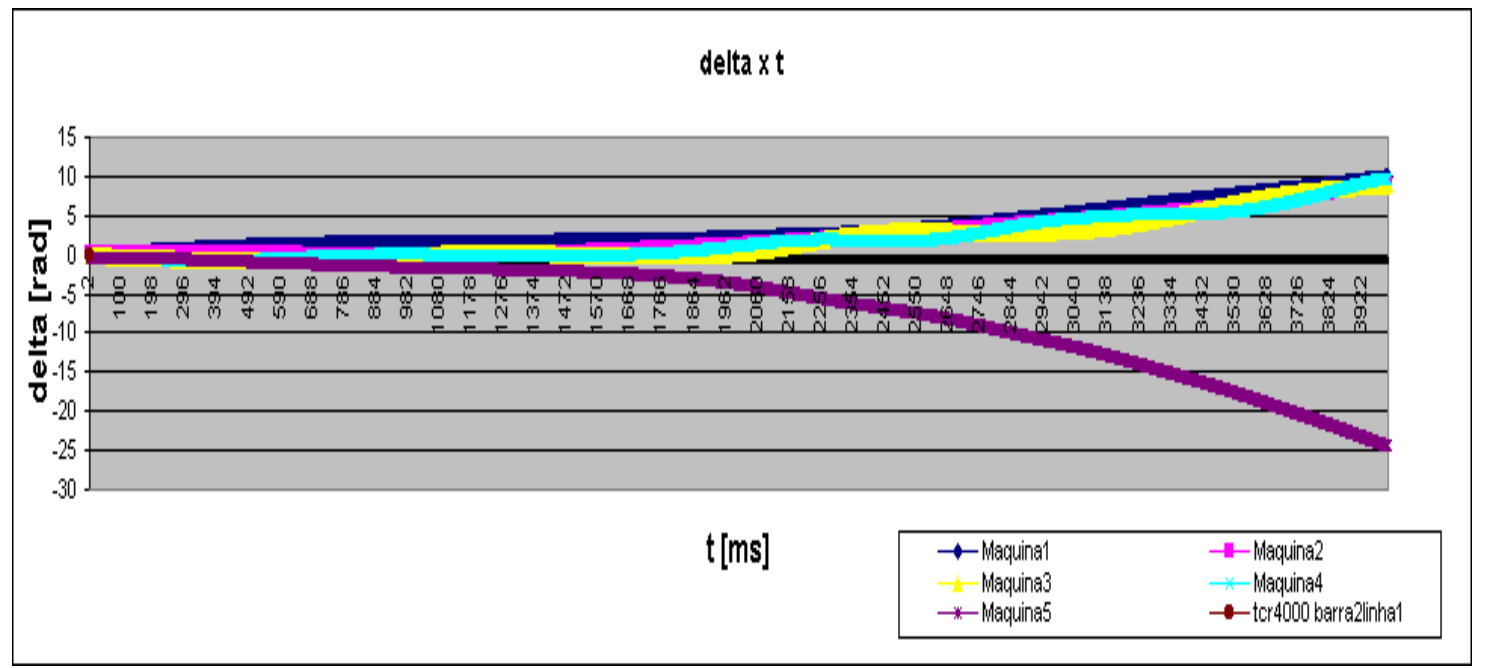

Figura 6.7 a: $\delta$ x t para $218[\mathrm{~ms}]$ na referência COA - algoritmo PEBS convencional

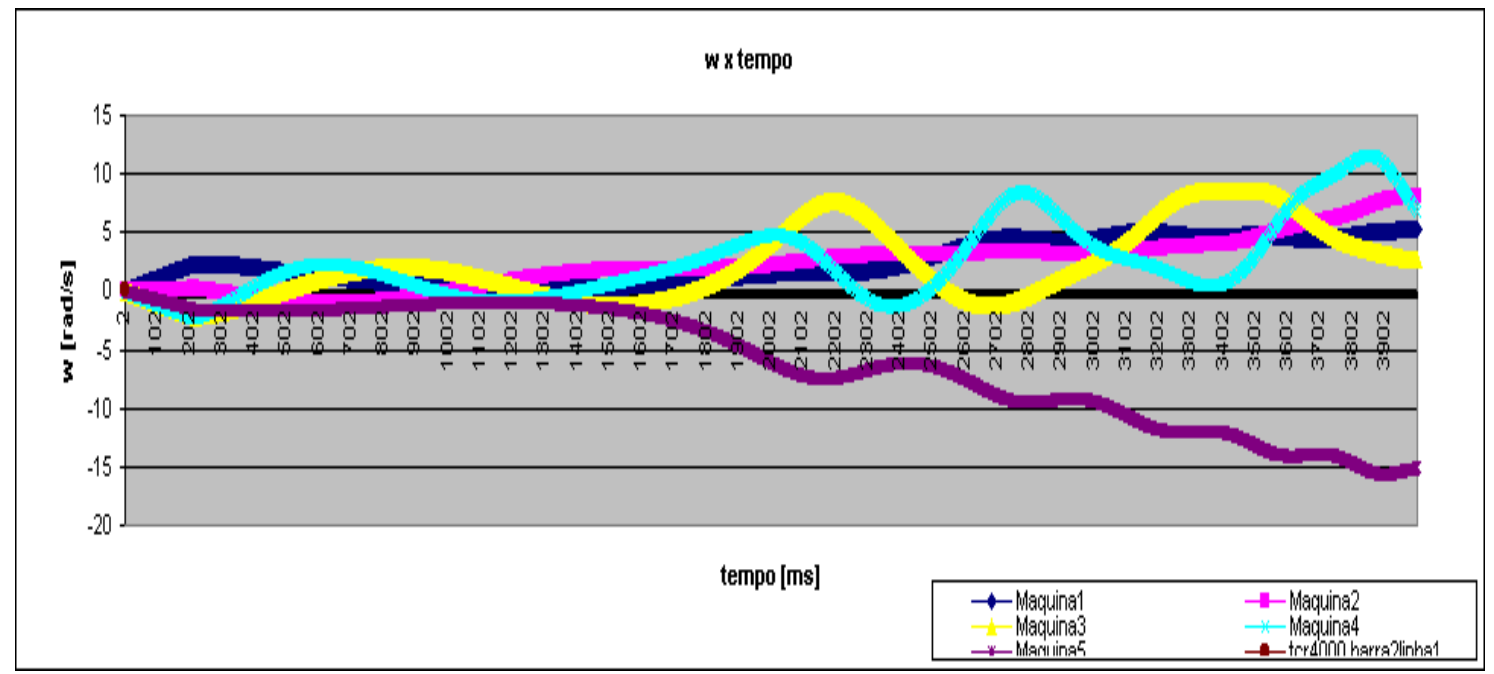

Figura 6.7 b: $\omega$ x t para $218[\mathrm{~ms}]$ na referência COA - algoritmo PEBS convencional

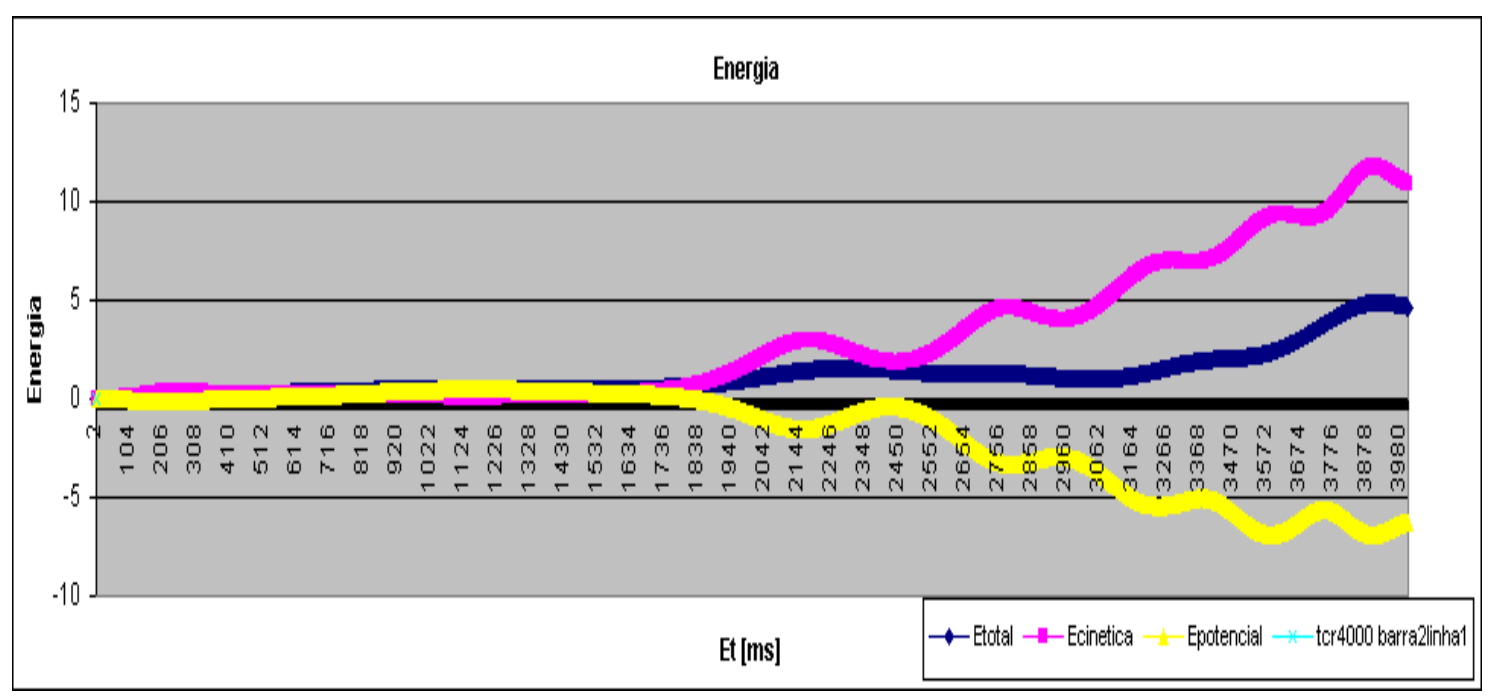

Figura 6.7 c: $E_{p}$ x t para 218 [ms] na referência COA - algoritmo PEBS convencional 


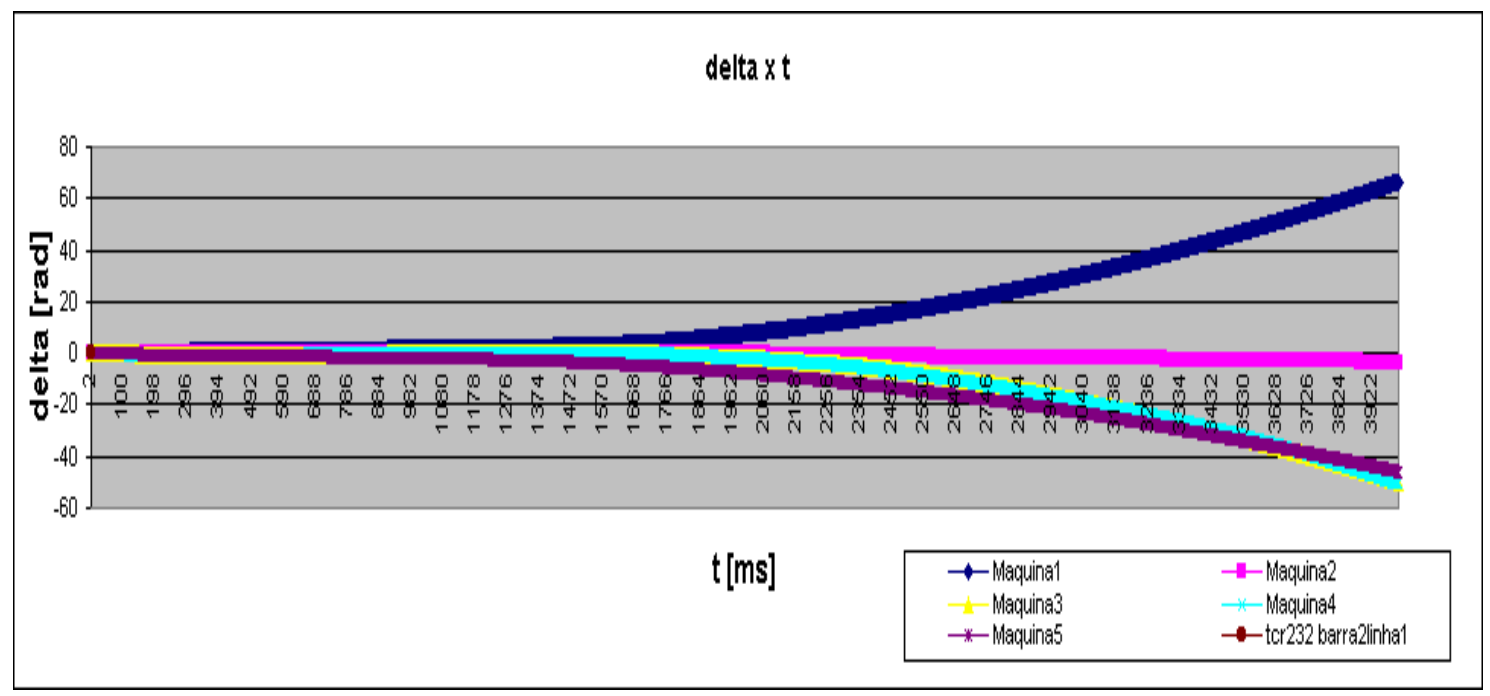

Figura 6.7 d: $\delta$ x t para $232[\mathrm{~ms}]$ para simulação convencional

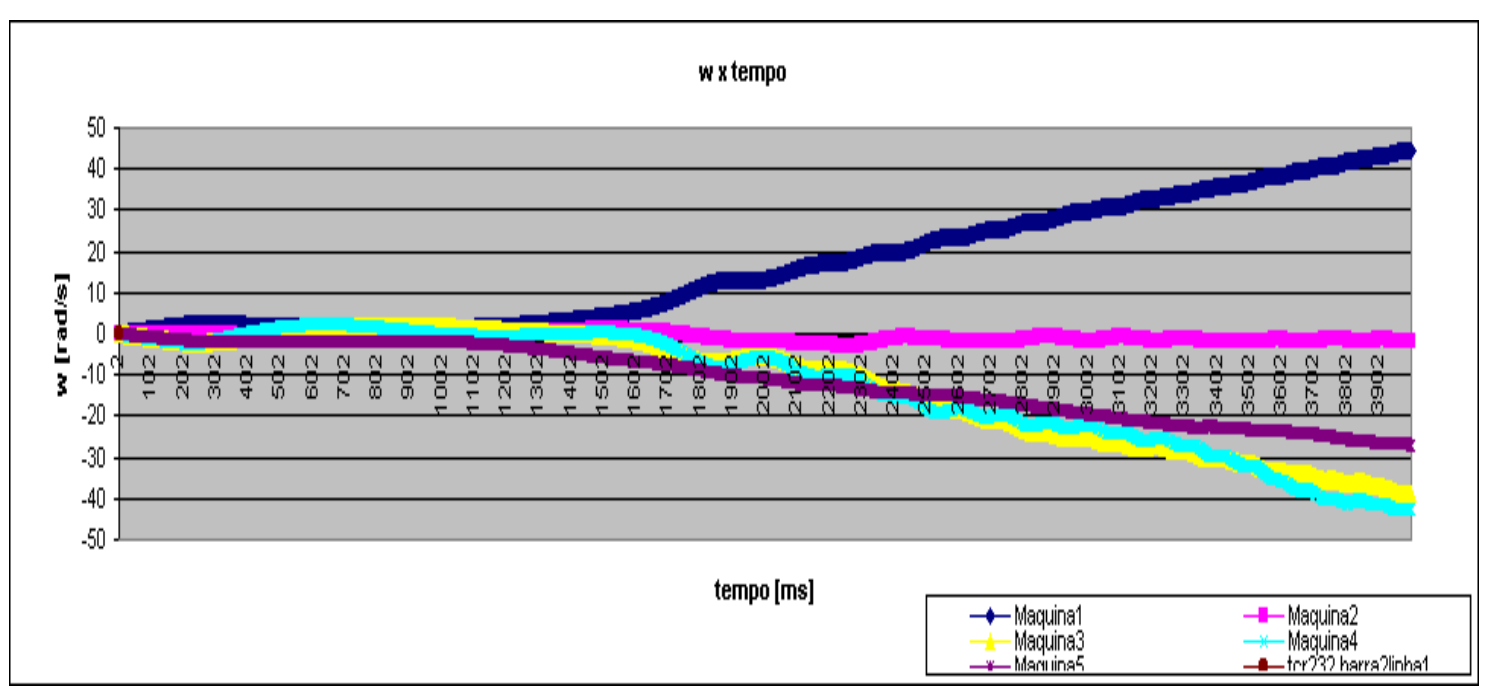

Figura 6.7 e: $\omega$ x t para $232[\mathrm{~ms}]$ para simulação convencional 


\subsection{Sistema New England - 39 barras (10 geradores)}

O sistema New England foi estudado para as contingências em todas as suas barras para o caso base cujos dados estão descritos no anexo C.

A figura 6.8 representa o sistema:

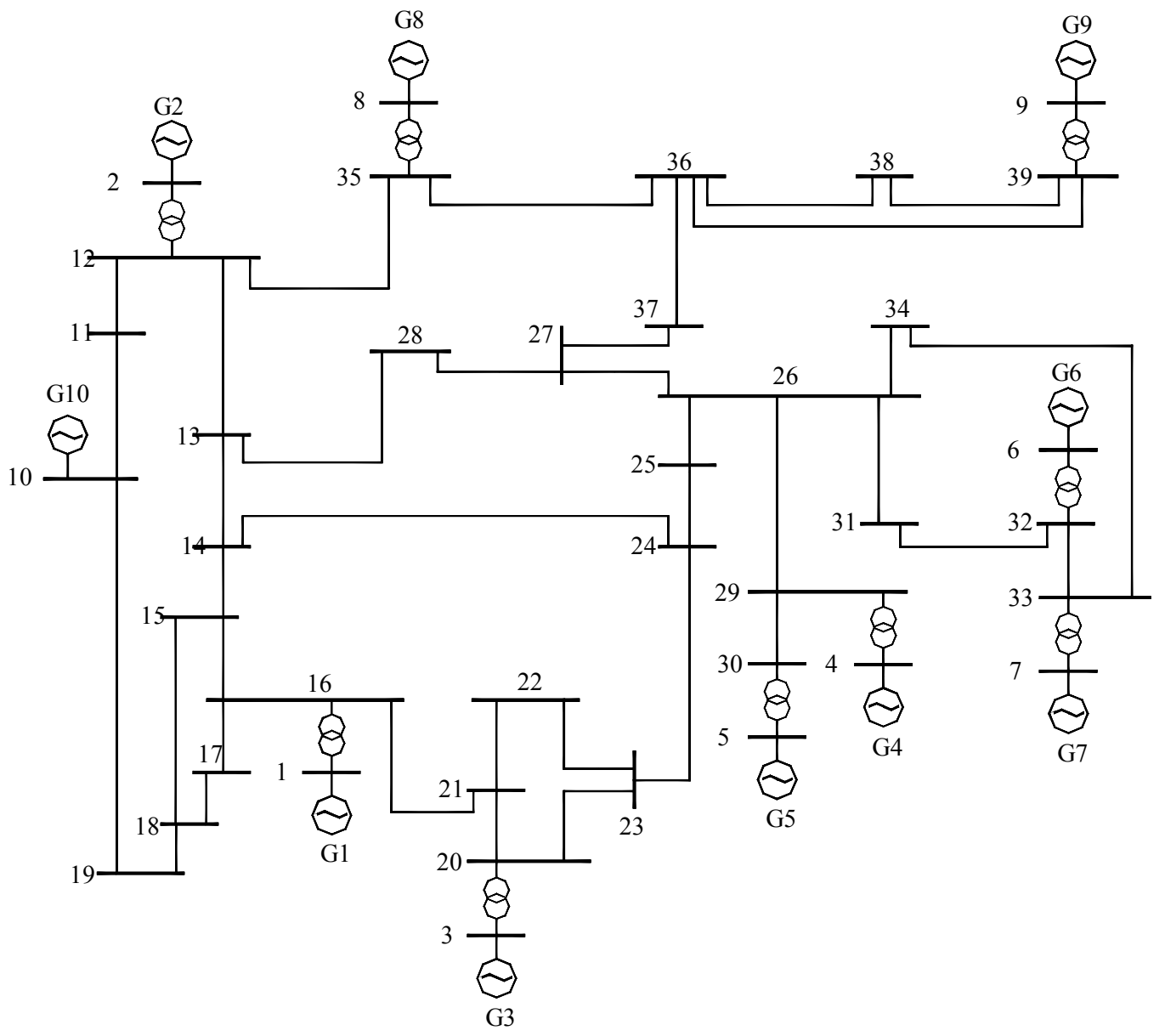

Figura 6.8: Sistema New England

Simulação do caso base: O sistema representado pela figura 6.8 foi submetido a um curto-circuito trifásico sólido em todas as suas linhas, próximos a todas as suas barras. Os resultados obtidos estão descritos na tabela 6.6. O formato da tabela 6.6 é semelhante ao da tabela 6.5 (sistema de 14 barras), excluindo-se as colunas 9, 10 e 11 . 


\begin{tabular}{|c|c|c|c|c|c|c|c|c|c|c|c|}
\hline 1 & 2 & 3 & 4 & 5 & 6 & 7 & 8 & 12 & 13 & 14 & 15 \\
\hline \multicolumn{2}{|c|}{$\begin{array}{l}\text { Curto- } \\
\text { circuito }\end{array}$} & \multicolumn{6}{|c|}{ tempo crítico $[\mathrm{ms}]$} & \multicolumn{4}{|c|}{ energia (pu) } \\
\hline \multirow{3}{*}{$\begin{array}{l}\mathrm{L} \\
\mathrm{i} \\
\mathrm{n} \\
\mathrm{h} \\
\mathrm{a}\end{array}$} & \multirow{3}{*}{$\begin{array}{l}\mathrm{B} \\
\mathrm{a} \\
\mathrm{r} \\
\mathrm{r} \\
\mathrm{a}\end{array}$} & \multicolumn{6}{|c|}{ Métodos Diretos } & \multirow{3}{*}{$\begin{array}{l}\mathrm{P} \\
\mathrm{E} \\
\mathrm{B} \\
\mathrm{S}\end{array}$} & \multirow{3}{*}{$\begin{array}{c}P \\
E \\
B \\
S \\
\text { din. }\end{array}$} & \multirow{3}{*}{$\begin{array}{l}\mathrm{B} \\
\mathrm{C} \\
\mathrm{U}\end{array}$} & \multirow{3}{*}{$\begin{array}{c}\mathrm{S} \\
\mathrm{M} \\
\operatorname{din}\end{array}$} \\
\hline & & \multicolumn{2}{|c|}{ exit point } & \multicolumn{4}{|c|}{ p.e.i. de controle } & & & & \\
\hline & & PEBS & $\begin{array}{l}\text { PEBS } \\
\text { din. }\end{array}$ & $\begin{array}{l}\mathrm{B} \\
\mathrm{C} \\
\mathrm{U}\end{array}$ & $\begin{array}{c}\text { BCU } \\
\text { Din }\end{array}$ & SM & $\begin{array}{l}\text { SM. } \\
\text { din }\end{array}$ & & & & \\
\hline $1-16^{9}$ & 1 & - & - & - & - & - & - & - & - & - & - \\
\hline $1-16^{9}$ & 16 & - & - & - & - & - & - & - & - & - & - \\
\hline $2-12^{9}$ & 2 & - & - & - & - & - & - & - & - & - & - \\
\hline $2-12^{9}$ & 12 & - & - & - & - & - & - & - & - & - & - \\
\hline $3-20^{9}$ & 3 & - & - & - & - & - & - & - & - & - & - \\
\hline $3-20^{9}$ & 20 & - & - & - & - & - & - & - & - & - & - \\
\hline $4-29^{9}$ & 4 & - & - & - & - & - & - & - & - & - & - \\
\hline $4-29^{9}$ & 29 & - & - & - & - & - & - & - & - & - & - \\
\hline $5-30^{9}$ & 5 & - & - & - & - & - & - & - & - & - & - \\
\hline $5-30^{9}$ & 30 & - & - & - & - & - & - & - & - & - & - \\
\hline $6-32^{9}$ & 6 & - & - & - & - & - & - & - & - & - & - \\
\hline $6-32^{9}$ & 32 & - & - & - & - & - & - & - & - & - & - \\
\hline $7-33^{9}$ & 7 & - & - & - & - & - & - & - & - & - & - \\
\hline $7-33^{9}$ & 33 & - & - & - & - & - & - & - & - & - & - \\
\hline $8-35^{9}$ & 8 & - & - & - & - & - & - & - & - & - & - \\
\hline $8-35^{9}$ & 35 & - & - & - & - & - & - & - & - & - & - \\
\hline $9-39^{9}$ & 9 & - & - & - & - & - & - & - & - & - & - \\
\hline $9-39^{9}$ & 39 & - & - & - & - & - & - & - & - & - & - \\
\hline $10-11$ & 10 & 412 & 414 & 386 & 386 & 386 & 386 & 4,44 & 4,48 & 3,81 & 3,81 \\
\hline $10-11$ & 11 & 482 & 480 & 476 & 476 & 476 & 476 & 3,88 & 3,89 & 3,81 & 3,81 \\
\hline $10-19$ & 10 & 540 & 538 & 498 & 498 & 498 & 498 & 8,26 & 8,27 & 6,84 & 6,84 \\
\hline $10-19^{10}$ & 19 & 462 & 460 & - & - & 496 & 496 & 6,06 & 6,06 & - & 6,84 \\
\hline $11-12$ & 11 & 458 & 456 & 454 & 454 & 454 & 454 & 3,41 & 3,42 & 3,35 & 3,35 \\
\hline $11-12^{11}$ & 12 & 214 & 212 & - & - & 150 & 150 & 6,93 & 6,99 & - & 3,35 \\
\hline $12-13^{11}$ & 12 & 262 & 260 & - & - & 226 & 226 & 11,89 & 11,90 & - & 8,54 \\
\hline $12-13$ & 13 & 244 & 242 & 220 & 220 & 220 & 220 & 10,31 & 10,53 & 8,54 & 8,54 \\
\hline $12-35^{10}$ & 12 & 202 & 200 & - & - & 214 & 214 & 5,97 & 6,02 & - & 6,75 \\
\hline $12-35^{10}$ & 35 & 140 & 138 & - & - & 186 & 186 & 3,69 & 3,69 & - & 6,75 \\
\hline $13-14^{11}$ & 13 & 240 & 238 & - & - & 190 & 190 & 10,40 & 10,41 & - & 6,46 \\
\hline $13-14$ & 14 & 208 & 206 & 192 & 192 & 192 & 192 & 7,60 & 7,59 & 6,46 & 6,46 \\
\hline $13-28$ & 13 & 242 & 240 & 242 & 242 & 242 & 242 & 10,56 & 10,55 & 10,53 & 10,53 \\
\hline $13-28^{10}$ & 28 & 230 & 228 & - & - & 244 & 244 & 9,41 & 9,40 & - & 10,53 \\
\hline $14-15^{11}$ & 14 & 212 & 210 & - & - & 172 & 172 & 8,01 & 8,00 & - & 5,16 \\
\hline $14-15^{11}$ & 15 & 186 & 184 & - & - & 166 & 166 & 6,59 & 6,59 & - & 5,16 \\
\hline $14-24^{10}$ & 14 & 216 & 216 & - & - & 240 & 240 & 8,41 & 8,49 & - & 10,31 \\
\hline $14-24^{10}$ & 24 & 230 & 230 & - & - & 254 & 254 & 8,50 & 8,56 & - & 10,31 \\
\hline $15-16^{10}$ & 15 & 182 & 182 & - & - & 218 & 218 & 6,13 & 6,16 & - & 9,08 \\
\hline
\end{tabular}

\footnotetext{
${ }^{9}$ ocorre ilhamento no sistema;

${ }^{10}$ método BCU e "shadowing method" falham na deteção do ponto;

${ }^{11}$ método BCU falha na deteção do ponto;
} 


\begin{tabular}{|c|c|c|c|c|c|c|c|c|c|c|c|}
\hline 1 & 2 & 3 & 4 & 5 & 6 & 7 & 8 & 12 & 13 & 14 & 15 \\
\hline \multicolumn{2}{|c|}{$\begin{array}{l}\text { Curto- } \\
\text { circuito }\end{array}$} & \multicolumn{6}{|c|}{ tempo crítico $[\mathrm{ms}]$} & \multicolumn{4}{|c|}{ energia (pu) } \\
\hline \multirow{3}{*}{$\begin{array}{l}\mathrm{L} \\
\mathrm{i} \\
\mathrm{n} \\
\mathrm{h} \\
\mathrm{a}\end{array}$} & \multirow{3}{*}{$\begin{array}{l}\mathrm{B} \\
\mathrm{a} \\
\mathrm{r} \\
\mathrm{r} \\
\mathrm{a}\end{array}$} & \multicolumn{6}{|c|}{ Métodos Diretos } & \multirow{3}{*}{$\begin{array}{l}\mathrm{P} \\
\mathrm{E} \\
\mathrm{B} \\
\mathrm{S}\end{array}$} & \multirow{3}{*}{$\begin{array}{c}\mathrm{P} \\
\mathrm{E} \\
\mathrm{B} \\
\mathrm{S} \\
\text { din. }\end{array}$} & \multirow{3}{*}{$\begin{array}{l}\mathrm{B} \\
\mathrm{C} \\
\mathrm{U}\end{array}$} & \multirow{3}{*}{$\begin{array}{c}\mathrm{S} \\
\mathrm{M} \\
\operatorname{din}\end{array}$} \\
\hline & & \multicolumn{2}{|c|}{ exit point } & \multicolumn{4}{|c|}{ p.e.i. de controle } & & & & \\
\hline & & PEBS & $\begin{array}{l}\text { PEBS } \\
\text { din. }\end{array}$ & $\begin{array}{l}\text { B } \\
\text { C } \\
\text { U }\end{array}$ & $\begin{array}{l}\text { BCU } \\
\text { Din }\end{array}$ & SM & $\begin{array}{l}\text { SM. } \\
\text { din }\end{array}$ & & & & \\
\hline $15-16^{10}$ & 16 & 172 & 174 & 214 & 214 & 214 & 214 & 5,96 & 5,99 & 9,08 & 9,08 \\
\hline $15-18^{10}$ & 15 & 194 & 192 & - & - & 224 & 224 & 7,19 & 7,26 & - & 9,77 \\
\hline $15-18^{10}$ & 18 & 222 & 222 & - & - & 256 & 256 & 7,24 & 7,30 & - & 9,77 \\
\hline $16-17^{10}$ & 16 & 184 & 184 & 214 & 214 & 214 & 214 & 6,72 & 6,79 & 9,40 & 9,40 \\
\hline $16-17^{10}$ & 17 & 222 & 222 & - & - & 258 & 258 & 6,86 & 6,91 & - & 9,40 \\
\hline $16-21^{10}$ & 16 & 176 & 176 & 190 & 190 & 170 & 170 & 6,21 & 6,22 & 7,15 & 5,72 \\
\hline $16-21^{11}$ & 21 & 196 & 190 & - & - & 148 & 148 & 5,87 & 5,90 & - & 3,45 \\
\hline $17-18^{10}$ & 17 & 226 & 226 & - & - & 266 & 266 & 7,28 & 7,34 & - & 10,14 \\
\hline $17-18^{10}$ & 18 & 224 & 222 & - & - & 260 & 260 & 7,34 & 7,40 & - & 10,14 \\
\hline $18-19^{10}$ & 18 & 174 & 182 & 214 & 214 & 214 & 214 & 4,48 & 4,48 & 6,08 & 6,08 \\
\hline $18-19^{10}$ & 19 & 442 & 440 & - & - & 474 & 474 & 5,37 & 5,37 & - & 6,08 \\
\hline $20-21^{11}$ & 20 & 186 & 184 & 196 & 196 & 166 & 166 & 5,76 & 5,75 & 6,38 & 4,51 \\
\hline $20-21^{11}$ & 21 & 196 & 196 & 198 & 198 & 168 & 168 & 6,27 & 6,32 & 6,37 & 4,51 \\
\hline $20-23^{11}$ & 20 & 188 & 186 & 200 & 200 & 188 & 188 & 6,01 & 6,03 & 5,91 & 5,91 \\
\hline $20-23^{10}$ & 23 & 208 & 208 & 216 & 216 & 216 & 216 & 6,30 & 6,03 & 6,77 & 6,77 \\
\hline $21-22^{10}$ & 21 & 210 & 210 & - & - & 248 & 248 & 7,68 & 7,68 & - & 10,95 \\
\hline $21-22^{10}$ & 22 & 472 & 472 & - & - & 568 & 568 & 8,30 & 8,30 & - & 10,95 \\
\hline $22-23^{10}$ & 22 & 472 & 472 & - & - & 568 & 568 & 8,28 & 8,30 & - & 10,95 \\
\hline $22-23^{10}$ & 23 & 222 & 222 & - & - & 266 & 266 & 7,51 & 7,55 & - & 10,95 \\
\hline $23-24^{11}$ & 23 & 202 & 200 & - & - & 192 & 192 & 5,84 & 5,84 & - & 5,19 \\
\hline $23-24^{11}$ & 24 & 224 & 222 & - & - & 182 & 182 & 7,97 & 7,96 & - & 5,19 \\
\hline $24-25^{11}$ & 24 & 230 & 228 & - & - & 202 & 202 & 8,58 & 8,56 & - & 6,54 \\
\hline $24-25^{10}$ & 25 & 222 & 222 & - & - & 188 & 188 & 9,27 & 9,28 & - & 6,54 \\
\hline $25-26^{11}$ & 25 & 214 & 212 & - & - & 190 & 190 & 8,32 & 8,33 & - & 6,47 \\
\hline $25-26^{11}$ & 26 & 148 & 148 & - & - & 144 & 144 & 6,97 & 7,15 & - & 6,47 \\
\hline $26-27$ & 26 & 124 & 122 & 122 & 122 & 122 & 122 & 6,71 & 6,71 & 4,67 & 4,67 \\
\hline $26-27^{11}$ & 27 & 166 & 164 & - & - & 122 & 122 & 4,93 & 4,93 & - & 4,67 \\
\hline $26-29^{9}$ & 26 & - & - & - & - & - & - & - & - & - & - \\
\hline $26-29^{9}$ & 29 & - & - & - & - & - & - & - & - & - & - \\
\hline $26-31^{10}$ & 26 & 132 & 134 & - & - & 172 & 172 & 5,45 & 5,61 & - & 9,31 \\
\hline $26-31^{10}$ & 31 & 154 & 158 & - & - & 224 & 224 & 4,45 & 4,68 & - & 9,31 \\
\hline $26-34^{10}$ & 26 & 164 & 162 & - & - & 182 & 182 & 8,85 & 8,96 & - & 11,02 \\
\hline $26-34^{10}$ & 34 & 196 & 196 & - & - & 216 & 216 & 9,01 & 9,09 & - & 11,02 \\
\hline $27-28^{10}$ & 27 & 180 & 178 & - & - & 202 & 202 & 7,98 & 8,00 & - & 9,98 \\
\hline $27-28^{10}$ & 28 & 224 & 222 & 240 & 240 & 240 & 240 & 8,76 & 8,76 & 9,88 & 9,98 \\
\hline $27-37^{10}$ & 27 & 188 & 188 & - & - & 200 & 200 & 9,04 & 9,07 & - & 10,09 \\
\hline $27-37$ & 37 & 184 & 186 & 122 & 122 & 122 & 122 & 5,40 & 5,59 & 2,41 & 2,41 \\
\hline $29-30^{9}$ & 29 & - & - & - & - & - & - & - & - & - & - \\
\hline
\end{tabular}

\footnotetext{
${ }^{9}$ ocorre ilhamento no sistema.

${ }^{10}$ método BCU e "shadowing method" falham na deteção do ponto;

${ }^{11}$ método BCU falha na deteção do ponto;
} 


\begin{tabular}{|c|c|c|c|c|c|c|c|c|c|c|c|}
\hline 1 & 2 & 3 & 4 & 5 & 6 & 7 & 8 & 12 & 13 & 14 & 15 \\
\hline \multicolumn{2}{|c|}{$\begin{array}{l}\text { Curto- } \\
\text { circuito }\end{array}$} & \multicolumn{6}{|c|}{ tempo crítico $[\mathrm{ms}]$} & \multicolumn{4}{|c|}{ energia (pu) } \\
\hline \multirow{3}{*}{$\begin{array}{l}\mathrm{L} \\
\mathrm{i} \\
\mathrm{n} \\
\mathrm{h} \\
\mathrm{a}\end{array}$} & \multirow{3}{*}{\begin{tabular}{l|}
$\mathrm{B}$ \\
$\mathrm{a}$ \\
$\mathrm{r}$ \\
$\mathrm{r}$ \\
$\mathrm{a}$
\end{tabular}} & \multicolumn{6}{|c|}{ Métodos Diretos } & \multirow{3}{*}{$\begin{array}{l}\text { P } \\
\text { E } \\
\text { B } \\
\text { S }\end{array}$} & \multirow{3}{*}{$\begin{array}{c}\mathrm{P} \\
\mathrm{E} \\
\mathrm{B} \\
\mathrm{S} \\
\text { din. }\end{array}$} & \multirow{3}{*}{$\begin{array}{l}\mathrm{B} \\
\mathrm{C} \\
\mathrm{U}\end{array}$} & \multirow{3}{*}{$\begin{array}{c}\mathrm{S} \\
\mathrm{M} \\
\mathrm{din}\end{array}$} \\
\hline & & \multicolumn{2}{|c|}{ exit point } & \multicolumn{4}{|c|}{ p.e.i. de controle } & & & & \\
\hline & & PEBS & $\begin{array}{l}\text { PEBS } \\
\text { din. }\end{array}$ & $\begin{array}{l}\mathrm{B} \\
\mathrm{C} \\
\mathrm{U}\end{array}$ & $\begin{array}{c}\text { BCU } \\
\text { Din }\end{array}$ & SM & $\begin{array}{l}\text { SM. } \\
\text { din }\end{array}$ & & & & \\
\hline $29-30^{9}$ & 30 & - & - & - & - & - & - & - & - & - & - \\
\hline $31-32^{10}$ & 31 & 162 & 106 & - & - & 188 & 188 & 2,13 & 2,28 & - & 6,23 \\
\hline $31-32^{10}$ & 32 & 88 & 92 & - & - & 180 & 180 & 1,79 & 1,93 & - & 6,23 \\
\hline $32-33^{10}$ & 32 & 192 & 194 & - & - & 214 & 214 & 8,62 & 8,62 & - & 10,92 \\
\hline $32-33^{10}$ & 33 & 192 & 192 & - & - & 222 & 222 & 8,12 & 8,13 & - & 10,92 \\
\hline $33-34^{10}$ & 33 & 166 & 166 & - & - & 216 & 216 & 5,26 & 5,41 & - & 9,22 \\
\hline $33-34^{10}$ & 34 & 160 & 162 & - & - & 206 & 206 & 5,59 & 5,74 & - & 9,22 \\
\hline $35-36^{11}$ & 35 & 208 & 208 & - & - & 192 & 192 & 11,61 & 11,63 & - & 9,40 \\
\hline $35-36$ & 36 & 126 & 126 & 102 & 102 & 102 & 102 & 3,24 & 3,28 & 2,05 & 2,05 \\
\hline $36-37$ & 36 & 140 & 140 & 112 & 112 & 112 & 112 & 5,63 & 3,95 & 2,48 & 2,48 \\
\hline $36-37$ & 37 & 190 & 190 & 126 & 126 & 126 & 126 & 5,63 & 5,60 & 2,48 & 2,48 \\
\hline $36-38$ & 36 & 124 & 122 & 90 & 90 & 90 & 90 & 1,55 & 3,00 & 1,55 & 1,54 \\
\hline $36-38$ & 38 & 106 & 104 & 106 & 106 & 106 & 106 & 1,51 & 1,52 & 1,55 & 1,55 \\
\hline $36-39$ & 36 & 116 & 114 & 78 & 78 & 78 & 78 & 2,58 & 2,58 & 1,19 & 1,19 \\
\hline $36-39$ & 39 & 78 & 78 & 82 & 82 & 82 & 82 & 1,12 & 1,12 & 1,19 & 1,19 \\
\hline $38-39$ & 38 & 50 & 48 & 46 & 46 & 46 & 46 & 0,52 & 0,52 & 0,47 & 0,47 \\
\hline $38-39$ & 39 & 40 & 38 & 40 & 40 & 40 & 40 & 0,48 & 0,47 & 0,47 & 0,47 \\
\hline
\end{tabular}

Tabela 6.6: tcr's e energias para caso base do sistema New England

Pode ser observado que em algumas contingências o "shadowing method" ou o BCU encontram p.e.i.s de controle com níveis energéticos maiores do que os "exit points" encontrados pelos algoritmos PEBS e PEBS dinâmico. Estes casos representam falhas dos algoritmos. Estas falhas serão discutidas no capítulo seguinte.

\subsection{Considerações finais dos testes realizados}

Os resultados obtidos evidenciaram o esforço na predição da estabilidade. É possível existirem outras situações de falha dos algoritmos PEBS e BCU, bem como situações onde o PEBS dinâmico e o "shadowing method" podem falhar. Porém os resultados obtidos mostram que os dois algoritmos robustos implementados são realmente mais eficientes que os tradicionais. No capítulo seguinte serão discutidas as características de falha dos dois algoritmos robustos implementados.

\footnotetext{
9 ocorre ilhamento no sistema.

${ }^{10}$ método BCU e "shadowing method" falham na deteção do ponto;

${ }^{11}$ método BCU falha na deteção do ponto;
} 


\section{Capítulo 7}

\section{Discussão dos Resultados Obtidos e Novas Metodologias}

Apesar dos algoritmos robustos implementados melhorarem a deteção dos pontos de interesse, ainda existem casos onde os mesmos falham. Este capítulo trata destes casos propondo novas metodologias através de mudanças nos algoritmos.

Na primeira e na segunda seções serão discutidos problemas relacionados à deteção do "exit point" pelo método PEBS dinâmico, e será proposto um algoritmo melhorado, bem como o esboço de seu funcionamento.

$\mathrm{Na}$ terceira e quarta seções serão discutidos problemas relacionados à deteção do p.e.i. de controle pelo "shadowing method", e será esboçado o funcionamento de um algoritmo melhorado.

\subsection{Discussão dos resultados obtidos pelo algoritmo PEBS dinâmico}

Os casos-base dos três sistemas analisados não apresentaram problemas de deteção do "exit point", que seriam os casos onde o algoritmo PEBS dinâmico deveria obter respostas corretas e diferentes das do algoritmo PEBS convencional. Pode ser observado que as diferenças entre os tcr e entre as energia encontradas, pelos dois algoritmos, são pequenas e devidas tão somente ao processo de cálculo de cada método.

De fato, o incremento no processo de deteção do "exit point" propiciado pelo algoritmo PEBS dinâmico está associado somente àqueles casos onde o sistema é instável e o comportamento da função energia não é monótono dentro da área de 
atração. Esta é uma condição que nem sempre ocorre, mas que não pode ser desprezada pelos pesquisadores, pois sua desconsideração implica em resultados de estabilidade muito conservadores.

Apesar do algoritmo PEBS dinâmico ser eficiente na deteção dos "swings" que ocorrem no sistema, seu processo de cálculo do "exit point" é falho em certas circunstâncias, a saber:

- a escolha do número de passos fixo e divisão da distância angular entre o "exit point" encontrado e o p.e.e. pós-falta, por este número de passos, leva a perda de informação sobre o comportamento do campo vetorial na região de estudo, o que se torna muito importante nas proximidades de pontos de equilíbrio;

- consideração de uma região estável formada pelos pontos onde as distâncias angulares até o p.e.e. pós-falta são menores que a distância angular entre o "exit point" e o mesmo p.e.e., o que nem sempre é verdade;

Para ilustrar estas circunstâncias de falha, seja a figura 7.1, que ilustra o retrato de fase do mesmo sistema de 3 barras utilizado para mostrar o funcionamento do algoritmo PEBS dinâmico:

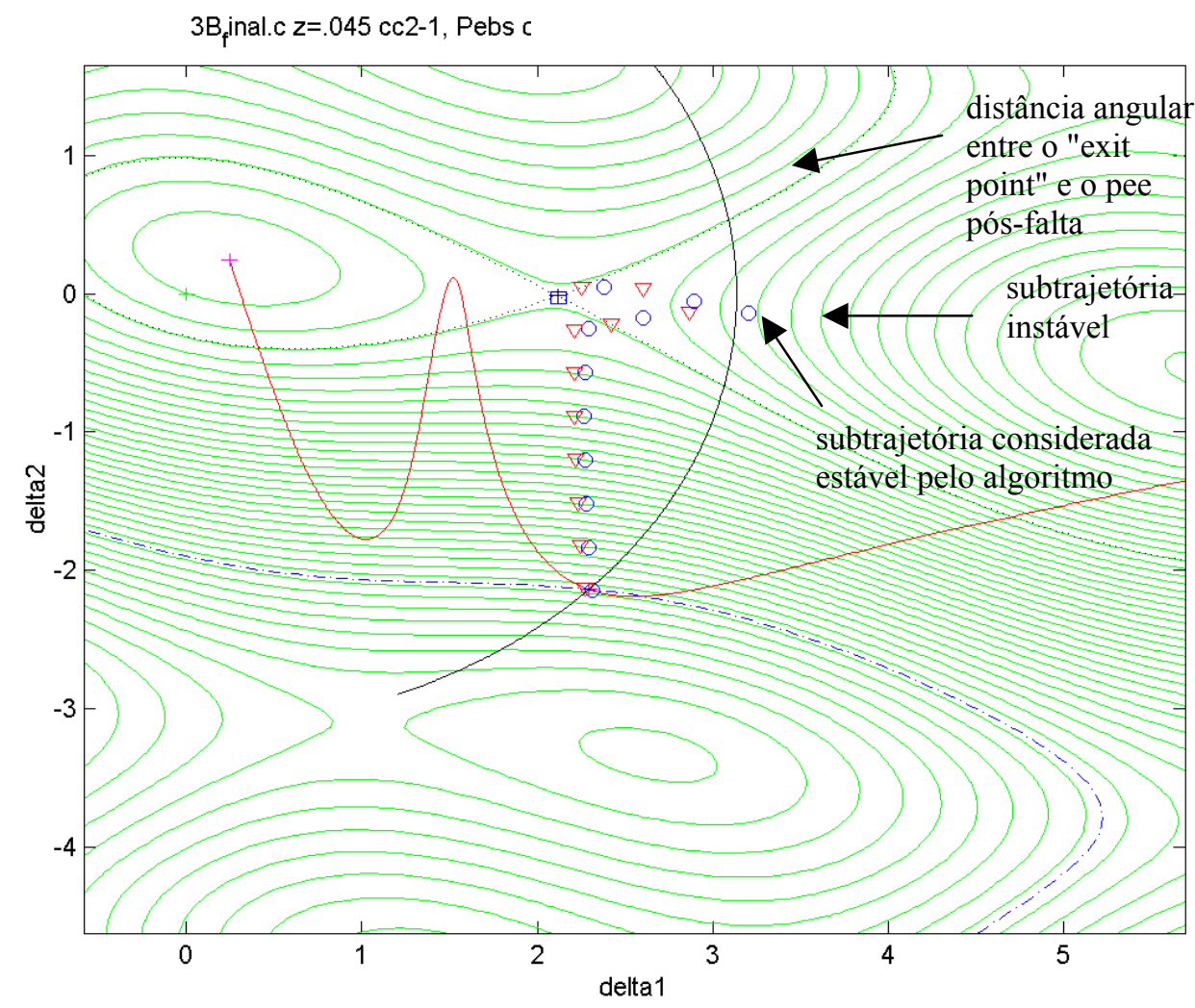

figura 7.1: Falha do algoritmo PEBS dinâmico 
Pode-se observar na figura 7.1 que o critério de comparação utilizado para deteção do "exit point" falha. Ele falha porque não considera a possível existência de um ponto de equilíbrio instável dentro da superfície que o algoritmo precisa delimitar para a deteção das sub-trajetórias.

Em outras palavras, o algoritmo compara distâncias angulares, o que é o mesmo que traçar uma circunferência com centro no p.e.e. pós-falta e raio igual a distância entre o centro e o "exit point" em estudo. Somente quando a sub-trajetória cruza esta circunferência, o algoritmo atinge as condições do critério de parada, encontrando o "exit point". No entanto, quando existe um ponto de equilíbrio dentro desta circunferência, as condições de estabilidade dentro da mesma já não são aquelas consideradas para a construção do algoritmo, levando ao caso mostrado na figura 7.1, onde existem sub-trajetórias instáveis dentro da circunferência em estudo.

\subsection{Propostas para melhoria do algoritmo PEBS dinâmico}

Um algoritmo PEBS dinâmico melhorado pode ser implementado para que os problemas acima citados não ocorram. A primeira tentativa realizada utilizava-se da análise de duas sub-trajetórias referentes a dois "exit points" sucessivos, como têm sido mostrado nas figuras desta dissertação (sub-trajetórias estável e instável), mas que não fazem parte do algoritmo PEBS dinâmico. Através da comparação da distância entre os pontos finais destas sub-trajetórias, que tenderiam a se afastar quando encontrassem o "exit point", poderia se encontrar o ponto em questão. Porém este critério recairia em problemas similares ao do algoritmo PEBS dinâmico, onde, devido a escolha de passos fixos, as condições muito variantes do campo vetorial nas proximidades de um possível ponto de equilíbrio não seriam consideradas.

A proposta mais consistente para um novo algoritmo PEBS dinâmico com passos variáveis baseia-se na utilização do somatório de uma norma (qualquer) do campo vetorial (já utilizada no algoritmo BCU) para ponderação do tamanho do passo do algoritmo, liberando o número de passos, até que o somatório das distâncias percorridas por cada passo fosse maior ou igual á distância angular calculada entre o p.e.e. pós-falta e o "exit point" candidato. O algoritmo para este método seria: 
Algoritmo do PEBS dinâmico Modificado:

1. Calcular a distância angular $\left(\delta_{d 1}\right)$ do p.e.e. pós-falta ao estado atual $\delta^{0}$. Seja $\delta=\delta^{0}$;

2. Escolha um número de passos iniciais $h_{0}$, sendo um inteiro maior que 0;

3. Defina $h_{\text {tot }}$ como sendo o total da distância angular percorrida;

4. Calcule o somatório norma do estado atual: $\sum\|f(\delta)\|$;

5. Calcule o novo tamanho do passo: $h=h_{0} \cdot \frac{\sum\|f(\delta)\|}{\sum\left\|f\left(\delta_{0}\right)\right\|}$ e some ao total percorrido $h_{\text {tot }}$;

6. Em $\delta$, encontre o vetor unitário normalizado $\bar{u}$, na direção do gradiente de energia potencial, dado por: $u=\frac{\dot{\delta}^{r}}{\sqrt{\sum_{i=1}^{n-1}\left(\dot{\delta}_{i}^{r}\right)^{2}}} ;$

7. Calcular $\delta_{\text {new }}$ dado por: $\delta_{\text {new }}=\delta+u \delta_{d 1} / h$;

8. Seja $\delta=\delta_{\text {new, }}$ e repita os passos 4, 5 e 6, calculando novos $\delta_{\text {new, }}$ até que $h_{\text {tot }} \geq \delta_{d 1}$

9. Calcule a distância $\delta_{d 2}$, no espaço- $\delta$, entre o ângulo resultante e o p.e.e. pósfalta.

10. Calcule $\mu_{P D}\left(\delta^{0}\right)=\delta_{d 1}-\delta_{d 2}$;

11. Se $\mu_{P D}\left(\delta^{0}\right)>0, \delta^{0}$ estará dentro do PEBS, caso contrário, não estará;

A figura 7.2 esboça a situação para o algoritmo descrito: 


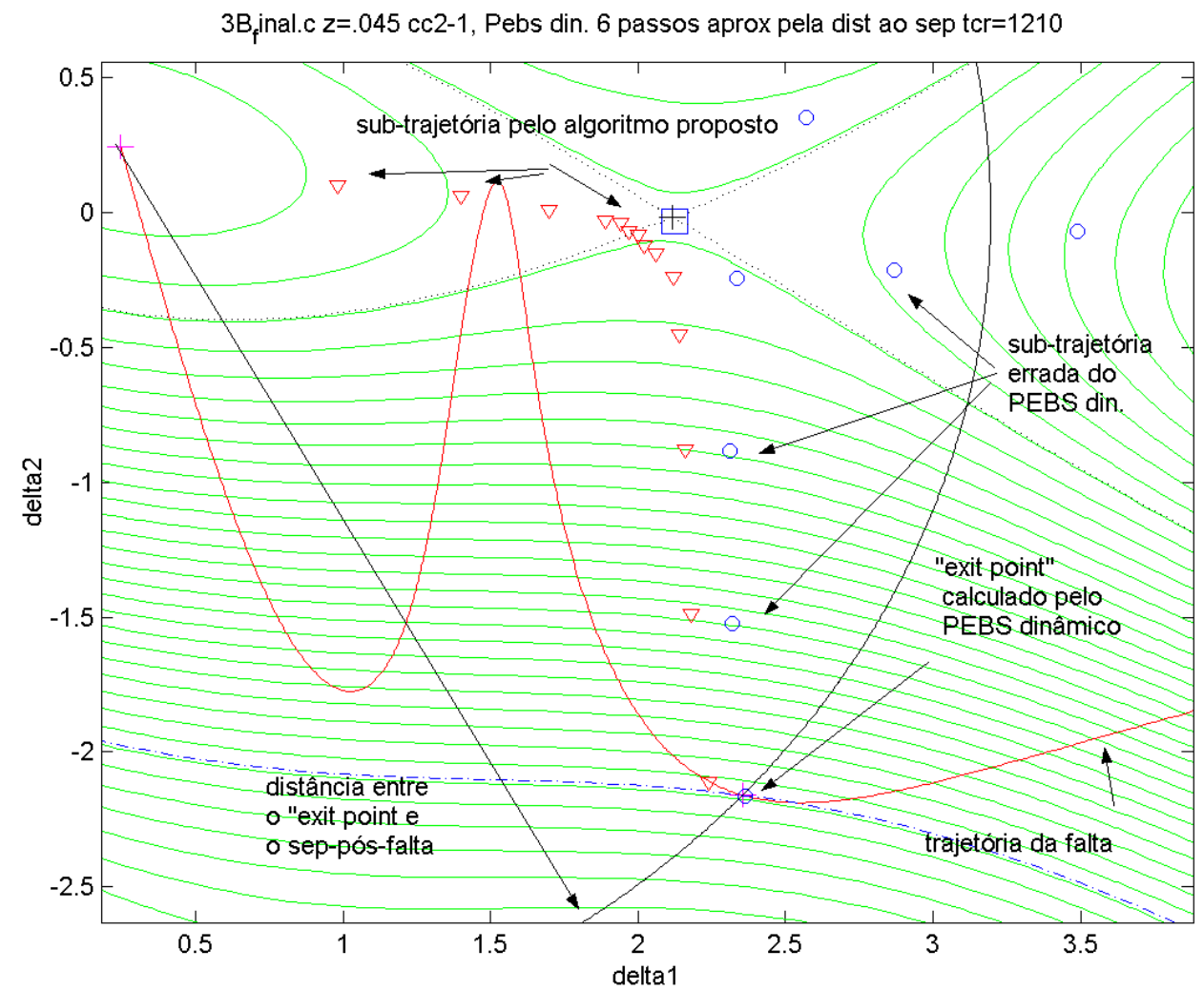

Figura 7.2: Esboço do novo Algoritmo PEBS dinâmico proposto

Uma analogia física que evidencia a principal característica deste algoritmo seria considerar que o novo algoritmo "freia" o processo em condições adversas, quando a simulação passa próximo a pontos de equilíbrio, onde o campo vetorial sofre grandes mudanças de direção e onde passos grandes demais fariam o algoritmo se perder.

\subsection{Discussão dos resultados obtidos pelo algoritmo "Shadowing Method"}

A comparação do número de falhas dos algoritmos de cálculo do p.e.i. de controle resultou na tabela 7.1, para os casos-base simulados dos sistemas com 3, 14 e 39 barras:

\begin{tabular}{|c|c|c|c|}
\hline sistema analisado & $\begin{array}{c}\mathrm{n}^{\text {o }} \text { de total de } \\
\text { curto-circuitos }\end{array}$ & $\begin{array}{c}\text { falhas do } \\
\text { Shadowing Method }\end{array}$ & $\begin{array}{c}\text { falhas do } \\
\text { BCU }\end{array}$ \\
\hline 3 barras (caso-base) & 6 & - & - \\
\hline 14 barras (caso-base) & 20 & 2 & 12 \\
\hline New England (caso-base) & 92 & 35 & 51 \\
\hline
\end{tabular}

Tabela 7.1: Comparação do número de falhas do algoritmo "shadowing method" em relação ao BCU para os casos analisados 
O caso-base do sistema de 3 barras não apresentou nenhum problema associado a aplicação do "shadowing method", bem como nenhum problema associado a aplicação do BCU. Já o caso-base do sistema de 14 barras do IEEE apresentou problemas de convergência para o "shadowing method" em dois curto-circuitos analisados (faltas na linha 1-2). O sistema New England apresentou problemas de convergência em 35 casos. Estes problemas, a princípio, estão associados ao encontro dos ângulos do ponto de máximo de energia potencial $\left(\theta_{m}{ }^{\prime} s\right)$ em cada corte realizado pelo método.

A tabela 7.1 mostra a robustez do "shadowing method" na deteção do p.e.i. de controle, solucionando todos os problemas do BCU no estudo do sistema de 14 barras e solucionando um maior número de casos que o BCU para o sistema New England.

Além dos casos de falha destacados na análise do sistema New England, o "shadowing method" têm um problema associado ao esforço computacional envolvido para simular numericamente o sistema gradiente reduzido, buscando a obtenção dos ângulos $\theta_{r}{ }^{\prime} s$ (passo genérico 1 do algoritmo). Um exemplo deste esforço está mostrado na figura 6.3 do capítulo 6, que apesar de ser um caso crítico, representa uma situação de contingência possível, onde 23 passos de 100 [ms] cada são simulados para a obtenção do p.e.i. de controle. Não obstante, foi incomum nas simulações a necessidade de mais de 10 passos de $100[\mathrm{~ms}]$ cada.

\subsection{Proposta para melhoria do algoritmo "Shadowing Method"}

O algoritmo "shadowing method" pode ser melhorado se for incorporado ao mesmo, as características do algoritmo PEBS dinâmico até agora mostradas.

As falhas do "shadowing method" são associadas a identificação do máximo de energia potencial, que gera os ângulos iniciais do processo de simulação do sistema gradiente.

Utilizando o algoritmo PEBS dinâmico, convencional ou modificado, verifica-se se os ângulos $\theta_{m}{ }^{\prime} s$, que são pontos de máximo de energia potencial sobre o corte, ou conjunto "ray", estão na fronteira da área de atração do sistema pós-falta, corrigindo o ponto sobre a reta quando necessário, fazendo com que o sistema gradiente não se afaste 
muito das vizinhanças da variedade estável do p.e.i. de controle e mantendo, portanto, o algoritmo na busca do p.e.i. correto.

A figura 7.3 abaixo esboça esta condição, para o caso da figura 6.3 do capítulo 6 :

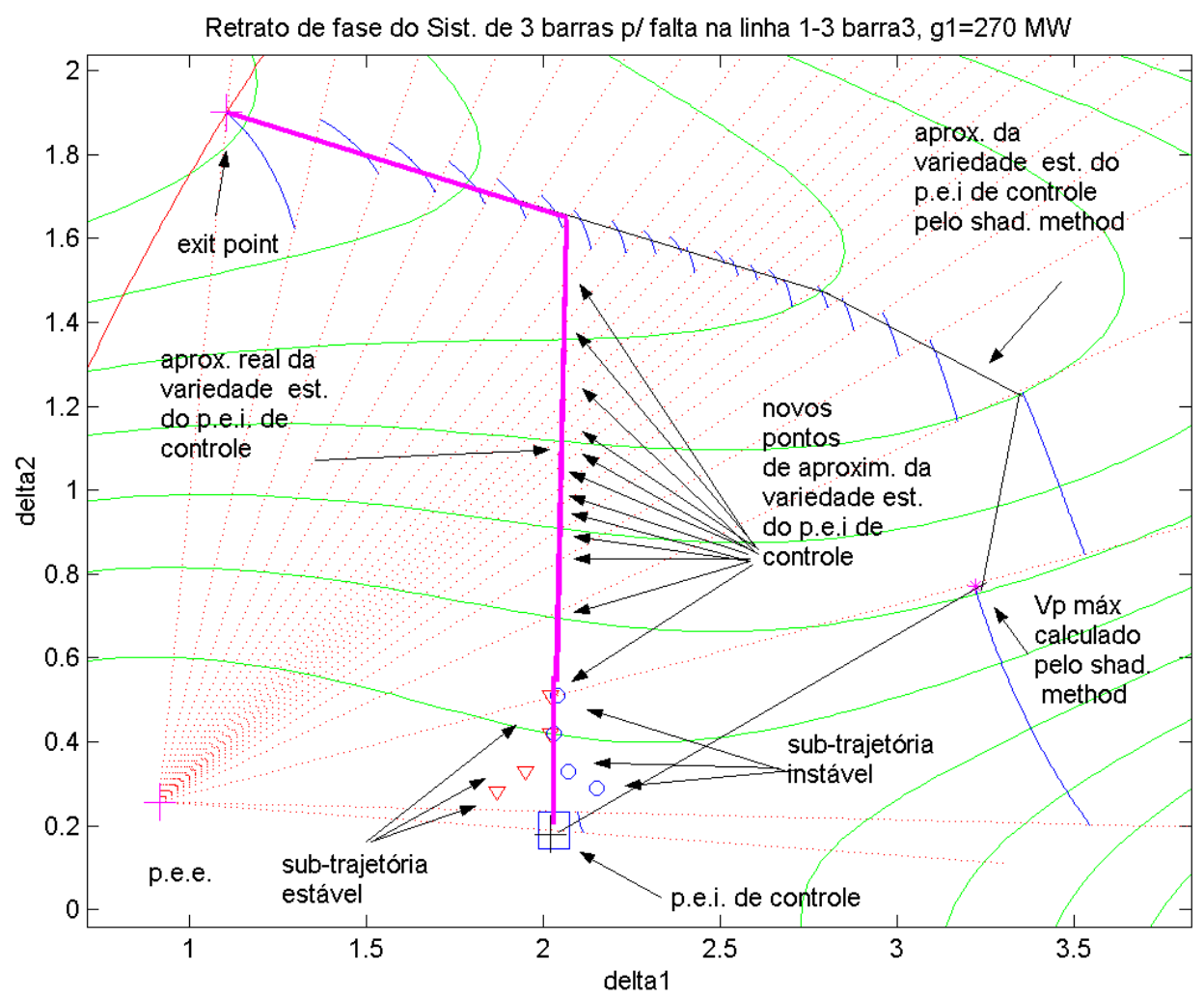

Figura 7.3: Esboço do algoritmo "Shadowing Method" modificado

Como pode ser visto na figura acima, apesar do "Shadowing Method" encontrar corretamente o p.e.i. de controle, o algoritmo não consegue ficar próximo da variedade estável do p.e.i. de controle $\left(W^{s}\left(\theta^{u}\right)\right)$ e isto leva o sistema a casos de falha. Utilizando o algoritmo PEBS dinâmico sobre a reta do conjunto "ray", consegue-se encontrar o ponto correto nas proximidades de tal variedade, evitando possíveis casos de falha. 


\section{Capítulo 8}

\section{CONCLUSÕES}

Através do forte embasamento teórico dos métodos diretos e da caracterização precisa da área de atração, dois métodos diretos foram propostos na literatura, o PEBS (Kakimoto et al.(1978)) e o BCU (Chiang et al.(1994)), para predição da estabilidade em sistemas de potência.

Como os métodos utilizam a aproximação local da fronteira de estabilidade, sua aplicação fica restrita ao estudo do primeiro "swing".

Apesar dos métodos diretos citados obterem a predição correta da estabilidade, em muitos casos estudados os mesmos falham. Estes casos de falha estão associados a prerrogativas utilizadas para construção e embasamento dos métodos, prerrogativas estas, que os métodos não verificam se são satisfeitas. Como exemplos têm-se os casos da suposição de cruzamento ortogonal da trajetória de falta com o PEBS, e da satisfação da condição de transversalidade para uso do algoritmo BCU.

Para dar robustez aos métodos diretos citados, pesquisadores sugerem na literatura metodologias derivadas das primeiras, que tentam utilizar características existentes, ou a própria definição associada aos métodos. Dentro deste contexto se encaixam os algoritmos PEBS dinâmico e "Shadowing Method". Como exemplo deste uso, temos o método PEBS dinâmico que tenta utilizar a própria definição do que é o PEBS para obter o "exit point" correto. Outro exemplo é o do "shadowing method" na utilização da forma da superfície equipotencial nas proximidades da variedade estável do p.e.i de controle. A robustez propiciada por estes métodos foi testada para casos extremos no sistema de teste de 3 barras, para o caso base no sistema de 14 barras do IEEE e para o caso-base do sistema New England de 39 barras, conforme resultados do capítulo seis. 
Conclui-se, com base nos resultados obtidos, que os métodos robustos estudados realmente melhoram a deteção dos pontos de equilíbrio do sistema, porém representam metodologias computacionalmente mais apuradas e por isso mais lentas.

Apesar do processo de deteção ser mais robusto, ainda existem casos de falha dos algoritmos PEBS dinâmico e "Shadowing Method".

Os casos de falha do algoritmo PEBS dinâmico estão associados ao problema de se utilizar passos fixos baseados em direções apontadas pelo gradiente, em regiões onde as condições do campo vetorial variam muito, como por exemplo, nas proximidades de pontos de equilíbrios.

Para estes casos foi proposta uma nova metodologia que considera as condições do campo vetorial, através de uma norma qualquer, fazendo com que o algoritmo avance com passos curtos em tais regiões, evitando problemas de deteção errônea do "exit points" fora da área de atração.

Os casos de falha do algoritmo "shadowing method" estão, a priori, associados a deteção do máximo de energia potencial sobre os cortes realizados pelo método. Para estes casos foi proposta uma nova metodologia que utiliza as características dinâmicas estudadas para o algoritmo PEBS dinâmico. A metodologia proposta verifica se o ponto de máximo sobre o corte está entre duas sub-trajetórias com comportamentos de estabilidade diferentes (sub-trajetórias estável e instável), fazendo com que o ponto encontrado não se afaste da variedade estável do ponto de equilíbrio instável de controle, como é objetivo do "shadowing method".

Ambas metodologias propostas bem como as metodologias analisadas estão entre uma vasta gama de idéias novas e promissoras para algoritmos aplicados a análise da estabilidade transitória através de métodos diretos. Maiores análises devem ser realizadas como intuito de diminuir os casos de falha de deteção dos pontos de interesse para os métodos estudados e também para os propostos, caso aconteçam. 


\section{Bibliografia}

ALBERTO, L.F.C. (1997). Análise de Estabilidade Transitória: Estudos do Método BCU; Proposta de Estimativa de Amortecimento para Estabilidade Absoluta em OMIBS, Dissertação de mestrado, Escola de Engenharia de São Carlos - USP.

ALBERTO, L.F.C. (2000). O Princípio de Invariância de LaSalle Estendido Aplicado ao Estudo de Coerência de Geradores e à Análise de Estabilidade Transitória MultiSwing, Tese de Doutorado, Escola de Engenharia de São Carlos - USP.

ALBERTO, L.F.C. e BRETAS, N.G. (1999). Synchronism versus Stability in Power Systems, Int. Journal of Electrical Power \& Energy Systems, v. 21/4, pp. 261-267, Maio.

ALBERTO, L.F.C. e BRETAS, N.G. (2000a). Required Damping to Assure MultiSwing Transient Stability: The SMIB Case, Int. Journal of Electrical Power \& Energy Systems, vol.22, pp. 179-185, Mar.

ALBERTO, L.F.C. e BRETAS, N.G. (2000b). Application of Melnikov's Method for Computing Heteroclinic Orbits in a Classical SMIB Power System Model, IEEE Trans. on Circuits and Systems I : Fundamental Theory and Applications, v.47, n.7, Jul .

ALBERTO, L.F.C. e BRETAS, N.G. (2001)., Estudo da Condição de Transversalidade em Sistemas de uma Máquina versus Barramento Infinito, Revista Controle $e$ Automação, v.12, n.1, Jan, Fev, Mar e Abr .

ANDERSON, P. M. e FOUAD, A. A. (1977). Power system control and stability, IEEE Press, New York. 
ATHAY, T.; PODMORE, R. e VIRMANI, S. (1979). A pratical method for direct analysis of transient stability, IEEE Trans on PAS, vol. PAS-98, pp. 573-584.

AYLETT, P.D. (1958). The energy-integral criterion of transient stability limits of power systems, Proc. IEE vol. 105c: 527-536.

BRAUER, F. e NOHEL, J.A. (1969). The Qualitative Theory of Ordinary Differential Equations, W.A.BENJAMIN INC., New York, Amsterdam.

BREtAS, N.G. e ALBERTO, L.F.C. (1997). Some Considerations About Power System Modeling Cocerning Transient Stability Analysis, IMACS/IFAC Symposium (2nd), Mathematic Modelling, MATHMOD '2, Technical University of Vienna, Fevereiro.

BRETAS, N.G. e ALBERTO, L.F.C. (2000). Estabilidade Transitória em Sistemas Eletroenergéticos, publicação da Escola de Eng. de São Carlos, Projeto REENGE.

BRETAS, N.G. e PHADKE, A.G. (1998). Real Time Instability Prediction Through Adaptive Time Series Coefficient, Proceedings of IEEE Winter Power Meeting.

CHIANG, H-D. e THORP, J.S. (1989). The Closest Unstable Equilibrium Point Method for Power System Dynamic Security Assessment, IEEE Trans on Circuits and Systems, Vol 36, nํำ, Setembro.

CHIANG, H-D.; WU, F.F. e VARAYA, P.P. (1987). Foundations of Direct Methods for Power System Transient Stability Analysis, IEEE Trans. on Circuits and Systems, CAS$34, \mathrm{n}^{\mathrm{o}} 2$, Fevereiro.

CHIANG, H-D.; WU, F.F. e VARAYA, P.P. (1988). Foundations of the Potential Energy Boundary Surface Method for Power System Transient Stability Analysis, IEEE Trans on Circuits and Systems, Vol 35, nํ6, Junho. 
CHIANG, H-D.; WU, F.F. e VARAYA, P.P. (1994). A BCU Method for Direct Analysis of Power System Transient Stability, IEEE Trans on Circuits and Systems, Vol 9, nº3, Agosto.

DA SILVA, F.H.J.R. (2001). Funçoes de Lyapunov para a Análise de Estabilidade Transitória em Sistemas de Potência. Dissertação de mestrado, Escola de Engenharia de São Carlos - USP.

El-ABIAD, A.H. e NAGAPPAN, K. (1966). Transient stability regions for multimachine power system stability, IEEE Trans. on PAS, vol. PAS-85, pp169-179, Feb.

GLESS, G.E. (1966). Direct Method of Lyapunov applied to transient power system stability, IEEE Trans. on PAS, vol. PAS-85, pp159-168, Feb.

GUCKENHEIMER, J.G. e HOLMES, P. (1985). Nonlinear Oscilations, Dynamical Systems, and Bifurcations of Vector Fields, Applied Mathematical Sciences, Vol. 42, Springer-Verlag.

HALE, J.K. e KOÇAK, H. (1991). Dynamics and Bifurcations, Springer-Verlag.

KAKIMOTO, N.; OHSAWA Y. e HAYASHI, M. (1978). Transient stability analysis of electric-power system via Lure-type Lyapunov function, Part I and II, Trans. IEE Japan, vol. 98, pp. 62-71, 72-79.

KHALIL, H. K. (1996). Nonlinear Systems, Prentice Hall, New Jersey.

KUNDUR P. (1994). Power system stability and control, EPRI: McGraw-Hill, New York.

LIMA, E.L. (1977). Espaços Métricos, Instituto de Matemática Pura e Aplicada CNPq, Rio de Janeiro. 
LLAMAS, A.; DE LA REE LOPEZ, J.; MILI, L.; PHADKE, A.G. e THORP, J.S. (1995). Clarifications of the BCU Method for Transient Stability Analysis, IEEE Trans. on Power Systems, Vol.10, $\mathrm{n}^{\mathrm{o}} 1$, Fevereiro.

MANUAL CEPEL do Usuário V05-04/94, Programa de Análise de Redes ANAREDE (1994). Rio de Janeiro;

MONTICELLI, A. J. (1983). Fluxo de carga em redes de energia elétrica, Editora Edgard Blucher Ltda., São Paulo.

NOBLE, B. e DANIEL, J.W. (1977). Álgebra Linear Aplicada, 2a edição, PHB, Rio de Janeiro.

OLIVEIRA, R.V. (2003). Análise da Coordenação entre Estabilizadores Clássicos e Robustos em Sistemas Elétricos de Potência. Dissertação de mestrado, Escola de Engenharia de São Carlos - USP.

PADIYAR, K.R. (1995). Power System Dynamics: Stability and Control, Interline Publishing Pvt Ltd, Bangalore, Índia.

PAI, M.A. (1981). Power System Stability: Analysis by the Direct Method of Lyapunov, North-Holland Publishing Company, Amsterdam, New York, Oxford.

RAMOS, R.A.; ALBERTO,L.F.C.; BRETAS,N.G. (2000). Modelagem de Máquinas Síncronas Aplicada ao Estudo de estabilidade de Sistemas Elétricos de Potência. Apostila, , Escola de Engenharia de São Carlos - USP.

RODRIGUES, H.M. (1996). Abstract Methods for Synchronization and Applications, Applicable Analysis, An. International Journal, vol. 62 pp 263-296.

RODRIGUES, H.M.; ALBERTO L.F.C. e BRETAS, N.G. (2000). On the Invariance Principle. Generalizations and Applications to Synchronism, IEEE Trans. on Circuits and Systems I : Fundamental Theory and Applications, vol. 47, n.5, Maio. 
RODRIGUES, H.M.; ALBERTO, L.F.C. e BRETAS N.G. (2001). Uniform Invariance Principle and Synchronization. Robustness with Respect to Parameter Variation, Journal of Differential Equations, Jan.

RUDIN, W. (1964). Principles of Mathematical Analysis, Mc-Graw Hill Book Company, Kögakusha Company Ltd, International Student Edition.

SCRUGGS, J.T. e MILI L. (2001). Dynamic Gradient Method for PEBS Detection in Power System Transient Stability Assessment, Int. Journal of Electrical power \& Energy Systems, vol 23, pp. 155-165.

TREINEN, R.T.; VITTAL, V. e KLIENMAN, W. (1996). An improved technique to determine the controlling unstable equilibrium point in a power system, IEEE Trans. On Circuits and Systems I, vol.43 nº, pp 313-323.

TSOLAS, N.A.; ARAPOSTATHIS, A. e VARAYA, P.P. (1985). A Structure Preserving Energy Function for Power System Transient Stability Analysis, IEEE Trans. on Circuits and Systems, CAS-32, nํ10, Outubro.

VARAYA, P.P.; WU, F.F. e CHEN, R-L. (1985). Direct methods for transient stability analysis of power systems: Recent results, Procedings of the IEEE, December 1985, pp. 1703-1715.

VIDYASAGAR, M. (1993). Nonlinear Systems Analysis, Prentice Hall, New Jersey. 


\section{Apêndice A}

Muitas equações diferenciais não possuem solução analítica, mas no entanto, os movimentos descritos por elas existem. Pode-se descrever estes movimentos através de simulações numéricas. Neste apêndice serão citados dois métodos numéricos para de solução de equações diferenciais: Euler Simples e Runge-Kutta.

\section{a.1 Método de Integração Numérica de Euler Simples}

Conforme descrito em Bretas e Alberto (1999), seja o problema de valor inicial:

$$
\frac{d x}{d t}=f(t, x) \quad x\left(t_{0}\right)=x_{0}
$$

Seja $x(t)$ a solução da equação diferencial. Como não se conhece a expressão de $x$ para todo $t$, escreve-se a expansão da série de Taylor de $x(t)$ em torno da condição inicial $x\left(t_{0}\right)=x_{0}$ :

$$
x\left(t_{1}\right)=x_{0}+\left.\frac{d x(t)}{d t}\right|_{t=t_{0}} \cdot\left(t_{1}-t_{0}\right)+\left.\frac{1}{2 !} \cdot \frac{d^{2} x(t)}{d t^{2}}\right|_{t=t_{0}} \cdot\left(t_{1}-t_{0}\right)^{2}+\ldots
$$

Truncando a série no termo de $1^{\mathrm{a}}$ ordem tem-se:

$$
x\left(t_{1}\right)=x_{0}+\left.\frac{d x(t)}{d t}\right|_{t=t_{0}} \cdot\left(t_{1}-t_{0}\right)+\mathfrak{R}\left(\Delta t^{2}\right)
$$

onde: $\lim _{\Delta t \rightarrow 0} \mathfrak{R}\left(\Delta t^{2}\right)=0$

O valor de $\frac{d x}{d t}$ é conhecido da própria equação diferencial, logo para um $\Delta t$ pequeno, o erro de truncamento $\Re$ poderá ser desprezado, podendo-se encontrar a solução num tempo $t_{1}$ próximo de $t_{0}$, através da equação: 


$$
x\left(t_{1}\right) \cong x\left(t_{0}\right)+f\left(t_{0}, x_{0}\right) \cdot\left(t_{1}-t_{0}\right)
$$

a solução completa da equação diferencial pelo método de Euler Simples pode ser encontrada por um processo iterativo onde:

$$
x\left(t_{n+1}\right) \cong x\left(t_{n}\right)+f\left(t_{n}, x_{n}\right) \cdot \Delta t
$$

\section{a.2 Método de Integração Numérica de Runge-Kutta}

Os métodos Runge-Kutta podem ser desenvolvidos para qualquer ordem, ou seja, para qualquer número de termos na expansão em série de Taylor. Dentre os de maior aplicação estão os métodos Runge-Kutta de $2^{\mathrm{a}} \mathrm{e} 4^{\mathrm{a}}$ ordens. O problema da utilização de ordens superiores é o fato de não se conseguir soluções explícitas das mesmas. No método Runge-Kutta este cálculo é substituído pelo cálculo de $f(x)$ em pontos convenientes que produzem o mesmo resultado que a solução explícita.

Conforme descrito em Bretas e Alberto (1999), seja a expansão em série de Taylor da equação diferencial truncada no termo de $2^{\mathrm{a}}$ ordem:

$$
x\left(t_{1}\right)=x_{0}+\left.\frac{d x(t)}{d t}\right|_{t=t_{0}} \cdot\left(t_{1}-t_{0}\right)+\left.\frac{1}{2 !} \cdot \frac{d^{2} x(t)}{d t^{2}}\right|_{t=t_{0}} \cdot\left(t_{1}-t_{0}\right)^{2}
$$

Como $\frac{d x}{d t}=f(t, x)$, obtém-se a equação (a.7):

$$
x\left(t_{1}\right)=x_{0}+f\left(t_{0}, x_{0}\right) \cdot \Delta t+\frac{1}{2 !} \cdot f^{\prime}\left(t_{0}, x_{0}\right) \cdot \Delta t^{2}
$$

onde: $\Delta t=\left(t_{1}-t_{0}\right)$.

Em vez de utilizar a expressão (a.7), utilizar-se-á fórmula:

$$
x\left(t_{1}\right)=x_{0}+\Delta t \cdot\left(a \cdot K_{1}+b \cdot K_{2}\right)
$$

onde: $a$ e $b$ são constantes a serem determinadas, e $K_{1}$ e $K_{2}$ são valores da função $f$ calculados em pontos convenientes. Para determinar os valores de $a, b, K_{1}$ e $K_{2}$ faz-se:

$$
\left(a \cdot K_{1}+b \cdot K_{2}\right)=f\left(t_{0}, x_{0}\right)+\frac{1}{2 !} \cdot f^{\prime}\left(t_{0}, x_{0}\right) \cdot \Delta t
$$

onde, $K_{1}$ e $K_{2}$ :

$$
\begin{aligned}
& K_{1}=f\left(t_{0}, x_{0}\right) \\
& K_{2}=f\left[t_{0}+p \cdot \Delta t, x_{0}+q \cdot \Delta t \cdot f\left(t_{0}, x_{0}\right)\right]
\end{aligned}
$$


Para resolver o problema é necessário encontrar $a, b, p$ e $q$, que satisfaçam a igualdade acima. Esta resolução pode ser encontrada em Bretas e Alberto (1999), e leva ao seguinte resultado:

$$
a=\frac{1}{2}, b \cdot p=\frac{1}{2} \text { e } b \cdot q=\frac{1}{2}
$$

Usualmente escolhe-se $b=\frac{1}{2}$, ficando:

$$
a=\frac{1}{2}, b=\frac{1}{2}, p=1 \text { e } q=1
$$

Logo, o método de Runge-Kutta de $2^{\mathrm{a}}$ ordem fica definido como sendo:

$$
\begin{aligned}
& x\left(t_{n+1}\right)=x\left(t_{n}\right)+\frac{\Delta t}{2} \cdot\left(K_{1}+K_{2}\right) \\
& K_{1}=f\left(t_{n}, x_{n}\right) \\
& K_{2}=f\left[t_{n}+\Delta t, x_{n}+q \cdot \Delta t \cdot K_{1}\right]
\end{aligned}
$$

O mesmo procedimento é utilizado para determinar os métodos de Runge-Kutta de ordens superiores a 2 . O método de $4^{\mathrm{a}}$ ordem pe definido assim:

$$
\begin{aligned}
& x\left(t_{n+1}\right)=x\left(t_{n}\right)+\frac{\Delta t}{6} \cdot\left(K_{1}+2 \cdot K_{2}+2 \cdot K_{3}+K_{4}\right) \\
& K_{1}=f\left(t_{n}, x_{n}\right) \\
& K_{2}=f\left(t_{n}+\frac{1}{2} \cdot \Delta t, x_{n}+\frac{1}{2} \cdot \Delta t \cdot K_{1}\right) \\
& K_{3}=f\left(t_{n}+\frac{1}{2} \cdot \Delta t, x_{n}+\frac{1}{2} \cdot \Delta t \cdot K_{2}\right) \\
& K_{4}=f\left(t_{n}+\Delta t, x_{n}+\Delta t \cdot K_{3}\right)
\end{aligned}
$$




\section{Apêndice B}

\section{b.1 Eliminação de Gauss}

A eliminação de Gauss-Jordan está associada a resolução de sistemas algébricos lineares de grandes dimensões. Estes sistemas são representados de uma forma geral por:

$$
A \cdot \underline{x}=\underline{b}
$$

onde:

- $A$ é a matriz dos coeficientes (n x n);

- $\quad x$ é o vetor dependente ( $\mathrm{n} \times 1)$;

- $\quad \underline{b}$ é o vetor independente ( $\mathrm{n} \times 1)$;

Uma maneira de resolver o sistema (b.1) seria pela obtenção da matriz $A^{-1}$ explicitamente. Porém, além de ser computacionalmente ineficiente, seria proibitivo para matrizes $A$ com grandes dimensões.

Uma outra maneira, que é computacionalmente eficiente, uma vez que não calcula explicitamente a inversa da matriz $A$, é o método da eliminação de Gauss.

Monticelli (1985) descreve o método de eliminação assim:

Seja o sistema algébrico linear (b.1), reescrito da seguinte forma:

$$
\left[\begin{array}{ccccc}
a_{1,1} & a_{1,2} & a_{1,3} & \cdots & a_{1, n} \\
a_{2,1} & a_{2,2} & a_{2,3} & \cdots & a_{2, n} \\
\cdots & \cdots & \cdots & \cdots & \cdots \\
a_{n, 1} & a_{n, 2} & a_{n, 3} & \cdots & a_{n, n}
\end{array}\right] \cdot\left[\begin{array}{c}
x_{1} \\
x_{2} \\
\cdots \\
x_{n}
\end{array}\right]=\left[\begin{array}{c}
b_{1} \\
b_{2} \\
\cdots \\
b_{n}
\end{array}\right]
$$

Aplicando-se o método de eliminação de Gauss em 3 etapas, onde:

- $1^{\text {a }}$ etapa: são zerados os elementos do triângulo inferior da matriz dos coeficientes pelas combinações lineares efetuadas com as equações que constituem o sistema (b.2); 
- $2^{\mathrm{a}}$ etapa: os elementos da diagonal principal são feitos iguais a 1 , dividindo-se cada equação pelo elemento correspondente a diagonal principal da matriz de coeficientes resultante do passo precedente;

- $3^{\text {a }}$ etapa: são zerados os elementos do triângulo superior (pelas combinações lineares), o que acaba por transformar a matriz dos coeficientes numa matriz identidade.

Os sistemas resultantes de cada uma das 3 etapas descritas anteriormente são dados por (b.3), (b.4) e (b.5), respectivamente.

$$
\begin{aligned}
& {\left[\begin{array}{ccccc}
a_{1,1}^{\prime} & a_{1,2}^{\prime} & a_{1,3}^{\prime} & \cdots & a_{1, n}^{\prime} \\
0 & a_{2,2}^{\prime} & a_{2,3}^{\prime} & \cdots & a_{2, n}^{\prime} \\
\cdots & \cdots & \cdots & \cdots & \cdots \\
0 & 0 & 0 & \cdots & a_{n, n}^{\prime}
\end{array}\right] \cdot\left[\begin{array}{c}
x_{1} \\
x_{2} \\
\cdots \\
x_{n}
\end{array}\right]=\left[\begin{array}{c}
b_{1}^{\prime} \\
b_{2}^{\prime} \\
\cdots \\
b_{n}^{\prime}
\end{array}\right]} \\
& {\left[\begin{array}{ccccc}
1 & a_{1,2}^{\prime \prime} & a^{\prime \prime}{ }_{1,3} & \cdots & a^{\prime \prime}{ }_{1, n} \\
0 & 1 & a_{2,3}^{\prime \prime} & \cdots & a_{2, n}^{\prime \prime} \\
\cdots & \cdots & \cdots & \cdots & \cdots \\
0 & 0 & 0 & \cdots & 1
\end{array}\right] \cdot\left[\begin{array}{c}
x_{1} \\
x_{2} \\
\cdots \\
x_{n}
\end{array}\right]=\left[\begin{array}{c}
b^{\prime \prime} \\
b_{2}^{\prime \prime} \\
\cdots \\
b^{\prime \prime}{ }_{n}
\end{array}\right]} \\
& {\left[\begin{array}{ccccc}
1 & 0 & 0 & \cdots & 0 \\
0 & 1 & 0 & \cdots & 0 \\
\cdots & \cdots & \cdots & \cdots & \cdots \\
0 & 0 & 0 & \cdots & 1
\end{array}\right] \cdot\left[\begin{array}{c}
x_{1} \\
x_{2} \\
\cdots \\
x_{n}
\end{array}\right]=\left[\begin{array}{c}
b^{\prime \prime \prime} \\
b^{\prime \prime \prime} \\
\cdots \\
b^{\prime \prime \prime}
\end{array}\right]}
\end{aligned}
$$

Note-se que as mesmas operações efetuadas com as linhas da matriz dos coeficientes são simultaneamente realizadas com o vetor independente.

Existem dois esquemas básicos de se aplicar o método da eliminação de Gauss para zerar os triângulos inferior e superior da matriz dos coeficientes, conforme pode ser visto na figura b.1: 

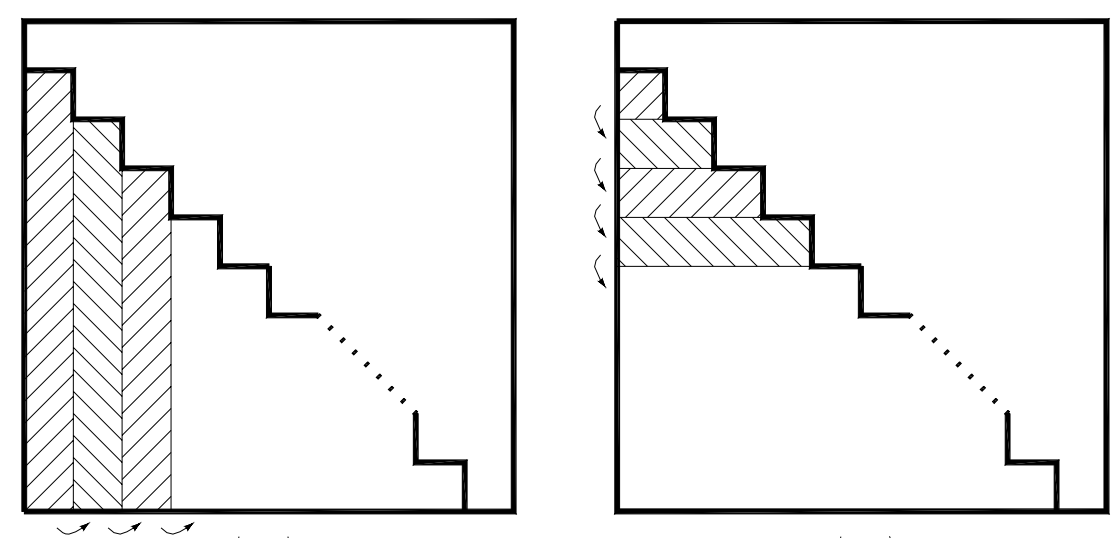

Figura b.1 - esquemas de eliminação por colunas $(a)$ e por linhas $(b)$

Para zerar o triângulo inferior pelo esquema $a$, as colunas são operadas uma por vez, da esquerda para a direita, sendo os elementos de cada coluna zerados de cima para baixo. No esquema $b$, as linhas são operadas uma por vez, de cima para baixo, sendo os elementos de cada linha zerados da esquerda para a direita. Para se zerar o triângulo superior, no esquema $a$, as colunas são percorridas da esquerda para a direita e no esquema $b$, as linhas são percorridas de baixo para cima. Estes procedimentos garantem que os zeros obtidos nos passos iniciais não serão destruídos nos passos subseqüentes do processo de eliminação.

O programa computacional foi implementado utilizando o esquema (b), ou seja, a eliminação por linhas. 


\section{Apêndice C}

\section{c.1 Carga de Arquivo com Dados do Sistema de 14 Barras do IEEE}

O dado abaixo listado contém as informações do caso base já convergido, ou seja, fluxo de carga não linear já obtido, para o sistema de 14 barras do IEEE, que está representado na figura 6.4. Os dados de barra (DBAR) e linha (DLIN) estão no formato do programa de análise de redes do CEPEL, o ANAREDE e podem ser encontrados em Manual Cepel (1994). Os dados de estabilidade (DEST) estão descritos em um formato parecido com os dados de barra e linha, só que não estão associados ao formato do mesmo programa. Portanto, os dados de estabilidade estão assim definidos:

- colunas 1 a 4: número da barra à qual o gerador está conectado;

- colunas 11 a 22: Nome associado ao gerador;

- colunas 23 a 27: $x_{d}^{\prime}$;

- colunas 28 a 31: Momento de inércia $M$;

Seja o formato de carga de arquivo:

\begin{tabular}{|c|c|c|c|}
\hline \multicolumn{4}{|l|}{ TITU } \\
\hline \multicolumn{4}{|c|}{ SISTEMA DE 14 BARRAS DO LIVRO DE ESTABILIDADE 14b4 } \\
\hline \multicolumn{4}{|l|}{ DBAR } \\
\hline 12 slack & 1060 & $32.5-22.7 \quad-99989998$. & \\
\hline $21 \mathrm{~g} 2$ & $1045-4.9$ & 40. $5.161-99989998$. & 21.712. \\
\hline $31 \mathrm{~g} 3$ & $1010-13$. & 0. $18.54-99989998$. & 94.219. \\
\hline $61 \mathrm{gc} 4$ & $1070-15$. & 0. $49.33-99989998$. & 11.27 .5 \\
\hline $81 \mathrm{gc} 5$ & $1090-13$. & 0. $27.75-99989998$. & \\
\hline $4 \quad$ carga 4 & $1031-10$ & $47.8-3.9$ & \\
\hline $5 \quad$ carga 5 & $1036-8.9$ & 7.61 .6 & \\
\hline 7 barra7 & $1045-13$. & & \\
\hline barra9 & $1050-15$. & 29.516 .6 & \\
\hline barra10 & $1046-15$ & 5.8 & \\
\hline
\end{tabular}




\begin{tabular}{|c|c|c|c|}
\hline 11 & barra11 $1054-15$. & $\begin{array}{ll}3.5 & 1\end{array}$ & 1.8 \\
\hline 12 & $1055-16$ & 6.11 & 1.6 \\
\hline 13 & $1049-16$ & 13.55 & 5.8 \\
\hline 14 & $1032-16$ & 14.9 & 5. \\
\hline \multicolumn{4}{|l|}{9999} \\
\hline \multicolumn{4}{|c|}{ DLIN } \\
\hline 1 & \multicolumn{3}{|l|}{$\begin{array}{llll}21 & 1.938 & 5.917 & 5.28\end{array}$} \\
\hline 1 & \multicolumn{3}{|l|}{$\begin{array}{lllll}51 & 5.40322 .304 & 4.92\end{array}$} \\
\hline 2 & \multicolumn{3}{|l|}{ 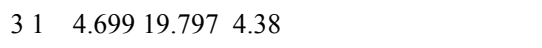 } \\
\hline 2 & \multicolumn{3}{|l|}{$\begin{array}{llll}41 & 5.811 & 17.632 & 3.74\end{array}$} \\
\hline 2 & \multicolumn{3}{|l|}{$\begin{array}{llll}51 & 5.695 & 17.388 & 3.4\end{array}$} \\
\hline 3 & \multicolumn{3}{|l|}{$\begin{array}{llll}41 & 6.701 & 17.103 & 3.46\end{array}$} \\
\hline 4 & \multicolumn{3}{|l|}{$\begin{array}{lllll}51 & 1.335 & 4.211 & 1.28\end{array}$} \\
\hline 4 & \multicolumn{3}{|l|}{$71 \quad 20.912$} \\
\hline 4 & \multicolumn{3}{|l|}{$91 \quad 55.618$} \\
\hline 5 & \multicolumn{3}{|l|}{$61 \quad 25.202$} \\
\hline 6 & \multicolumn{3}{|l|}{$\begin{array}{lll}111 & 9.498 & 19.89\end{array}$} \\
\hline 6 & \multicolumn{3}{|l|}{$121 \quad 12.29125 .581$} \\
\hline 6 & \multicolumn{3}{|l|}{$131 \quad 6.61513 .027$} \\
\hline 7 & \multicolumn{3}{|l|}{$81 \quad 17.615$} \\
\hline 7 & \multicolumn{3}{|l|}{$91 \quad 11.001$} \\
\hline 9 & \multicolumn{3}{|l|}{$\begin{array}{lll}101 & 3.181 \quad 8.45\end{array}$} \\
\hline 9 & \multicolumn{3}{|l|}{$141 \quad 12.71127 .038$} \\
\hline 10 & \multicolumn{3}{|l|}{$111 \quad 8.20519 .207$} \\
\hline 12 & \multicolumn{3}{|l|}{13122.09219 .988} \\
\hline 13 & \multicolumn{3}{|l|}{$141 \quad 17.09334 .802$} \\
\hline \multicolumn{4}{|l|}{9999} \\
\hline \multicolumn{4}{|c|}{ DEST } \\
\hline 0001 & \multicolumn{3}{|l|}{ GERADOR1 0.1000 .079} \\
\hline 0002 & \multicolumn{3}{|l|}{ GERADOR2 1.2500 .053} \\
\hline 0003 & \multicolumn{3}{|l|}{ GERADOR3 0.7500 .026} \\
\hline 0006 & \multicolumn{3}{|l|}{ GERADOR6 1.5000 .014} \\
\hline 0008 & \multicolumn{3}{|l|}{ GERADOR8 1.2000 .067} \\
\hline \multicolumn{4}{|l|}{9999} \\
\hline FIM & & & \\
\hline
\end{tabular}




\section{c.2 Carga de Arquivo com Dados do Sistema de 39 Barras - New England}

Os dados abaixo listados, no mesmo formato dado acima, contém as informações do caso base já convergido, ou seja, fluxo de carga não linear já obtido, para o sistema New England, que está representado na figura 6.8.

\begin{tabular}{|c|c|c|c|}
\hline \multicolumn{4}{|c|}{ TITU } \\
\hline \multicolumn{4}{|c|}{ **** Sistema de 39 barras e 10 geradores - New England - Convergido $* * * *$} \\
\hline \multicolumn{4}{|c|}{ DBAR } \\
\hline 1 & 0 Barra01 & $1036-9.3000 .000$ & 0.00 .0 \\
\hline 2 & 0 Barra01 & $1019-6.4000 .000$. & 0.00 .0 \\
\hline 3 & 0 Barra03 & $0991-9.4000 .000$. & $322.0 \quad 2.0$ \\
\hline 4 & 0 Barra04 & $0955-10.000 .000$. & 500.0184 .0 \\
\hline 5 & 0 Barra05 & $0954-9.1000 .000$. & 0.00 .0 \\
\hline 6 & 0 Barra06 & $0955-8.3000 .000$ & 0.00 .0 \\
\hline 7 & 0 Barra07 & $0947-11.000 .000$. & 233.084 .0 \\
\hline 8 & 0 Barra08 & $0947-11.000 .000$. & $522.0 \quad 176.0$ \\
\hline 9 & 0 Barra09 & $1008-11.000 .000$. & 0.00 .0 \\
\hline 10 & 0 Barra10 & $0961-5.6000 .000$ & 0.00 .0 \\
\hline 11 & 0 Barra11 & $0958-6.5000 .000$ & 0.00 .0 \\
\hline 12 & 0 Barra12 & $0939-6.5000 .000$ & 8.088 .0 \\
\hline 13 & 0 Barra13 & $0960-6.4000 .000$ & $\begin{array}{ll}0.0 & 0.0\end{array}$ \\
\hline 14 & 0 Barra14 & $0961-8.2000 .000$ & 0.00 .0 \\
\hline 15 & 0 Barra15 & $0969-8.5000 .000$ & $320.0 \quad 153.0$ \\
\hline 16 & 0 Barra 16 & $0988-7.0000 .000$ & 329.032 .0 \\
\hline 17 & 0 Barra17 & $0992-8.1000 .000$ & $\begin{array}{ll}0.0 & 0.0\end{array}$ \\
\hline 18 & 0 Barra18 & $0991-9.1000 .000$. & 158.030 .0 \\
\hline 19 & 0 Barra19 & $0989-1.2000 .000$. & 0.00 .0 \\
\hline 20 & 0 Barra20 & $0987-2.1000 .000$ & 628.0103 .0 \\
\hline 21 & 0 Barra21 & $0985-4.5000 .000$ & 274.0115 .0 \\
\hline 22 & 0 Barra22 & 10220.09000 .000 & $\begin{array}{ll}0.0 & 0.0\end{array}$ \\
\hline 23 & 0 Barra23 & $1020-0.2000 .000$ & 275.085 .0 \\
\hline 24 & 0 Barra24 & $0997-6.9000 .000$. & $309.0-92.0$ \\
\hline 25 & 0 Barra25 & $1028-5.0000 .000$ & 224.048 .0 \\
\hline 26 & 0 Barra26 & $1018-6.2000 .000$ & 139.017 .0 \\
\hline 27 & 0 Barra27 & $0999-8.3000 .000$ & 281.076 .0 \\
\hline 28 & 0 Barra28 & $1019-2.5000 .000$ & 206.028 .0 \\
\hline 29 & 0 Barra29 & 10200.41000 .000 & 284.027 .0 \\
\hline 30 & 1 Barra30 & $1047-4.0$ 250. 166.-999. 999. & 0.00 .0 \\
\hline 31 & 2 Barra31- & lk 09820.00552 .149$. & 9.05 .0 \\
\hline 32 & 1 Barra32 & 09832.32 650. 148.-999. 999 & 0.00 .0 \\
\hline 33 & 1 Barra33 & $09974.04632 .48 .5-999.999$. & 0.00 .0 \\
\hline
\end{tabular}




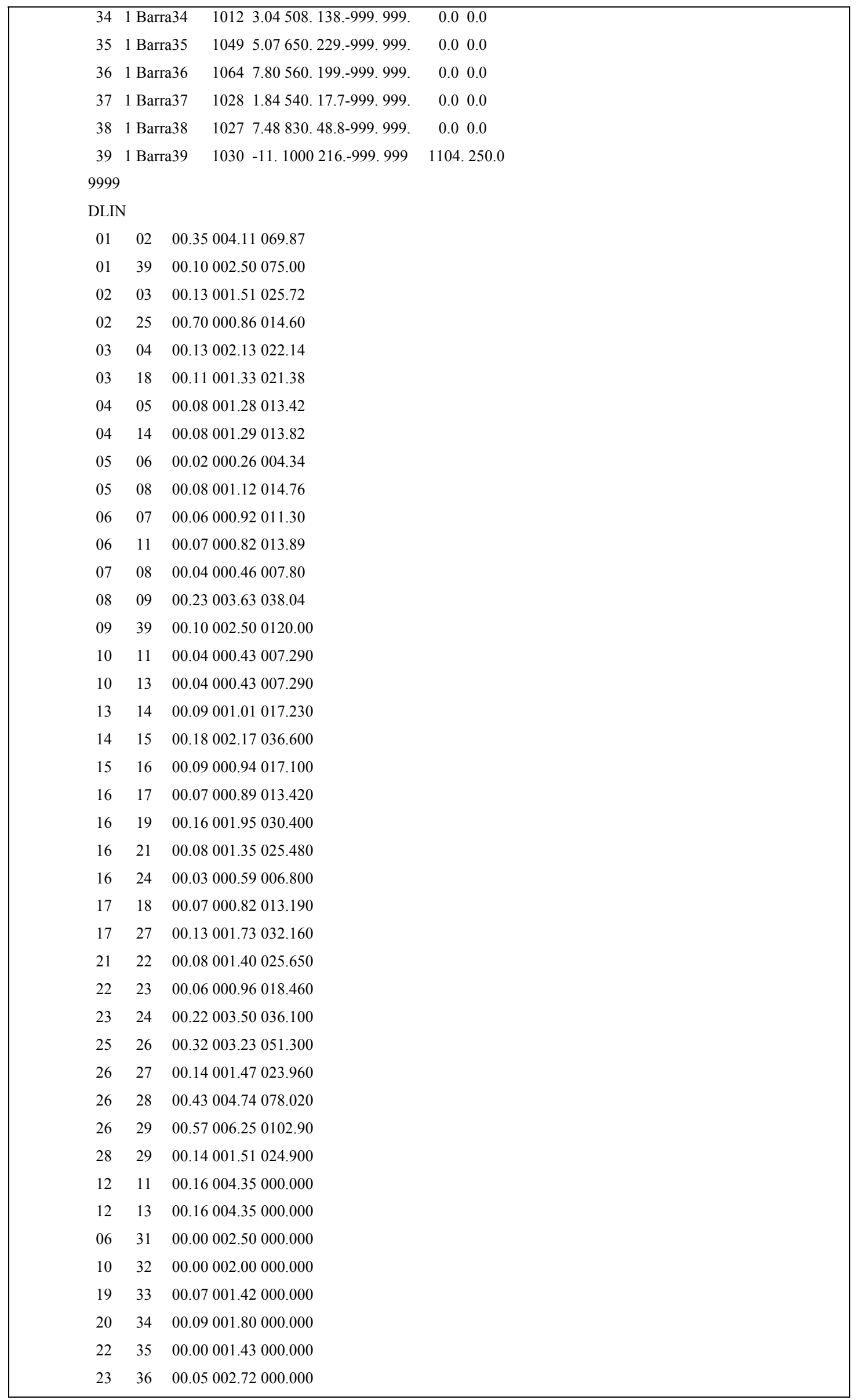




\begin{tabular}{|ccc|}
\hline 25 & 37 & 00.06002 .32000 .000 \\
02 & 30 & 00.00001 .81000 .000 \\
29 & 38 & 00.08001 .56000 .000 \\
19 & 20 & 00.07001 .38000 .000 \\
9999 & \\
DEST & \\
30 & 0.0310 .223 \\
31 & .06970 .161 \\
32 & .05310 .190 \\
33 & .04360 .205 \\
34 & 0.1320 .138 \\
35 & 0.0500 .185 \\
36 & 0.0490 .140 \\
37 & 0.0570 .129 \\
38 & 0.0570 .183 \\
39 & 0.0062 .650 \\
\hline 999 & \\
\hline
\end{tabular}


Ficha catalográfica preparada pela Seção de Tratamento da Informação do Serviço de Biblioteca - EESC/USP

Nazareno, Ivo Sechi

Método dinâmico para deteção do PEBS e "Shadowing Method" para cálculo do ponto de equilíbrio de controle em estudos de estabilidade transitória / Ivo Sechi Nazareno. -- São Carlos, 2003.

Dissertação (Mestrado) -- Escola de Engenharia de São Carlos-Universidade de São Paulo, 2003.

Área: Engenharia Elétrica.

Orientador: Prof. Dr. Newton Geraldo Bretas.

1. Estabilidade transitória. 2. Métodos diretos. 3. Tempo real. I. Título. 